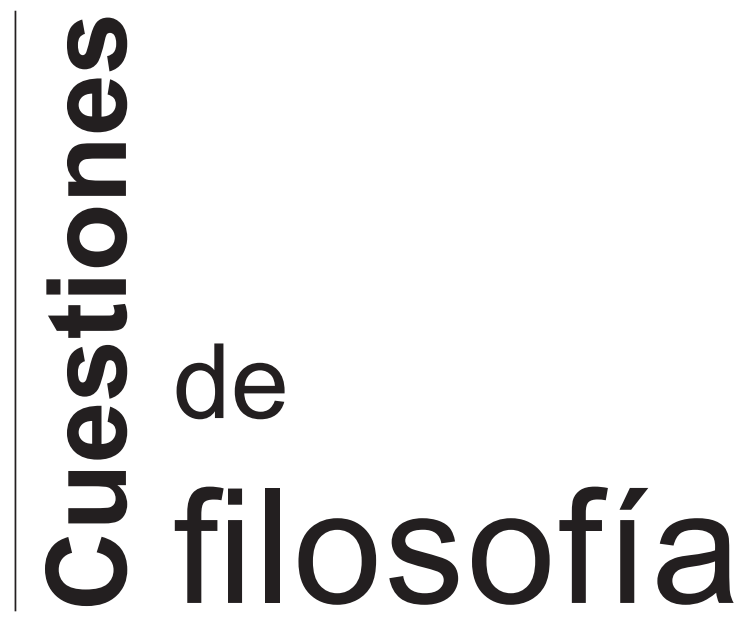

Revista de la Escuela de Filosofía y Humanidades de la Universidad Pedagógica y Tecnológica de Colombia

Vol. 6 No. 26-2020

Tunja, Boyacá-Colombia 
Cuestiones de Filosofía es una revista institucional de la Escuela de Filosofia y Humanidades, de la Facultad de Ciencias de la Educación de la Universidad Pedagógica y Tecnológica de Colombia. Fundada en el año 1998, está dirigida a lectores interesados en reflexiones e investigaciones en el ámbito de la filosofía y sus relaciones con otros campos del saber. Publica artículos de investigación originales, teorizaciones y reflexiones de carácter conceptual que indagan sobre diferentes corrientes de pensamiento en el ámbito de la filosofía y su conexión con otras áreas. Con el objetivo de mejorar la calidad cientifica y editorial de la revista, los artículos son evaluados en la modalidad de doble ciego. Cuestiones de Filosofia acoge los parámetros que consagran la ley y la Universidad sobre derechos de autor.

latindex

THE Philosopherís'inex

EBSCO

Humanities Source

Publindex

\section{Publicación semestral}

Escuela de Filosofía

Facultad de Ciencias de la Educación

Universidad Pedagógica y Tecnológica de Colombia

Vol. 6. N²6, enero-junio de 2020.

\section{Publicación financiada por:}

Vicerrectoría de investigación y extensión

Universidad Pedagógica y Tecnológica de Colombia

Prof. Dr. Alfredo Rocha de la Torre

\section{Editor}

David Pineda Medina

Iván Darío Muñoz

Melissa Espitia Igua

Asistentes Editoriales

Editorial Jotamar S.A.S.

editorialjotamar@yahoo.com

Diseño

\section{Suscripción, adquisición y Canje}

Universidad Pedagógica y Tecnológica de Colombia Biblioteca Central Jorge Palacios Preciado

Escuela de Filosofía cuestiones.filosofia@uptc.edu.co

Oficina C- 325 Edificio Central,

Avenida Central del Norte 39-115 - Tunja

Tel: 57-8-7405626. Ext. 2491

https://revistas.uptc.edu.co/index.php/cuestiones_filosofia

Diagramación e impresión:

EDITORIAL JOTAMAR S.A.S.

Calle 57 No. 3 - 39

Tunja - Boyacá - Colombia.

ISSN 0123-5095 E - ISSN 2389-9441

Revista indizada en:

DOAJ, The Philosopher's Index; Latindex; Ebsco Humanities Source; VLex; Sapiens Research Group.

Cuestiones de filosofia / Escuela de Filosofía.

Facultad Ciencias de la Educación. $N^{o} .1$ (1993). UPTC

Tunja, Boyacá-Colombia

Periodicidad: SEMESTRAL

ISSN: 0123- 5095 / E-ISSN 2389-9441

1. Filosofía-Publicaciones Periódicas

2. Humanidades - Publicaciones Periódicas.

Aspecto físico: tamaño 17.5 x 25 papel propalibros 70 gramos a (1) tinta, (8) separadores papel propalcote de 150 gramos policromía, carátula propalcote de 240 gramos en policromía plastificada al mate con parciales UV.

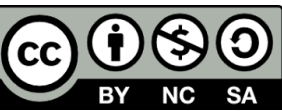

La revista está autorizada por una licencia https://creativecommons.org/licenses/by-nc-sa/4.0/ 


\title{
Editor
}

Prof. Dr. Alfredo Rocha de la Torre

\section{Editor invitado}

Prof. Dr. Jacinto Rivera de Rosales, UNED, España

\section{Directivos UPTC}

\author{
Rector \\ Oscar Ramírez \\ Vicerrector Académico \\ Manuel Humberto Restrepo Domínguez \\ Director Vicerrectoría de Investigación y Extensión \\ Enrique Vera López \\ Directora de Investigaciones \\ Zaida Zarely Ojeda Pérez \\ Editora en Jefe \\ Lida Esperanza Riscanevo Espitia \\ Decano Facultad Ciencias de la Educación \\ Julio Aldemar Gómez Castañeda \\ Directora CIEFED \\ Claudia Liliana Sánchez Sáenz \\ Director Escuela de Filosofía \\ Patrick Durand Baquero \\ Comité Científico \\ Prof. Dr. Adriano Fabris \\ Università di Pisa, Italia \\ Prof. Dr. Alberto Constante \\ Universidad Nacional Autónoma de México \\ Prof. Dr. Emilio Martínez Navarro \\ Universidad de Murcia, España \\ Prof. Dr. Gaetano Chiurazzi \\ Universitá degli Studi di Torino, Italia \\ Prof. Dr. Josep Esquirol \\ Universitat de Barcelona, España \\ Prof. Dr. Óscar Pulido Cortés \\ Universidad Pedagógica y Tecnológica de Colombia \\ Prof. Dr. Raúl Fornet Betancourt \\ Escuela Internacional de Filosofía Intercultural, España \\ Prof. Dra. Remedios Ávila \\ Universidad de Granada, España
}


Prof. Dr. Stefano Bancalari

Sapienza. Università di Roma, Italia

Prof. Dra. Teresa Oñate y Zubía

UNED, España

Prof. Dr. Werner Stegmaier

Greifswald Universität, Alemania

\title{
Comité Editorial
}

Prof. Dr. Alejandro Tomasini

Universidad Nacional Autónoma de México

Prof. Dr. Félix García Moriyon

Universidad Autónoma de Madrid, España

Prof. Dr. Jacinto Rivera de Rosales UNED, España

Prof. Dr. Juan Guillermo Díaz Universidad Pedagógica y Tecnológica de Colombia

Prof. Dra. Marcela Lisseth Brito Universidad Centroamericana, El Salvador

Prof. Dr. Mario Adrián Bertorello Universidad de Buenos Aires, Argentina

Prof. Dr. Miguel Gómez Mendoza Universidad Tecnológica de Pereira, Colombia

Prof. Dra. Olga Grau Duhart Universidad de Chile

Prof. Dra. Rebeca Maldonado Universidad Nacional Autónoma de México

Prof. Dr. Silvio Donizetti de Oliveira Gallo Universidad Estadual de Campinas, Brasil

Prof. Dr. Alberto Fragio Gistau Universidad Autónoma Metropolitana, México

\section{Comité de arbitraje}

ÁRBITROS EVALUADORES CUESTIONES DE FILOSOFÍA Vol. 6 № 26

\author{
Dr. Adrian Muñoz \\ Bauhaus-Universität Weimar, Alemania \\ Prof. Dr. Alberto Constante \\ Universidad Nacional Autónoma de México \\ Prof. Dr. Ángel Alfonso Centeno \\ Universidad Centroamericana, El Salvador \\ Prof. Dr. Elías Fuentes Guillén \\ Universidad Nacional Autónoma de México
}


Cand. Dr. Edwin Velasco

Albert-Ludwigs-Universität Freiburg, Alemania

Prof. Dr. Eric Pommier

Pontificia Universidad Católica de Chile

Cand. Dra. Federica González Luna

Eberhard Karls Universität Tübingen, Alemania

Prof. Dr. Fernando García Leguizamón

Universidad Pedagógica Dominicana

Prof. Dr. Hernán Martínez Ferro

Universidad Pedagógica y Tecnológica de Colombia

Prof. Dr. lago Ramos

Universidad de Salamanca, España

Prof. Dr. Jacinto Calderón

Fundación Updea, España

Prof. Dr. José Rosero Morales

Universidad del Cauca, Colombia

Prof. Dr. Jorge Acevedo Guerra.

Universidad de Chile

Prof. Dr. Luis Niel

CONICET / Universidad Nacional del Litoral, Argentina

Prof. Dra. Marcela Lisseth Brito

Universidad Centroamericana, El Salvador

Prof. Dr. Mariano Ure

Universidad de Buenos Aires, Argentina

Cand. Dr. Nino Rosanía Maza

Benemérita Universidad Autónoma de Puebla, México

Cand. Dr. Onasis Ortega Narváez Universidad del Valle

Prof. Dr. Olvani Sánchez

Pontificia Universidad Javeriana, Colombia

Cand. Dr. Osman Choque Aliaga

Albert-Ludwigs-Universität Freiburg, Alemania

Cand. Dr. Pablo Veraza Tonda

Albert-Ludwigs-Universität Freiburg

Prof. Dr. Ulises Amaya

Universidad de Antioquia, Colombia

Prof. Dr. Wilson Alcides Valenzuela

Universidad Pedagógica y Tecnológica de Colombia 



\section{Contenido}

Editorial

Prof. Dr. Alfredo Rocha de la Torre

Editor

Por un nuevo humanismo hoy

Prof. Dr. Adriano Fabris

Lenguaje, narración y cultura de la vida: la realidad inmanente de lo humano en la fenomenología de Michel Henry

Prof. Dr. Cesare Aníbal del Mastro Puccio

El final del humanismo como lugar del pensar de Pirjevec

Prof. Dr. Dean Komel

Humanismo y transhumanismo al final de la metafísica: la era digital como paradigma de la metafísica de la subjetividad

Prof. Dr. Dune Valle Jiménez

Humano, demasiado humano, ultrahumano: el desafío de

Nietzsche al humanismo

Prof. Dr. Helmut Heit

El concepto de humanidad en Edmund Husserl:

delimitación y proyecciones

Prof. Dr. Luis Flores Hernández

Conciencia histórica y relatos identitarios: en búsqueda de una ética de la experiencia social de la historia

Prof. Dr. Miguel Ángel Guzmán López

Nunca hemos sido animales. El posthumanismo de Heidegger 165

Prof. Dr. Steven Crowell

\section{Reseñas}

Valencia, A. (2008). Conversaciones con Estanislao Zuleta.

Medellín: Hombres Nuevos Editores

Jorge Alberto Valcárcel Guzmán 


\section{Content}

Editorial

Prof. Dr. Alfredo Rocha de la Torre

Editor

Towards a new humanism today

Prof. Dr. Adriano Fabris

Language, narration and culture of life: the immanent reality of

the human in the phenomenology of Michael Henry

Prof. Dr. Cesare Aníbal del Mastro Puccio

The end of humanism as the locus of Pirjevec's thinking

Prof. Dr. Dean Komel

Humanism, transhumanism and the end of metaphysics:

the digital age as the paradigm of the metaphysics of subjectivity

75

Prof. Dr. Dune Valle Jiménez

Human, all too human, transhuman: Nietzsche's challenge

to humanism

Prof. Dr. Helmut Heit

Humanity's concept in Edmund Husserl: delimitation and projections

Prof. Dr. Luis Flores Hernández

Historical consciousness and identity stories: searching for

an ethic of history'social experience

Prof. Dr. Miguel Ángel Guzmán López

We have never been animals. Heidegger's posthumanism

Prof. Dr. Steven Crowell

\section{Reviews}

Valencia, A. (2008). Conversaciones con Estanislao Zuleta.

Medellín: Hombre Nuevo Editores

Jorge Alberto Valcárcel Guzmán 
Con este número de Cuestiones de Filosofía inicia una nueva etapa de esta publicación periódica de la Escuela de Filosofía de la Universidad Pedagógica y Tecnológica de Colombia, con sede en Tunja. Entre los aspectos más importantes a destacar en esta etapa están los siguientes:

1. Se ha incrementado y modificado en lo esencial el número de miembros de los Comités científico y editorial, con el objetivo de ampliar la cobertura y alcances internacionales de la publicación.

2. Se acudirá en cada volumen semestral a la figura de "editor internacional invitado", buscando de esta manera cualificar aún más los procesos de evaluación y aceptación de la revista, así como también visibilizar en los más exigentes y amplios ámbitos del quehacer filosófico mundial las publicaciones de cada uno de los autores aceptados.

3. Coincidiendo con los objetivos plasmados en los dos anteriores numerales, la revista está abierta a partir de la fecha a publicaciones originales en varios idiomas reconocidos por su valor en la tradición filosófica occidental: inglés, alemán, italiano, francés y, por supuesto nuestra lengua natal, el español.

4. Con el ánimo de abrir este espacio impreso de diálogo académico a la mayor cantidad posible de áreas, ámbitos, autores, problemáticas y escuelas filosóficas, se ha decidido que la convocatoria del primer número de cada año sea de carácter misceláneo, mientras el segundo número lo será de carácter monográfico.

El editor invitado de este número de la revista es el Prof. Dr. Jacinto Rivera de Rosales de la UNED (España), quien posee una amplísima trayectoria académica reconocida a nivel internacional, tal como puede apreciarse en la reseña de la portada de la presente publicación. Para el número misceláneo correspondiente al primer semestre de 2021, contaremos con la presencia del Prof. Dr. Josep Esquirol de la Universitat de Barcelona (España), uno de los pensadores 
contemporáneos de más renombre en el ámbito filosófico hispanohablante. En el segundo semestre del mismo año abriremos la convocatoria monográfica en torno a la filosofía de la interculturalidad, cuyo editor invitado es el Prof. Dr. Raúl Fornet Betancourt de la Universität Bremen (Alemania), y de Escuela Internacional de Filosofía Intercultural EIFI (España), referente mundial en este campo del saber filosófico.

El volumen 6 (No. 26), que el lector tiene en sus manos, está dedicado a una de las problemáticas fundamentales de la historia de la Filosofía y de las letras en general: el Humanismo. Alrededor de esta problemática tan actual, no obstante su aparente antigüedad, si se tratara de tasar en años su origen como objeto de reflexión, se reúnen ocho trabajos del más alto nivel académico internacional. Encontramos, en primer lugar, el escrito del Prof. Dr. Adriano Fabris (co-director del International Center of Studies on Contemporary Nihilism) "Por un nuevo humanismo hoy", en el que a partir de un horizonte propio desde el que propone una TeoEtica, resalta el carácter relacional del trato entre los hombres, concebido como principio posibilitador de un nuevo humanismo más allá de las posturas muy bien conocidas de Martin Heidegger y Emmanuel Levinas. A este punto se llega luego de llevar a cabo un análisis de la situación de la era tecnológica actual, caracterizada por el individualismo, así como acerca del origen filosófico de esta posición del hombre en el mundo.

Más adelante tenemos la reflexión en torno a la filosofía de la vida, desarrollada por el Profesor Dr. Cesare del Mastro Puccio con su trabajo acerca del fenomenólogo francés Michel Henry, en el que a partir de una contraposición a la dualidad tradicional de sujeto-objeto se plantea la unidad ontológica de lo humano, con el objetivo fundamental de postular lo denominado por el autor "la recuperación de lo humano" y del lenguaje de la vida. En palabras del autor, el trabajo tiene el objetivo de mostrar "la teoría henriana de los lenguajes del afecto respecto al debate en torno al humanismo y el post-humanismo, y al vínculo entre fenomenología y hermenéutica". En torno a la posición del pensador esloveno Dušan Pirjevec acerca de la crisis del humanismo, el también filósofo esloveno, director del Forum for the humanities (FORhUM), Prof. Dr. Dean Komel resalta el distanciamiento de aquel ante la orientación postestructuralista de 
la década de los 60 , y su concepción del fin del humanismo como expresión del hombre, de la vida, de la libertad, de la poiesis y lo humano a diferencia del sujeto del subjetivismo, la acción, la verdad, la ciencia y la tecnocracia.

El vínculo entre humanismo y despliegue del pensamiento calculador propio de la técnica, visto desde el marco de la tradición metafísica, es el tema del trabajo escrito por el Prof. Dr. Dune Valle, quien acorde con lo planteado por Heidegger, señala a Nietzsche como culmen de la metafísica occidental y, con ello, como punto de máximo desarrollo de la voluntad de hacer disponible todo lo ente como tal. Para el autor, el Ge-stell, esencia de la era técnica, se manifiesta en el dataísmo y en el transhumanismo, propuestas tan en boga hoy en día. El Prof. Dr. Helmut Heit, director del Kolleg Friedrich Nietzsche der Klassik Stiftung Weimar, por su parte, desarrolla la muy interesante tesis de una cierta "ambigüedad" en el pensamiento de Nietzsche en torno al humanismo: partiendo de su actitud crítica ante lo humano (la enfermedad de la piel de la tierra), Heit logra visualizar que a través de los postulados nietzscheanos de la superación de sí mismo y del refinamiento del carácter, se llega a una antropología política de la libertad, que culmina en una invitación a la transformación positiva de lo humano.

Poniendo en el centro de su reflexión el concepto husserliano de humanidad, el Prof. Dr. Luis Flores Hernández sigue rigurosamente el proceder de Husserl desde el concepto de crisis de la humanidad europea hasta la propuesta de una humanidad más auténtica, como expresión de un llegar a ser hombres, como está consignado en Hua XXVII (p. 55). La historicidad, concebida como universal de la existencia, la racionalidad considerada como proceso fundamental de la humanización (salida épica ante el naturalismo) y la pretensión central de hallar proyecciones del concepto de humanidad en la ética, la antropología y la cultura, son elementos centrales de este artículo. Por su parte, el Prof. Dr. Miguel Ángel Guzmán busca en su escrito hallar una ética de la experiencia social, a partir de su reflexión en torno a los vínculos de la conciencia histórica (que recae sobre la historia efectual) y los relatos cohesionadores a lo largo del tiempo. Para lograr este objetivo acude muy coherentemente a la interpretación del concepto de tradición en cuatro vertientes (pertenencia, 
interpelación, proclividad y resistencia), que aprehendidas en el contexto de su objetivo dan sentido a la conclusión a la que llega el autor.

Finalmente, este número de la revista culmina con el escrito del Prof. Dr. Steven Crowell, quien se concentra en primer lugar en el pensamiento heideggeriano en torno a la diferencia entre el animal y el Dasein, para resaltar la profunda distancia planteada por el filósofo de Messkirch entre estos entes, y así contraponer esta posición a la del "bio-posthumanismo", que minimiza tal diferencia. Con base en esta contraposición, el Prof. Crowell señala el carácter post-humanista y fenomenológico de Heidegger.

Prof. Dr. Alfredo Rocha de la Torre Universidad Pedagógica y Tecnológica de Colombia 


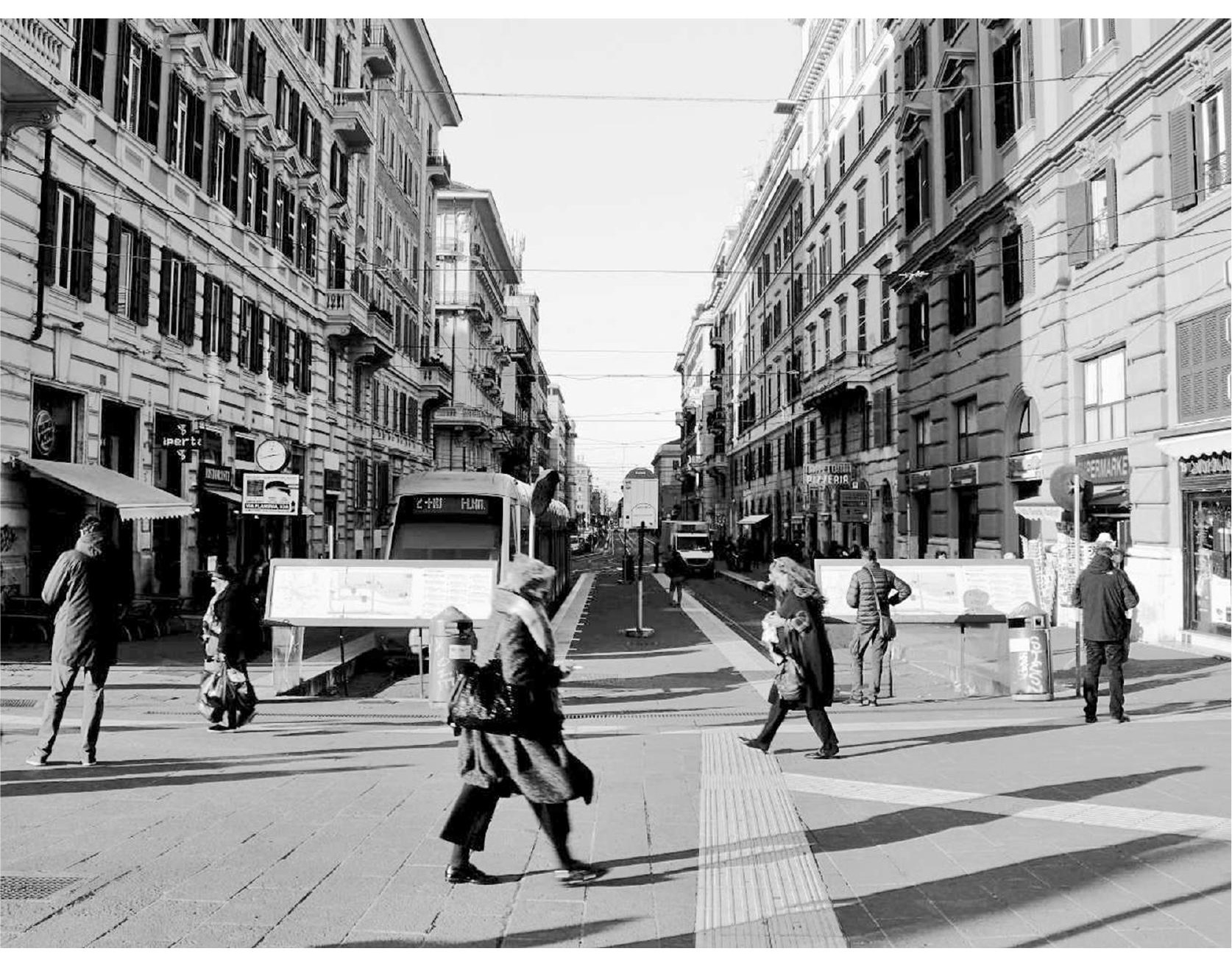

Il popolo

Roma, Italia

Autor: Johan Sebastián Pinilla 



\title{
Por un nuevo humanismo hoy
}

\author{
Towards a New Humanism Today ${ }^{l}$
}

Adriano Fabris ${ }^{2}$

Università di Pisa, Italia

Recepción: 12 de junio del 2020

Evaluación: 15 de julio del 2020

Aceptación: 20 de julio de 2020

1 Traducción del italiano por Mari Carmen Llerena del Castillo, Università di Pisa.

2 Doctor por la Università di Pisa y profesor de filosofía moral en la misma institución, donde dirige la revista "Teoria. Rivista di Filosofia" y el Centro Interdisciplinario de Investigación y Servicios en Comunicación. Co-director del Centro Internacional de Estudios sobre el Nihilismo Contemporáneo (CeNic).

Correo electrónico: adriano.fabris@unipi.it 


\title{
Resumen
}

El artículo desea discutir algunos aspectos concernientes al rol del ser humano y su actividad en nuestra era tecnológica. Partiendo de la idea moderna de "humanismo" se explican brevemente los conceptos de subjetividad de Descartes y Hobbes, y se señalan sus límites. Luego de hacer referencia a la interpretación heideggeriana del Dasein como ser-con (Mitsein) y a la categoría de sujeto en Levinas, el artículo busca desarrollar desde una perspectiva ética un concepto relacional de humanismo. Esta concepción puede ser más útil en la práctica, y más justificada éticamente, para enfrentar los nuevos retos que el artículo señala para el mundo actual.

Palabras clave: Humanismo, ética, técnica, Heidegger, Levinas

\begin{abstract}
The essay wants to discuss some aspects concerning the role of human being and its activity in our technological era. Starting from the modern idea of "humanism" it briefly explains Descartes' and Hobbes' concepts of subjectivity and shows the limits of them. Then, by referring to Heidegger's interpretation of Dasein as Mitsein and to Levinas' category of subject, the essay tries to develop from an ethical viewpoint a relational idea of humanism. This idea can be practically more useful, and ethically more justified, for facing the new challenges of our world, the essay argues.
\end{abstract}

Keywords: Humanism, ethics, technology, Heidegger, Levinas 


\section{La situación actual}

Hoy en occidente vivimos en un contexto cultural en que predomina el interés por las minucias antes que por las amplias perspectivas. Todo se concentra en el individuo, a lo sumo en el grupo al cual pertenece, y se considera obvio salvaguardar el espacio de acción de cada uno de sus miembros. Lo único que queda al individuo, una vez salvaguardado su espacio, es concentrarse en él, gozarlo e incluso contemplarlo y analizarlo, conservando igualmente su propio aislamiento.

Este es en general el modo en que se ha pensado y vivido, desde el sentido común, la humanidad del ser humano. Pero justo cuando quiere reivindicar la expresión de la individualidad propia y particular - de su especificidad y los derechos que le pertenecen- pronto descubre el individuo que todo aquello que puede hacer está en función de otros fines y sigue una suerte de "heterogénesis de los fines". De hecho, estos fines no son establecidos casi nunca por aquel que se esfuerza en pro de su realización. Son inherentes a determinadas estructuras generales -económicas, sociales, tecnológicas-que ciertamente pueden ser explicadas, pero difícilmente se puede incidir en ellas por el simple ejercicio de la buena o mala voluntad individual. Por ende, el individuo se encuentra dividido entre la impotencia a nivel global y la potencia, real o aparente, al interior de su limitado espacio de acción.

Puesto que las "grandes narraciones" han desaparecido, no existe ni siquiera la posibilidad de informar a alguien comprometido que su actuar, por limitado que sea, tiene sentido a un nivel superior. Ya no basta con el hecho de concebir al individuo singular en función del todo, aún si el todo es concebido como una individualidad más amplia, colectiva, como Hegel hace al hablar de los estados y su desarrollo histórico en Grundlinien der Philosophie des Rechts (Hegel, 2016). Al contrario, solo queda la atención a las cosas pequeñas: resta la "micrología", el refugio en la minucia analítica, hasta el momento en que su insensatez sea descubierta.

En suma: actualmente el ser humano es pensado en su individualidad aislada. Y en efecto, etimológicamente, 'individuum' significa "individido" e 'indivisible’. Sin embargo, en la época del individualismo triunfante, el individuo mismo es dueño de un espacio cada vez más reducido, ya sea de expresión o de acción. De esta manera aumenta la desazón, aunque este espacio operativo resulte suficientemente amplio y, en general, cómodo. Sin embargo, el individuo no puede satisfacerse con el mero moverse en este espacio, ya que 
de hecho se percata de que todo aquello que lo trasciende no sólo escapa a su control, sino que -al contrario de aquello que pensaba Hegel- parece no tener sentido alguno.

Esta es, entonces, la ambigua convicción de fondo que invade la mentalidad común y que hoy, al menos en Occidente, goza de hegemonía cultural. Se trata de ideas no siempre explícitas, que ofrecen una estrategia parcial y precaria para tranquilizar a un individuo cada vez más encerrado en su limitado espacio de acción. Análisis, explicación, control: en virtud de este triple esfuerzo preliminar, el individuo tiene la posibilidad de que todo su actuar, si es constructivo, sea exitoso, por lo que se ilusiona, siguiendo correctamente el procedimiento, con poder vivir asegurado frente a cualquier imprevisto. Toda la investigación científica -lo podemos ver con facilidad- está orientada en esta dirección.

Este fondo tranquilizante es, sin embargo, tal como ya fue dicho, algo precario: no es necesario recurrir a la ideología de la amenaza terrorista (de la cual se ha abusado y se abusa) para percatarse de esto (Duque, 2004). En cuanto advertimos esta precariedad emerge, precisamente, una experiencia de desazón. Es una situación muy compleja. En primer lugar, se presenta la desazón debido al hecho de que muchas veces el hombre mismo no puede controlar ni prever las consecuencias de su actuar. En segundo lugar, se encuentra la desazón que surge de la conciencia de que una explicación, aún completa, de una situación particular, no responde a la pregunta por el sentido de esta situación: al 'por qué' de su existencia, independientemente del hecho de que el hombre pueda o no explicarla. Es por ello que existe la desazón que surge frente a la conciencia del carácter inconcluso, es decir, infinitamente repetible de cada análisis. Tanto es así que la misma idea de análisis amerita ser analizada, y así también la conciencia que nos empuja a emprender este último análisis, así como la pulsión que nos induce a tal profundización: en un proceso que puede decirse que termina solo arbitrariamente o por agotamiento.

En el plano de nuestra experiencia existencial todo esto señala los límites de la ciencia y de la técnica. A pesar de sus premisas, las dos no ofrecen soluciones definitivas a la necesidad de seguridad que tienen los seres humanos. Los individuos y los grupos parecen encontrarse en una condición en la que la desazón es una condición inevitable.

No se trata ya, como en la época moderna, de afinar los instrumentos de análisis, de explicación y de control para poder habitar el mundo de una manera 
cada vez más cómoda, eliminando de esta forma toda sorpresa restante y reivindicando así la capacidad únicamente humana de lograr este objetivo -sin que sea necesario por ello, entonces, recurrir a la hipótesis de Dios. No obstante, tampoco como lo es en la condición posmoderna, deben subrayarse los límites del poder humano, basándose en el reconocimiento de estos límites, para con ello inducir a la prudencia en el actuar o para recuperar algunos espacios de acción en los cuales se trascienda la dimensión mundana. La situación es hoy diferente; diferente es la tarea que nos espera a los hombres, especialmente como filósofos.

Es necesario, en consecuencia, pensar de manera adecuada la trama de potencia e impotencia que se anuncia en la situación ya descrita: es necesario, entonces, comprender y profundizar el análisis de la relación de dependencia e independencia que envuelve al ser humano. Es necesario comprender las formas de actuar que se anuncian en esta situación de desazón, sin llegar a considerar que para salir de ella sea necesario retornar a la idea de una omnipotencia individual y anárquica, o que se termine aceptando la disolución del individuo en una estructura global sobre la que él ya no tiene la posibilidad de incidir. Es necesario, en suma, repensar la humanidad del ser humano: para desarrollar una nueva forma de humanismo que vaya más allá de la idea de un individuo autocentrado y de su subordinación a una estructura impersonal.

\section{El origen de la interpretación individualista del ser humano}

El humanismo que tiene en su centro al individuo, es para el ser humano sólo una posibilidad de pensarse y de actuar en el mundo. Ciertamente ésta es la posibilidad predominante hoy en día en el sentido común. Pero en realidad se trata únicamente de una interpretación: una interpretación que tiene un origen histórico preciso, y que a lo largo de la historia ha impregnado progresivamente a este sentido común.

El esquema básico, que reitero en este momento, sostiene que el punto de partida de cada pensamiento y de cada acción es propiciado por el individuo en cuanto tal: singular, aislado, referido en primer lugar a sí mismo. La relación con los otros, el surgimiento de una comunidad, cada una de las formas de relación que pueden incluir al individuo, dependen en último término de la manifestación de sus exigencias específicas. En principio es el yo; en principio son, para ser más precisos, varios, muchos yo. El yo es en sí mismo múltiple (Freud). En principio es la fragmentación. 
En este esquema, si observamos bien, no hay nada nuevo respecto a lo que Descartes había ya anunciado en su Discurso del método (Descartes, 1984) haciendo del yo en primera persona, que se autoafirma performativamente (según la lectura de Hintikka, 1967), el fundamento de cada relación: con el mundo, con los otros yo, con Dios mismo. En efecto la relación del yo consigo mismo, es decir, la autorelación, es el principio de la relación del yo con los otros, en otras palabras, de la heterorelación. Es por esto, entonces, que no debe sorprender, por ejemplo, el hecho de que acorde con esta perspectiva la comunidad misma se funde en una serie de procesos originados en el individuo, y que encuentran en él su fundamento.

De esta manera, entonces, actualmente el ser humano -aun también en sociedad- no es considerado más como un yo comunitario, colectivo y genérico, sino que es concebido como un ser individual, relativo y particular: originariamente contrapuesto a otros yo. Esta contraposición, que puede asumir formas violentas, emerge ya desde el inicio de la época moderna. El autor que más claramente desarrolla este enfoque es Thomas Hobbes en su Leviatán (Hobbes, 2014).

Hobbes comparte con Descartes una reflexión filosófica basada en experimentos mentales (aquello que para Descartes es la duda metódica, que tan sólo hace valer una "moral provisional", deviene para Hobbes en la función de la inicial "guerra de todos contra todos"). Pero aquello que Descartes concibe en términos de una autoafirmación teórica de lo individual en el pensarse a sí mismo, se transforma en Hobbes en un acto de voluntad, esto es, en una decisión práctica, que debe ser motivada o al menos explicada. Aquello que la explica, como bien sabemos, es un principio egoísta, relativo al sujeto en su particularidad: el sujeto está aquí motivado por la voluntad de salvaguardar dicha particularidad. Se trata del miedo por la propia vida, de la exigencia de la seguridad propia, de la necesidad de la autoconservación. La antropología autoreferencial del yo cartesiano, que se piensa a sí mismo deviene, en suma, para Hobbes, en una antropología autoconservadora del individuo, que para salvarse a sí mismo cede amplios espacios de su libertad a un soberano. Y de esta manera - propiamente a partir de esta fragmentación, sin que ella sin embargo se resuelva definitivamente- nace la dimensión comunitaria.

La guerra, en efecto, es la condición natural propia del individuo múltiple y fragmentado. El posible nacimiento de una comunidad se explica con base en una actitud específica individual y, más aún, se considera como una 
consecuencia de una concesión particular del ser humano, y como el fruto de la acción de su voluntad. A través de la legislación la comunidad reglamenta aquellas relaciones que los individuos no son capaces de establecer y conservar de modo pacífico, y de esta manera ella posibilita que el individuo conserve su vida justamente en la forma de la primigenia individualidad fragmentada.

Se trata, no obstante, de un éxito paradójico, pues, por un lado, es verdadero que el principio de la comunidad reside en la decisión del individuo y, por ende, la subsistencia de la comunidad y la definición de sus valores dependen de los individuos mismos. Pero por el otro lado, la afirmación de la comunidad implica un efecto represivo, justamente en el enfrentamiento de tal afirmación individual. El individuo, entonces, con el fin de salvarse a sí mismo $-\mathrm{y}$, en consecuencia, con la intención de mantener espacios de autoafirmación- se ve obligado a interactuar con aquello que lo limita. Esto es debido a que el individuo no es capaz de limitarse por sí mismo: no es capaz -aunque ésta será la solución kantiana en la cumbre de la modernidad- de comprender sus propios límites. En otras palabras: la anulación del individuo, si bien parcial, es condición de su propia realización. En la necesidad de anularse a sí mismo para poder afirmarse vemos expresado todo el carácter nihilista del individualismo contemporáneo.

Es evidente que esta solución propuesta por Hobbes no puede ser duradera, ya que una vez asumido el principio de la autoafirmación individual como fundamento de la comunidad, no se entiende por qué el individuo mismo deba entonces buscar necesariamente una instancia que lo limite. El temor por la propia vida, en efecto, está destinado a desaparecer si yo soy, o me considero, el más fuerte. Siendo de esta manera las cosas, no está determinado que yo tenga que subordinarme al soberano: es posible considerar que yo mismo sea el soberano. Nietzsche, bien ponderado, no hace otra cosa que desarrollar tal concepción hasta sus últimas consecuencias.

Pero si en cambio desaparece el remedio de la comunidad, si fracasa la necesidad de un control común externo en un plano histórico, tan sólo quedaría la antropología del individuo aislado. Se mantendría la perspectiva de la guerra de todos contra todos. En otras palabras, si el hombre es el lobo para el hombre, y si no existe una autoridad común que pueda regular su voluntad, el conflicto resulta inevitable, y la violencia se hace difusa y parcializada. En el caso de que no exploten conflictos globales, aquellos conflictos locales 
corren el riesgo de multiplicarse, tal como precisamente sucede en la actualidad -no obstante, todo tipo de reivindicación humanista-, en la que incluso se justifica el uso de la violencia por motivos "humanitarios".

\section{Propuestas alternativas en el siglo $\mathrm{XX}$}

Está claro que hay algo que no funciona. Algo que no funciona, en primer lugar, en el plano teórico, pero también desde un punto de vista práctico, con todas las consecuencias que esto produce en la vida de los seres humanos. Basta con pensar en las experiencias vividas en la vieja Europa de los últimos doscientos años -experiencias de guerra, de estragos, de exterminios- para comprender que el camino recorrido hasta ahora no es un buen camino. Basta con pensar también en las constantes tensiones que atraviesan el modelo de vida y de pensamiento en los Estados Unidos.

Es por esto que se hace necesario cambiar de perspectiva. Es por esta razón que la cuestión del humanismo se propone siempre nuevamente. En general se entiende por "humanismo" no solamente el modo a través del cual el ser humano concibe y vive su propio ser, sino, ante todo, el modo mediante el cual éste se relaciona consigo mismo y con sus semejantes. En una palabra: se ratifica verdaderamente de modo auténtico como ser humano; llega a ser propiamente aquello que es.

Pero la autocomprensión del ser humano llevada a cabo en la época moderna -aquella que lo considera como individuo autofundante- se revela, como hemos visto, insuficiente e incluso peligrosa. El siglo XX ha vivido directamente las consecuencias negativas de esta concepción, razón por la cual sus pensadores han buscado en buena medida enfrentarse a ella. En efecto, ellos han examinado soluciones alternativas en variados aspectos. Podemos profundizar en algunas de estas soluciones, haciendo una breve referencia a dos autores muy diversos entre sí: Martin Heidegger y Emmanuel Levinas.

Al final de sus primeros cursos universitarios de los años veinte, Heidegger elaboró una concepción del ser humano contraria a la perspectiva cartesiana. Como él sostiene al final del curso universitario de 1925, Prolegomena zur Geschichte des Zeitbegriffs (GA 20, 1985), para hacer filosofía es necesario revisar la afirmación de Descartes: no se debe experimentar más el cogito, ergo sum, sino referir el cogitare al esse, considerando el primero como una modalidad del segundo. Esta es la base de por qué la filosofía heideggeriana en su totalidad se presenta como una ontología. Es la base de por qué en su 
obra principal de 1927, Sein und Zeit (Heidegger, 1977), realiza un análisis del Dasein, del ente que somos nosotros mismos, justo en su carácter específico: fundamentando entonces, en polémica con los neokantianos, la gnoseología en la ontología.

Más aún: el ser del Dasein, analizado en su existencia, es visto en relación a un significado del ser más amplio y articulado. El Dasein, entonces, es el ente capaz de comprender el ser en general -de esta forma los entes Vorhanden, los Zuhanden, los seres vivos y los otros Dasein- solo porque siempre está ya en relación con el ser mismo. Se trata de una relación constituida por el ser mismo, y que se realiza en la forma de la desocultamiento (Entdecktheit, aletheia) de aquello que se da como fenómeno.

No sorprende, por tanto, el hecho de que después de la segunda guerra mundial -un acontecimiento radicalmente deshumanizante-, Heidegger haya acentuado fuertemente, a diferencia de otros pensadores contemporáneos, el aspecto antihumanista de su filosofía. Lo hizo, sin embargo, en sentido positivo. No se trata, en efecto, solamente de tomar distancia de Sartre, como lo hace en su "Humanismusbrief" (GA 9, pp. 313-364), ni únicamente de reafirmar la forma de pensar que lo caracteriza, como hemos visto, al final de los años veinte: aquella por la cual la relación con el ser es el fundamento de toda iniciativa del hombre. Se trata más bien, ante todo, de subrayar cómo el sentido del hombre reside en la relación con aquello que es otro diferente al ser humano. Se trata, entonces, de invertir la idea de que la autorelación es el fundamento de la heterorelación. Esta es la razón de por qué para Heidegger el principio del pensar y el vivir -el modo en que él enfrenta la cuestión del humanismo hoy- está dado por la relación con el ser: una relación en la que el hombre está implicado, pero que no depende de él mismo. Justo de esta manera, es decir, como una modalidad de la manifestación del ser, Heidegger interpreta también la técnica, explicando de modo coherente el poder deshumanizante que le es propio.

Sin embargo, Heidegger no logra llevar a cabo hasta el fondo esta inversión de la autorelación en la heterorelación. El Dasein mantiene siempre un primado: el primado que es propio de un ente que está llamado a reconocerse y a realizar con su decisión la relación misma que lo implica. Justamente, afirmando tal primado, el Dasein reafirma, aunque sea de forma paradójica, la necesidad de una referencia preliminar a sí mismo, de una autoreferencia fundamental. En otras palabras, el Dasein es fundamento en cuanto 
Abgrund: pero solamente así es, no obstante, fundamento. Está en relación con los otros Dasein, pero a partir del profundo aislamiento en que lo pone su Sein-zum-Tode.

Levinas tiene razón, en consecuencia, al iluminar y condenar esta ambigüedad de fondo en el pensar heideggeriano. En esta ambigüedad Heidegger se pone en peligro de regresar a la típica perspectiva de la edad moderna que él precisamente quería evitar. Levinas tiene razón, por tanto, al mostrar la inmoderada aproximación teórica propia de tal pensamiento. Si realmente se quiere partir de la relación, y conservarla como principio, es necesario pasar de la teoría a la ética; se vuelve necesario partir de la relación con el otro hombre. Es imprescindible elaborar un Humanisme de l'autre homme (Levinas, 1987), como reza el título de un importante texto de dicho pensador hebreo. Es necesario partir aún más radicalmente, no de la propia muerte, sino de la muerte de los otros; confróntese acerca de esto Dieu, la mort et le temps (Levinas, 1995).

Precisamente esto es lo que hace Levinas al proceder de un modo extremadamente concreto, partiendo de una serie de experiencias vividas, como es posible verlo ahora revisando sus Carnets de captivité (Levinas, 2009). Lo hace también en sus obras principales, desde Totalité et infini (1990a) hasta Autrement que'etre (1990b). La relación con el otro hombre, que es la modalidad encarnada de vivir el primado de la relación, remite en Levinas a algo que va más allá de esta misma relación: es la huella de una relación más alta, de una manifestación de "altura" (hauteur) en la que cada ser humano está implicado: la relación con Dios.

Sin embargo, la propuesta de Levinas tampoco es satisfactoria. No parece adecuada a nuestro tiempo, porque éste, tal como ya ha sido dicho al inicio de este trabajo, es el tiempo en el que no basta con enfrentarse al individuo autocentrado. Desde esta perspectiva, ciertamente, la ética del rostro del Otro y la remisión a la epifanía de este rostro pueden ser una solución adecuada. Pero en nuestro tiempo es preciso también enfrentar una situación en la cual no solo el antropocentrismo está en crisis, sino que también parece necesario poder abandonar cualquier forma de antropología. De hecho, en la época en que vivimos, en la que dominan las nuevas tecnologías, parece que no tiene sentido hablar del hombre en cuanto tal, es decir, del hombre concebido en su naturaleza, y en su humanidad. Esta es la razón por la que en esta época, en lugar de perspectivas humanistas, se proponen concepciones referidas 
a estructuras impersonales, casi divinizadas (como ya sucedió en el pensamiento de Spinoza), o soluciones holísticas, por ejemplo nuestra relación con el ambiente según la propuesta de Arne Naess, o la anti-especie de Peter Singer (Fabris, 2012).

¿Qué hacemos entonces con el llamado al rostro del Otro en este contexto? ¿De qué sirve este llamado si el rostro del Otro quizá sea el de un robot antropomórfico? Más allá de las reflexiones de Heidegger y Levinas es necesario, entonces, retomar el discurso en torno al humanismo y buscar nuevas vías para una elaboración más adecuada a la actualidad.

\section{El principio de la relación como principio de un nuevo humanismo}

Repitámoslo por última vez: el sentido común actual se caracteriza por una ambigüedad sustancial. Por un lado, está la reivindicación de derechos cada vez más específicos de un sujeto humano progresivamente encerrado en sí mismo, autoreferencial, fragmentado. Por otra parte, se encuentra el reconocimiento de su progresiva disolución y la transferencia de sus prerrogativas a una dimensión transhumana, que se presenta como un destino, y sobre la cual parece que no podemos tener ningún control. Por un lado, vivimos en la época de la hipermodernidad, y morimos de exceso de individualidad. Por el otro lado, sin embargo, asistimos al triunfo posmoderno de la tecnología, y nos confiamos a ella como a una nueva religión.

Ambos aspectos son complementarios entre sí, y así deben ser afrontados. No sólo desde una perspectiva teórica -analizando, entonces, sus características y consecuencias-, sino también, ante todo, en un plano ético: para reconocer entonces las modalidades correctas y genuinas de hacer frente a ellos e impulsar hacia una acción adecuada.

La pregunta por el humanismo hoy debe ser pensada en esta dirección. Pero tiene que serlo de manera renovada, y esto significa que se haga de una forma tal que no parta del ser humano, de su análisis y de su definición, sino de aquello que el ser humano hace, es decir, que no esté basada en un plano meramente teórico, sino que proceda de una forma ética. Exponiendo la manera como he intentado realizar mi más reciente investigación, se trata entonces de una profunda motivación ética que anima a la teoría. He llamado a este tipo de investigación que considera a la ética, a la puesta en acto de un buen comportamiento, el corazón mismo de la teoría, "TeorEtica" (Fabris, 2011). 
¿Cómo puede ayudarnos esta perspectiva a responder la pregunta por un nuevo humanismo? ¿Cómo opera la ética que se encuentra en el corazón de la teoría? Lo que hace la filosofía en cuanto TeorEtica es empezar de nuevo a partir de las relaciones -tal como ya nos enseñaron Heidegger y Levinas en el siglo XX: el ser humano es tal solamente en un contexto relacional. Pero estas relaciones no pueden ser solamente explicitadas, contempladas y analizadas, sino que tienen que ser practicadas, deben ser puestas en acto, precisamente como relaciones.

Sucede entonces que el principio del filosofar, pero también primordialmente el principio que caracteriza la humanidad del ser humano, se revela como algo que ciertamente está más allá del individuo aislado, pero de una manera completamente diferente a lo impersonal. No es algo que se impone como un destino, no es algo que escapa a nuestro control, sino que es más bien el principio de una interacción que cada uno de nosotros debe realizar. De esta manera, nos encontramos más allá de la alternativa entre el primado del sujeto individual, aparentemente señor del mundo, y la subordinación a una serie de procesos incontrolables. El ser humano, al contrario, está inserto en una relación en la cual interactúa. El principio es algo que es y que se realiza como relación, y que por tanto reclama e involucra nuestra responsabilidad concreta.

Desde este punto de vista, la relación no se lleva a cabo en un segundo momento, arbitrariamente, de parte de algo o alguien que como individuo sea capaz de afirmarse a sí mismo aisladamente. Al contrario: aquello que está como principio es la relación misma, pero no como algo que se impone insensatamente. Es una relación que nos precede, que nos involucra, y que para su plena realización requiere que cada uno de nosotros la ponga en práctica.

Se trata de una relación dinámica que se extiende efectivamente, que se amplía progresivamente. Es decir, la relación involucra generando otras relaciones; se realiza extendiéndose universalmente. Operando de esta manera, incita al individuo -suponiendo que éste quiera proponer de nuevo su carácter de fundamento exclusivo- a ir más allá de sí mismo, evitando ya las fijaciones de la teoría y el arbitrio de una relación sin motivo. La universalidad a la que me refiero ha de ser entendida correctamente: el principio universal no es algo que pueda ser fijado y que una vez fijado pueda ser contemplado, pues va más allá de la teoría: es principio ético. Lo es en virtud de la dinámica relacional que lo anima y que justamente la ética debe expresar y poner en 
obra. En otras palabras, no se trata de un principio que en su universalidad se contraponga a lo particular para luego ser aplicado a éste. Al contrario, en la medida en que es una relación capaz de incluir, que puede extenderse universalmente, se realiza entonces a través de aquellos elementos particulares que en nuestro presente se encuentran en relación mutua, y que requieren nuestro responsable cuidado.

La universalidad del principio universal puede ser entonces definida de una manera más precisa como "universabilidad": como potencial comunión, como crecimiento de un espacio común, como dinámica de difusión y de crecimiento del elemento particular en sus relaciones con otros elementos particulares. De este modo nace la comunidad, pero no por el miedo de los individuos en guerra. Esto es precisamente lo que impide que el individuo se conciba en su aislamiento absoluto y que se considere como sujeto completamente irresponsable, subordinado a un destino tecnológico que no es capaz de controlar.

Desde esta perspectiva, entonces, se puede desarrollar un nuevo humanismo adecuado a la situación que vivimos hoy. Pero eso puede realizarse solamente si nos asentamos en un terreno ético. La ética, en efecto, pensada como disciplina específica de la filosofía, hace exactamente esto: no solo estudia, sino que permite realizar las formas de la buena relación. La fórmula que expresa el carácter específico de la ética como disciplina filosófica es la fórmula en la que se manifiesta la condición misma de una buena relación. Dicha fórmula permite definir lo que es propiamente ético y lo que no lo es. Ella reza: la relación específicamente ética, en tanto que realiza el bien, es aquella que es capaz de producir otras relaciones que pueden extenderse potencialmente al infinito.

En síntesis: la relación ética opera como promulgadora de sí misma, por lo que ella es capaz de ser inclusiva y universal. Solamente de esta manera, entonces, pueden llevarse a cabo un pensamiento y una acción que tengan sentido y que puedan otorgar sentido a sus manifestaciones. Solamente de esta manera la vida del ser humano no está determinada por la alternativa entre el aislamiento prometeico y la aceptación impotente de su propio destino, sino que puede recorrer otros caminos. En suma, solo por este camino puede realizarse un nuevo humanismo adecuado a los desafíos de nuestro tiempo. 


\section{Referencias}

Descartes, R. (1984). Discours de méthode. Paris: Vrin.

Duque, F. (2002). Terror tras la postmodernidad. Madrid: Abada.

Fabris, A. (2011). TeorEtica. Filosofia della relazione. Brescia: Morcelliana.

Fabris, A. (2012). Etica delle nuove tecnologie. Brescia: La Scuola.

Hegel, G. W. F. (2016). Grundlinien der Philosophie des Rechts. Berlin: Walter de Gruyter

Heidegger, M. (1988). Prolegomena zur Geschichte des Zeitbegriffs. Jaeger. P. (Hrsg). (GA 20). Frankfurt a. M.: Klostermann.

Heidegger, M. (1977). Sein und Zeit. Herrmann. v. F. W. (Hrsg.). (GA 2). Frankfurt a. M.: Klostermann.

Heidegger, M. (1996). Brief üben den „Humanismus”. Wegmarken. Herrmann. v. F. W. (Hrsg.). (GA 9). Frankfurt a. M.: Klostermann.

Hintikka, J. (1967). Cogito, Ergo Sum: Inference or Performance? W. Doney (Ed.). Descartes. A Collection of Critical Essays. (pp. 108-139). Notre Dame: Univ. of Notre Dame Press.

Hobbes, T. (2014) Leviathan. London: Oxford University Press.

Levinas, E. (1987). Humanisme de l'autre homme. Paris: Livre de poche.

Levinas, E. (1990a). Totalité et infini. Paris: Livre de poche.

Levinas, E. (1990b) Autrement que'etre ou au-delà de l'essence. Paris: Livre de poche.

Levinas, E. (1995). Dieu, la mort et le temps. Paris: Livre de poche.

Levinas, E. (2009). Carnets de captivité et autres inédits Euvres complete, Tome 1). Paris: Grasset. 


\title{
Lenguaje, narración y cultura de la vida: la realidad inmanente de lo humano en la fenomenología de Michel Henry
}

\author{
Language, narration and culture of life: \\ the immanent reality of the human in the \\ phenomenology of Michel Henry ${ }^{l}$
}

Cesare del Mastro Puccio ${ }^{2}$

Universidad del Pacífico, Perú

Recepción: 15 de junio del 2020

Evaluación: 07 de julio del 2020

Aceptación: 20 de julio de 2020

1 Este artículo presenta algunos resultados del proyecto de investigación titulado "Lengua fenomenológica y escritura novelesca: investigaciones a partir de Michel Henry", iniciado en el Fondo Michel del Instituto Superior de Filosofía de la Universidad Católica de Lovaina - UCL, con el apoyo del Fondo Nacional de la Investigación Científica Belga - FNRS, y concluido en el Centro de Investigación de la Universidad del Pacífico en Lima.

2 Doctor en Filosofía, Magíster en Estudios ibéricos e iberoamericanos y Licenciado en Lingüística y Literatura con mención en Literatura hispánica de la Université Louvain-la Neuve, la Université catholique de Louvain y la Pontificia Universidad Católica del Perú, respectivamente.

Correo electrónico: c.delmastropuccio@up.edu.pe 


\title{
Resumen
}

A partir de los conceptos de "cultura" y "unidad ontológica de lo humano" en la fenomenología de la vida de Michel Henry, se afirma en este artículo la identidad entre el saber de la vida auto-afectiva y dos de los rasgos distintivos del viviente humano: la palabra y la narración. Abordada desde un lenguaje de la vida anterior a toda configuración lingüística y narrativa, la exposición a las palabras no se inscribe en el aparecer del mundo designado por ellas, sino en la realidad originaria del sentirse inmanente de la vida en ellas. Si bien todo lenguaje proviene del poder y del deseo de la vida subjetiva de experimentarse a sí misma en cada gesto del cuerpo, el hablar cotidiano y la creación literaria acrecientan de manera particularmente intensa dicha capacidad y dicho deseo. En efecto, lejos de representar la vida, la "narración del pathos" realiza la figuración inmediata del afecto y de la fuerza. Así, este trabajo pretende mostrar la novedad de la teoría henriana de los lenguajes del afecto respecto, por un lado, al debate en torno al humanismo y el post-humanismo y, por otro lado, al vínculo entre fenomenología y hermenéutica.

Palabras clave: Michel Henry, Paul Ricoeur, fenomenología, hermenéutica, humanismo.

\begin{abstract}
Based on the concepts of "culture" and "ontological unity of the human" in the phenomenology of life of Michel Henry, it is pointed out in this article the identity between the knowledge of self-affective life and two of the distinctive features of living human: the word and the narration. Approached from a language of life prior to any linguistic and narrative configuration, the exposure to words is not inscribed in the appearance of the world designated by them but in the original reality of feeling immanent in life in them. Although all language comes from the power and desire of the subjective life to experience itself in every gesture of the body, daily speech and literary creation increase in a particularly intense way this capacity and said desire. Indeed, far from representing life, the "narration of the pathos" realizes the immediate figuration of affect and force. Thus, this work aims to show the novelty of the Henrian theory of the languages of affect regarding, on the one hand, the debate around humanism and post-humanism and, on the other hand, the link between phenomenology and hermeneutics.
\end{abstract}

Keywords: Michel Henry, Paul Ricoeur, phenomenology, hermeneutics, humanism. 
En su libro de 1987, La barbarie, el fenomenólogo francés Michel Henry rechaza la reducción de la llamada crisis de la cultura a un simple momento en el que, como ha ocurrido siempre en la historia, tras una etapa de expansión viene un periodo de declive. Lo que acontece en nuestro tiempo es, por el contrario, "lo nunca visto". En efecto, a diferencia de los otros momentos de declive en los que "un nuevo despliegue tiene lugar, llevando más lejos el desarrollo de la vida" (Henry, 1996, pp. 15-16), a lo que nos enfrentamos hoy es a la destrucción misma de la vida. Ocurre que mientras que en otros periodos de la historia "era la totalidad de los valores que constituyen la humanidad los que se expandían a la vez" (Henry, 1996, pp. 15-16), la preeminencia del conocimiento objetivo y eficaz del que somos herederos desde la Modernidad ha desvinculado progresivamente el saber técnico de esa totalidad de valores; grave hundimiento que cuestiona nuestra existencia porque "es la misma vida la que es herida, son todos sus valores los que se tambalean; no solamente la estética, también la ética, lo sagrado -y con ellos la posibilidad de vivir cada día" (Henry, 1996, pp. 15-16).

"Lo nunca visto" es la ausencia radical de una perspectiva de conjunto sobre la existencia humana y su sentido. Los valores del arte, la ética y la religión se encuentran reducidos a la esfera de lo individual o a la mera decoración de lo que "realmente cuenta", es decir, de lo que es objetivo y útil. Henry denuncia la destrucción de la vida provocada por la ideología cientificista y técnica, ya que la praxis humana es amenazada en su constitución misma cada vez que la vida es olvidada en las estructuras de la cultura, del arte y de la educación. En efecto, vivir sin arte y sin memoria supone negar las expresiones más inmediatas de la realidad subjetiva y afectiva de la vida, la cual es substituida por una serie de abstracciones artificiales propuestas como el único saber válido. La barbarie denunciada por él consiste, pues, en un proceso de inversión de la lógica de crecimiento de la vida porque la primacía del saber objetivo impide que la afectividad y la sensibilidad proliferen en su deseo de experimentarse y de compartirse.

¿Cómo está involucrado el humanismo en esta barbarie; en qué medida este podría haber contribuido a la destrucción de la vida? Si la ontología de Michel Henry implica una filosofía del hombre, ¿cómo repensar lo humano en la realidad de la vida, en el ámbito de lo invisible, más acá de los rasgos de la humanitas, definidos por los diferentes humanismos a los que la historia de Occidente ha dado lugar? La primera parte de este artículo intenta responder a esta primera pregunta, mientras que los apartados segundo y 
tercero abordan la siguiente cuestión: ¿este enraizamiento inmanente de la humanitas en la vida subjetiva radical implica una redefinición de dos de los rasgos distintivos del viviente humano, a saber, el uso del lenguaje que hace de él un homo loquens, y la elaboración de relatos que permiten describirlo como homo narrans?

\section{De la dualidad humanista a la unidad ontológica de lo humano}

En la medida en que responde a una problemática ontológica radical, la filosofía del hombre de Henry se distancia del humanismo que define al ser humano a partir de rasgos exteriores, provenientes de la naturaleza o del pensamiento entendido como representación del mundo. En efecto, el problema radica en que dicho humanismo remite a un saber sobre el mundo que está ya siempre desarraigado del ámbito original del viviente humano, es decir, de la plenitud de la realidad en la inmanencia de su ser: esta vida subjetiva de naturaleza afectiva en la que él se experimenta a sí mismo de manera inmediata, "este ser esencialmente subjetivo y afectivo que marca con un índice de sufrimiento y de alegría todo lo que hace y todo lo que piensa" (DufourKowalska, 1996, p. 144) ${ }^{3}$. El saber humanista, que atribuye al ser humano los rasgos propios del homo loquens y del homo narrans no es, pues, el saber de la vida, sino el producto de definiciones elaboradas en el marco de una escuela. Construidas desde el exterior, dichas definiciones operan "fuera de la vida", según la estructura dual sujeto-mundo que pone al homo loquens delante de situaciones que él es capaz de representar a través de diferentes sistemas de signos. El ser humano observa luego satisfecho estos escenarios construidos por él; sin embargo, estos lo reafirman en una humanitas que no es ya fiel a lo real en su unicidad interna -aparecer invisible de la vida subjetiva en su pura inmanencia-, sino que proviene de una dualidad trascendente alienante -aparecer visible del mundo ante el sujeto.

La estructura dual en virtud de la cual se asocian el mundo-por-conocer y el sujeto-que-conoce, atraviesa todos los proyectos humanistas, tanto los que reivindican la trascendencia simbólico-axiológica del ser humano cuanto aquellos que se sitúan en el campo de su trascendencia técnico-científica. Así, por ejemplo, la orientación filológica del humanismo clásico estaba

\footnotetext{
Salvo que se indique lo contrario, todas las citas tomadas de obras escritas originalmente en francés han sido traducidas por el autor de este artículo.
} 
fundada en una antropología del lenguaje: el hombre habla y escribe porque es heredero de una tradición conformada por textos cuyo conocimiento lo distingue del resto de los seres vivos. El humanismo letrado confía en el poder de las propuestas de sentido del pasado para "domesticarnos": solo quien sabe apropiarse de las grandes obras del pensamiento y del arte de otros siglos se despoja de su "animalidad". Por su parte, el humanismo moderno subraya la condición de homo faber. El ser humano es valorado por su fuerza de trabajo, sumido en los instrumentos de la ciencia y la producción que conducen al progreso. El laboratorio y la fábrica se convierten en las nuevas bibliotecas; en ellas el ser humano traduce el mundo en lenguaje matemático y en artefacto, y se redime así de su "bestialidad". Si la estructura dual propia del humanismo clásico colocaba al homo loquens ante el objeto de su "intencionalidad filológica", la dualidad del humanismo moderno sitúa ora a la res cogitans ante la realidad visible que ella transforma en conocimiento, ora al homo faber frente a la realidad que él convierte en objeto manipulable y en producto de consumo. Todo rasgo distintivo del ser humano está fundado en esta dualidad humanista.

Incluso el discurso actual en torno al post-humanismo responde a esta estructura dual sujeto-objeto. Convertidos en los nuevos "domesticadores", sus representantes expulsan del parque humano al "club de lectores de obras antiguas", pero lo hacen a través de nuevos lenguajes en los que el sujeto sigue frente a la cara visible del mundo que él intenta transformar por medio de la convergencia de los avances de la tecnología, la biología y las ciencias cognitivas. Esta propuesta nos presenta nuevamente una definición de la especie humana "desde fuera", desde lo que el ser humano aún no es, pero podría llegar a ser: mientras que en el pasado el hombre produjo la técnica, hoy la técnica produce al ser humano y permite imaginarlo, en su constitución biológica misma, cualitativamente mejor. El post-humanismo prolonga el proyecto humanista de domesticación que pretende haber superado. En efecto, si el humanismo clásico definía al homo loquens por su relación con las letras del pasado, el post-humanismo imagina a la especie biológica humana mejorada gracias a la convergencia de los lenguajes de la biología y la técnica (Sloterdijk, 2000).

¿Es posible describir de otro modo lo humano en su posibilidad misma de experimentarse, por ejemplo, como este humano que habla y narra; desde un lenguaje de la vida anterior a todo esfuerzo de definición externa; desde una irrupción de lo humano en su realidad inmanente siempre afectiva, en 
su unidad original anterior a cualquier exigencia de "domesticación", en un espacio de inmediatez invisible en el que nada aparece y nada se ofrece al conocimiento - ni el lenguaje de los textos del pasado ni el innovador de la tecnología- y en el que, sin embargo, el lenguaje y los relatos son este resonar de la vida en mí, esta reconducción por ellos hacia mí mismo, hacia mi poder de sentir, hacia la capacidad de experimentarme como esta subjetividad radical que habla y narra? En la medida en que supera el esquema dual del humanismo, la unidad ontológica de la vida auto-afectiva henriana nos permite acercarnos al hablar y al narrar humanos de otro modo.

Para ello es necesario describir toda cultura como una cultura de la vida, en virtud de la cual lo humano se experimenta a sí mismo en su inmediatez y en su unidad antes de cualquier definición del hombre en clave cultural-libresca, científico-económica o biológico-técnica. Esto exige, a su vez, asumir la prioridad del aparecer de la vida sobre el aparecer del mundo, lo que nos remite a una de las experiencias fundamentales de Michel Henry. En 1943, el filósofo se compromete en la Resistencia y experimenta la vida de la clandestinidad:

La experiencia de la Resistencia tuvo una profunda influencia en mi concepción de la vida. (...) Durante todo este periodo, se tenía que disimular lo que uno pensaba e incluso lo que uno hacía. Gracias a esta hipocresía permanente, la esencia de la vida verdadera me era revelada: ella es invisible. En los peores momentos, cuando el mundo se volvía atroz, yo lo experimentaba en mí como un secreto que debía proteger y que me protegía. Una manifestación más profunda y más antigua que la del mundo determinaba nuestra condición de seres humanos (...) Comprendí desde ese momento que la salvación del individuo no puede venirle del mundo (Henry, 2007, pp. 13-14).

Desde sus primeras obras (1963 y 1965), Henry describe esta duplicidad del aparecer en la que se enfrentan la exterioridad de lo visible y la interioridad de lo invisible. Por un lado, el aparecer del mundo corresponde a la trascendencia que permite a una conciencia salir de ella misma para ser "conciencia de algo", un "algo" que se encuentra fuera de ella, una realidad exterior que se ofrece a la vista y al conocimiento que se pretende objetivo. Este terreno de lo visible corresponde al ámbito de la exterioridad en el que se distinguen lo que aparece, aquel ante quien algo aparece y el acto mismo de aparecer. Por otro lado, el aparecer de la vida adviene en la inmanencia que remite al individuo a su propio sentir-se y experimentar-se. No hay aquí, entonces, separación entre lo que aparece y aquel ante quien algo aparece, pues no hay 
nada que aparezca fuera del viviente. Se trata del ámbito de la interioridad en el que se da el aparecer mismo de la vida en su invisibilidad, en un "espacio" de inmediatez interior, en el acto mismo de aparecer entendido como el poder de experimentarse según diversas tonalidades afectivas.

A partir de una crítica radical de las filosofías que confinan la fenomenalidad al horizonte de la visibilidad de "un mundo", Henry se distancia de todo pensamiento que remite al hombre directamente al mundo, olvidando el vínculo con la vida misma, vínculo que precede, funda y genera el lazo con el mundo. El poder del cuerpo que percibe es, antes que un poder intencional ("conciencia de algo"), un poder patético, es decir, consentimiento interior a sentirse afectado, a sufrir-se en el deseo de experimentar-se como subjetividad absoluta. Todo aparecer del mundo es posible gracias a este fondo de subjetividad $\mathrm{y}$, a su vez, toda percepción del mundo reconduce a este espacio invisible en el que el cuerpo viviente está en una postura de unidad y de coincidencia consigo mismo, con su poder de ser afectado al afectar-se: "Es, en suma, el inmenso proyecto de una fenomenología de la afectividad en la que ésta no es concebida como un simple contenido de experiencia, sino como la condición interior y primera de toda experiencia posible" (Leclercq, 2010, p. 15).

Este proyecto conduce al filósofo francés a considerar que toda cultura se basa en un saber distinto al de la ciencia y al de la conciencia: "Este saber es precisamente el de la vida, la cual, según nosotros hemos dado a entender, constituye por esencia tal saber, al ser ella el hecho mismo de experimentarse a sí misma en cada punto de su ser, y al ser así autorrevelación con la que comienza y acaba la vida" (Henry, 1996, p. 26). Henry ilustra este saber de la vida a través del ejemplo de un estudiante de biología. Este mueve sus manos para pasar las hojas de un manual en cuyas páginas está contenido el saber de una ciencia particular referido, en este caso, al código genético. Simultáneamente, mueve sus ojos para dar lugar, a través de la identificación de una serie de caracteres impresos, a un proceso complejo de conceptualización que corresponde al saber de su conciencia, realidad mental en la que se asocian una serie de significantes a sus correspondientes significados. Sin embargo, "no es el saber científico el que le permite adquirir el saber científico contenido en el libro; no es gracias a él por lo que mueve sus manos o sus ojos, o concentra su espíritu" (Henry, 1996, p. 27). Efectivamente, el saber abstracto que nos coloca ante el contenido del libro que se encuentra ahí-delante, no es el "saber-mover-las-manos" ni el "saber-mover-los-ojos". En su concreción, estos últimos corresponden al saber de la vida porque no 
son objetivos en sentido alguno, no tienen objeto porque no suponen relación con el objeto. No existe aquí la distancia de la objetividad. ¿Cómo describir, entonces, este saber de la vida que es el del movimiento mismo de las manos que pasan las páginas del libro y el de los ojos que leen? Henry responde:

La capacidad de unirse al poder de las manos y de identificarse con él, de ser lo que él es y hacer lo que él hace, solo la posee un saber que se confunde con ese poder porque no es sino la experiencia que éste hace constantemente de sí; porque no es sino su subjetividad radical (...) un saber que no ve nada y para el que no hay nada que ver, que consiste, al contrario, en la subjetividad inmanente de su pura experiencia de sí y en el pathos de esta experiencia: este es el saber de la vida (Henry, 1996, pp. 27-28).

Esta fidelidad a la realidad inmanente de la vida permite tomar distancia respecto de algunas de las definiciones del ser humano propuestas por el humanismo moderno para pasar, de esta manera, de la dualidad epistemológica humanista a la unidad ontológica de lo humano. Henry se distancia de la idea según la cual el ser humano se distingue debido al pensamiento, ya que al postular que el poder de la conciencia radica en representarse una cosa como esto o aquello, se asume la dualidad en virtud de la cual al representarme algo, estamos ante la cosa puesta delante de mí y mi mirada: el objeto se muestra a partir de las propiedades con las que él aparece en el mundo según mi representación. Por su lado, el realismo objetivista de la ciencia y del marxismo mantiene esta dualidad, debido a que el universo material supone necesariamente el poder de la conciencia ante la que los objetos aparecen y sin la cual estos no existirían. Con la pretensión de superarlo, el realismo del objeto repite en el fondo la dualidad del idealismo de la conciencia.

¿Cuál es, entonces, esta realidad irreductible a las representaciones de la conciencia? ¿Cómo describirla sin caer prisioneros de la dicotomía sujeto-objeto de la que dependen tanto la definición idealista del ser humano cuanto aquella que pretende abordarlo desde una realidad objetiva y material? Henry sostiene que "hay que decir con Marx: esta realidad es la realidad de la vida. En su lenguaje: la realidad de la historia es la de los individuos vivientes; la realidad social es una praxis subjetiva" (Henry, 1990, p. 42). El individuo está ya siempre inmerso en la vida, sumergido por ella y en ella: se trata, pues, de volver a la realidad de lo humano en su inmanencia original, en su unidad ontológica, en su coincidencia fundamental con la vida auto-afectiva. Ningún lenguaje exterior "domestica al hombre", porque la realidad de lo humano está ya siempre dada como esta vida subjetiva radical. La determinación 
fundamental y original del ser desde la que se asume lo humano es la subjetividad que se define y se realiza en ella misma, en su inmanencia radical y en su auto-afección, anteriores a la trascendencia que el humanismo busca en el conocimiento de los textos o de la realidad material y social. En consecuencia, abordar lo humano desde el punto de vista ontológico implica reconocer que las representaciones de los mundos letrado, social y técnico-científico, a partir de las cuales los diversos humanismos confieren al ser humano sus rasgos distintivos, tienen como condición de posibilidad un fenómeno más original que la trascendencia: la vida subjetiva absoluta presente a ella misma en el seno de su auto-afección en la inmanencia.

Henry considera que las representaciones del ser humano elaboradas por las ideologías comunista y capitalista, niegan esta inmanencia de la vida al reemplazar los afectos y la fuerza de los individuos reales en su existencia cotidiana por categorías abstractas, tales como la sociedad, el pueblo, la historia, las clases sociales, la técnica, la producción y el consumo. El "universo de la muerte" se impone y excluye todas las manifestaciones inmediatas del "universo de la vida": lo bello, lo bueno, lo sagrado. Se ha olvidado, por ejemplo, que el fundamento del universo económico está en esta realidad de la vida que, además de caracterizarse por la subjetividad, es una fuerza, un poder productivo. Cuando se olvida que la vida es el fundamento de todo proceso real de producción y que, como sostiene Marx, toda actividad humana es ante todo una fuerza subjetiva de trabajo, entonces tiene lugar la alienación: la vida de los individuos reales -fuerza y afecto- es reducida a una proyección conceptual, a un "ser colectivo" incapaz de sentirse a sí mismo, de desear, de sufrir y gozar. Separado de la idea que él ejemplifica imperfectamente, pudiendo incluso ser sacrificado en nombre de esa idea, el individuo es considerado por las realizaciones históricas del humanismo moderno como un ejemplar de la especie, un instrumento al servicio de un proyecto, un número prescindible, un efecto de las leyes científicas, sociales y económicas. En rechazo a este olvido de lo humano en su realidad y en su concreción, Henry afirma que la realidad inmanente de la vida -la estructura misma del ser- tiene:

La forma de una existencia cada vez individual: (...) esta experiencia singular que se vive y se experimenta a ella misma, (...) que siente y que se siente primero a sí mismo, constantemente afectado por sí mismo y por nada más, y que no es nada más: ninguna alteridad, ninguna objetividad que se pueda ver o tocar, sino, por el contrario, lo que ve y toca, que toma y que actúa" (Henry, 1990, p. 33). 
El comunismo y el capitalismo son precisamente, según Henry, el resultado de haber substituido la vida del individuo real por una serie de entidades abstractas dependientes de la dualidad sujeto-objeto. El racionalismo, en virtud del cual la objetividad de la ciencia moderna es la única garantía de la verdad y del ser, conduce a la negación del individuo: esta razón objetiva y sin vida sobre la cual se fundan el humanismo y el post-humanismo no sabe nada del hombre. El orden ontológico del ser -las potencialidades subjetivas de cada individuo viviente- es reemplazado por "la irrealidad de una entidad objetiva, trascendente, extraña por naturaleza a su vida inmanente. La inversión teórica explica inmediatamente, en los regímenes que ella determina, las perversiones prácticas" (Dufour-Kowalska, 1996, p. 146). En las antípodas del "universo de la muerte" comunista y capitalista, el filósofo reivindica la vida de los afectos y de la fuerza que confieren realidad humana a cada una de las acciones y creaciones del individuo. Como se señaló antes, este individuo real:

(...) no es únicamente el índice de un valor posible, y en consecuencia contingente y variable, sino el origen absoluto de todo valor, porque el individuo encierra la plenitud de la realidad en la inmanencia de su ser, es decir, en esta vida subjetiva de naturaleza afectiva que lo constituye y lo distingue de una piedra o de un robot. [El individuo es] este ser esencialmente subjetivo y afectivo, que marca con un índice de sufrimiento y de dicha todo lo que hace y todo lo que piensa (Henry, 1990, p. 144).

Lejos de la autosuficiencia del homo faber, Henry recuerda que el individuo creador de la economía, y de la cultura en general, no se ha creado a sí mismo. En la medida en que se ha recibido de la vida ya siempre a sí mismo, él es pasivo respecto de su propio ser. Esta pasividad que funda toda posibilidad de acción y de creación cultural marca la esencia original de la realidad inmanente de lo humano:

Es justamente esta pasividad radical del individuo respecto de sí mismo lo que hace de él un viviente. Porque la vida consiste en experimentarse uno mismo de manera tal que esta experiencia es insuperable, que nadie tiene el poder de escapar de ella, de deshacerse de su vida, de ponerla o tenerla a distancia de la manera que fuere. Como viviente (...), el individuo es puesto en la situación que es la suya, la de no haberse creado sino encontrarse a sí mismo, estar siempre de alguna manera ya allí para sí mismo, como si su propio ser lo precediera de cierta manera, como si él fuese segundo no, sin duda, en relación con lo que él quiere cada vez sino respecto del brote primitivo e ininterrumpido de la vida en él. Ser un viviente es ser esto: es nacer de la 
vida, ser llevado, engendrado por ella, de manera que este nacimiento y este engendramiento no cesan, que el individuo solo es la experiencia de este engendramiento interior ininterrumpido que resuena a través de él sin que él lo haya querido y con el que, sin embargo, él se confunde (Henry, 1990, p. 34).

\section{Homo loquens: del lenguaje del mundo al lenguaje de la vida}

Aplicado este proyecto fenomenológico a la descripción del lenguaje como rasgo distintivo del homo loquens, ¿es posible distinguir un lenguaje del mundo y un lenguaje de la vida? Si el aparecer es doble -aparecer mediato del mundo como configuración de sentido y distancia, aparecer inmediato de la vida como fuerza y afecto- y la estructura del lenguaje coincide con la del aparecer, entonces el lenguaje está marcado con el sello de esta duplicidad: lenguaje del mundo (o Logos de la trascendencia) y lenguaje de la vida (o Palabra de la vida):

Si (...) la fenomenalidad se fenomenaliza originariamente según un modo de fenomenalización radicalmente diferente al del mundo, a saber la vida misma comprendida en su esencia fenomenológica pura como autorrevelación, entonces debe existir, tributario de este modo de fenomenalización propio de la vida y en la medida que este se opone rasgo por rasgo al aparecer del mundo, un lenguaje distinto al del mundo, distinto a este lenguaje hecho de significados noemáticos ajenos a la realidad de su referente y al que se limita en general el concepto de lenguaje (Henry, 2004a, p. 335).

Como en todo aparecer, en el lenguaje puede operarse el olvido de la vida. Esto ocurre cuando el sentido, asumido como representación o como configuración de significados noemáticos, introduce una distancia respecto de la realidad inmediata e interna del afecto: la falsificación del pathos en la designación de la cosa por medio de la palabra, en la representación de un evento por medio de la combinación de unidades lingüísticas. Cada vez que, en palabras de Henry, el lenguaje es reducido al cristal transparente del tren a través del cual observamos el paisaje, aquel se agota en su función referencial y niega el aparecer de la vida; en este caso, "el lenguaje no existe (...) Este lenguaje no es, de ningún modo, lenguaje de sí mismo, es siempre lenguaje de otra cosa y se borra delante de esta referencia" (Henry, 2004b, p. 322). Por ejemplo, al decir "el ladrido de este perro me molesta", las palabras empleadas y la frase construida con ellas solo valen en tanto remiten al perro real, es decir, en virtud de una referencia externa que hace invisible e incluso inexistente el lenguaje mismo. Esta distancia establecida entre el lenguaje y 
la realidad se produce cuando el primero aparece según el aparecer del mundo: el empleo de signos lingüísticos, y de las reglas necesarias para su combinación, corresponde a la designación de una serie de elementos que participan en un evento cuyo lugar es el mundo exterior al lenguaje. El lenguaje del mundo niega, de esta manera, la experiencia interna que la vida subjetiva tiene de su propia expresión en el instante en el que, expresándose, se siente a sí misma como este viviente específico que habla y narra. El lenguaje del mundo olvida que la experiencia inmanente de la expresión (o Palabra de la vida) precede siempre a la representación trascendente de dicha experiencia.

No obstante, esta aproximación negativa al lenguaje como lenguaje del mundo es superada por el lenguaje de la vida, entendido como expresión inmediata de la fuerza y del afecto que distinguen lo humano. En efecto, el lenguaje de la vida reconduce tanto el lenguaje del cuerpo, como a las lenguas naturales, a la pura experiencia de sí del cuerpo subjetivo originario: en cada percepción, en cada gesto y en cada acto de habla hay, más que signos que designan un contenido objetivo o ideal, una revelación de la vida a sí misma. El lenguaje de la vida habla allí donde ésta no dice nada más que ella misma: la vida que adviene a sí en la pura experiencia de sí.

Este lenguaje de la vida funda el lenguaje del cuerpo. Todo movimiento percibido desde y por el cuerpo orgánico remite, antes que a un significado exterior, al movimiento corporal mismo, al cuerpo subjetivo originario. Este último funda la realidad del primero como movimiento interior de la vida que no cesa de advenir a ella misma, puesto que en cada uno de los movimientos del cuerpo la vida se dice a sí misma. En este sentido, cada gesto del cuerpo es "símbolo primero", pues su poder significativo es experimentado en la inmanencia de la extensión interior que le es propia. El lenguaje de la vida, que hace posible el "lenguaje corporal en su exteriorización", no sale nunca de su interioridad, ya que remite al puro sentirse y experimentarse como cuerpo que lleva en sí lo invisible que es su propia vida. El lenguaje del cuerpo no es tal porque remita a un contenido en el mundo, sino porque reconduce al propio poder de sentir del cuerpo subjetivo, a un cuerpo en posesión de sus poderes, porque expresa algo que no se ve: una Palabra de la vida, lo humano que se experimenta dado a sí mismo.

Asumido así, como lenguaje de la vida, el lenguaje del cuerpo debe ser descrito por un saber distinto al de la ciencia y al de la conciencia, según se vio en el ejemplo del estudiante de biología. El poder del cuerpo que percibe 
es un poder patético, es decir, consentimiento interior a sentirse afectado, a sufrirse en el deseo de experimentarse como subjetividad absoluta. Aquello que nuestro cuerpo percibe "afuera" es ya siempre, en su origen, pura interioridad. Lejos de constituir el término o correlato trascendente de la conciencia intencional, el árbol percibido afecta al cuerpo viviente en la medida en que lo remite a su poder de sentir, al pathos vivido por quien no puede dejar de ser afectado por esta percepción en toda su radicalidad presente, aquí y ahora. El mundo es simbólico debido a que toda percepción de "lo otro" remite a una pura experiencia afectiva del cuerpo originario. Se puede ilustrar este lenguaje del cuerpo como lenguaje de la vida a través de la manera como, en mi percepción de este árbol, dicho árbol significa:

Este árbol lleva en él toda una constelación de significados que tienen su lugar en mi cuerpo orgánico: su verticalidad que remite a una pura experiencia interior (la de mi propia estatura, la de estar de pie en lucha contra el peso de la gravedad), su verde profundo que ofrece una sombra refrescante en verano, su surgimiento de la tierra, sus raíces sólidamente clavadas, su solidez, la rugosidad de su corteza, la unidad en la que aparece ante mí, experiencias interiores que tienen lugar en la vida inmanente (Vidalin, 2006, p. 62).

En cuanto a las lenguas naturales, hay en el hablar y el escuchar una revelación de la vida a sí misma, en la medida en que el hablante se experimenta y se siente como el hablante que es: no hay separación entre él mismo y su hablar. Las palabras presuponen esta subjetividad que desea poder-sentirse-hablar-y-escuchar: revelación originaria en la que no hay signos, pero que funda y hace resonar toda expresión verbal. La lectura de la teoría de Maine de Biran acerca del doble empleo de los signos, desarrollada por el joven Henry, permite describir, por ejemplo, cómo la palabra "ver" constituye un signo de la experiencia de la visión, que ella expresa en el lenguaje solo en tanto dicha palabra remite a lo que llamamos su interioridad o su profundidad, a saber, la manera como este signo lingüístico coincide con la experiencia interna de la visión: la manera como "el lenguaje está fundado en la vida de la subjetividad absoluta que él expresa" (Henry, 1965, pp. 153-155). Pero no solo el lenguaje natural que expresa inmediatamente la vida de la subjetividad remite incesantemente a esta última. Lo propio ocurre con las operaciones en apariencia mediatas del lenguaje de la reflexión. En efecto, puesto que la representación de la visión como correlato intencional de la reflexión que yo dirijo sobre ella cuando digo "yo veo", ya no es "la visión que ve", esta expresión verbal "presupone la visión real como su fundamento" (Henry, 1965, 
pp. 153-155); en otras palabras, antes de erigirse en designación de la visión en la esfera del ser trascendente, la frase "yo veo" remite a la interioridad del pronombre y del verbo en cuestión, que son el experimentarse inmanente e invisible del ver en su inmediatez patética. Antes de dar cuenta del saber de la conciencia, la construcción verbal "yo veo" coincide con la unidad del saber primitivo del ver como experiencia interna del ser subjetivo del cuerpo, como lenguaje de la vida:

Suponiendo que las palabras "yo veo" designen la representación de mi visión y no mi visión misma, es sobre ésta, sin embargo, sobre su experiencia radicalmente inmanente y sobre ella sola, que reposa en última instancia su significación (...). En el seno de esta vida sensible y motriz que se conoce originariamente a sí misma, y no en la representación de nuestros órganos o de sus propiedades, los signos a través de los cuales expresamos sus diversas modalidades encuentran contenido y sentido (Henry, 1965, pp. 153-155).

Las expresiones verbales entran en posesión de ellas mismas bajo las diversas tonalidades afectivas del cuerpo que se experimenta como cuerpo-que-habla-y-escucha. Las palabras entran en posesión de la realidad de su significado cuando no olvidan su condición de pura experiencia afectiva, del mismo modo como "un color, por ejemplo, una sensación de color, es siempre experimentada y se experimenta ella misma al mismo tiempo que es vista" (Dufour-Kowalska, 1996, p. 189). La encarnación de la palabra en la voz, tal como es simbolizada por la fonación emitida por las cuerdas vocales y transmitida por la garganta y la boca, da testimonio de esta realidad de las lenguas naturales en su experiencia inmanente interior. En esta remisión incesante de cada palabra al saber interior de la vida (sentirse-escuchar-y-hablar), la intencionalidad lingüística se experimenta como poder del cuerpo viviente en el que la vida quiere significarse a ella misma. Una expresión verbal:

(...) solo puede alcanzar tal o tal significado si ya está en posesión, no solamente de ella misma (auto-afección de la trascendencia), sino de la realidad de este significado como pura experiencia afectiva del cuerpo orgánico. Designar el árbol con la palabra "árbol" es posible únicamente porque estoy en posesión de él a través de esta memoria de mi cuerpo que lleva en ella todas las experiencias de mi vida por las cuales estuve presente ante un árbol al estar presente ante mí mismo. Esta es la razón por la cual esta designación es posible, incluso en la ausencia del árbol (Vidalin, 2006, p. 65).

Todo lo que significa en la percepción y en las lenguas naturales remite a aquello que no se manifiesta; a lo invisible. O, como afirma Henry, "se puede 
extender la demostración al mundo que también está hecho de formas y de colores, y mostrar que en el fondo la revelación es doble: todo lo que se muestra fuera de mí [lenguaje del mundo] se revela conjuntamente como un desarrollo de la vida en mí [lenguaje de la vida]. El universo tiene, entonces, su realidad en nuestra vida en tanto esta es dinámica y patética" (Henry, 2007, p. 110). Puesto que el Logos de la trascendencia es ante todo 'Palabra de la vida', podemos estar presentes ante las cosas y ante las palabras tal como nos son dadas porque estamos ya siempre, originariamente, presentes ante nosotros mismos.

\section{Homo narrans: del conocimiento del texto a la exposición patética al relato}

La concepción de la humanitas propia del antropocentrismo renacentista, reafirmada por el pensamiento moderno, se tradujo en el campo de la aproximación a los textos, en los proyectos estrictamente filológicos orientados a conocer la intención original del autor en el marco de un horizonte histórico preciso. En su intención de conocer el texto a partir de este método, en lugar de dejarse abordar por él, el lector-filólogo coincide con el lector-estructuralista. Allí donde el primero funda su erudición en el develamiento de la verdad sobre el origen de los escritos, el segundo hace suyos los esfuerzos de la narratología por constituir una verdadera ciencia del relato basada en la distinción entre el aspecto interno y ficcional del texto, por un lado, y la dimensión externa y real del mismo, por otro lado. Solo si se mantiene dentro de las fronteras del texto, el estudioso de la literatura será capaz de emprender la reconstrucción racional de las reglas subyacentes a la actividad narrativa.

Sin desconocer los aportes de estas dos empresas -filología y narratología-al estudio de la configuración del relato, ellas resultan insuficientes para quien quiere escuchar "el Decir" de una palabra viva nunca ofrecida al conocimiento definido de "lo dicho", nunca reducida a su pretendida adecuación a las expectativas de un método preciso; en otras palabras, para quien rechaza el "irracionalismo de la comprensión inmediata", así como el "racionalismo de la explicación que extendería al texto el análisis estructural de los sistemas de signos" (Mongin, 1994, p. 135). Por ello, la hermenéutica en tanto fenomenología de la experiencia literaria tal como la vive el lector, se asume a sí misma como la descripción de una "inteligencia narrativa siempre previa" y, por ello, crítica respecto de "la decisión metodológica, propia del análisis estructural, de tratar a la literatura con las categorías lingüísticas que imponen la distinción entre lo 
interno y lo externo", oposición contraria a "aquello que hemos comprendido, cuando niños, como una historia” (Ricoeur, 2009, p. 49).

La hermenéutica ha llevado a cabo un desplazamiento del lector-filólogo-estructuralista hacia el lector-pastor-del-ser heideggeriano, el lector-interlocutor levinasiano y el receptor-vivo de Ricœur. Aunque cada uno de estos lectores merecería un desarrollo detenido, baste resaltar, para los fines de este artículo, que los tres son confrontados a los textos en su exterioridad y en su alteridad: los tres se abren a propuestas de sentido que los preceden, que no provienen de ellos mismos y que, por ello, no agotan su densidad en los métodos del científico de la literatura. En el caso de Heidegger, este movimiento de exposición a "lo otro" remite al horizonte del ser cuya casa es la poesía. En el pensamiento del joven Levinas, dicho movimiento implica dejarse interpelar por los textos del pasado como quien escucha el llamado de un interlocutor, con todo el vigor de la oralidad y del diálogo entre maestro y discípulo, para descubrir la expresión (el poder decir de una palabra-viva) que supera la intención (el querer decir de las palabras-signo o las palabras-imagen fijadas por la escritura) (Levinas, 2011). En la obra de Ricœur, esta salida de uno mismo se realiza al acoger las narraciones recibidas de la cultura que nos precede, cuyas intrigas coinciden con nuestra temporalidad humana y hacen posible la conformación de nuestra identidad narrativa. Estas tres formas de alteridad narrativa fundan, respectivamente, la proyección de un mundo, la responsabilidad frente al rostro del Otro y la identidad de un cogito herido y capaz.

Como es evidente, esta alteridad narrativa exige mantener una dualidad que pretende integrar lo interno y lo externo. Desde esta dualidad define Ricœur el espacio de intersección en el que se ubica la hermenéutica, a saber, el punto de unión entre la configuración (interna) del sentido en el relato y la refiguración (externa) de la vida por medio del relato: la posibilidad de "hacer cercano lo lejano" al interpretar (Ricoeur, 1983). Pero ¿cómo describir este modo de lo imaginario en cuyo seno la historia narrada en estructuras lingüísticas precisas, y desde una estructuración ficcional de la intriga, es al mismo tiempo -no en dos tiempos- vivida? ¿Cuál es, fenomenológicamente, el fondo de unidad y de simultaneidad primeras sobre el cual resuenan a la vez lo narrado y lo vivido, lo ficticio y lo real, antes de cualquier distinción entre el antes y el después del texto; antes de que el mundo vivido $u$ horizonte del lector se comprenda una vez levantado ante él el horizonte o mundo del texto; con anterioridad, entonces, a la separación entre el ser humano y el mundo, entre 
el ser humano y los otros seres humanos, entre el ser humano y él mismo, instancias cuya mutua comprensión está garantizada, según Ricœur, por toda mediación anamnética ficcional que tenga como sujeto narrativo a uno cuya historia desea efectuarse según el modo de la referencialidad no descriptiva, la comunicabilidad no utilitaria y la reflexividad no narcisista? (Ricoeur, 2009, pp. 49-50).

Si intentamos responder a estas preguntas a la luz de la fenomenología henriana del lenguaje, expuesta en el apartado anterior, podemos sostener que las narraciones a las que el viviente humano es expuesto, resuenan en el ámbito inmanente de la auto-afección del que provienen: ellas son, antes que una refiguración de la acción en el mundo, lenguaje de la vida. Este nivel de interioridad auto-afectiva, de inmediatez patética, es, precisamente, el "fondo de unidad primera" al que aluden las preguntas formuladas en el párrafo anterior. Se trata de la realidad inmanente de lo humano en su poder de auto-afección: el pathos fundamental al que los relatos remiten, y en el que lo humano se experimenta y se acrecienta sin cesar.

Puesto que esta realidad inmanente de lo humano funda toda experiencia, sin ser ella misma fundada, los relatos inscritos en la cultura de la vida subjetiva radical exceden el régimen del significado y, con él, las representaciones del ser humano elaboradas por el humanismo clásico, el humanismo moderno y el post-humanismo. Se pueden señalar tres consecuencias importantes de esta aproximación henriana al homo narrans en el marco de una cultura de la vida auto-afectiva:

a) Antes de cumplir el rol de mediación simbólica, antes de ser interpretados en el marco del universo simbólico de una cultura, los relatos son elaborados y transformados por el deseo de la vida subjetiva de experimentarse y de sentirse a sí misma en el seno de las narraciones a las que es expuesta. Los relatos son, en este sentido, lo que la vida elabora y transforma (la vida como sujeto del narrar humano). Pero, en el deseo de significarse a sí misma, la vida resulta ser también lo que es elaborado y transformado por los relatos (la vida como objeto del narrar humano). El saber de la vida que hace posible toda creación narrativa y que, simultáneamente, es repotenciado por ésta, es el saber de la cultura: "Toda cultura es una cultura de la vida, en el doble sentido en que la vida constituye a la vez el sujeto de esta cultura y su objeto. Es una acción que la vida ejerce sobre sí misma y por la que se transforma a sí misma en cuanto que es ella misma la que transforma y lo que es transformado" (Henry, 1987, p. 19). 
b) Sobre el fondo de la auto-afección, cada exposición a los relatos confronta al viviente a un debate interno que coincide con la dinámica misma de la vida. En efecto, la exposición a los relatos del pasado coincide con el deseo de la vida de auto-afectarse en esta adhesión primera e inevitable a sí misma, en este no poder distanciarse ni escapar de sí - pathos del sufrimiento-, que se transforma de inmediato en la alegría de sentirse aún más, de modificarse y recrearse a través de nuevas experiencias de escritura y de lectura-pathos del gozo de la creación y de la recepción literarias. En virtud de este debate afectivo interno, la vida subjetiva consiente a dejarse afectar por las imágenes y el ritmo de los relatos, los cuales constituyen descargas creativas del pathos de la vida. Como toda expresión de la cultura, los relatos expresan el pathos cargado de sí mismo -instante del sufrimiento- $\mathrm{y}$ abren, a la vez, a un movimiento igualmente patético de catarsis - momento de la exaltación, de la ebriedad:

(...) el arte ha tenido por móvil este pathos cargado de sí mismo, que quiere descargarse de su propio peso y que, al no poder hacerlo, se modifica profundamente por la alegría, por la dicha-el arte es un arte de dicha para mí, incluso cuando cuenta cosas atroces (...). Porque la vida es siempre este esfuerzo que atraviesa el sufrimiento, el malestar, para ir hacia una cierta liberación (Henry, 2004b, p. 323).

De esta manera se encuentran ya siempre fusionadas, antes de cualquier distinción entre lo interno y lo externo, la exposición a los relatos y la realidad inmanente de lo humano, cuya fuerza irrumpe de una manera particularmente intensa cuando la vida subjetiva se siente afectada por la intriga de los relatos de ficción -exposición padecida en el "aquí y ahora" de la configuración textual-, pathos del sufrimiento que deviene de inmediato en pathos del gozo, es decir, en deseo de gozar de nuevas variaciones imaginativas, de fuerzas y márgenes de acción inéditos -apertura al "allá" de múltiples refiguraciones y connotaciones.

c) Puesto que coinciden con la realidad auto-afectiva de lo humano, tanto en la violencia y el peso de su adhesión a la vida como en su deseo de acrecentarse en cada nueva expresión cultural, los elementos del relato expresan de manera inmediata el sufrir y el gozar de la vida subjetiva por un fenómeno de co-impresión. En efecto, antes de toda "operación dinámica de puesta en intriga", dichos elementos remiten a aquello que no se manifiesta, a lo invisible. Los relatos dan testimonio de la profundidad de 
lo visible: estas narraciones significan en el horizonte de la exterioridad $\mathrm{y}$, sin embargo, resuenan en nosotros según su tonalidad interior. Y tienen un interior porque la vida de los relatos es esta vibración, este quiebre estremecedor de nuestra vida:

En cuanto a los objetos, solo nos tocan y solo existen en esta resonancia patética, su experiencia es nuestra subjetividad misma. Es cierto que hemos dejado de oír esta resonancia en las cosas más simples. Su uso inmediato, hacia el que nos empuja la existencia ordinaria, ha cubierto con un velo su sonoridad profunda. La función de extrañeza del arte, al superar el significado de utensilio del que los objetos se cargan en los asuntos cotidianos, consiste en devolver a los objetos eso que llamamos su vida: este estremecimiento de la nuestra, este estremecimiento en el que ellos nos advienen (Henry, 2004c, p. 239).

Las palabras explotadas en su fuerza sensorial y afectiva -más allá de la pretendida univocidad de los conceptos- provienen de este deseo de auto-afectarse de la vida como apertura a sensaciones y significados inéditos potenciados por la materialidad misma de los relatos. Esta materialidad es dinámica y patética, ya que su función referencial (exterior al lector) queda subordinada a la impresión de las palabras en el espacio invisible de la subjetividad: "el lugar del arte no tiene nada de objetivo (...) el universo de la pintura [como el de la literatura] no es el de lo visible" sobre todo si "el ser de cada color [como el de cada palabra] no es, en realidad, sino su impresión en nosotros" (Henry, 2004d, p. 284). El despliegue icónico de lo real, operado según Ricœur por la literatura, persigue entonces, antes que la extensión de nuestra visión del mundo, el acrecentarse de "la sensibilidad de las formas, su poder de ser experimentadas por nosotros, la auto-afección constitutiva de todo ser sensible" (Dufour-Kowalska, 1996, pp. 239-240).

Antes de proponernos un mundo en el que podríamos habitar, las representaciones de la praxis humana propuestas por el quehacer narrativo en el marco de los diversos humanismos, nos remiten a la realidad inmanente del pathos de la vida. En lugar de responder a la abstracción de las leyes internas del relato propias de la semiótica narrativa, la interioridad patética de los relatos, fundada en una cultura de la vida auto-afectiva, traduce el arraigo de las narraciones en la vida subjetiva radical: la remisión incesante del cuerpo subjetivo a la realidad inmanente de lo humano en el instante de su exposición al cuerpo viviente de los relatos. 


\section{Conclusión: la educación semántica o la recuperación de lo humano}

A partir de estas pistas de reflexión elaboradas en diálogo con Michel Henry, proponemos revalorar la exposición a los relatos del pasado en el marco de una cultura de la vida y de la educación semántica: el trabajo por el desarrollo humano supone también exponer al viviente a la creatividad lingüística y a la densidad humana de los relatos propios y ajenos. Se trata de asumir, en diversos espacios de formación, la lectura de las narraciones de nuestra y de otras tradiciones culturales en tanto experiencia radical de una subjetividad, es decir, en tanto realidad humana que se siente y se experimenta como la vida que es, gracias a la manera como los elementos del relato son elaborados y transformados por la vida, y son a la vez los agentes de elaboración y de transformación de la vida.

La realidad inmanente de lo humano se desea a sí misma en el "aquí y ahora" de la configuración narrativa y, simultáneamente, es apertura al "allá" de las múltiples connotaciones que la interpretación atenta del relato consigue escuchar. Los relatos que no debemos dejar de transmitir de generación en generación, provienen de este movimiento inmanente de lo humano y permiten a este movimiento proliferar en el lector que es expuesto a dichas narraciones. En efecto, los relatos del pasado exponen al viviente a su propia humanidad, en la medida en que quien lee o escucha se siente afectado por el ritmo y por la densidad existencial del relato que le es ofrecido. Pero este movimiento de auto-afección puede abrirse al rostro del otro ficcional que habita el relato, así como al de aquellos con quienes los textos pueden compartirse y recrearse. Por ello, este pathos radical al que el relato nos enfrenta, se transforma en el deseo de compartir dicho relato con el otro, quien se descubre capaz de recrear esta narración y abrirse, así, a todas las expresiones culturales en las que la realidad inmanente de lo humano se auto-afecta y crece.

En consecuencia, la exposición a los relatos del pasado constituye una respuesta a la barbarie de "lo nunca visto", porque en dicha exposición se integran los valores que el predominio de la técnica tiende a desarticular: la realidad inmanente de lo humano en las manifestaciones de lo bello, lo bueno y lo sagrado. Allí donde se suele reducir la calidad de vida de las personas a su margen de utilidades o a la posesión de determinados recursos, consideramos muy importante afirmar que el despliegue integral de lo humano no incluye únicamente las herramientas técnicas de la ciencia económica -útiles para atacar las causas objetivas de la desigualdad-, sino los recursos 
y procedimientos de la literatura, la memoria histórica y el arte. Estos lenguajes permiten abordar los factores subjetivos, intangibles pero latentes, de dicha desigualdad, a través de nuevas narrativas promotoras de libertad y de cambios culturales profundos. La lectura de relatos motiva la recreación de significados, testimonios y experiencias del pasado para reconfigurarlo todo desde una acción cultural, que no solamente cambie los programas políticos y económicos, sino también los modos de pensar y de sentir.

Desde una motivadora relectura de Marx (Henry, 1976 y 2011), Henry nos advierte de los peligros de una alienación capitalista que podríamos encontrar también en las políticas sociales y de transferencia de recursos que reducen el desarrollo humano a la satisfacción de necesidades, como si dicha satisfacción se diera de manera natural, mecánica, inmediata. Cuando las necesidades son naturalizadas, se desconectan del enigma de la vida del vulnerable y de su deseo de vivir. Olvidamos, entonces, que las necesidades del viviente en relación con su medio de vida y de muerte están marcadas por la injusticia y que, por lo tanto, la satisfacción de dichas necesidades está atravesada, ante todo, por la experiencia subjetiva y afectiva que hace de toda necesidad una necesidad de cultura. Pan y palabra, salud e imagen, abrigo y narración van de la mano porque, en el socialmente vulnerable, las necesidades de alimento, de integridad física y de vestido deben poder ante todo experimentarse en su carga, en su peso, en su pathos radical. En ese sentirse humano en la necesidad, el vulnerable vive ya dicha carencia como necesidad de cultura y de memoria, es decir, como una apertura a la creatividad y a la puesta en relato del deseo vital de comer, de curarse y de abrigarse, que es al mismo tiempo deseo de que otras vidas igualmente particulares puedan gozar de alimento, salud y cobijo: necesidad de cultura porque toda necesidad es, de entrada, elaborada humanamente y deseosa de tomar posesión de la necesidad que ella es, de narrarse, de reconocerse, de ser afectada, de experimentarse en el consentimiento violento de su propio peso y en la apertura a compartirse con otros.

Este es el sentido primero del rostro del vulnerable que brota de la exposición a los relatos de su propia fragilidad, a saber, su poder y su deseo de experimentarse, de auto-afectarse, de adherirse con violencia y dolor a la vida golpeada que él es, para encontrar en el seno mismo de esta adhesión sufriente la alegría de gustar y sentir, de ser vivo en tanto vulnerable. Solo entonces, habiéndose recibido a sí mismo con todo el peso del "aquí" y el "ahora" -la 
vida que él es y que no puede dejar de ser-, el socialmente vulnerable puede abrirse al "allá" de sus capacidades para hacer frente a dicha vulnerabilidad -la vida en la que él adviene como desborde y como creación.

Por ello, frente a los modelos educativos que ponen el acento en el rendimiento calculable y en la competencia, debemos asumir la exposición a los relatos como una fuente de responsabilidad frente a los socialmente vulnerables, a partir de un gozar de la literatura y el arte que se transforma de inmediato en sufrir 'por y con' el hambre del otro, así como en la alegría del servicio concreto al que dicho sufrimiento nos consagra. La donación de los relatos recibidos del pasado está fundada, pues, en el sufrir 'por y con' el no reconocimiento de los vulnerables y en la alegría de saberse escogido para responder desde una concepción integral del desarrollo fiel a la realidad inmanente y auto-afectiva de lo humano. Los procesos educativos en los que el socialmente vulnerable no se limita al rol de consumidor pasivo, sino que asume la exposición a los relatos como una actividad creativa, liberadora y transformadora de su propia situación, juegan un papel fundamental en la constitución de nuevas narrativas y mentalidades generadoras de cohesión social. El instante en el cual la creación y la escucha de los relatos golpean nuestras conciencias y revelan los significados abiertos por quienes son considerados como insignificantes en una sociedad es un instante a la vez ético y estético: un camino fundamental para responder al otro socialmente vulnerable y contribuir responsablemente con la educación de los hombres y mujeres de nuestro continente.

\section{Referencias}

Dufour-Kowalska, G. (1996). L'art et la sensibilité. De Kant à Michel Henry. Paris: Vrin.

Henry, M. (1963). L'essence de la manifestation. Paris: Presses Universitaires de France.

Henry, M. (1965). Philosophie et phénoménologie du corps. Essais sur l'ontologie biranienne. Paris: Presses Universitaires de France.

Henry, M. (1987). La barbarie. Paris: Presses Universitaires de France.

Henry, M. (1990). Du communisme au capitalisme. Théorie d'une catastrophe. Lausanne: Éditions L'Âge d'Homme. 
Henry, M. (1996). La barbarie. (Trad. Domingo Moratalla, T). Madrid: Caparrós.

Henry, M. (2004a). Phénoménologie matérielle et langage (ou pathos et langage). hénoménologie de la vie (Tome III). De l'art et du politique. Paris: Presses Universitaires de France.

Henry, M. (2004b). Narrer le pathos. Phénoménologie de la vie (Tome III). De l'art et du politique. Paris: Presses Universitaires de France.

Henry, M. (2004c). La peinture abstraite et le cosmos (Kandinsky). Phénoménologie de la vie (Tome III). De l'art et du politique. Paris: Presses Universitaires de France.

Henry, M. (2004d). Art et phénoménologie de la vie. Phénoménologie de la vie (Tome III). De l'art et du politique. Paris: Presses Universitaires de France.

Henry, M. (2007). Entretiens. Arles: Sulliver.

Henry, M. (2011). Marx (Tome I). Une philosophie de la réalité. Paris: Gallimard, 1976. En castellano Marx (Tomo I). Una filosofía de la realidad. (Trad. Gómez, N). Buenos Aires: La Cebra.

Leclercq, J. (2010). Biographie de Michel Henry. Leclercq, J (Ed.). Pour une phénoménologie de la vie. Entretien avec Olivier Salazar-Ferrer. Mayenne: Éditions de Corlevour.

Levinas, E. (2011.) Euvres 2. Parole et silence et autres conférences inédites. Paris: Éditions Grasset et Fasquelle.

Mongin, O. (1994). Paul Ricœur. Paris: Éditions du Seuil.

Ricoeur, P. (1983). Temps et récit (Tome I). Paris: Éditions du Seuil.

Ricoeur, P. (2009). La vida: un relato en busca de narrador. Educación y politica. De la historia personal a la comunión de libertades. Buenos Aires: Prometeo.

Sloterdijk, P. (2000). Règles pour le parc humain. Paris: Éditions Mille et Une Nuits.

Vidalin, A. (2006). La Parole de la Vie. Paris: Éditions Parole et Silence. 



\title{
El final del humanismo como lugar del pensar de Pirjevec ${ }^{1}$
}

\author{
The End of Humanism as the Locus \\ of Pirjevec's Thinking ${ }^{2}$
}

Dean Komel ${ }^{3}$

Universidad de Ljubjana, Eslovenia

Recepción: 12 de junio del 2020

Evaluación: 06 de julio del 2020

Aceptación: 20 de julio del 2020

1 Este trabajo fue realizado en el marco del programa de investigación P6-0341 y J6-9354, en el Institute of Nova revija for Humanities, Ljubljana, Eslovenia.

2 Traducción del alemán por Federica González-Luna, Eberhard Karls Universität Tübingen, Alemania.

3 Dr. por la University of Ljubljana (Eslovenia), investigador del Institute Nova Revija de Humanidades y Presidente de la Phenomenological Society of Ljubljana. Investigador del Centro Internacional de Estudios sobre el Nihilismo Contemporáneo (CeNic).

Correo electrónico: dean.komel@ff.uni-lj.si.

Komel, D. (2020). El final del humanismo como lugar del pensar de Pirjevec.

Cuestiones de Filosofía, 6 (26), 53-74.

doi: https://doi.org/10.19053/01235095.v6.n26.2020.11212 


\title{
Resumen
}

En su reflexión acerca de la crisis del humanismo, el teórico literario y filósofo esloveno Dušan Pirjevec parte de la crítica a la orientación humanista representada por los filósofos postestructuralistas de la década de 1960, pero aborda el problema del "fin del humanismo" de una manera mucho más compleja, a la luz del nihilismo de la época del mundo. La experiencia existencial directa de la Segunda Guerra Mundial, así como de las ideologías totalitarias que marcaron el siglo XX, fue de crucial importancia en su comprensión del problema del humanismo. Pirjevec desarrolló sus intuiciones filosóficas clave principalmente en sus estudios acerca de la novela europea desde Cervantes hasta Robbe-Grillet, siguiendo la orientación existencial que es necesaria para reconocer el ethos humano, antes de cualquier intento (revolucionario) de afirmar las ideas de la "nueva humanidad".

Palabras clave: Dušan Pirjevec, humanismo, nihilismo, revolución, historia del ser, novela europea.

\begin{abstract}
In his reflection upon the crisis of humanism, the Slovenian literary theorist and philosopher Dušan Pirjevec proceeds from the critique of the humanistic orientation as represented by poststructuralist philosophers in the 1960s, but treats the problem of the "end of humanism" in a much more complex light of nihilism of the epoch of the world. At the same time, direct existential experience from the Second World War as well as with the totalitarian ideologies that marked the $20^{\text {th }}$ century was of crucial importance for his understanding of the problem of humanism. Pirjevec developed his key philosophical insights mainly in his studies on the European novel ranging from Cervantes to Robbe-Grillet, following the basic existential orientation that it is necessary, before any (revolutionary) attempt to assert the ideas of "new humanity," to recognize the human ethos.
\end{abstract}

Keywords: Dušan Pirjevec, humanism, nihilism, revolution, history of being, european novel. 
La tentativa de reflexionar acerca del pensamiento de Pirjevec ${ }^{4}$ nos pone inmediatamente ante la pregunta acerca de su actualidad. Si esta reflexión ha de tener un punto de partida, hay que hacerlo, entonces, dirigiéndose previamente a aquel lugar desde el cual la actualidad del pensamiento de Pirjevec se aclara.

Ser actual en sentido histórico-espiritual significa abrir el pasado perdido y el futuro que aún no llega de un presente viviente: Dušan Pirjevec fue capaz de llevar a cabo esto. En esta labor -como lo han subrayado varios intérpretes- debió haberse apoyado en el pensamiento heideggeriano de la diferencia ontológica. A pesar de que esto no puede ser negado, es seguro que Pirjevec debió haber descubierto algo esencial antes de encontrar un asidero en Heidegger. Esto no precisa de una aclaración exhaustiva, sino que basta con encargarnos de su primera obra de historia literaria Ivan Cankar in europska literatura (Ivan Cankar y la literatura europea) (1964). En esta obra ya está claramente prefigurado el camino a una experiencia pensante-existencial, que hizo posible el encuentro con el pensamiento heideggeriano de la diferencia ontológica. Es importante tomar esto en cuenta, ya que la última

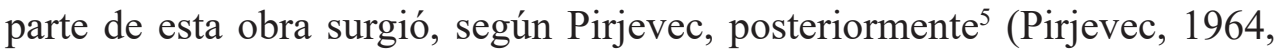
p. 484). En el capítulo final de ésta se encuentra una cita de la "Carta sobre el humanismo" de Heidegger, que señala el modo en que "Marx, al haber experimentado la alienación, penetró en una dimensión esencial de la historia" (Heidegger, 1978, p. 336). No se trata aquí, empero, de una justificación del marxismo, pues esta cita pertenece al marco de la determinación histórico-espiritual de la extrañeza (Fremdartigkeit) de Cankar, la cual corresponde a la más extrema y funesta di-ferencia entre Poiesis y Praxis, en la que la teoría marxista también resulta problemática ${ }^{6}$ (Pirjevec, 1972, pp. 65ss.).

${ }_{4}$ Información bibliográfica: https://en.wikipedia.org/wiki/Du\%C5\%A1an_Pirjevec

5 "A la hora de juzgar este libro es preciso tomar en cuenta que su primera parte presenta el texto ligeramente cambiado del tratado que fue escrito en 1961 y admitido en el mismo año como tesis de doctorado. En el mismo año fue redactada también la segunda parte, mientras que la tercera lo fue recién al final de 1963" (Pirjevec, 1964, p. 484).

6 De esta manera, en el artículo de Pirjevec "Mer Marxom in Stalinom" ("Entre Marx y Stalin") se enfatiza especialmente: "La pregunta que se plantea hacia el final del estalinismo es la siguiente: ¿Qué son la técnica y la ciencia en la exposición de su nada? Todo esto muestra que el tema primero y esencial que impone el estalinismo y nuestra experiencia estalinista reside precisamente en la pregunta por el Ser. Stalin, este invitado ausente, es fatalmente un verdadero elemento de unión. El estalinismo no es un error ni una desviación y, por ende, no admite repliegue alguno, ni siquiera mediante el retorno a la inocencia del pensar original de Marx" (Pirjevec, 1972, pp. 65ss.).

Komel, D. (2020). El final del humanismo como lugar del pensar de Pirjevec.

Cuestiones de Filosofía, 6 (26), 53-74.

doi: https://doi.org/10.19053/01235095.v6.n26.2020.11212 
Pirjevec se plantea la siguiente cuestión: ¿Acaso la obra de Cankar logró recuperar su praxis revolucionaria? Si se respondiera afirmativamente, surge entonces la siguiente pregunta: ¿Acaso el destino de la literatura de Cankar representa una prueba de que en un mundo alienado el arte de la palabra se ha desprendido casi, si no completamente, de la praxis, y con ello ha perdido su sentido esencial? (Pirjevec, 1964, p. 453). Si aceptamos esto, podría reprochársele a Pirjevec, entonces, haber subordinado la poesía a la praxis, y más aún a la praxis revolucionaria. Las vivencias del siglo $\mathrm{XX}$ atestiguan asimismo los resultados ya bien conocidos de lo que significa subordinar el arte y los artistas. Pirjevec continúa: “¿No es acaso esta distancia que separa a la poesía de la praxis un presagio del descrédito de la praxis misma, lo cual significaría que la alienación de esta $\mathrm{u}$ otra manera ha alcanzado incluso a la praxis revolucionaria?" (1964, p. 453). La alienación se ha apoderado de la humanidad del hombre que está determinado esencialmente por la praxis. Dado que esta alienación está determinada ontohistóricamente, ella posee el sentido de la carencia de tierra natal (Heimatlosigkeit). De acuerdo a la esencia de su destino ontohistórico, el hombre no tiene un hogar (Heimat), no tiene casa. ¿Dónde se encuentra entonces? Siguiendo el pensamiento fundamental de Pirjevec, nos internamos aquí en el lugar de un advenimiento, de un ensancharse y de un resurgir del hombre en la determinación esencial de su humanidad.

¿Cómo se llama dicho lugar? El nombre ya es conocido por los entendidos en el pensamiento de Pirjevec, y no obstante él sigue siendo hoy un gran enigma. Este lugar es el fin del humanismo. Pero también es conocido el nombre del camino que determina este lugar del fin del humanismo como punto cero de un tránsito, de la re-evolución del $\operatorname{ser}^{7}$. ¿En dónde se muestra la copertenencia del fin del humanismo y la re-evolución del ser? ¿Qué voluntad alberga en la abulia del fin y en la voluntad del ser revolucionario? ¿De qué manera serán superadas esta voluntad y esta abulia que Pirjevec pensó como amor activo en su interpretación de Los hermanos Karamazov de Dostojewski? ¿Significa acaso la copertenencia de praxis y poiesis? ¿Y por qué tiene el sentido del amor por la nada? ¿Cómo acaece el paso de los dioses a la luz de esta nada? ¿Por qué aparece aquí el simbolismo de la cruz

\footnotetext{
7 Ivan Urbančič afirma que Pirjevec "en estas palabras acumuló todos los esfuerzos filosóficos de sus últimos años de vida. Estas son palabras que poco a poco maduran y que, a su vez, para poder ser escuchadas, requieren de una larga preparación de aquellos que las reciban" (Urbančič, 1986, p. 110).
} 
y la cruz del lenguaje que Pirjevec ha decidido cargar? ${ }^{8}$. Frente a tantas y complejas cuestiones, sería quizás más adecuado hablar de toda una localidad y no simplemente de un lugar del pensamiento de Pirjevec. No obstante, queremos evitar la mera enumeración de los diversos temas que aparecen en él. Pretendemos, más bien, manifestar la singularidad de aquello que Pirjevec descubrió en su experiencia pensante-existencial: el final del humanismo y la re-evolución del ser que se realiza a través de éste.

Pirjevec prestó atención al problema del final del humanismo en diversos tratados. En mi opinión, el tratado publicado en el número de febrero de 1968 de la revista Problemi "Vprašanje o humanizmu" ("La pregunta por el humanismo") (Pirjevec, 1968) es de especial interés. Dado que en mayo del mismo año fue presentado el manifiesto postista de Derrida "Fines hominis" (Derrida, 1999), existe la posibilidad de comparar el razonamiento de Pirjevec y el movimiento (post-)estructuralista francés de aquel entonces. Dichas comparaciones exigen cierta precaución, pues Pirjevec pretende mostrar en su tratado que aquello que él comprende bajo el "fin del humanismo", no es equivalente a la "muerte del hombre" establecida por el estructuralismo. Pirjevec subraya de entrada que la problemática del fin del humanismo no fue formulada en primer lugar por el estructuralismo. Aguzando aún más este asunto, se puede decir que el fin del humanismo ha sido impulsado desde dentro por todo aquello que ha sido configurado como filosofía moderna, expresado en distintas direcciones -estructuralismo, existencialismo, marxismo, fenomenología, nietzscheanismo, lacanismo, heideggerianismo etc.-, ya sea que se trate de una corriente reconocida o no reconocida dentro de estas orientaciones.

Más allá de esto, Pirjevec designa con la expresión "estructuralismo"-como es evidente a partir de su tratado- no solamente el movimiento espiritual francés de los años sesenta. Con este nombre Prijevec abarca mucho más y con mayor profundidad. El estructuralismo es para él aquella corriente de ciencia moderna cuyo movimiento interior se encuentra justamente en el fin del humanismo. A partir de él se anunciaron y se emplearon los criterios del

8 Así como Tine Hribar escribió en memoria de Dušan Pirjevec: "Fue humillado y ofendido, pero no bajó de la cruz" (Hribar 1982a, p. 278). Con esto se conecta Hribar a las palabras de Pirjevec en su estudio de Los hermanos Karamazov, en la medida en que la víctima sagrada de Jesús el nazareno "no constituye una trascendencia metafísica. Jesús, por tanto, no baja de la cruz" (Pirjevec, 1979, p. 698). "No bajar de la cruz" significa para Pirjevec: sostenerse en la más extrema soledad humana.

Komel, D. (2020). El final del humanismo como lugar del pensar de Pirjevec. 
comportamiento científico. "Estructuralismo" y "estructura" deben entenderse a partir del verbo latino "struere": unir, acumular, probar, construir, poner, comparar, preparar, organizar. De esta manera, en la denominación de "estructura" se reconoce aquello que según Heidegger agota la determinación de la esencia de la ciencia técnica: el Gestell.

La fuente de inspiración de esta reflexión en torno a la problemática del fin del humanismo, que tuvo su manifestación más notable en Eslovenia, en primer lugar a través de la revista Perspektive (1959-1964), la encontró Pirjevec en el artículo "Strukturalistična kritika humanistične zavesti" ("Crítica estructuralista de la conciencia humanista”), publicado en 1968 en la revista Sodobnost del crítico cultural marxista Vlado Vodopivec (1968). El autor pone de manifiesto allí la inadmisibilidad en la "praxis social" de las tendencias estructuralistas antihumanistas. Él resume su postura crítica prohumanista en el lenguaje de una aguda crisis personal:

Frente al dilema de renunciar a mi propio conocimiento crítico humanista, de conservar el único sentido posible para mi existencia, de mantener mi historicidad, de seguir siendo el sujeto de mi propia acción, hay otro dilema, el de identificarse con una fe inaceptable contra mi propio conocimiento, renunciar a mi propia identidad y, en ese instante, convertirme en objeto, si bien de una manipulación históricamente progresiva (Vodopivec, 1968, p. 116).

Pirjevec presta especial atención a la formulación "sujeto de mi propia acción", que de acuerdo con él muestra claramente que el humanismo es en el fondo un "acontecimiento del subjetivismo, del activismo y de la libertad" (Pirjevec, 1968, p. 240). Con la discusión acerca de la génesis del concepto de "sujeto", Pirjevec llega a la conclusión de que con la acuñación "hombre-como-sujeto" no se puede "cubrir o abarcar toda la historia de la humanidad" (Pirjevec, 1968, p. 241), lo cual significa eo ipso que un humanismo basado en el sujeto no está en condiciones de lograr algo así.

El hombre-como-sujeto abarca tan sólo una estructura, es decir, se ajusta a esta estructura. En este punto el humanismo cae en su propia trampa. Dado que "el hombre-como-sujeto es puesto mediante una estructura, es decir que es el objeto de dicha estructura" (Pirjevec, 1968, p. 241), se trastoca el humanismo, apoyado y fundamentado en la subjetividad, y se convierte "de súbito en estructuralismo", es decir "en aquello que le pone fin, en su contrario, en su negación” (Pirjevec, 1968, p. 245). Según Pirjevec, la paradoja fundamental de la conciencia humanista reside en el hecho de que su verdad constituye 
aquello que ella misma rechaza como no-humano de esta conciencia. El humanismo mismo resulta ser un peligro mortal para el hombre en la figura de la tecnocracia. Pirjevec resume esta idea de la siguiente manera:

Se ha mostrado que el humanismo en tanto subjetivismo se ha realizado cual triunfo y autoanulación del sujeto, y de hecho en una situación tal que puede ser caracterizada mediante el pensamiento de Heisenberg de que el hombre aún se encuentra asimismo en todas partes. Esta autorrealización como autoanulación del hombre, o bien del sujeto, se encuentra en la figura del dominio de la naturaleza y de sí mismo en tanto tecnocracia y autocracia. La tecnocracia y la autocracia son la realización, la culminación del humanismo en tanto subjetivismo; son su verdad y, a la vez, aquello que sería normalmente descrito por un humanista como aquel mundo absurdo y ominoso de Kafka (Pirjevec, 1968, p. 245).

La obra de Kafka representa para Pirjevec el testimonio fundamental del fin del humanismo. En Kafka se realiza un proceso en el cual el hombre condena a muerte su humanidad subjetivista. Asimismo, Pirjevec afirma que El proceso de Kafka es el "proceso judicial y el juicio del héroe tradicional, mientras que en El castillo se muestra una situación que ha surgido una vez realizados los ideales humanistas" (Pirjevec, 1968, p. 246).

En mi trabajo Razprtost prebivanja (La demora accidentada) denomino antropodicea a este estado de un humanismo final y definitivamente culminado (Komel, 1996, pp. 173-183). La dimensión fundamental de la antropodicea reside en que el hombre condenado y ejecutado en su humanidad, recién llega al poder que le asegura el dominio irrestricto sobre la tierra. No obstante, este hombre no puede responder a la cuestión por el lugar desde el cual se ha promovido este proceso de empoderamiento. No puede cargar con la responsabilidad que sigue de algo que él mismo no puede entender. Es alguien que llega tarde, un servidor (sujeto) no responsable de aquello donde él erige su dominio, hacia donde no logra fundar su existencia de ninguna manera. ¿Qué resulta entonces del predominio de lo terrestre -del hecho de que el sujeto humano, que debió subordinarse, se haya estructurado voluntariamente cual objeto sumiso? ¿Y qué pasa con el sentimiento de la vergonzosa infamia que sobreviene al hombre de cara a la supuesta dignidad del sujeto? "Con los ojos agrietados K. miraba aún cómo los señores cerca de su cara, mejilla con mejilla, contemplaban la decisión. 'Cual perro' dijo, fue como si me fuera a sobrevivir la vergüenza” (Kafka, 1971, p. 165).

Komel, D. (2020). El final del humanismo como lugar del pensar de Pirjevec. 
Asimismo, el final del humanismo no será acompañado, según Pirjevec, del final de una conciencia humanista o de formas de conciencia, sino del acontecimiento de la "diferencia entre hombre y sujeto, vida y acción, verdad y libertad, poiesis y praxis, pensamiento y poesía, por un lado, y, por el otro, humanismo y ciencia" (1968, pp. 250s). La apertura de la diferencia muestra también, según Pirjevec, la ceguera fundamental del estructuralismo, que habla simultáneamente de la muerte del hombre y de la descentración del sujeto. El estructuralismo desea instituir un sujeto cabal a través de la muerte del hombre. Pirjevec ve, por ello, en la muerte, la victoria del hombre sobre su propia historicidad: "El significado histórico-universal de esta victoria se mantiene oculto" (Pirjevec, 1968, p. 251). A esto se podría añadir que es necesario que se mantenga oculto, puesto que ya no existe el sentido histórico-universal que podría revelarlo. Esto no significa, empero, que aquella reflexión sea superficial. En este lugar acontece el desocultamiento ambiguo de la di-ferencia, que -en la medida en que en el fondo no es un fundamentoes incomparablemente más fundamental que el desocultamiento de alguna identidad significativa. Es por esta razón que en primer lugar vale la pena indagar por ella, a pesar de que ella es también lo último que aparece como significativo para el hombre post-histórico.

El estructralismo -hemos visto que Pirjevec designa con este concepto el movimiento de la tecnociencia inspirado por el final del humanismo- declara la muerte del hombre con el fin de establecer plenamente al sujeto. Pirjevec desea, por el contrario, prestar oídos al fin del humanismo para alcanzar el lugar de la diferencia entre sujeto y hombre: "La idea del fin del humanismo no es igual a la idea estructuralista de la muerte del hombre. Para la conciencia eslovena, crítica y humanista, sería de gran importancia que se entendiera esta diferencia" (Pirjevec, 1968, p. 253). La comprensión de esta diferencia no resulta importante a causa de razones ideológicas, sino para que el necesario ocultamiento del sentido histórico mundial de la victoria del hombre sobre su propia historicidad sea reconocido, y el instante de este reconocimiento traiga consigo una de-cisión en la di-ferencia.

A través de la muerte "estructualista" del hombre, la subjetividad del sujeto se realiza y el humanismo llega a su culmen. ¿Cómo pueden ser ambos uno y el mismo movimiento? El humanismo no es, como se cree a primera vista, la obra de un sujeto, y el sujeto a su vez no es resultado del humanismo, pues ambos desembocan por igual en el estructuralismo. Ambos realizan una 
labor recíproca. Pero ¿qué es aquello que los obliga a trabajar por igual? En este punto nos enfrentamos con el poder de aquello que Pirjevec pensó en términos de la re-evolución del ser. Ésta no es una acción del sujeto, sino la re-acción del ser mismo. Es una re-acción que reactiva a la humanidad del hombre mismo hacia su culmen. Solamente esta reactivación abre el espacio para la realización incondicionada de la subjetividad. Dicha realización de la subjetividad, en tanto culminación de la humanidad, puede suceder solamente desde aquel lugar donde surge el hombre, en latín homo, no sólo en su nombre, sino también en su esencia. El homo surge del humus, de acuerdo a su origen fundamental, es decir, surge de la tierra. ¿Qué significa esto terrestre?

En el escrito de Pirjevec "Revolucija in njena dramatargija" ("Revolución y su dramaturgia") puede leerse lo siguiente:

En la revolución, y a través de la revolución, el hombre alcanza la verdad de su humanidad, la finitud como una verdad fundamental e inalienable. El problema de la revolución es el problema de la fidelidad a la verdad de la muerte, y la verdad de la muerte es la diferencia entre muerte y proceso fisiológico. La revolución es la llegada del hombre a esta verdad, pues a través de la revolución de su muerte se le revela que todo existe únicamente en esta tierra y supeditado a los hombres (Pirjevec, 1991, p. 180).

La verdad de la revolución es la revolución de la verdad misma. Esta revuelta, esta convulsión, es denominada por Pirjevec 're-evolución del ser'. ¿Qué significa el ser como re-evolución? La afirmación de que "todo existe únicamente en esta tierra y supeditado al hombre" apunta a que el final del humanismo y la re-volución del ser que acontece a través de éste, acontecen esencialmente con miras a lo terrestre, según la voluntad de los habitantes de la tierra. La formulación de esta afirmación expresa asimismo que la "tierra" significa el suelo de todo ser, en donde el hombre habita cual habitante de la tierra. Aquello que evoluciona infra-estructuralmente en la re-evolución del ser es lo terrestre mismo.

La idea de que aquello que evoluciona a través del final del humanismo es lo terrestre, parece extraño a primera vista. Sin embargo, Pirjevec mismo nos ha guiado hacia esta idea. No obstante, fue Ernst Jünger, el pensador de la movilización total, quien introdujo dicha idea. Éste no es el lugar adecuado para explicitar si y de qué modo la "re-evolución del ser" de Pirjevec y la movilización total de Jünger pertenecen a este debate, que sería bien recibido 
en el marco del bosquejo de la historia de la metafísica del siglo $\mathrm{XX}^{9}$. Solo nos referiremos aquí a la obra ensayística de Jünger "En el muro del tiempo" de 1960, a cuya importancia también hizo referencia Hermann Hesse inmediatamente después de su publicación. En este ensayo Jünger retrata la movilización total desde el punto de vista de su vencedor, a saber, la tierra, que finalmente es también el final de la época histórica ${ }^{10}$. El dia-gnóstico de la época de Jünger está teñido de gnosticismo, lo cual no reduce de ninguna manera la credibilidad de una descripción "radiográfica" de la evolución de lo terrestre. Aquello que salta a la vista a través de la imposición del fundamento titánico de lo terrestre es la destrucción de cualquier límite: "Los límites desaparecen claramente, desaparecen no solo como apariencias, sino también en su significación, según su valor. Con ellos desparece el Nomos, el poder limitante" (Jünger, 1991, p. 206). El hombre aparece aquí como el "destructor de las marcas limítrofes, cuya última marca es el muro del tiempo" (Jünger, 1991, p. 201). Los límites desparecen y son destruidos en la misma medida en que los dioses, creadores de límites, caen a través del surgimiento de lo terrestre. No hace falta subrayar que todo esto también es relevante para Pirjevec ${ }^{11}$.

Con la acentuación del elemento originario de lo terrestre, de la re-evolución del ser, debe mencionarse, sin duda alguna, lo siguiente: en la habitual discusión acerca del intento de Heidegger por superar la metafísica en el pensamiento de la diferencia ontológica, al cual Pirjevec adhiere sus reflexiones, comúnmente se olvida que el logro esencial de esta superación -en la medida en que se trata de una superación- reside en la apertura del mundo en tanto cuaternidad de tierra y cielo, mortales y divinos. En "El origen de la obra de arte", escrito de 1936, lo terrestre es pensado por Heidegger en conexión con el Ereignis, es decir, con el ocultante auto-desocultamiento

\footnotetext{
9 A Jünger y a Pirjevec los une la inmediata experiencia de la guerra y de la revolución social, así como la reflexión en torno a esta experiencia en el reflejo de la literatura y la filosofía.

${ }^{10}$ La época histórica se determina, según Jünger, a través de la lucha entre el poder titánico y el derecho divino. A través de la victoria del primero terminaría la época histórica.

${ }^{11}$ La destrucción de los límites que acompañan a la evolución terrestre se caracteriza, de acuerdo a Pirjevec, concretamente en el planteamiento de la pregunta por lo nacional, que por lo demás surge en el marco de una meditación en torno al final del humanismo.
} 
del ser en cuanto tal ${ }^{12}$. Sin tomar esto en consideración, no puede comprenderse completamente la superación de la metafísica, la meditación acerca de la esencia de la técnica en tanto Gestell, la apertura de la mundanidad del mundo en la cuaternidad ni la referencia a la co-pertenencia del pensar y la poesía. No se puede comprender tampoco, en consecuencia, el apoyo de Pirjevec en Heidegger.

Permanezcamos por un instante en la afirmación de que "todo existe únicamente en la tierra y supeditado al hombre". ¿Significa esto que lo terrestre es exclusivamente aquello que ofrece al hombre su habitar y su hogar? Con la reflexión hecha hasta ahora, es claro que lo que se lleva a cabo es lo contrario, es decir, el hombre pierde cada vez más la tierra natal debido a la avanzada evolución de lo terrestre. ¿Y cómo podría alcanzar el hombre su hogar (heimisch werden) en lo ilimitado que crece paralelamente al aumento de la movilización total iniciada a través de la tierra? A través del hecho de que todo es con miras a la tierra, y según la voluntad del hombre, no se resuelve la cuestión del hogar y el habitar del hombre en este tiempo, sino que apenas se plantea. También aquí reside la semilla de la reflexión desarrollada por Pirjevec acerca de la re-evolución del ser a través del forzoso entretiempo del final del humanismo.

No se debe desconocer que el héroe del Castillo de Kafka es un topógrafo ${ }^{13}$, un (innecesario) topógrafo de la tierra, en la que ya no puede encontrar (más) ninguna medida para el hombre y en donde esta desmesura se ha convertido en un (des-)orden mundial. El símbolo de esta desmesura inconmensurable de lo terrestre es, por ejemplo, la selva de la novela de Malraux Der Königsweg. El intento revolucionario de Perken por abandonar "la cicatriz en el mapa del mundo" siempre vuelve a fracasar porque no existe el mapa del

12 "Dicha aparición y surgimiento era denominada physis por los griegos. Ella ilumina simultáneamente aquello 'hacia' y 'en donde' el hombre funda su habitar. Nosotros lo llamamos 'tierra'. En cuanto al sentido de esta palabra es necesario alejarse tanto de la idea de una masa material sedimentada, como de la idea exclusivamente astronómica de un planeta. La tierra es aquello hacia donde el brotar (Aufgehen) de todo lo que brota, y de hecho, en cuanto tal, vuelve a ser cobijado. En lo que brota (im Aufgehenden) la tierra acontece como aquello que cobija" (Heidegger, 1977, p. 28).

${ }^{13}$ El propio Pirjevec reconoce asimismo que esto no es mera coincidencia: "No se requiere de nadie que vuelva a medir la tierra, ya todo se encuentra en orden, por lo que dicho reordenamiento negaría lo ya ordenado, y sería un acto subversivo o revolucionario. Por ello y por otros detalles que aquí no serán enumerados, Wilhelm Emrich afirma que la medición de la tierra tiene el significado de una labor revolucionaria en la novela de Kafka. En la terminología del presente trabajo esto significaría que el medidor de la tierra encarna al héroe de la novela tradicional" (Pirjevec, 1979, p. 216).

Komel, D. (2020). El final del humanismo como lugar del pensar de Pirjevec.

Cuestiones de Filosofía, 6 (26), 53-74.

doi: https://doi.org/10.19053/01235095.v6.n26.2020.11212 
mundo, porque todo no es más que una masa lodosa y deforme en la que no se puede incidir o como dice Pirjevec:

Aquello que amenazaba constantemente a Claud y Perken, posee el carácter de un lodazal deforme, pegajoso y peligroso del mismo nivel. Esta pasividad no significa que el lodazal no pueda asesinar, a pesar de que el asesinato no acontezca como la lucha entre dos hombres, de la lucha del hombre contra el hombre. El lodazal no se defiende ni ataca activamente, porque es el lodo de un pantano, y el hombre está en peligro siempre que está ante el lodazal y tenga que cruzarlo ${ }^{14}$.

Lo humano y lo terrestre se oponen como lo activo y lo pasivo. Pero lo pasivo-terrestre puede absorber lo activo-humano y finalmente se muestra como algo hiperactivo o, más exactamente, como algo subversivo. Lo activo no se identifica necesariamente con la forma y lo pasivo con la materia. Más bien la identidad contraria resulta posible con un efecto subversivo-revolucionario.

Lo terrestre se muestra a primera vista como "materia". Sin embargo, lo que se muestra a primera vista aún no es lo primigenio. Más primigenio que la materia es la tierra - Gaia, según la tradición griega, la madre de dioses y hombres. El hecho de que lo materno se haya transformado, especialmente en la modernidad, en lo material, y que en esto se busque asimismo una sustancia natural, es ya 'en sí' y 'para sí' una muestra ontohistórica de la subversión de lo material. Comentando un escrito de Josip Vidmar, el crítico cultural más influyente de Eslovenia, así como ideólogo del régimen comunista, dice Pirjevec en su estudio del Castillo de Kafka:

Aquí habla el activista partisano y éste habla palabras de una ideología materialista. La materia tiene aquí el sentido de sustancia primaria de la cual todo surge, es decir que tiene un significado ontológico en la medida en que este ser es algo ente y este ente es el ente supremo. La materia-ser posee como carácter principal la tendencia a formas cada vez más complicadas y superiores. Esta tendencia fundamental la otorga el ser a todo lo que surge de él y, por ende, también al hombre. Esta tendencia deviene así en la guía del desarrollo milenario y, finalmente, se transforma en un criterio moral, en

\footnotetext{
14 "Smrt in akcija" -"Muerte y acción"- (Pirjevec, 1979, p. 304). Cfr. El estudio sobre "La náusea" de Sartre, donde Pirjevec enfatiza especialmente las palabras de Cankar en su cuento "Domov" ("A casa"): "Toda circunstancia (...) todo sería completamente asqueroso, todo me resultaba aterrador, repugnante, como si oliera a lodo y barro" ("Ob Sartrovem Gnusu" ["En torno a La náusea de Sartre"]) ( Pirjevec, 1979, p. 41). La insoportable repugnancia del lodo y el barro revela aquí al hombre como alguien perdido en el pantano de la vida terrenal.
} 
el único fundamento real del comportamiento humano en el sentido de todo su actuar. El comportamiento del hombre y la transformación de su mundo se fundan, entonces, en la fidelidad al ser, esto es, en el regreso al ser, en la re-evolución. La evolución es una acción significativa, pues el sentido está implícito en el ser, ya que sentido y ser son uno y lo mismo. Justo aquí, justo en el fundamento y en la fuente de la acción significativa, se abre la pregunta fundamental (Pirjevec, 1979, p. 202).

La revolución es comprendida aquí activamente como un retorno reactivado hacia el ser desde el ser a través del carácter esencial de la materia. En lo subsiguiente, Pirjevec subraya la diferencia entre lo revolucionario, la acción que continuamente regresa a la nada y la re-evolución del ser, que en esta acción es cada vez más repelida hacia la nada.

En el estudio acerca de la novela de Stendhal Lucien Leuwen, Pirjevec piensa el vínculo entre la revolución y la naturaleza material, expresamente como el establecimiento moderno de lo terrestre:

En la revolución el Ser es nulo porque ella es la destrucción de la naturaleza en tanto ser metafísico y es el desocultamiento de la diferencia ontológica cuando ya no existe más un nombre para el Ser, como si éste en realidad ni siquiera existiera. El desocultamiento de la diferencia ontológica es la apertura al Ser, que solo sucede como si éste no existiera. En lugar del Ser pleno, como aquél que apareció bajo el nombre de Naturaleza, 'aparece súbitamente algo' que no hay (was es nicht gibt), 'aparece' la Nada (...). La Nada se desoculta al término de la naturaleza como un Ser metafísico y, por ello, es su realización y la verdad de la revolución misma, que 'trae consigo' justamente la superación de la Naturaleza (Pirjevec, 1979, p. 383).

El fin de la Naturaleza tiene el mismo aspecto fundamental que el fin del humanismo -la naturaleza recién se empieza a realizar en su acabamiento y, específicamente, como una naturaleza ilimitadamente disponible. Si al hombre le pareciera que ha perdido todo lo natural, sin embargo, aún está en posesión de la naturaleza toda, cual una fuente material inagotable. Recién aquí se puede formar realmente una concepción de mundo materialista, que, empero, desde su inicio amenaza con permanecer sin nada. El nihilismo no es únicamente una amenaza del materialismo revolucionario, sino que representa su carácter aterrador.

El nihilismo velado por la esquizofrenia del "tener-todo-y-sin embargo-estar-sin-nada" provoca menor terror, y justo por ello mayor es la desazón. En El testigo de Robbe-Grillet aparece esta esquizofrenia. Esta obra podría ser

Komel, D. (2020). El final del humanismo como lugar del pensar de Pirjevec. 
caracterizada como un tipo de novela estructuralista. A mi entender, el estudio redactado por Pirjevec acerca de esta novela se queda a medio camino en lo tocante a la revelación de la constelación Naturaleza, Humanismo y Tragedia, que Robbe-Grillet mismo prefigura en sus escritos teóricos. ¿Quizá El testigo de Robbe-Grillet no sea apropiado para el planteamiento de esta cuestión? Parece, en efecto, que la mirada literaria de Robbe-Grillet, atada a la separación (no di-ferenciación) total entre poiesis y praxis, no basta para tematizar la libertad del ser del hombre, que es precisamente el tema central en la discusión de Pirjevec sobre el fin del humanismo. Justo por esta razón, Pirjevec juzga como necesario sostener la distinción entre el fin del humanismo y la muerte del hombre. Más allá de esto, en la literatura novelística de Robbe-Grillet la situación de la víctima permanece insondable y, por ello, anula al héroe.

Pirjevec toca expresamente este problema en su tratado en torno a la novela de Andrić El puente sobre el Drina (Pirjevec, 1991b). Se concentra en el fenómeno de la construcción del puente y señala que allí lo terrestre no solo aparece como naturaleza, tampoco solamente como dando a luz a la naturaleza, sino ante todo como asentamiento:

Se trata de un espacio fecundo y hogareño, es decir, un lugar donde el hombre encuentra su habitar y su tierra natal. Este espacio es la tierra y el cielo que lo rodean; surge del puente y no solo se encuentra con el paisaje, la llanura, el collado o cualquier cielo. La tierra y el cielo devienen espacio solo cuando el hombre se ha asentado allí, y se convierten en espacio a partir del puente. El espacio se genera en el puente, que también ha sido poblado, el lugar donde además surgirán ciertas relaciones entre los hombres y donde emerge la historia específica de una comunidad de hombres (Pirjevec, 1992, p. 139).

Pero en este asentamiento irrumpe siempre la violencia, en la medida en que se trata de un espacio terrenal, que como tal es liberado 'en' y 'a partir' de la libertad de haber tendido un puente entre el Ser y la Nada ${ }^{15}$ (Sófocles, 1938, p. 419). El imperar de lo terrestre se abre violentamente cual sacrificio que el hombre en cuanto hombre puede realizar. La víctima del sacrificio está encarnada en el martirio de Radislav, quien consagra la tierra al espacio sagrado de la libertad y la libera del pasado, esto es, del encantamiento en sí mismo.

\footnotetext{
${ }^{15}$ El canto del coro de Antígona de Sófocles canta en torno al hombre: “(...) la noble diosa Tierra lo somete, / jamás cansada de trabajar lo alimenta: / Él se vuelve hacia ella, la destroza con el arado, / continuamente al entrar y al salir el año".
} 
A través del infligir y aceptar el dolor, en consonancia con la diferencia entre violencia y el imperar (Gewalt und Walten), acaece lo liberador-que-abre. La tierra se libera del encantamiento en sí mismo a través de la apertura que ofrece el espacio para el asentamiento, es decir, el hogar para los hombres.

La liberación del dolor (Erlösung des Leids) no es igual a la liberación del dolor (Erlösug vom Leid). La liberación del (des) dolor asienta al hombre en la tierra y la tierra se abre para él cual hogar, mientras que la liberación del (vom) dolor lo expande a través del despertar del deseo por la tierra. Por doquier, donde el dolor tensa, también serpentea el deseo. Lo serpenteante-terrenal domina sobre los dos eternamente en el hombre. Pero entre la eternidad del dolor y la eternidad del deseo surge una brecha del tiempo, que madura a partir de la finitud de la existencia terrena del hombre en el mundo. El dolor del tiempo es infligido a lo humano, más la eternidad pertenece solo a lo divino.

El poderío de lo terrestre es capaz de dirigir la violencia del hombre contra lo divino. A cambio de esto el hombre ansía un placer eterno en la forma de un "paraíso en la tierra". En el estudio en torno a Los hermanos Karamasov, que se concentra en la pregunta por Dios, Pirjevec cita las siguientes palabras de Iván:

En cuanto el hombre reniegue unánimemente de Dios (y yo creo que este periodo aparecerá como paralelo a los periodos geológicos), entonces desaparecerá por sí misma toda la moral previa sin ningún tipo de antropofagia, y vendrá algo completamente nuevo (...) El hombre, quien hora tras hora y sin límites coloniza la naturaleza a través de su voluntad y su ciencia, será reemplazado por el habitar del deleite celestial hora tras hora (Dostoyevsky, 1975$, p. 860$)^{16}$.

El dominio de la naturaleza a través de la voluntad y la ciencia no significa, como tal vez se podría creer, la derrota de lo terrenal, sino precisamente su victoria, pues de lo terrenal se han prometido todos los deleites a los hombres, que suplen la esperanza en deleites celestiales de una manera más que

\footnotetext{
${ }^{16}$ Esta afirmación está vinculada inmediatamente con el anuncio de una revolución geológica. Dostoyevsky escribe: "Pero la tierra actual se ha repetido quizás un billón de veces, murió, se congeló, se hizo gigante, se desmoronó, cayó en sus pedazos, y después regresó el agua sobre lo estable, después un cometa, después de nuevo el sol, luego la tierra desde el sol -esta evolución se ha repetido quizá incontables veces, y siempre tal cual hasta en el más mínimo detalle. Un aburrimiento total e indecente (...)" (Dostoyevsky, 1975, p. 853).
}

Komel, D. (2020). El final del humanismo como lugar del pensar de Pirjevec. 
satisfactoria. El dominio de la naturaleza por parte de los hombres abarca también el caso de lo celestial, y lo terrenal se enaltece realmente en primer lugar a través de la victoria sobre la naturaleza. En la medida en que la tierra se remonta hacia el cielo, el hombre lo hace hacia Dios. Pirjevec resume lo dicho del siguiente modo:

La libertad que trae el mundo moderno es una satisfacción libre y que se realiza de acuerdo a la ley fundamental de la igualdad de las necesidades, así como de su respectivo aumento, de donde se sigue necesariamente que aquello que es común a los hombres en el mundo moderno, y según el cual todos son iguales, es algo que puede ser designado con la expresión necesidad-producción-consumo. La esencia universal del hombre que hace posible que todos los hombres sean iguales y se sientan libres únicamente en esta igualdad, no es algo suprasensible o espiritual, sino algo terrenal (resaltado por D.K.), por así decirlo, algo material y sensible. Sin embargo, esto material y sensible posee aún el mismo significado y la misma estructura que el ente suprasensible y absoluto en el sentido del Ser; posee aún, en consecuencia, la estructura y el efecto de la trascendencia, pues: el hombre es ante todo en la medida en que es sus necesidades y su respectiva satisfacción. Si él no satisface sus necesidades, cesa de vivir y ya no existe. Sin embargo, es claro que ya no se puede utilizar más la palabra 'trascendencia'. El Ser en cuanto ente absoluto ya no está más en el más allá. Se ha mudado al más acá y ha de ser denominado con la palabra 'rescendencia'. De esto se sigue que la ciencia, la técnica y la revolución no serían posibles sin la 'transformación' de la trascendencia en rescendencia. Ellas son posibles en tanto convulsión al interior de la metafísica. En la filosofía acontece esta convulsión a través de Marx y Nietzsche. Es casi imposible evadir la pregunta por el 'de dónde' y 'para qué' de esta convulsión (1979e, pp. 680-681).

La respuesta a esta pregunta se insinúa en las palabras de Ivan Karamazov: "El hombre se elevará en el espíritu del orgullo titánico, divino, y aparecerá el hombre-Dios" (Dostoyevsky, 1975, p. 860). La convulsión de la trascendencia en rescendencia surge del espíritu titánico, es decir, terrenal, que enciende en el hombre la voluntad revolucionaria de convertirse en Dios. El sentido profundo del deseo de convertirse en hombre-Dios está en el hecho de que "el hombre quiere 'superar' la muerte ya en este mundo" (Pirjevec, 1979e, p. 683).

La aclaración de la "muerte del hombre" a través del estructuralismo, que paradójicamente lleva hacia la idea de que el hombre tan sólo se encuentra consigo mismo, la entiende Pirjevec evidentemente desde el horizonte 
de las intuiciones presentadas por Dostoyevsky en su novela Los hermanos Karamazov. En la aclaración de la "muerte del hombre" se muestra la voluntad de superar la muerte en este mundo, esto es, por mor de la tierra y según la voluntad del hombre. Aquí opera una subjetividad incondicional, o bien una antropodicea ilimitada, que permite todo y nada. Todo está en la tierra y supeditado al hombre y, no obstante, allí nada ni nadie está en casa.

El hombre, en cuanto habitante de la tierra, está llamado a realizar el sueño del paraíso en la tierra a través de la superación de la muerte, lo que tiene un fondo humanista y subjetivista. Éste es un aspecto esencial del final del humanismo y de la re-evolución del ser que se consuma en él, que se manifiesta exteriormente en el repunte de la tecnociencia. Sin embargo, es precisamente lo "técnico" lo que oculta el otro aspecto esencial. Esto podría ser denominado 'lo poético', pero no como su opuesto, sino como el contrincante de lo "técnico", en donde es preciso atender al potencial significativo de la voz griega téchne. De esta manera nos topamos con la determinación poetológica de la re-evolución del ser de Pirjevec: "El ponerse-a-sí-mismo del ser en la obra poética, de modo que brilla en misterioso esplendor y se llama Dios"17.

$¿$ No ha sido Dios quien finalmente se ha anulado por el bien de la tierra y por nuestra propia voluntad? ¿O quizá tan sólo hemos superado aquello que está disponible a nuestra voluntad en cuanto fe en Dios? La cuestión de Dios no se anula mediante la re-evolución del ser, sino que realmente es preparada; o dicho de otra manera: así como el "final del humanismo" no es idéntico a la "muerte del hombre", así tampoco la "ausencia de Dios" es idéntica al "ateísmo".

La voluntad que se manifiesta superficialmente como voluntad de dominio sobre la naturaleza es, en el fondo, la voluntad de superar la muerte, es decir, la voluntad de exiliar el dolor del tiempo. Esto pertenece esencialmente a la gestión y dominio de la naturaleza, mediante la cual lo terrestre se eleva a las alturas celestes. No es ninguna coincidencia que en su estudio de la

${ }^{17}$ Esta determinación interpretativamente problemática de Pirjevec no se expresa a nivel ontoteológico, no identifica al ser con Dios ni viceversa. Esta determinación es poetológica. Es reveladora si se atiende su pertenencia a la poesía. El poema "Mir" ("Der Frieden") del poeta esloveno Josip Murn (1879-1901) reza: "Incontables estrellas / centelleante silencio / dorada suave / la noche bajo ellas. Todo sin voz, / lleno de paz (...) Y el abrigo de Dios brilla más claro" (Murn, 1967, p. 58).

Komel, D. (2020). El final del humanismo como lugar del pensar de Pirjevec. 
concepción de la "muerte natural", Pirjevec critique frecuentemente, y en especial enfatice, que ésta no agota completamente la muerte del hombre ${ }^{18}$.

¿Podría afirmarse aún que todo está en la tierra y supeditado a los hombres? Esta expresión es en esencia revolucionaria, pero no colma la esencia de la re-evolución del ser, que incluso esencialmente se vacía. Esto resulta significativo para comprender la re-evolución del ser como evolución de lo terrestre, que es 'en sí' y 'por sí' carente de esencia, pues bloquea aquella fundamentación conforme a la esencia del Ser. El Ser, en cuanto fundamento del ente, no es un ente, no tiene a su vez un fundamento óntico, sino que se muestra desde la nada. Asimismo, el fundamento del hombre se muestra como la nada. Se destaca aquí la ambivalencia fundamental del final del humanismo, que es a su vez signo de una culminación ambigua de la re-evolución del ser. El hombre es, por un lado, retado por la tierra a empoderarse a sí mismo en su subjetividad incondicional. Pero en este punto de partida extremo de la subjetividad humanista está incluida una transición, dado que el hombre se revela a sí mismo como un hombre fundado sobre la nada. Visto subjetiva y humanísticamente, esta revelación es anonadadora, nihilista. Sin embargo, tal postura oculta justamente aquello que no se muestra en la revelación de la fundamentación del hombre en la nada: la libertad en el claro del ser. La reveladora respuesta a la fundamentación en la nada es el amor a la nada. El amor a la nada no puede darse por mor de la tierra misma ni por la voluntad humana, su corazón se abre tanto a la tierra como al cielo, tanto a los mortales como a los divinos y de esta manera está el corazón abierto (offenherzig) ante el Dasein en el mundo.

El paraíso terrenal es ambiguo como la imagen del paraíso mismo, donde el alma humana puede volverse adicta o conquistar su corazón. El paraíso puede convertirse en la adicción a un lugar prometido con variados placeres de una vida en el más allá o en el más acá. El paraíso puede ser la alegría amorosa del Dasein que reivindica todo como un don de la vida, y que no pide nada a cambio. El paraíso terrenal no significa más, por tanto, una realización revolucionaria de una idea, sino el claro misterioso del ser. Este paraíso es una fiesta alegre frente al eterno juego mundano del cielo y la tierra. El lugar de tal celestial esencia se revela únicamente en el corazón del hombre.

${ }^{18}$ Cfr. su estudio sobre la interpretación de la "muerte natural" (Pirjevec, 1979e, p. 694). 
El corazón del hombre no es un mero órgano con una determinada función, sino el centro ocultante y desocultante de la apertura del mundo. El hombre, en cuanto ser cordial (Herzwesen), habita en la tierra bajo el cielo y permanece en medio del mundo: "Pleno de mérito más poéticamente habita el hombre en esta tierra". Esta frase del misterioso poema de Hölderlin "En dulce azul" ofrece una respuesta a la siguiente cuestión: “¿Es Dios un desconocido? / ¿Es tan evidente como el cielo? Esto es más bien lo que creo. Él es la medida del hombre”. A esto sigue únicamente la pregunta: “¿Hay una medida en la tierra?" Y la respuesta reza: "No / hay". Se esconde aquí la pregunta fundamental acerca de un tiempo del cual se ha de devenir contemporáneo. En el contexto de la respuesta a esta cuestión se erige el pensar de Pirjevec acerca del fin del humanismo, que es complementado de manera especial con la meditación acerca de $\operatorname{Dios}^{19}$ (Pirjevec, 1979e, pp. 690ss.).

De la ausencia de una medida en la tierra se sigue que ésta, y con ella el mundo, se agotan en diversos diámetros de la tierra y del cielo, del hombre y de Dios. Así medidos, se nos muestran la tierra y el cielo en el claro ocultante del ser y no en la luz o en la oscuridad del ente. La medición que funda mundo, que desde su lejanía de lo divino acerca la medida del mundo al hombre, acaece en la poesía. El habitar poético en la tierra, bajo el cielo y en medio del mundo, es amor activo como el elevado entramado de la di-ferencia entre praxis y poiesis, que corresponde a la re-evolución del ser. En esto reside el mensaje esencial del pensamiento de Pirjevec, absorto en el fin del humanismo y en la perspectiva de un lugar para la humanidad.

Si se pregunta por la actualidad del pensamiento de Pirjevec para el presente, es posible afirmar que es especialmente actual en la medida en que admite la actualidad, es decir, que no supera la abulia ante el fin del humanismo con una voluntad de origen -sino que lo pretende a través de un permanecer en el origen, que recién otorga peso a lo originario. Escuchemos el poema de Hölderlin "La caminata": "Difícilmente abandona su lugar aquello que habita cercano al origen". La pesadez (die Schwere) revela la pertenencia a la tierra. Y la tierra tan sólo admite ser escuchada desde una única pretensión, desde las medidas -desde el existir poético en la tierra, que permite la emergencia del cielo desde el amor a la nada.

${ }^{19}$ No debe soslayarse que Pirjevec considera la relación entre pensar y poetizar, ser y Dios, a la luz de
la hermenéutica de preguntar y responder.

Komel, D. (2020). El final del humanismo como lugar del pensar de Pirjevec. 
En el ingrávido final del humanismo se esconde el lugar de un silencioso equilibrio entre la tierra y el cielo. En el silencioso equilibrio relucen la tierra y el cielo, mortales y divinos, en la aceptación del mundo y el perdón sagrado. "Las costuras del presente, la caída de las estrellas / en el pasado, el claro corte / el golpe de las horas dispersado en la noche / ligero peso: / todo / uno"20 (Grafenauer, 1996, p. 74). La voz del poeta debe advertir ante todo que a través del pensar de Pirjevec somos interpelados desde un afortunado diálogo con la poética, que Pirjevec ha hecho posible en su modo peculiar. Justo en este punto es posible otra discusión con este pensar, no sólo en cuanto a la cuestión de la poética, sino también, y quizá aún más, en relación con las respuestas a la praxis, pues evidentemente se muestra la acción del hombre al final del humanismo como algo extremadamente problemático y aún no agotado. Asimismo, la determinación del "amor activo" o la paradójica concepción de la "actividad inactiva" no abarca el fenómeno de la acción, es decir, está aún abierta para su respectiva meditación.

\section{Referencias}

Derrida, J. (1999). Fines Hominis. Engelmann, P. (Hrsg.). Randgänge der Philosophie (pp. 133-157). Wien: Passagen.

Dostoevskij, F. D. (1975). Die Brüder Karamasow (Trad. Ruoff. H und Hoffmann, R). Stuttgart: Heyne.

Grafenauer, N. (1982). Roža ničesar, nikogaršnja roža [Die Rose von niemand, die Niemandsrose]. Hribar, T (Ed.). Pirjevčev zbornik (pp. 210231). Maribor: Obzorja.

Heidegger, M. (1977). Der Ursprung des Kunstwerkes. Herrmann. v. F. W. (Hrsg.). Holzwege (GA 5). (pp. 1-74). Frankfurt a. M.: Klostermann.

Heidegger, M. (1978). Briefüber den Humanismus. Herrmann. v. F. W. (Hrsg.). Wegmarken (GA 9). (pp. 313-364). Frankfurt a. M.: Klostermann.

Hribar, T. (Hrsg.). (1982). Pirjevčev zbornik. Maribor: Obzorja.

\footnotetext{
${ }^{20}$ Od: vrjena, trepalnice svetllobe, Psiha 1-2, Palimpsesto [ Las pestañas negadas de la luz, Psyche 1-2, Palimpsesto]. El poeta esloveno Niko Grafenauer (1940) concluye su ensayo poético "Roža nikogar, nikogaršnja, rož" ["La rosa de nadie"], que dedica a Pirjevec.
} 
Hribar, T. (1982a). Revolucija, katarza in imitatio Christi [Revolution, Katharsis und imitatio Christi]. Pirjevčev zbornik (pp. 232-279). Maribor: Obzorja.

Jünger, E. (1991). An der Zeitmauer (Sämtliche Werke VIII). Stuttgart: Klett Cotta.

Kafka, F. (1971). Der Prozeß. Frankfurt a. M.: Suhrkamp.

Komel, D. (1996). Razprtost prebivanja. O razmejitvi filozofske antropologije in hermenevtične fenomenologije. Ljubljana: Nova revija.

Murn, J. (1967). Topol samujoč. Pirjevec, D (Ed). Ljubljana: Mladinska knjiga.

Pirjevec, D. (1964). Ivan Cankar in evropska literatura. Ljubljana: Cankarjeva založba.

Pirjevec, D. (1968). Vprašanje o humanizmu. Problemi, 62, pp. 238-255.

Pirjevec, D. (1972). Med Marxom in Stalinom. Aktualnost misli Hegla, Marxa in Lenina. Anthropos - Teorija in praksa. Ljubljana: Filozofska fakulteta.

Pirjevec, D. (1979). Evropski roman. Kos, J (Ed.). Ljubljana: Cankarjeva založba.

Pirjevec, D. (1979a). Ob Sartrovem Gnusu [Zu Sartres Der Ekel]. Evropski roman (pp. 27-48). Ljubljana: Cankarjeva založba.

Pirjevec, D. (1979b). Franz Kafka in evropski roman [Franz Kafka und der europäische Roman]. Evropski roman (pp. 173-230). Ljubljana: Cankarjeva založba.

Pirjevec, D. (1979c). Revolucija in njena resnica. Evropski roman (pp. 323398). Ljubljana: Cankarjeva založba.

Pirjevec, D. (1979d). Smrt in akcija. Evropski roman (pp. 273-322). Ljubljana: Cankarjeva založba.

Pirjevec, D. (1979e). Bratje Karamazovi in vprašanje o Bogu. Evropski roman (pp. 575-702). Ljubljana: Cankarjeva založba.

Pirjevec, D. (1986). Dnevnik in spominjanja. Nova revija, V (45), pp. 24-78. 
Pirjevec, D. (1991). Filozofija in umetnost in drugi spisi. Zabel, I (Ed.). Ljubljana: Aleph.

Pirjevec, D. (1991a). Revolucija in njena dramaturgija. Filozofija in umetnost in drugi spisi (pp. 155-188). Ljubljana: Aleph.

Pirjevec, D. (1991b). Andrićev na Drini most. Filozofija in umetnost in drugi spisi (pp. 123- 54). Ljubljana: Aleph.

Sophokles (1938). Tragödien des Sophokles. (Übers. Woerner, R). Leipzig: Insel Verlag.

Urbančič, I. (1986). Re-evolucija biti. Pirjevčeva osnovna misel in njeno obzorje. Nova revija, V (45), pp. 107-114.

Vodopivec, V. (1968). Strukturalistična kritika humanistične zavesti. Sodobnost, XVI (2), pp. 113-116. 


\title{
Humanismo y transhumanismo en el final de la metafísica: la era digital como paradigma de la metafísica de la subjetividad $^{1}$
}

\author{
Humanism, Transhumanism and the End of \\ Metaphysics: The Digital Age as the paradigm of the \\ Metaphysics of Subjectivity
}

Dune Valle Jimenez ${ }^{2}$

Universidad Sergio Arboleda, Colombia

Recepción: 18 de junio del 2020

Evaluación: 04 de julio del 2020

Aceptación: 20 de julio de 2020

1 Investigación realizada en el grupo de investigación CODICE de la Universidad Sergio Arboleda.

2 Doctor en Filosofía de la Universidad de Salamanca, España. Docente de la Escuela de Comunicación Social y Periodismo de la Universidad Sergio Arboleda, Bogotá, Colombia. Pertenece al grupo de investigación CODICE de la Universidad Sergio Arboleda.

Correo electrónico: dune.valle@usa.edu.co

Valle, D. (2020). Humanismo y transhumanismo en el final de la metafísica: la era digital como paradigma de la metafísica de la subjetividad. Cuestiones de Filosofía, 6 (26), 75-97. doi: https://doi.org/10.19053/01235095.v6.n26.2020.11242 


\title{
Resumen
}

En el presente trabajo nos proponemos analizar el problema del humanismo y la técnica en la filosofía de Martin Heidegger, destacando su posición crítica frente a la idea de humanismo surgido en el marco de la tradición metafísica, pues sería la manifestación más visible de la subjetividad moderna. Esto se plasmaría, según Heidegger, en la filosofía de Nietzsche, especialmente en su interpretación de la voluntad de poder y en la figura del superhombre como consumación y fase última de la metafísica, donde la voluntad de dominar y disponer del hombre y de la naturaleza en todas sus formas expresa la destinación del ser como Gestell (lo dispuesto), que en la era digital se manifiesta en fenómenos tales como el dataísmo y el transhumanismo, cumpliendo así la interpretación que Heidegger adelantaba hace más de cincuenta años: la racionalidad técnico científica, a través del pensar calculante, se manifiesta como consumación de la metafísica

Palabras claves: humanismo, transhumanismo, técnica, metafísica, Nietzsche, Heidegger.

\begin{abstract}
This paper delves into Heidegger's views on humanism and technique. We emphasize his critics to the idea of humanism proposed by the traditional metaphysics that he considers the most prominent expression of Modernity's subject. Heidegger remarks how this idea can be found in Nietzsche's philosophy, mainly in his interpretation of the Power of Will and the Übermensch as the fulfillment, and last stage, of Metaphysics. In this metaphysical Gestell (stage), the human desire to dispose and dominate nature in all its forms expresses the destination of the Being. In the Digital Age, this desire manifests itself in movements like the dataism and Transhumanism, fulfilling the interpretation advanced by the Heidegger more than fifty years ago. The technical-scientific rationality becomes then the enforcement of Metaphysics towards its End.
\end{abstract}

Keywords: Humanism, transhumanism, technique, metaphysics, Nietzsche, Heidegger. 


\section{Introducción}

Sin lugar a dudas la humanidad parece deslumbrada por los desarrollos y beneficios que brindan las tecnologías de la información y la comunicación, propias de la era digital, en la cual las promesas del progreso ilimitado y la felicidad están a la orden del día. En este contexto nos proponemos analizar ciertos visos de la llamada crisis del humanismo y su relación con el despliegue planetario de la técnica en el horizonte del pensamiento contemporáneo. Este objetivo será llevado a cabo a través de la crítica heideggeriana a la metafísica tradicional, y en este caso en la figura del humanismo entendida como una expresión de la subjetividad moderna. Esto se manifestaría, según Heidegger, en la formulación de la voluntad de poder nietzscheana, en la que la voluntad de dominar y disponer del hombre y de la naturaleza a su antojo se expresaría en la era digital en el dataísmo y en el surgimiento de la figura de un superhombre bajo la égida del transhumanismo más radical.

\section{Humanismo y metafísica}

Seguramente a más de uno debe llamar la atención la notoriedad y relevancia que ha adquirido el concepto del humanismo en los últimos tiempos, pues parece ser que se ha transformado en la palabra clave de la cultura contemporánea, que engloba toda suerte de encomiables virtudes y sólidas creencias de la cultura occidental, refrendando así perdidas actitudes y prácticas de la antigüedad clásica y romana que reflejaban toda la riqueza intelectual, artística y cultural de la humanidad recuperada en el Renacimiento. Es por esta razón que:

El humanismo contemporáneo queda marcado por la añoranza de algo perdido y por lo incierto de una esperanza sin contenido. Así receloso en admitir una humanitas -difícilmente conciliable con la existencia histórica-, el pensamiento humanista admira las realizaciones humanas en el arte, el derecho -e incluso en las posibilidades que ofrecen las nuevas tecnologías- como expresiones de la verdad sobre las cosas y sobre nosotros mismos; y advierte que esta verdad nos convoca y hermana como ningún interés práctico puede hacerlo (Flamarique, 2000, p. 774).

Difícilmente se podría poner en tela de juicio o hacer un cuestionamiento a este conjunto de valores y prácticas humanas que suponen el humanismo, pues parece ser que "el ideal humanista representa el último reducto que acoge y resguarda las pocas cosas, convicciones sin las que la libertad 
y racionalidad se transforman en palabras vacías o valores contradictorios" (Flamarique, 2000, p. 774). Sería pues el humanismo una especie de reservorio de la historia de la humanidad en la que se alojan gran parte de las obras, pensamientos y prácticas humanas relevantes por su valor cultural imperecedero; obras tanto materiales como inmateriales, razón por la cual el término humanismo se entiende incluso como equivalente o sinónimo de cultura.

Sin embargo, se hace sentir desde algunos sectores cierto resquemor con la palabra humanismo que se traduce, según Vattimo (1987), en una crisis. A pesar de esto, sin embargo, es clara la pervivencia de su valoración, pues: "no deja de suscitar perplejidad la extraña unanimidad con que, de un rincón a otro (...) se celebra al "Humanismo". Desde las más variopintas posiciones, y como si tras tantas postrimerías se ansiara volver a sólidos principios" (Duque, 2003, p. 9). Esto a simple vista podría ser un indicio de que algo está mal o algo no anda bien en la sociedad contemporánea, signada por los desarrollos tecnológicos y la crisis medio ambiental. Podemos ver que a lo largo de la historia la pregunta o preocupación por el humanismo y sus valores resurge cada cierto tiempo, cuando la humanidad parece estar en peligro. Es justamente en estos escenarios donde se revitaliza o resurge con más fuerza la pregunta por el humanismo.

En estas preocupaciones se motivaría la apelación que Beaufret dirige a Heidegger y da origen, precisamente, a la Carta sobre el humanismo, en la que el pensador francés se pregunta: ¿Cómo devolverle el sentido a la palabra "Humanismo"? Esto sería un indicio de la preocupación de Beaufret por la situación histórica que enfrentaba la humanidad en aquel momento, signada claramente por los horrores y secuelas de la Segunda Guerra Mundial. En este conflicto, el aparataje bélico militar adquiría su poder de destrucción, precisamente, gracias al desarrollo técnico científico, que desde tiempo atrás, principalmente al alero del Positivismo y la Ilustración, se venía presentado como la solución y el camino directo para el desarrollo y progreso ilimitado de la humanidad en su totalidad; conduciéndola así, sin más, hacia una plenitud nunca vista en su historia.

Ahora bien, en este contexto Heidegger formula su crítica al concepto de humanismo en su famoso escrito de 1946. Heidegger presenta allí un cuestionamiento a las distintas figuras del humanismo que se han ido dando a lo largo de la historia, pues ve en ellas un elemento común: la interpretación de la esencia del hombre como sujeto, como substancia. En efecto, si entendemos 
la esencia del hombre como sujeto, si lo situamos como el fundamento subyacente, como la substancia sobre la cual se constituye el mundo y nuestra relación con lo que nos rodea -incluida la naturaleza y el medio ambiente-, lo que, según el filósofo alemán, sería una manifestación concreta del olvido del ser, esto no sería más que una consecuencia de aquella interpretación del ser que ha dominado la historia del pensamiento occidental sin ningún contrapeso, y en la que la relación sujeto objeto se establece como el modo privilegiado de conocimiento y acceso a la realidad. A juicio del pensador alemán, estas consideraciones no han hecho más que devaluar la pregunta por el ser del hombre, pues, en definitiva, "las 'categorías' de la filosofía tradicional -'substancia', 'sujeto', 'realidad', etc.- son radicalmente ineptas para apresar y expresar el ser del hombre, puesto que están pensadas solo en función y a partir de los 'vorhanden'” (Carpio, 1977, p. 204).

Ahora bien, esta consideración dominante ha llevado la tradición a interpretar los entes del mundo y su propia existencia desde este sentido, en lo que va involucrado cierta idea del tiempo. Esta concepción llama la atención de Heidegger, quien comenta: "resulta llamativo el hecho de que los griegos interpretaran el ser a partir del tiempo: ousía significa presencia, presente. Porque el ser significa esto, se puede decir que el verdadero ser es aquello que jamás está ausente, es decir, lo que está siempre ahí: aei on" (Heidegger, 2009, p. 97). El filósofo alemán sostiene que en la filosofía griega prima una consideración del ser que concibe que el verdadero ente, el ente por excelencia, está constantemente ahí, es decir, está presente en grado máximo y es la presencia o substancia constante por antonomasia.

En este mismo sentido, la noción de humanismo estaría claramente determinada por la metafísica y, por ende, toda pregunta relacionada con dicha idea debe partir y tener en cuenta esa determinación. Pues: "todo humanismo se basa en una metafísica, excepto cuando se convierte él mismo en el fundamento de la metafísica (...) y, en concreto desde la perspectiva del modo en que se determina la esencia del hombre, lo particular y propio de toda metafísica se revela en el hecho de que es 'humanista'. En consecuencia, todo humanismo sigue siendo metafísica” (Heidegger, 2006, p. 24).

En definitiva, la crítica de Heidegger se dirige principalmente hacia la concepción del ser de la tradición metafísica, pues todas las consideraciones y clases de humanismo presuponen y dan por supuesta que la esencia del ser humano, reconocida universalmente, es la de animal racional. El hombre 
sería entendido como un animal más entre otros, con el status distinto proveniente de la razón, pero aun dentro de esos parámetros. En otras palabras, "la metafísica piensa al hombre a partir de la animalitas y no lo piensa en función de su humanitas" (Heidegger, 2006, p. 27). Esto significaría, entre otras cosas, que no se pregunta por la esencia del hombre, ni por su sentido originario, sino que se le concibe desde una perspectiva cuyo modelo ontológico es la naturaleza: lo Vorhandenheit. Relegando a un segundo plano la importancia o valor de la constitución esencialmente histórica de la existencia y su relación de privilegio con el ser mismo, como un ente que se define principalmente por su mortalidad, entendida como su posibilidad más propia (Heidegger, 1997b).

Como es bien sabido, Heidegger ha cuestionado desde sus primeros cursos de Friburgo las definiciones o interpretaciones provenientes de la tradición filosófica que pretenden dar cuenta del hombre En este sentido se expresa el filósofo alemán, cuando afirma en 1923 que:

(...) al llamar "hombre" al existente que se va a investigar se le pone de antemano dentro de una determinada concepción categorial, puesto que el examen se lleva a cabo siguiendo la pauta de la definición tradicional de "animal racional" (...) la perspectiva que se tiene del hombre según la pauta de la definición de "animal rationale" hace que se le vea dentro del ámbito de los entes que junto con él existen en el modo de lo viviente (plantas, animales) (Heidegger, 1999, pp. 46-47).

Si bien critica estas definiciones, poniendo en cuestión su proveniencia, su origen, eso no significa que venga a decir que las interpretaciones humanísticas son falsas o carentes de legitimidad, pues lo que sostiene al respecto es que éstas son derivadas y no tienen un carácter originario: "Por el contrario, se puede afirmar que el único pensamiento es el de las supremas determinaciones humanísticas de la esencia del hombre que todavía no llegan a experimentar la auténtica dignidad del hombre" (Heidegger, 2006, p. 37). Esto implicaría que la pregunta por la esencia del hombre no solo quedaría completamente oscurecida, sino que, incluso, ni siquiera llega a ser planteada originariamente.

Heidegger plantea así una crítica al humanismo debido a que la humanitas del hombre no se ha posicionado en el lugar y altura que le corresponde, es decir, no se ha pensado de forma originaria. Ahora bien: "es claro que la altura esencial del hombre no consiste en que él sea substancia de lo ente en 
cuanto su 'sujeto' para luego, y puesto que él es el que tiene en sus manos el poder del ser, dejar que desaparezca el ser de lo ente en esa tan excesivamente celebrada 'objetividad"' (Heidegger, 2006, p. 38). Como podemos ver aquí, el filósofo de la Selva Negra presenta con claridad aquello a lo que se dirige cuando crítica al humanismo, y esto no tiene que ver con una idea contraria a los valores, ideales o máximas que han guiado los intereses del humanismo (del todo loables, sea dicho), sino, más bien, que está poniendo en tela de juicio es la concepción de la humanidad del hombre definida exclusivamente en estos términos.

Como Heidegger sostiene, el hombre es porque ha sido arrojado, ex-siste contra el arrojo del ser y, desde esa perspectiva, es más que un simple animal racional, pues es menos respecto al hombre que se entiende a partir de la subjetividad. El hombre no es amo y dominador de lo ente, sino que es "el pastor del ser" (Heidegger, 2006, p. 57). El humanismo así caracterizado, "piensa la humanidad del hombre desde su proximidad al ser (...) es un humanismo en el que lo que está en juego ya no es el hombre, sino la esencia histórica del hombre en su origen procedente de la verdad del ser" (Heidegger, 2006, p. 58). Ahora bien, si se considera la opción de conservar el concepto de humanismo, este adquiere una connotación peculiar, por decir lo menos, pues ahora la esencia del hombre es fundamental en su relación con la verdad del ser. El hombre debe ser interpretado a partir de su relación de ser con el ser mismo, como abierto a sus posibilidades y a su mortalidad como lo más propio (Heidegger, 1997b).

\section{Nietzsche y el estadio último de la metafísica de la subjetividad}

Como recordaremos, la crítica de Heidegger a la noción de humanismo se centraba, principalmente, en la idea de sujeto que predomina en las distintas interpretaciones que han tratado de dar cuenta del hombre a lo largo de la historia, pues se entiende al sujeto como fundamento y medida de lo existente. Una consecuencia directa es la interpretación técnica de nuestra época, que viene determinada desde la modernidad. Es decir, la esencia de la técnica moderna es idéntica a la esencia de la metafísica de la subjetividad, pues:

(...) en la metafísica se lleva a cabo la meditación sobre la esencia de lo ente así como una decisión sobre la esencia de la verdad. La metafísica fundamenta una era, desde el momento en que, por medio de una determinada interpretación de lo ente y una determinada concepción de la verdad, le procura a esta el fundamento de la forma de su esencia. Ese fundamento domina por 
completo todos los fenómenos que caracterizan dicha era, y viceversa: quien sepa meditar puede reconocer en estos fenómenos el fundamento metafísico (Heidegger, 2010, p. 63).

Y, en este caso, la técnica es metafísica, dado que ésta se caracteriza por mostrar al ente de una u otra forma de acuerdo con la concepción metafísica dominante, que en nuestra época se muestra como despliegue técnico científico o Gestell, y determina en modo decisivo la imagen del mundo y del hombre, estableciendo de antemano de qué forma se muestran los entes del mundo y cómo los comprendemos.

Ahora bien, en este contexto de la crítica heideggeriana a la metafísica de la subjetividad, surge la figura de Nietzsche, quien sería el que llevaría la metafísica a su "finalización", pues, como apunta Heidegger: "Debemos comprender la filosofía de Nietzsche como metafísica de la subjetividad (...) La metafísica de Nietzsche y por lo tanto el fundamento esencial del nihilismo clásico se pueden definir ahora con mayor precisión como metafísica de la incondicionada subjetividad de la voluntad de poder" (Heidegger, 2001, pp. 163-164). Es importante hacer notar que la interpretación heideggeriana de la filosofía de Nietzsche es en clave metafísica y no intenta dar cuenta de su pensamiento o sus ideas de forma cabal y apegada al texto, más bien apunta a leer su filosofía desde la historia del ser, desde la cual adquieren sentido todos los fenómenos de la era actual. Lo que hace el filósofo de la Selva Negra es utilizar la filosofía de Nietzsche para hablar de la situación del mundo contemporáneo. Valga esta aclaración, pues al "adoptar como hilo conductor y condición previa para la comprensión del sentido de los fenómenos la 'historia del ser', no es conjugable con la tarea de dar una interpretación 'correcta' del pensamiento de Nietzsche" (Sánchez, 2006, p. 341).

Ahora bien, si atendemos a la historia del ser en esta era como final de la metafísica:

En el pensamiento de Nietzsche (...) viene a la luz el ente como voluntad de poder, representando este pensamiento de la voluntad de poder el punto de llegada y la culminación de la prepotencia del ente sobre el ser. El olvido del ser es ahora completo en cuanto todo, incluso la verdad queda reducida al ente como voluntad de poder (...) El superhombre designa aquella humanidad que es exigida por esa totalidad (Sánchez, 2006, p. 351).

En la lectura que hace Heidegger resalta, entre otras cosas, la voluntad de poder y el superhombre como conceptos que permitirían mostrar de qué manera 
en el pensamiento de Nietzsche se manifiesta el cumplimiento definitivo de la metafísica de la subjetividad, y cómo estos conceptos revelarían esa posición metafísica propia de la era técnica con su afán de dominio absoluto sobre el ente humano y la naturaleza, donde el mundo se transforma en un objeto más de su dominio y voluntad. Esto exigiría para sí un nuevo hombre.

Heidegger sostiene al respecto:

El hombre cuya esencia es querida por la voluntad de poder, es el transhombre (Übermensch) (...) Nietzsche ha pensado la esencia de la humanidad que, en el destino del ser de la voluntad de poder ha sido determinada a asumir el dominio de la tierra (...) un ser que aparece en su esencia volitiva en cuanto voluntad de poder, y por medio de esa aparición hace época, concretamente la última época de la metafísica (Heidegger, 2010, pp. 187-188).

Esto significaría que el hombre a través de la voluntad de poder, expresada en la figura del superhombre, se transformaría en la medida absoluta y el centro de todas las cosas, lo que le permitiría disponer a su antojo de todo cuanto le hace frente. La tierra se revela solamente como un objeto a disposición para la manipulación y explotación del hombre. Así la naturaleza y el hombre solo se convierten en un objeto más de explotación para la técnica, que termina de esta manera ampliando su dominio sobre todo ente sin ningún contrapeso: "con el inicio de la lucha por el dominio de la tierra, la era de la subjetividad se encamina hacia su consumación" (Heidegger, 2010, p. 191).

Ahora bien, desde la óptica de Heidegger queda claro desde un principio que entre técnica y metafísica existe una conexión indisoluble. Esto significa que el despliegue planetario de la técnica moderna tiene un fundamento metafísico y tiene su origen en el pensamiento moderno como modulación de la historia del ser, que en definitiva es la interpretación de la esencia de la técnica como final de la metafísica. Final no quiere decir acabamiento ni cesación; significa ante todo que:

En la época moderna acaba la metafísica porque ella es su plenificación. Final no puede significar entonces mera cesación, ni tampoco interrupción, abandono o arrojamiento al "trastero de la historia", etc. Final quiere decir consumación, cumplimiento pleno, llevar hasta el extremo las posibilidades internas de algo, agotar todo lo que puede dar de sí (Rodríguez, 2006, p. 150).

En otras palabras, la metafísica ha llegado a su fin en la época moderna, esto quiere decir que ha desplegado completamente sus posibilidades a través del despliegue técnico como manifestación visible de la metafísica de 
la subjetividad y su correspondiente interpretación del ente y del mundo. Se evidencia aquí un desprendimiento o devaluación del ser hacia la maquinación (Machenshaft) en la era del acabamiento de la metafísica, donde "la lucha por el dominio de la tierra y el completo despliegue de la metafísica que lo sustenta lleva a su acabamiento una era de la tierra y de la humanidad histórica, aquí se realizan, en efecto, posibilidades extremas de la dominación del mundo y del intento que emprende el hombre por decidir sobre su esencia puramente desde sí" (Heidegger, 2001, p. 212). Lo que precisamente adquiere su relieve y manifestación más visible en el dominio absoluto del pensar técnico-científico. El final de la metafísica es, entonces, el instante histórico en el que se agotan las posibilidades esenciales de la metafísica, como consumación y despliegue en la época moderna de la interpretación griega del ser como presencia, que en la época actual se destina como técnica y subjetividad.

\section{Heidegger y el peligro de la técnica}

Heidegger percibió, especialmente en el llamado segundo periodo de su pensamiento, que el despliegue tecnológico correspondía a un fenómeno global con alcance planetario, que dirigiría y determinaría por largo tiempo el destino de la humanidad. Concibió también que las consecuencias y desarrollos de ésta alcanzarían todos los rincones de la realidad, es decir, influirían en el destino del hombre en su totalidad; la tierra y el hombre quedarían a merced de una interpretación unilateral de la realidad, signada de principio a fin por el pensar calculante.

En la conferencia Gelassenheit, que el filósofo de la Selva Negra presentó en 1955, sostiene que el hombre se encuentra en una peligrosa situación en la tierra. Sin embargo, dicho peligro no se fundamentaría en el temor a una Tercera Guerra Mundial, a la explosión de una nueva bomba atómica o a la destrucción medio ambiental, cuestiones de por sí bastante preocupantes, sino que, afirma Heidegger: "El hombre se encuentra en una situación peligrosa en esta tierra (...) en cuanto que la revolución de la técnica que se avecina en la era atómica pudiera fascinar al hombre, hechizarlo, deslumbrarlo y cegarlo de tal modo, que un día el pensar calculador pudiera llegar a ser el único válido y practicado" (Heidegger, 2002, p. 30). Como podemos ver, Heidegger vincula directamente el predominio y la revolución de la técnica con el dominio absoluto de una forma de pensar: el pensar calculante; relación en la cual estribaría aquel peligro supremo que enfrentaría la humanidad venidera. De alguna manera queda establecido que entre el dominio del pensar calculante 
y la revolución de la técnica se produce una relación de dependencia mutua, lo que sería el fundamento no expresado de la era técnica.

Ahora bien, en esta conferencia Heidegger expresa con total claridad su interpretación de la técnica, con la cual no pretende demonizar la tecnología y sus desarrollos, pues, a su juicio, sería de una enorme ceguera negar sus beneficios. Desde su perspectiva, lo preocupante radicaría en que no estamos enfrentando meditativamente, o desde la destinación del ser, estas transformaciones radicales que enfrenta la humanidad, es decir, estamos dejando en manos del pensar calculante y del racionalismo técnico-científico, y a su desarrollo técnico desmesurado, todas las respuestas a las preguntas e inquietudes del mundo contemporáneo. Así pues, "semejante pensar sigue siendo cálculo aun cuando no opere con números ni ponga en movimiento máquinas de sumar ni calculadoras electrónicas. El pensamiento que cuenta, calcula; calcula posibilidades continuamente nuevas, con perspectivas cada vez más ricas y a la vez más económicas” (Heidegger, 2002, p. 19).

Heidegger viene a decir que esta forma de pensar es la que determina el desarrollo y la esencia de la técnica, pues lo que buscan en último término los desarrollos técnico-científicos es sacar la mayor rentabilidad y provecho de todo aquello que tienen a su alcance y de aquello de lo que se puede disponer a través del cálculo, en el que los criterios de eficacia, optimización y productividad adquieren un valor superlativo. En este contexto, la ciencia y la tecnología prometen esclarecer y brindar toda suerte de soluciones y respuestas a la más variopinta gama de problemáticas presentes en la tierra, como hace notar Heidegger en Serenidad. Como ejemplo de esto Heidegger recuerda la declaración de un conjunto de científicos galardonados con el Premio Nobel, que sostenían con total obsecuencia que la ciencia era el camino directo a la felicidad sin más.

Sin embargo, como dice Heidegger, esto no es algo casual, sino que:

(...) se debe a que, desde hace algunos siglos, tiene lugar una revolución en todas las representaciones cardinales (massgebende Vorstellungen). Al hombre se le traslada así a otra realidad. Esta revolución radical de nuestro modo de ver el mundo se lleva a cabo en la filosofía moderna. De ahí nace una posición totalmente nueva del hombre en el mundo y respecto al mundo. Ahora el mundo aparece como un objeto al que el pensamiento calculador dirige sus ataques y a los que ya nada debe poder resistir. La naturaleza se convierte así en una única estación gigantesca de gasolina, en fuente de energía para la técnica y la industria modernas (Heidegger, 2002, p. 23). 
En otras palabras, esta situación estaría marcada por el despliegue de la esencia de la técnica moderna que domina toda interpretación del ente en su totalidad, donde el hombre y la naturaleza quedan sometidos a este dominio interpretativo unilateral. La naturaleza, el medio ambiente, la vida humana y social en su conjunto, se rigen bajo los dictados del cálculo y la planificación en todas sus esferas, lo que se agudiza en la llamada era digital. La esencia de la técnica no es nada técnico y no tiene nada que ver con aquellos artilugios, útiles, instrumentos, herramientas tecnológicas. Así, pues, como apunta Heidegger "Los poderes que en todas partes y a todas horas retan, encadenan, arrastran y acosan al hombre bajo alguna forma de utillaje o instalación técnica, estos poderes hace ya tiempo que han desbordado la voluntad y capacidad de decisión humana porque no han sido hechos por el hombre" (Heidegger, 2002, p. 25).

Es necesario precisar que esta posición va a contramano de lo que generalmente se sostiene respecto a las tecnologías y sus instrumentos, dado que gran parte de los discursos sostienen que "la máquina es un producto más del homo faber, la producimos nosotros, los seres humanos, por lo que comparte nuestros límites, nuestro mundo y, como producto, está sometida a nuestros designios. En resumen, la máquina está muy lejos de ser algo ajeno o independiente de lo humano" (Ramos \& Fuentes, 2020, p. 88).

Antes bien, la técnica no es obra exclusiva del hombre, ya que su valor, poder e importancia no dependen del hombre ni de su venia, pues su esencia y su verdad va más allá de todo quehacer y planificación propiamente humana y solo responde a una destinación del ser mismo. Asimismo, la técnica moderna no surge o debe su aparición a que el mundo contemporáneo sea el tiempo de las máquinas o de la técnica, sino más bien porque esta es una época técnica, maquinal, por ser una destinación del ser y no al contrario.

Para entender con mayor claridad este designio de la era de la técnica, debemos retrotraernos unos años antes a su escrito La pregunta por la técnica de 1953, en la que Heidegger (1997a) plantea de forma sistematizada su pensamiento respecto al fenómeno técnico, que desde la verdad del ser viene destinado en tanto Gestell (lo dispuesto) al hombre contemporáneo. En este sentido, si comprendemos la destinación del ser como lo dispuesto, atendemos el llamado del ser en nuestro tiempo presente, como aquello que nos concierne de forma directa y esencial, como lo más propio en todo lugar y en cualquier dimensión de la utilización o manipulación de instrumentos; más 
allá de cualquier objeto técnico determinado, más que toda máquina o tecnología de la información que nos haga frente y nos provoque técnicamente.

Ahora bien, das Gestell es un vocablo acuñado por Heidegger, que se compone del prefijo Ge (aquello que reúne, coliga, congrega), y el verbo stellen, que significa poner, colocar. Este término se entiende, entonces, como aquello que reúne o coliga: "Dispuesto significa lo reunidor de aquel poner, que pone al hombre, esto es, lo provoca a desocultar lo real en el modo de establecer en cuanto lo constante. Dispuesto significa el modo de desocultar que impera en la esencia de la técnica moderna y que al mismo tiempo no es nada técnico" (Heidegger, 1997a, p. 130). Desde esta óptica, como habíamos adelantado, se descarta cualquier intento de concebir la esencia de la técnica como un medio para un fin, o como un simple hacer del hombre, lo que llevaría a descartar completamente su interpretación instrumental y antropológica, por lo demás bastante corriente. Heidegger (1997a) denomina a este desocultar que impera en la era de la técnica como desocultar provocante.

El desocultar provocante es el que impera en todo cuanto hay y existe. Esto tiene como consecuencia directa la transformación del medio ambiente y de la naturaleza, que concebidas bajo este prisma solamente se consideran como una fuente inagotable de recursos y reservas. En otras palabras, solo se concibe como un almacén de reservas del cual es posible extraer la mayor cantidad de energías explotables, acumulables y disponibles para su explotación planificada, calculada y programada; ahí dispuesta para manipular y disponer de ella a nuestro antojo, para un consumo planificado y calculado (Linares, 2008; Acevedo, 1999).

Bajo la misma lógica y ratio la humanidad del hombre, el hombre mismo es considerado un ámbito, o un objeto más de explotación planificada y calculada, y así deviene mano de obra, cerebro en obra, material humano (Acevedo, 1999), en último término como constante. De esta manera:

(...) la técnica moderna, como el desocultar estableciente, no es un simple hacer humano. Por eso debemos tomar, tal y como se muestra, el pro-vocar que dispone al hombre a tomar lo real como constante. Este pro-vocar reúne al hombre en el establecer. Esto reuniente concentra al hombre a establecer lo real como constante (Bestand) (Heidegger, 1997a, p. 128).

Efectivamente, todo ente, incluido el hombre, es entendido como constante, esto quiere decir que todo ente es considerado como una reserva o un fondo explotable, reemplazable, manipulable y calculable, como algo constante 
que está ahí como objeto de explotación y así ejerce su dominio como señor de la tierra, bajo la destinación del ser como lo dispuesto (Gestell).

Como habíamos visto anteriormente, Heidegger vislumbra el peligro que se cierne sobre la tierra por el dominio incondicionado de la técnica moderna. A esto podríamos agregar que lo preocupante o peligroso no es la técnica en sí misma, sino que lo es la interpretación unilateral y absoluta que se hace de ella según los dictados del pensar calculante. Queda así oculta su esencia como lo dispuesto, en un desocultar provocante que interpela al ente a aparecer como constante. A este respecto, aclara Heidegger:

La amenaza no le viene al hombre principalmente de que las máquinas y aparatos de la técnica puedan actuar quizás de modo mortífero. La más peculiar amenaza se ha introducido en la esencia del hombre. El dominio de lo dis-puesto amenaza con la posibilidad de que el hombre pueda rehusarse a retrotraerse a un desocultar más originario (Heidegger, 1997a, p. 139).

Cómo sostiene el pensador alemán, la amenaza no la constituyen los objetos técnicos ni tampoco sus aplicaciones: el peligro lo constituye el dominar absoluto de lo dispuesto como la única y excluyente modalidad de desvelamiento, de verdad. Heidegger hace una invitación a pensar meditativamente en este despliegue desmesurado de la tecnología y en sus consecuencias, buscando o ejercitando una forma de desocultar más originaria que corresponda a esa esencia de la técnica moderna no solo como lo dispuesto o constante. En otras palabras, en un desocultar que no devalúe la esencia del hombre y la naturaleza en simple objeto a su disposición, explotación y dominio incondicionado, sometido a los caprichos del señor de la tierra.

\section{Dataismo y transhumanismo: la consumación de la metafísica de la sub- jetividad en la era digital}

Hace más de cincuenta años Heidegger prestaba especial atención a las tecnologías de la información y comunicación que comenzaban a hacerse cada vez más omnipresentes en aquel entonces, cuando la ciencia cibernética daba sus primeros pasos con la obra de Norbert Wiener publicada en 1948. En este texto Wiener sentaba las bases y las definiciones de la llamada era digital y afirmaba que la tesis fundamental de su libro "consiste en que sólo puede entenderse la sociedad mediante el estudio de los mensajes y de las facilidades de comunicación de que ella dispone y, además, que, en el futuro, desempeñarán un papel cada vez más preponderante los mensajes cursados entre 
hombre y máquinas, entre máquinas y hombres y entre máquina y máquina" (Wiener, 1988, p. 16). Se daría inicio así a una nueva ciencia, a una nueva era de la historia de Occidente, marcada por las tecnologías de la información y la comunicación, en la que éstas tomarían el protagonismo absoluto para señalar el progreso y el desarrollo social en todas sus esferas, a tal nivel que se ha llegado incluso a denominar la era actual como Sociedad de la Información.

Ahora bien, este hito no fue ignorado por Heidegger, quien le prestó especial atención, dejando en claro su preocupación respecto a estas propuestas, tal como lo sostenía en 1966 cuando pronunciaba la conferencia El final de la filosofía y la tarea del pensar. En esta conferencia Heidegger expresa con total claridad su preocupación por el poder que está adquiriendo dicha ciencia, e incluso llega a situarla a un nivel equivalente a la técnica, es decir, como la manifestación más visible de la razón técnico científica. En este sentido afirma:

(...) no hace falta ser profeta para saber que las ciencias que se van estableciendo, estarán dentro de poco determinadas y dirigidas por la nueva ciencia fundamental, que se llama Cibernética. Esta corresponde al destino del hombre como ser activo y social, pues es la teoría para dirigir la posible planificación y el trabajo y organización del trabajo humano. La cibernética transforma el lenguaje en intercambio de información. Las artes se transforman en instrumentos de información manipulados y manipuladores (Heidegger, 2000, p. 79).

Como podemos ver, el filósofo alemán preludiaba de alguna forma la situación que enfrenta el hombre contemporáneo con la revolución tecnológica, y preveía una simplificación de la realidad y del hombre bajo el dominio de esta nueva ciencia, que, como hemos dicho, sería la ciencia de la racionalidad técnico científica por antonomasia y su adalid más destacado: el pensar calculante. Esto, en definitiva, sería el fiel reflejo del final de la metafísica y, por ende, de la filosofía, que se devaluaría, según Heidegger, en pura cientificidad cuyo rasgo fundamental sería la cibernética y su carácter técnico.

\section{Dataísmo y pensar calculante}

Ciertamente, nadie podría negar en la actualidad la prevalencia o el dominio absoluto que ha adquirido la cibernética en todos los ámbitos de la sociedad, pues las tecnologías de la información y la comunicación se han transformado en elementos de uso imprescindible para llevar a cabo cualquier trabajo 
o actividad que demande la vida cotidiana en casi en todas las esferas de la vida personal y social. Esto daría nacimiento a una nueva era: la era digital. En este escenario la utilización de internet, Big Data, redes sociales, teléfonos inteligentes y una serie de aplicaciones de diversa índole, diseñadas por los genios de Sillicon Valley, se convierte en un imperativo y una obligación quasi ontológica en esta nueva definición o comprensión del ser humano, cuyas relaciones sociales, comunicativas, así como su libertad, adquieren un nuevo estatus: estar conectado las veinticuatro horas del día.

El hombre de la era digital está determinado en su constitución desde el cálculo y la planificación a la que está sometido continua y libremente en cada momento de su vida online, en la que todas las interacciones o acciones que ejercemos cuando utilizamos estas tecnologías se convierten en datos que quedan almacenados en el Big Data, con el objetivo de hacer el mejor uso de ellos. Esto traduce en monetizar toda aquella información obtenida por nuestra navegación en la web. Las consecuencias más visibles de dicha monetización serían la personalización de la información que recibimos, las recomendaciones de productos, amigos, películas, rutas, viajes, noticias, parejas etc., que son enviadas por las empresas que han invertido en la consecución de esos datos. Todo esto con la promesa de que el único objetivo que se persigue con estas acciones es facilitarnos la vida.

Se ha de puntualizar que en estas promesas y utopías subyace una ideología de un determinado carácter filosófico que la sostiene. Nos encontraríamos, según esto, subsumidos en una ideología técnica (Garcia \& Valle, 2020), que en una de sus vertientes más representativa puede ser denominada dataísmo. Una definición que propone van Dijk al respecto es la siguiente:

El dataísmo revela una creencia en la objetividad de la cuantificación y en el potencial de rastrear todo tipo de comportamiento y socialidad humana a través de datos en línea. En segundo lugar, los (meta) datos se presentan como "materia prima" que puede analizarse y procesarse en algoritmos predictivos sobre el comportamiento humano futuro, activos valiosos en la industria minera. Los métodos cuantitativos piden interrogatorios cualitativos para refutar la afirmación de que los patrones de datos son fenómenos "naturales" (van Dijk, 2014, p. 201).

En esta creencia se sostienen gran parte de las promesas y utopías presentes en la era digital, que consideran que gran parte de los problemas humanos y sociales se podrán comprender y solucionar gracias a la gran cantidad de 
datos que recogen los monopolios tecnológicos de la navegación web de todos los usuarios de internet, en el que toda información se convierte en dato $y$, en consecuencia, puede ser cuantificada, mensurada y así monetizada. En definitiva, "el hombre digital digita en el sentido que cuenta y calcula constantemente. Lo digital absolutiza el número y el contar (...) Hoy todo se hace numerable, para transformarlo en el lenguaje de rendimiento, de la eficiencia. Así hoy deja de ser todo lo que no puede contarse numéricamente" (Han, 2014b, p. 42).

No obstante, el discurso de esta doctrina nos hace creer que el manejo de estos datos solo tiene valor social, benéfico y neutral, esto es, que dicho manejo no responde a ningún tipo de interés político o comercial. En este sentido: "la popularización de la datificación como un paradigma neutral, llevado por una creencia en el dataísmo y apoyada por guardianes de confianza institucionales, gradualmente arrojó una visión de la vigilancia de datos como una forma 'normal' de monitoreo social"' (van Dijk, 2014, p. 206).

En un contexto de cuantificación y medición cuantitativa de la realidad, a través de las conductas que los usuarios tienen en su vida online, se sostiene un nuevo paradigma propio de la revolución técnico científica, en la que impera absolutamente el pensar calculante y sus supuestos. De esta manera, cada click, gusto, búsqueda, interacción, relación comunicativa, sentimiento que expresamos a través del uso de estas tecnologías de la información y la comunicación, se pueden transformar en datos para su posterior utilización y, por qué no decirlo, manipulación de las conductas humanas. Todo esto se consigue por medio del perfilamiento psicológico que logran las redes con nuestros datos, lo que nos conduciría, según Han, a un totalitarismo digital (Han, 2014a, p. 47), esto es, a una barbarie de los datos, donde el imperativo del cálculo y la medida domina todas las esferas de la sociedad para lograr aumentar la optimización, productividad y rendimiento del hombre contemporáneo. De esta forma se pondría en peligro la soberanía, autodeterminación y libre albedrío del hombre signado por lo digital. Como sostiene Han, "la persona misma se positiviza en cosa que es cuantificable, mensurable, controlable. Sin embargo, ninguna cosa es libre. Sin duda alguna, la cosa es más transparente que la persona. El Big data es el fin de la persona y de la voluntad libre" (Han, 2014a, p. 14).

En definitiva, el dataísmo reclama para sí la redención de toda problemática o dificultad bajo el imperio de la tecnología y los datos, como receta perfecta 
para el desarrollo y progreso de la humanidad. Transforma, en consecuencia, al propio hombre, que ya no es considerado como simple objeto, trabajador o producto de consumo, ni siquiera ya una cosa, sino que se reduce a un dato cuantificable y mensurable. Es decir, tal como afirmaba Heidegger, en constante (Bestand), como insumo o capital humano ahí dispuesto para su explotación comercial, gracias a la prevalencia sin contrapeso del cálculo y la planificación en todas las esferas de nuestra existencia por medio de las tecnologías.

\section{El superhombre nietzscheano en la utopía transhumanista}

La mayor parte del planeta ve cada día con menos asombro la cantidad ingente de avances tecnológicos que se presentan de forma constante, casi cotidiana. Desarrollos que por lo general se fundamentan en los éxitos de la inteligencia artificial y su capacidad para apoyar los distintos procesos humanos y sociales en la salud, la economía, el derecho, la planificación social, etc. A pesar de los beneficios que nos han brindado este tipo de avances tecnológicos, con la inteligencia artificial a la cabeza, no podemos soslayar algunas de las preocupaciones que éstos han despertado en parte de la sociedad. Preocupaciones que se dirigen principalmente hacia las consecuencias humanas resultantes de la aplicación de estos avances, cuyos efectos en nuestra vida cotidiana están apenas visibles para gran parte de los usuarios de dichas tecnologías.

Sin embargo, lo que es aún más inquietante son las utopías que emergen desde una razón técnico-científica que no parece tener más límites que su propia imaginación, prometiendo así una infinidad de beneficios, desarrollos y avances de toda índole para la humanidad; promesas que muchas veces, como sostienen algunos pensadores, no poseen una base científica sólida (Sadin, 2014; Diéguez, 2017). Todo esto ha derivado en un nuevo ismo: el transhumanismo.

Este movimiento o filosofía, si se quiere, plantea en una de sus corrientes más radicales que:

La muerte empieza a no ser vista como un destino, como una condición básica e inexorable de nuestro ser en el mundo, de nuestra índole biológica, o como un referente de nuestra comprensión como seres humanos, tal como las religiones y la filosofía nos habían venido enseñando, sino que se está transformando en un problema técnico. Algo que tarde o temprano nuestro ingenio podrá solventar (Diéguez, 2017, p. 7). 
Nos situaríamos, de esta manera, en el estadio último del progreso de la tecnología, que con sus desarrollos permite al fin crear ese superhombre que dejará de temer a la muerte y se encumbrará como amo y señor de la tierra, capaz a fin de disponer, no solo de la tierra, sino también de la muerte y hacerla desaparecer. Se terminaría de esta manera con toda debilidad humana y con la finitud de la existencia, alejando, de paso, al hombre del dolor y el sufrimiento gracias al desarrollo tecnológico (Valle, 2018). Finalmente, gracias al desarrollo tecnológico, el hombre lograría su ansiada inmortalidad y se alejaría del dolor y el sufrimiento. Es importante hacer notar que este movimiento está dirigido principalmente por los responsables de los monopolios tecnológicos de internet que manejan y administran los datos de los usuarios: “todos ellos están convencidos de que las tecnologías (...) van a transformar todo para 'mejorar' hasta la vida misma, que finalmente quedará liberada de su término" (Sadin, 2018, p. 220).

Es necesario hacer algunas precisiones respecto al concepto de transhumanismo, pues, como es de suponer, tiene las más variadas interpretaciones, más allá de aquellas corrientes que propugnan una suerte de perfeccionamiento del potencial del ser humano en todas sus esferas, haciendo del progreso humano su meta principal. Comprendiendo al ser humano como un ente que puede ser mejorado y no solo en su dimensión física, sino también psicológica, cognitiva y moral, donde la tecnología sería la que permitiría todo tipo de mejoras. Esta visión, apunta Diéguez (2017), no sería nada novedosa, pues dicha perspectiva habría sido refrendada por distintos pensadores que han dejado manifiestas las limitaciones del ser humano, mostrando que su perfeccionamiento no era solo deseable sino necesario. En este contexto destacan las figuras de Bacon, Rousseau, Hegel, Schopenhauer, Nietzsche, Lessing, Unamuno, Ortega y Gasset.

Por otra parte, como comenta Luc Ferry, el transhumanismo

(...) es el heredero, un tanto, paradójico, pero verosímil en muchos aspectos, de una cierta forma de humanismo clásico, el que insiste (...) sobre la perfectibilidad infinita de este ser humano que no está en un principio encerrado en una naturaleza intangible y determinante, como puede serlo un animal guiado por la programación instinto natural común a su especie. El transhumanismo también puede ser heredero del optimismo cientificista y tecnófilo que se ha desarrollado en la Edad Moderna a partir de la Ilustración y de la revolución científica hasta el nacimiento de los NBIC, la robótica y la inteligencia artificial (Luc Ferry, 2017, p. 40).

Valle, D. (2020). Humanismo y transhumanismo en el final de la metafísica: la era digital 
Sin embargo, algo bastante distinto sería la corriente transhumanista representada principalmente por Ray Kurzweil, que se traduciría, a juicio de Luc Ferry, en un preocupante proyecto cibernético que propone:

Una hibridación sistemática de hombre/máquina que recurre a la robótica y a la inteligencia artificial más que a la biología (...) se trata de crear una especie nueva, radicalmente diferente de la nuestra, miles de veces más inteligente y poderosa que ella, una humanidad diferente, para la que la memoria, las emociones, la inteligencia, todo lo que se relaciona con la vida del espíritu, se podría almacenar en soportes materiales de un tipo nuevo. Como cargamos ficheros en una USB (...) Podríamos entonces: 1) separar la inteligencia y las emociones del cuerpo biológico (como la información y su soporte) y 2) almacenar la memoria, así como la conciencia, en máquinas (...) que no dejan de recibir un eco mayoritario en el mundo de los especialistas de la inteligencia artificial (Luc Ferry, 2017, p. 42).

Esta propuesta apuntaría a conseguir la ansiada inmortalidad, dejando atrás las limitaciones de nuestro cuerpo finito e imperfecto. Esto podrá ser logrado a través de la superación de dichas limitaciones en manos de la tecnología, según la cual la dualidad cuerpo y alma queda subsumida en la de máquina y datos. Esta dualidad es concebida como el nuevo reservorio de la humanidad del hombre. La vida del espíritu y el ser del hombre quedan reducidos por tanto "a un sistema de tratamiento de información que equipara el cerebro con una estricta calculadora" (Sadin, 2018, p. 227). No es asunto menor que esta propuesta tenga amplio apoyo en los especialistas en inteligencia artificial, pues ellos parecen ser los llamados a dirigir el destino del hombre. En sus manos está conducir el progreso sin límites de la humanidad, según afirman los transhumanistas.

El destino técnico del hombre como Gestell parece consumarse al mismo tiempo con la metafísica de la subjetividad en sus manifestaciones más notorias en la era digital, lo que plantea una "incertidumbre acerca de la esencia del hombre, justamente porque los seres humanos se han convertido en el fondo de reserva (...) materia prima del mundo tecnológico" (Linares, 2008, p. 106). La existencia se convertiría en la substancia por antonomasia, la presencia eterna del ser humano, a través de la inteligencia artificial y la pervivencia inmortal de la existencia y sus procesos cerebrales, emociones y sentimientos en un dispositivo cibernético, donde sería posible almacenar el ser del hombre en un nuevo híbrido superhumano. Resuena en esta interpretación la tesis metafísica del ser como presencia: una presencia eterna que 
pervive en el compuesto máquina y datos, como la humanidad peculiar al superhombre, reclamado por la voluntad incondicionada de dominio sobre el hombre y la tierra. Se presenta así la disolución absoluta de la diferencia entre el ser y el ente llamado hombre, llegando incluso a identificarse completamente.

Ahora bien, como dice Duque (2002), cualquier conocedor de Nietzsche podría poner en entredicho la comparación o relación entre estos tecno-organismo y cuerpos superhumanos con el planteamiento del superhombre, prevención surgida con toda razón. Sin embargo, lo que está fuera de discusión es lo mencionado por Heidegger en su Carta sobre el humanismo. La crisis del humanismo que se manifestaría a "causa de un proceso general de deshumanización que comprende ora el eclipse de los ideales humanistas de la cultura en favor de una formación del hombre centrada en la ciencia y en la facultades productivas racionalmente dirigidas" (Vattimo, 1987, p. 35), que como hemos visto tienen como fiel reflejo las utopías y supuestos de la era digital.

\section{Conclusiones}

Ciertamente a través de los desarrollos y promesas surgidas en la era digital, cuyo epítome serían el dataísmo y el transhumanismo, se cumplirían plenamente las preocupaciones que Heidegger manifestaba en su interpretación de la era técnica. Época donde la metafísica de la subjetividad llega a su cumplimiento y lleva al extremo sus posibilidades en el presente. Así, la voluntad de dominio incondicionado sobre todo ente se expresa, por una parte, en la vertiente más dura del transhumanismo, que promete el advenimiento de un superhombre de carácter inmortal en una hibridación hombre máquina, $\mathrm{y}$, por otra, el dataísmo, que a través del rastreo y acumulación de la mayor cantidad de datos, promete prever y solucionar, a través del cálculo, la planificación y medida de nuestras conductas, todas la problemáticas presentes y futuras de la existencia, lo que sin lugar a dudas nos llevaría directamente a una vida más plena y feliz, como el gran relato del siglo XXI.

¿Cómo devolver el sentido a la palabra humanismo? Difícil responder, quizá, como sostiene Heidegger, teniendo en cuenta el peligro que se cierne sobre el hombre contemporáneo, dominado y subyugado por las tenazas de las tecnologías y sus discursos. Pensando en las consecuencias humanas de estos desarrollos surgidos en la era digital, en la que la libertad y el ser más propio del hombre parece estar amenazado por los designios de la manipulación y el cálculo. 


\section{Referencias}

Acevedo, J. (1999). Heidegger y la época de la técnica. Santiago: Editorial Universitaria.

Carpio, A. (1977). El sentido de la historia de la filosofía. Buenos Aires: EUDEBA.

Diéguez, A. (2017). Transhumanismo. Barcelona: Herder.

Duque, F. (2003). Contra el humanismo. Madrid: Abada Editores.

Flamarique, L. (2000). El humanismo y el final de la filosofía. Anuario filosófico, 33 (68), pp. 773-796.

Ferry, L. (2017). La revolución transhumanista. Madrid: Alianza.

García \& Valle. (2020). Los impactos de la ideología técnica y la cultura algorítmica en la sociedad: una aproximación crítica. Revista de Estudios Sociales, 2020 (71), pp. 15-27.

Han, B. C. (2014a). Psicopolitica. Barcelona: Herder.

Han, B. C. (2014b). En el enjambre. Barcelona: Herder.

Heidegger, M. (1997a). Ser y tiempo. Santiago: Editorial Universitaria.

Heidegger, M. (1997b). Filosofía, ciencia y técnica. Santiago: Editorial Universitaria.

Heidegger, M. (1999). Ontología: hermenéutica de la facticidad. Madrid: Alianza.

Heidegger, M. (2000). Tiempo y ser. Madrid: Tecnos.

Heidegger, M. (2001). Nietzsche II. Barcelona: Destino.

Heidegger, M. (2002). Serenidad. Barcelona: Ediciones del Serbal.

Heidegger, M. (2006). Carta sobre el humanismo. Madrid: Alianza.

Heidegger, M. (2009). Tiempo e historia. Madrid: Trotta.

Heidegger, M. (2010). Caminos de bosque. Madrid: Alianza. 
Linares, J. (2008). Ética y mundo tecnológico. México: FCE.

Ramos \& Fuentes. (2020). Tecnología y Transparencia. Trans /form/acao: Revista de Filosofía, 43 (1), pp. 77-98.

Rodríguez, R. (2006). Heidegger y la crisis de la época moderna. Madrid: Síntesis.

Sadin, E. (2018). La siliconización del mundo. Buenos Aires: Caja Negra.

Sánchez, D. (2006). La experiencia dionisiaca del mundo. Madrid: Técnos.

van Dijck, J. (2014). Datafication, dataism and dataveillance: Big Data between scientific paradigm and ideology. Surveillance \& Society, 12 (2), pp. 197-208.

Valle, D. (2018). Dolor y autoexplotación en la era digital. Contrastes. Revista Internacional de Filosofía, 23 (3), pp. 163-180.

Vattimo, G. (1987). El fin de la modernidad. Barcelona: Gedisa.

Wiener, N. (1988). Cibernética y sociedad. Buenos Aires: Editorial Sudamericana. 



\title{
Humano, demasiado humano, ultrahumano El desafío de Nietzsche al humanismo ${ }^{1}$
}

\author{
Human, All too Human, Transhuman \\ Nietzsche's Challenge to Humanism ${ }^{2}$
}

Helmut Heit ${ }^{3}$

Kolleg Friedrich Nietzsche. Klassik Stiftung Weimar, Alemania

Recepción: 20 de junio del 2020

Evaluación: 03 de julio del 2020

Aceptación: 20 de julio del 2020

1 Este artículo es un resultado del proyecto de investigación "Nietzsche's Philosophy of Modernity", que fue auspiciado por la Tongji Universität Shanghai, de la República Popular de China, en el marco del "Double First Class Development Project of Tongji University". Una parte de esta contribución fue publicada originalmente en alemán en Heit, 2018.

2 Traducción del alemán por Mikhail Krasnov, Instituto Internacional de Idiomas, Universidad Pedagógica y Tecnológica de Colombia. Revisión conceptual, corrección y complementos a la traducción por Alfredo Rocha de la Torre, Escuela de Filosofía, Universidad Pedagógica y Tecnológica de Colombia.

3 Dr. Phil. por la Leibniz Universität Hannover (Alemania), Profesor asociado en la Tongji University Shanghai y Director del Kolleg Friedrich Nietzsche der Klassik Stiftung Weimar.

Correo electrónico: helmut.heit@klassik-stiftung.de

Heit, H. (2020). Humano, demasiado humano, ultrahumano. El desafío de Nietzsche 


\title{
Resumen
}

Nietzsche se burla del humanismo en reiteradas ocasiones, en parte debido a su antropología naturalizada, no obstante el hecho de que los conceptos de superación de sí mismo, de refinamiento y liberación son presentados regularmente en sus escritos. Este artículo señala que el nexo entre el naturalismo y el perfeccionismo en el pensamiento de Nietzsche deriva del 'enigmático doble-carácter' de la naturaleza humana y culmina en una antropología política de la libertad. La primera sección explica el discurso de Zaratustra acerca del superhombre, no como una doctrina o un mandamiento, sino como un intento de persuasión y una invitación a alcanzar el desarrollo superior de la humanidad. La segunda sección muestra la forma como Nietzsche utiliza sus lecturas de fisiología de su época para elaborar una concepción de lo humano en términos de una dinámica de organización corpórea. En la tercera sección se muestra que el desarrollo natural e histórico-cultural de la especie humana ha creado una posibilidad para impulsar conscientemente una transformación. El proyecto de una disposición plausible estéticamente no está determinado natural ni moralmente, sino que resulta de una-como yo la denomino- 'fuerza normativa de lo posible', que puede ser realizada a través de un ejercicio cultural. El reto de Nietzsche al humanismo es una invitación a ser mejores seres humanos.

Palabras clave: Libertad, superación de sí mismo, naturalismo, perfeccionismo, humanismo, transhumanismo.

\begin{abstract}
Nietzsche mocks humanism at various occasions, in part because of his naturalized anthropology, while concepts of human self-overcoming, refinement, and liberation are regularly present in his writings. This paper argues that the connection between naturalist and perfectionist aspects in Nietzsche's thought derive from the 'mysterious double-character' of human nature and result in a political anthropology of freedom. The first section explains Zarathustra's talk of the Over-Human not as a doctrine or commandment, but as persuasion and invitation to attempt a higher development of humanity. The second section shows how Nietzsche uses his readings of contemporary physiology to develop a conception of the human as a dynamic body-organization. In the third section, it is argued that the history of nature and culture of the human species has created a possibility for further conscious transformation. The
\end{abstract}


ambition to design an aesthetically approvable character is neither naturally determinated nor morally required, but results from a - as I call it - 'normative force of the possible', which can be realized through cultural exercise. Nietzsche's challenge to humanism is an invitation to become better humans.

Keywords: Freedom, self-overcoming, naturalism, perfectionism, humanism, transhumanism. 
El hombre en sus más nobles y elevadas funciones es enteramente naturaleza y porta en sí mismo su inquietante doble carácter (Nietzsche, KSA 1, p. 783).

\section{¿Nietzsche como enemigo del humanismo?}

Nietzsche parece tener poco que ver, en general, con el humanismo, especialmente cuando este término está marcado por el artículo definido como una doctrina filosófica. Sus declaraciones explícitas acerca del término suelen ser, especialmente a primera vista, negativas y de rechazo. Se podría pensar que sus reflexiones sobre este tema culminan en la triple exclamación de Más allá del bien y del mal: "¡Oh Voltaire! ¡Oh humanitarismo! ¡Oh imbecilidad!" (Nietzsche, 2013, p. 77; KSA 5, p. 54)4. De hecho, más recientemente, Volker Gerhardt, entre otros, tomó esta observación como una oportunidad para distinguir su propio concepto de humanidad de los reproches y objeciones de Nietzsche. Según Gerhardt, uno debe defender la idea de amar en cada hombre individual al mismo tiempo la humanidad, contra un "desdén común (...) a cuya cabeza lamento encontrar a Friedrich Nietzsche con su inmaduro desprecio por la palabra humanidad" (Gerhardt, 2019, p. 37). Por supuesto, al comprobado experto en la filosofía de Nietzsche no se le escapa el hecho de que éste, en su programática del individuo productivo y soberano, puede estar "más cerca de la idea de humanidad que muchos otros pensadores del siglo XIX" (Gerhardt, 2019, p. 37). Gerhardt tampoco deja ninguna duda de que una filosofía humanista debe reconocer en primer lugar que el hombre nace, es completamente natural y sigue siendo parte inseparable del contexto natural. Todas las más altas capacidades del hombre no están solamente ligadas al origen, sino de forma permanente "ligadas a la presencia del cuerpo", como aclara Gerhardt con vistas al discurso de Zaratustra acerca de la gran razón del cuerpo (Gerhardt, 2019, p. 96). Incluso la idea del superhombre, que parece estar en contradicción directa con las concepciones del humanismo clásico que apuntan a la universalidad y la igualdad, puede entenderse como el ideal de un ser humano superior, en el que "una intención humanista tiene un efecto" (Gerhardt, 2019, p. 39). Si bien algunos aspectos de la filosofía de Nietzsche pueden ser consistentes con el concepto de humanidad de Gerhardt, probablemente la diferencia decisiva resulta del diseño

\footnotetext{
${ }^{4}$ Las traducciones de los textos de Nietzsche al español, realizadas por Andrés Sánchez Pascual, son por lo general las versiones utilizadas en este artículo. En los casos en que no sea referida la correspondiente versión castellana, se sobreentiende que la versión pertenece al traductor de este escrito.
} 
universalista que este autor ilustra en la distinción entre filantropía y humanidad: "Mientras que la filantropía está relacionada con un comportamiento de apertura, de ayuda y de preocupación ante el otro existente $-\mathrm{y}$ con ello está vinculada gustosamente con modos concretos de comportarse-, presupone a la humanidad (Menschheit) en su generalidad en el hombre particular (Gerhardt, 2019, p. 32).

Es precisamente esta orientación, que tiene su origen en Kant, según la cual una ética y política humanista es efectiva o concebible si las razones dadas para ello "derivan su poder de persuasión de su validez general" (Gerhardt, 2019, p. 225), la que no llega a ser compartida por Nietzsche. Las diferencias entre Nietzsche y Gerhardt a este respecto parecen claras, y quizás Gerhardt también haga bien en contornear de esta manera su propia posición contra el papel de la crítica en Nietzsche. Sin embargo, vale la pena, en mi opinión, considerar la contribución de Nietzsche a una filosofía de lo humano, y también a una filosofía humana, de una manera diferente. Como punto de partida me gustaría hacer una cita que antepongo también en este ensayo como un lema. Al comienzo de la introducción al quinto de sus libros no escritos para Cósima Wagner, El duelo en Homero, se encuentran ya los motivos centrales de sus reservas contra el humanismo tradicional:

Cuando se habla de humanidad se piensa en lo que separa y distingue al hombre de la naturaleza. Pero tal separación no existe en realidad: las propiedades 'naturales' y las denominadas propiamente 'humanas' son inseparables. El hombre en sus más nobles y elevadas funciones es enteramente naturaleza y porta en sí mismo su inquietante doble carácter. Sus terribles capacidades, consideradas como inhumanas, son incluso quizás el terreno más fructífero en el que pueden crecer todos aquellos impulsos, hechos y obras de toda humanidad (Nietzsche, KSA 1, 783).

En estas tempranas reflexiones escritas en los días navideños del 1872, y aun bajo el claro hechizo de su amor por Wagner y Schopenhauer, se encuentran ya los motivos centrales de su desarrollo posterior, al menos en relación con la pregunta central para el tema del humanismo; la pregunta por la antropología filosófica. En una clara posición negativa al respecto, Nietzsche se opone a una concepción idealista de que el hombre deba distinguirse esencialmente de la naturaleza y que nuestras cualidades y logros culturales, que en general se consideran especialmente valiosos, deban explicarse por este carácter sobre o extranatural del hombre. Por el contrario, desde temprano Nietzsche insiste en que las llamadas capacidades naturales, y las llamadas capacidades 
culturales del hombre, están "entretejidas inseparablemente", es decir, representan una continuidad. A diferencia de muchos pensadores anteriores, Nietzsche no define al hombre como un zoon logon echon y como un animal rationale, pues en general ya no pertenece a aquellos que ven en la razón la cualidad más distinguida y distintiva del hombre. En lugar de distinguir a los humanos de otros animales sobre la base de su racionalidad y, en general, de distinguir la razón de la naturaleza, Nietzsche quiere "(...) retraducir el hombre a la naturaleza" (2013, p. 223; KSA 5, p. 169). Es por esto que Nietzsche ha sido puesto una y otra vez, y no sin razón, en relación con antropologías naturalistas. Por otro lado, los pensamientos e imágenes de la superación de sí mismo y del supremo desarrollo, del refinamiento, de la liberación y trascendencia están siempre presentes en sus escritos (Heit, 2018).

Con esta naturalización del hombre se vincula, ya en El duelo en Homero, la conjetura teórica cultural de Nietzsche, según la cual las instituciones y logros con los cuales nos distinguimos en tanto humanos de la otra naturaleza, y también nos elevamos sobre ella, son a su vez producto de fuerzas y acciones que hoy son consideradas inhumanas. Esta sospecha consiste en que el llamado 'malvado' no solo no es una simple contradicción del denominado 'bueno', sino que, tanto históricamente como en la actualidad, posiblemente el uno tiene al otro como condición. La metáfora en la que estos elementos conflictivos del hombre se unen es el discurso acerca del "inquietante doble carácter”. Deseo seguir esta expresión, relacionándola con otro pasaje igualmente enigmático, aunque mucho más conocido, como lo es el del prólogo de Así habló Zaratustra:

Habéis recorrido el camino que lleva desde el gusano hasta el hombre, y muchas cosas entre vosotros continúan siendo gusano. En otro tiempo fuisteis monos, y aun ahora es el hombre más mono que cualquier mono. Y el más sabio de vosotros es tan solo un ser escindido, híbrido de planta y fantasma. Pero ¿os mando yo que os convirtáis en fantasmas o en plantas? ¡Mirad, yo os enseño el superhombre! El superhombre es el sentido de la tierra. Diga vuestra voluntad: ¡Sea el superhombre el sentido de la tierra! (1993, p. 34; KSA 4, p. 14).

Sobre la base de una interpretación ejemplar de este pasaje, no solo se pueden concretar los problemas, sino también las posibilidades conceptuales de un humanismo filosófico. En las primeras líneas de esta cita, Zaratustra lleva a cabo una narrativa con fuertes ecos biológico-evolutivos. Los hombres interpelados en el colectivo son puestos en una conexión diacrónica y sincrónica 
con el gusano y, más claramente, en asociación con el darwinismo, con el mono. Sin duda, el hombre ha recorrido un largo camino desde el gusano y el mono hasta su estado actual, pero es al mismo tiempo en muchos aspectos un reptil y ridículamente irracional. El hombre se caracteriza entonces por una simultaneidad tensa y disonante. Incluso una persona sutil, educada y cultivada, es al mismo tiempo solo la antítesis entrelazada (¿inextricablemente?) de la mera espiritualidad y de la naturaleza espiritualmente viva. La referencia a la planta y al fantasma lleva al dualismo clásico a una fórmula irónica y, al mismo tiempo, lo trasciende en una figura híbrida ambigua, especialmente porque uno sabe bien que no existen fantasmas. De esta manera se pueden entender los comentarios de Zaratustra en el contexto del discurso naturalista contemporáneo, en el que Gerhardt también inscribe la naturaleza del hombre. Al mismo tiempo, la aliteración metafórica de ambigüedad e hibridación enfatiza también, sin embargo, una unidad de opuestos y, por tanto, una tensión dinámica, una carga y una fuerza de la cual surgen nuevas opciones.

Con la posterior pregunta retórica, el texto deja lo meramente diagnóstico y va en dirección del futuro desarrollo. Sin embargo, Zaratustra no cambia repentinamente de lo doctrinal a lo normativo e imperativo, sino más bien a lo protréptico y a lo persuasivo. La tensión dinámica debe hacerse fructífera y ser dirigida en cierta dirección. El narrador llama a evitar la alternativa falsa del fantasma y la planta, la mente y la naturaleza y, en cambio, anuncia de manera no individualista otra idea a un colectivo: "Os enseño el superhombre" y "El superhombre es el sentido de la tierra" (Nietzsche, 1993, p. 34; KSA 4, p. 14). Si en el contexto de la narrativa del Zaratustra este pasaje nos permite hablar del superhombre como una doctrina de Nietzsche, es algo que puede permanecer sin ser decidido por el momento. De interés en el contexto de mis elaboraciones está más bien la conexión retórica de una narrativa evolutiva con una llamativa invitación, que trasciende las alternativas actuales con la ayuda de una nueva metáfora. La afirmación solo supuestamente constatable de que el superhombre "es" el sentido de la tierra, pertenece a este contexto retórico. El carácter persuasivo de esta constatación (Fest-Stellung) surge en la siguiente aclaración: "Vuestra voluntad dirá: ¡el superhombre sea el sentido de la tierra!" (Nietzsche, 1993, p. 34; KSA 4, p. 4). Esta frase no expresa doctrina alguna, sino una invitación. La supuesta voluntad libre de un destinatario en plural debe ser motivada hacia una determinada decisión, a saber, a definir al superhombre como sentido global. Esta definición del sentido no se refiere en primer lugar a una existencia individual, sino a la totalidad del mundo humano. En segunda instancia, el subjuntivo enfatiza el contrafactual trascendente de esta disposición. La palabra superhombre no se 
refiere a un ideal moral, sino a una atractiva posibilidad. Es una invitación a la autosuperación de la especie humana.

Ciertamente, la interpretación de un solo pasaje, especialmente de Zaratustra, difícilmente puede ser considerada como una reconstrucción general de la antropología filosófica de Nietzsche, y de hecho no se entiende como tal. Este pasaje ejemplifica más bien una conexión original de alternativas supuestamente exclusivas. Se podría con ello superar las dicotomías clásicas de naturalismo versus trascendencia, y de existencialismo individualista versus antropología sociológica cultural. A continuación me gustaría señalar que Nietzsche esboza una propuesta para la autocomprensión filosófica del hombre, que vincula motivos naturalistas con una praxis del trascender. Sus procedimientos de naturalización son tan específicamente suyos que la etiqueta 'naturalismo' tiende a causar más confusión que lo que aporta en claridad. Además, no solo se centra en existencias aisladas, sino que también toma en consideración la naturaleza fundamentalmente social de lo humano. Lo social se manifiesta no solo en las altas instituciones histórico-culturales del hombre, principalmente en el lenguaje, sino también en la naturaleza humana en tanto organización viva y jerárquica. La individualización es el producto de la organización social, y es la que permite al sujeto desarrollar la capacidad de autoformación y autodeterminación. Nietzsche demuestra ser un filósofo filantrópico y un defensor de una antropología política de la libertad. Sus objeciones al humanismo clásico son como las críticas productivas que se pueden esperar de un buen amigo.

\section{El hombre como animal demasiado humano}

La dimensión naturalista de la concepción nietzscheana del hombre ha sido resaltada regularmente en la investigación ${ }^{5}$. Sin embargo, el hecho de que él asocie repetidamente la naturalización con la terminología sociopolítica ha recibido menos atención hasta ahora ${ }^{6}$. Un punto de partida común para sus consideraciones a este respecto es el cuarto discurso de Zaratustra, ya referido por Volker Gerhardt. Dirigida a los despreciadores del cuerpo, la distinción entre cuerpo (Leib) y alma en el sentido de dos existencias separadas

\footnotetext{
5 Realizo un resumen de las interpretaciones naturalistas de Nietzsche y sus dificultades en Heit (2016a). En Heit (2013), discuto más detalladamente en qué sentido Nietzsche considera al sujeto humano como parte de la naturaleza.

6 Una excepción, aparte de Jyung-Hyun Kim (1995), es Herman Siemens (2016).
} 
es caracterizada como infantil. Sin embargo, el discurso del niño no es rechazado como completamente inútil, pues "¿por qué no se debe hablar como los niños?” (Nietzsche, KSA 4, p. 39). La concepción dualista no es refutada o generalmente prohibida, sino desacreditada en ciertos contextos. Parece inmadura e ingenua, irreflexiva y mal informada, hace hincapié en lo increíble y sucumbe a la seducción del lenguaje. En el contexto de las investigaciones filosóficas, el dualismo ya es admisible. La visión alternativa, por otro lado, establece una unidad psicofísica: "Pero el despierto, el sapiente, dice: cuerpo soy yo íntegramente, y ninguna otra cosa; y alma es sólo una palabra para designar algo en el cuerpo" (Nietzsche, 1993, p. 60; KSA 4, p. 39). El alma es subsumida en el cuerpo. Sin embargo, este naturalismo aparentemente monista no se presenta como una verdad científica comprobada, sino como un estado de alerta y conocimiento equipado con los atributos de una mentalidad intelectualmente superior. Solo por esta razón es aconsejable comprender este motivo naturalista en el sentido de una heurística interesada por la ciencia y no como una doctrina basada en la ciencia ${ }^{7}$.

En una nota muy informativa del contexto de su trabajo preparatorio sobre el Zaratustra, Nietzsche aplica explícitamente la reserva epistemológica a un ideal científico de interpretación de las condiciones de existencia del sujeto: "Para que exista un sujeto, debe haber aquí algo que persista" (Nietzsche, Nachlass 1881 11[268], KSA 9, p. 543). Tanto la existencia como la percepción autoconsciente de la subjetividad requieren una cierta estabilidad, un permanecer-se idéntico en el espacio y en el tiempo. Pero esta persistencia, que después de hablar de identidad personal es idéntica incluso a sí misma, se echa de menos bajo el presupuesto del cambio y la transformación permanentes. Nietzsche no atribuye, por tanto, la posibilidad de subjetividad a una existencia "propia" o "auténtica" de lo que persiste, sino a un productivo engaño:

Sin embargo, creo ahora: el sujeto podría surgir en tanto surge el error de lo idéntico (Gleichen), por ejemplo cuando un protoplasma de fuerzas diversas (la luz presiona la electricidad) recibe siempre solamente un impulso particular y de acuerdo con este impulso colige una identidad (Gleichheit) de las causas: o cuando en general solamente se está en capacidad de recibir un impulso y todos los otros son sentidos como idénticos (Nachlass 1881 11[268], KSA 9, pp. 544s.).

7 Schacht (2012) destaca especialmente esta diferencia. 
Es de destacar que Nietzsche refiere de manera casual y ejemplar, precisamente, a las tres fuerzas a las que también se dirige Hermann von Helmholtz para explicar los procesos de percepción óptica. Independientemente de si la retina se estimula visual, eléctrica o mecánicamente, nuestro organismo 'interpretará' siempre inevitablemente este estímulo como luz. Por esta razón, entre otras cosas, Helmholtz se ve a sí mismo autorizado para hablar de la percepción como una operación activa de los órganos sensoriales, que llegan a juzgar el mundo exterior con la ayuda de "conclusiones inconscientes de las sensaciones sobre sus causas", con lo cual su validez, como en todas las conclusiones de inducción y analogía, está infradeterminada (Helmholtz, 1867, p. 430; Schiemann, 2014, pp. 46-75). Al mismo tiempo, lo simple y lo persistente son indispensables para la educación y la preservación de la vida y la subjetividad. Por esta razón cuando Nietzsche afirma que "(...) la simplificación es la necesidad fundamental de lo orgánico" (Nachlass 1881 11[315], KSA 9, p. 563), se relaciona de esta manera con la fisiología contemporánea. Un organismo vivo no solo se basa en estos supuestos, sino que los realiza también en cierta medida mientras dure su existencia; ellos son efectivos y reales en él y a través de él. De hecho, en este sentido, el "error es el padre de lo vivo" (Nietzsche, Nachlass 1881 11[270], KSA 9, p. 545).

De particular interés en el campo de la antropología filosófica, por lo tanto, aparte de la reserva cognitiva crítica, es ante todo que los engaños y las simplificaciones son funcionales y se convierten en una realidad viva en el organismo. En este sentido también podemos entender la continuación del discurso que Zaratustra pone en boca del despierto y del sapiente: "El cuerpo es una gran razón, una pluralidad dotada de un único sentido, una guerra y una paz, un rebaño y un pastor" (1993, p. 60; KSA 4, p. 39). Este denso enunciado no solo afirma cuatro veces lo que es el cuerpo, sino que simultáneamente plantea una serie de preguntas. Se prestó especial atención con ello a la primera determinación del cuerpo como una gran razón (Gerhardt, 2011). A través de esta memorable fórmula se atribuye la facultad del espíritu, hasta ahora más distinguida, al cuerpo o se identifica con él. Esta es una de las razones por las cuales se demostró que Nietzsche fue pionero en las nuevas discusiones acerca de la encarnación (Embodiment) y la cognición encarnada (embodied cognition). Sin embargo, las relaciones entre el cuerpo, el yo y el sí-mismo, y entre la gran y la pequeña razón, siguen siendo algo enigmáticas. Me parece útil en este contexto prestar atención a las otras tres determinaciones, que giran en torno a la relación entre la unidad y la multiplicidad. El cuerpo en sí mismo no es monista, sino una pluralidad caracterizada por un sentido 
común y por metáforas del conflicto interno y de la tensa organización. El cuerpo consiste en la simultaneidad de multiplicidad disonante y unanimidad, conflicto y armonía, séquito y enseñoreamiento. El hombre vivo puede entenderse como una "organización corporal” dinámica-agonal (Abel, 2001, p. 31).

Las metáforas del pastor y del rebaño, especialmente, en las que se combinan connotaciones biológico-naturalistas con connotaciones políticas y sociales, pueden dilucidar decisivamente la relación entre libertad y determinismo, así como entre el individuo y la sociedad. Sin embargo, con una pregunta tan sistemática se sale adelante casi sin referencia al escrito póstumo. Las principales características de una "socio-fisiología del yo" pueden observarse ante todo en las notas de principios de la década de 1880, en las que Nietzsche, según la observación de Herman Siemens, "profundiza su giro hacia la fisiología" y desarrolla "una prehistoria socio-fisiológica del individuo" (Siemens, 2016, p. 167), no obstante que la idea fundamental ya se encuentra en El duelo en Homero. En La gaya ciencia (1882) y en Así habló Zaratustra (1883/85) ya juegan estas características un claro, aunque subterráneo rol, sin ser precisadas detalladamente. Esto está reservado para los escritos posteriores al Zaratustra, que están fuertemente influenciados por las lecturas y reflexiones fisiológicas. En una formulación más contundente del verano de 1885, como es típico de los escritos póstumos, se unen en el fondo todas las reflexiones para la comprensión de la antropología fisio-política de Nietzsche. El apunte está en el contexto de reflexiones críticas al cogito cartesiano, que se han incorporado reformuladas al primer capítulo de Más allá del bien y del mal. Aunque solo es un apunte no publicado por Nietzsche, el texto contribuye significativamente a la comprensión temática de su presunta antropología y de su obra publicada en vida.

En este apunte Nietzsche pregunta: "Punto de partida del cuerpo y de la fisiología: ¿por qué razón?”. Inmediatamente incluye la respuesta: “-Logramos la correcta representación del talante de nuestra unidad-subjetiva (...)" (Nachlass 1885 40[21], KSA 11, p. 638). Al caracterizar expresamente la fisiología como un "punto de partida" del cual podemos derivar la "correcta representación", él subraya la función hipotética de ésta. Nietzsche no desarrolla su antropología como un científico natural, sino (solo) en relación al "hilo conductor del cuerpo" (Nachlass 1885 36[35], KSA 11, p. 565), como se afirma repetidamente en otras partes del escrito póstumo (Sommer, 2016, p. 152). A diferencia de las más sutiles capacidades de la razón, Nietzsche 
considera que el cuerpo es capaz de ofrecer un testimonio de carácter informativo. La fisiología, y con ello el naturalismo y el sensualismo, son convenientes como "hipótesis reguladoras" o como "principios heurísticos" debido a su productiva función epistemológica (Nietzsche, 2013, p. 43; KSA 5, p. 29). Partiendo de esta perspectiva, se logra una concepción más confiable de la unidad del sujeto "(...) como regente en la cima de la comunidad, no como 'almas' o 'fuerzas vitales', así como también de la dependencia de estos regentes ante los gobernados, y de las condiciones de jerarquía y división del trabajo como posibilitación simultánea del individuo y del todo" (Nieztsche, Nachlass 1885 40[21], KSA 11, p. 638). La atención de Nietzsche se centra en la naturaleza específica de la constitución del sujeto, cuya existencia no se niega. Su demarcación se refiere en particular a la negación de las especulaciones platónico-cristianas-cartesianas acerca del alma, así como al vitalismo contemporáneo $^{8}$ (Ioan, 2015, p. 219). El sujeto es una organización jerárquica, política y funcional de la división del trabajo.

Nietzsche precisa estas determinaciones en las siguientes líneas. En primer lugar, las "unidades vivas" se caracterizan por su carácter emergente y por su transitoriedad, ya que "la eternidad no pertenece al "sujeto" (Nietzsche, Nachlass 1885 40[21], KSA 11, p. 638); el sujeto es enteramente mortal. En segundo lugar, se muestra en el sujeto una lucha que se expresa en obediencia y mando, ya que "a la vida pertenece una fluyente delimitación del poder" (Nietzsche, Nachlass 1885 40[21], KSA 11, p. 638). Con esta determinación se muestra, especialmente, la dimensión política que Nietzsche considera, una y otra vez, como subyacente a su concepción de sujeto. En Más allá del bien y del mal Nietzsche traduce la pregunta acerca de 'quién se es' en la pregunta "en qué orden jerárquico se encuentran recíprocamente situados los instintos (Triebe) más íntimos de su naturaleza" (2013, p. 35; KSA 5, p. 20). Unas páginas más adelante, Nietzsche hace referencia al "alma como estructura social de instintos (Triebe) y afectos" (2013, p. 43; KSA 5, p. 27), y luego al cuerpo como una "estructura social de muchas almas" (2013, pp. 51-52; KSA 5, p. 33). El apunte del escrito póstumo especifica dos aspectos adicionales que pueden entenderse con la ayuda de metáforas políticas. En tercer lugar, una "cierta ignorancia en la que el gobernante se mantiene por

\footnotetext{
8 Razvan Ioan ha demostrado convincentemente que Schopenhauer es un padrino y un objeto de crítica, ya que Nietzsche no solo se distingue (con Schopenhauer) del alma clásica, sino también de su idea de la fuerza vital.
} 
encima de los asuntos individuales e incluso de los disturbios de la comunidad", pertenece no solo a las condiciones funcionales necesarias del organismo, sino también a su capacidad de control (Nachlass 1885 40[21], KSA 11, p. 638). A partir de la comprensión de la ignorancia funcional del regente, se produce además "una valoración para el no saber, que visto en líneas generales es el simplificar y falsear, lo perspectivista" (Nachlass 1885 40[21], KSA 11, pp. 638s.), que al final del apunte Nietzsche reafirma a favor de su heurística fisiológica en lugar de la introspección y la reflexión: "El cuestionamiento directo del sujeto sobre el sujeto, y toda autorreflexión del espíritu, tiene sus peligros en que podría ser útil e importante para su actividad de malinterpretarse" (Nachlass 1885 40[21], KSA 11, p. 639). Si bien esta dimensión heurística vuelve a ser relevante al final de mi reflexión, en este punto me interesa principalmente una cuarta precisión, que Nietzsche enfatiza en particular: "Lo más importante es, sin embargo: que vemos al dominador y a sus dominados de la misma manera, todos sintiendo, queriendo, pensando (...)" (Nachlass 1885 40[21], KSA 11, p. 639).

A la luz de estas líneas pueden entenderse de mejor manera las peculiaridades específicas de la combinación de conceptos naturalistas y políticos en la antropología de Nietzsche. Los regentes y los gobernados son del mismo tipo; las diferencias de rango entre ellos son graduales y no son fundamentales. También se deduce que la jerarquía es variable. Por lo tanto, ésta no tiene que basarse, como lo supone Gerhardt, en el concepto de igualdad como criterio ${ }^{9}$ (Gerhardt, 2019, p. 38). La jerarquía tampoco representa un orden 'correcto, 'ideal' o 'natural' más o menos bueno, sino que es precisamente tal como ella es. En una unidad viva se forman coaliciones más o menos estables sobre la base de procedimientos de negociación agonistas, en los que la fuerza superior, así como el reconocimiento voluntario debido a objetivos comunes o superpuestos, pueden cumplir un rol. Todas las partes de esta unidad existen sintiendo (epitimótico), queriendo (timótico) y pensando (lógico). Solo por esta razón no es útil asociar la concepción del alma de Nietzsche con las tres partes cualitativamente distintas del alma de la politeia platónica, como ha sucedido ocasionalmente. Sin embargo, en el contexto del discurso de "la estructura social de los instintos y los afectos" (Nietzsche, 2013, p. 43; KSA 5, p. 27), se afirma que "debe estar claro que Nietzsche toma su perspectiva homuncular de los instintos del tratamiento platónico de las

9 "La igualdad es en esto la medida que permite medir el rango de la grandeza humana".

Heit, H. (2020). Humano, demasiado humano, ultrahumano. El desafío de Nietzsche 
partes del alma" (Clark and Dudrick, 2015, p. 272). Esta especulación está basada probablemente en la plausibilidad general de la referencia siempre correcta de Nietzsche a Platón, pero al mismo tiempo ignora la literatura fisiológica y psicológica realmente consultada por Nietzsche. De esta manera, se puede observar un paralelo en el hecho de que Nietzsche también entiende al sujeto como una composición de partes normativamente densas, aunque las diferencias predominan tanto que el intento de construir la propuesta de Nietzsche como un "refinamiento" de la teoría de Platón (Clark and Dudrick, 2012, p. 167) finalmente conduce a demasiados desvíos.

En primera instancia debe resaltarse que Nietzsche, en contraste directo y explícito con Platón, asume la mortalidad del alma (2013, p. 38; KSA 5, p. 23; Janaway, 2014, p. 14). Es por esto que no está claro si Platón realmente califica como un crítico del atomismo del alma, como tampoco si Nietzsche lo percibió como tal. Evidentemente el "relato de John Cooper acerca de la psicología de Platón" (Clark and Dudrick, 2012, p. 164) no contribuye en nada a la comprensión de la interpretación de Nietzsche acerca del filósofo griego, debido a que Nietzsche no conoció ni podría haber conocido obviamente la lectura de Cooper de 1998. Por el contrario, la historia de la religión europea de Julius Lippert se encuentra aún hoy en día con algunos rastros de lectura en la biblioteca personal de Nietzsche.

En el capítulo acerca de la fisiología platónica dice Lippert: “Aunque en las mentes se asienta el alma divina e inmortal con sus 'vuelcos' como fuerza motriz, en el cuerpo del servidor habita un alma mortal compuesta" (1881, p. 263). Lippert ve en la idea de un alma inmortal y divina el efecto posterior de la religiosidad más antigua y la continuación de una "concepción popular" (1881, p. 263). Este pasaje puede considerarse, por tanto, como una inspiración para la polémica antiplatónica de Nietzsche, según la cual la "superstición del alma" es una "superstición de los pueblos de los tiempos prehistóricos" (KSA 5, p. 11). En tercer lugar, Platón tiene una idea de justicia en la que cada parte del alma tiene y hace lo suyo y, de esta manera, tal como los estoicos, proyecta sus concepciones normativas de un orden justo en la naturaleza (humana) (KSA 5, pp. 21s.). La organización de las partes del alma puede ser para Platón correcta o incorrecta, buena o mala, mientras que para Nietzsche la suposición de una escala de medida externa se ha vuelto inverosímil. La "construcción social de instintos y afectos" expresa una jerarquía de preferencias, pero es categóricamente incorrecto preguntar sobre la naturaleza buena o malvada de este orden. En cuarto lugar se presenta el 
caso de que para Nietzsche los instintos y afectos son de diversas maneras y esencialmente iguales, mientras que para Platón las tres partes limitadas del alma nunca pueden ser del mismo tipo ni contar con el mismo derecho.

En contraste con el especulativo y esencialmente engañoso intento de explicar la antropología de Nietzsche como un refinamiento de lo platónico, la importancia de Der Kampf der Theile im Organismus (La lucha de las partes en el organismo), de Wilhelm Roux (1881), por ejemplo, que es positivamente comprobable, ha sido bien documentada durante más de cuarenta años, y ha sido evidente hasta en la metafórica política (Müller-Lauter, 1978). Roux ve la lucha como un principio regulador a través del cual los elementos en conflicto forman una precaria unidad, que al mismo tiempo se combinan en una transformación dinámica. Además de Roux puede hacerse referencia también a la lectura de Nietzsche realizada por Lange, Espinas, Schneider, Rolph, Drossbach y otros, que también entienden fisiológicamente al organismo como una multiplicidad organizada ${ }^{10}$ : "Todo ser vivo no es un individuo, sino una pluralidad; incluso en la medida en que nos parece un individuo, sigue siendo una unión de seres vivos autónomos", tal como ya ha sido dicho por Goethe (1998 [1817], p. 56) ${ }^{11}$. La multiplicidad necesita organización, pero al mismo tiempo esta organización se basa en una tensión interna continua que la mantiene en desarrollo. Roux precisa que al igual que en un Estado, la diversidad interna y la competencia son necesarias en un organismo, pues él no "se desarrollaría sin esta competencia de los individuos, simplemente a través de la lucha con los Estados vecinos" (Roux, 1881, p. 274). Según Nietzsche, "la batalla de los tejidos se convierte en un principio regulador" (Nachlass 1883 7[190], KSA 10, p. 303).

De acuerdo con esta imagen del sujeto como una organización agonal, Nietzsche hace un apunte en el contexto de su lectura de Roux:

Así como la célula está fisiológicamente junto a la célula, el instinto (Trieb) lo está junto al instinto (Trieb). La imagen más general de nuestra naturaleza es una socialización de instintos (Triebe), con rivalidad constante y alianzas individuales entre sí. El intelecto objeto del concurso (Nachlass 1883 7[94], KSA 10, p. 274).

\footnotetext{
${ }^{10}$ Para conocer acerca de las lecturas de Nietzsche y acerca de su biblioteca personal cfr. Campioni, D'Iorio, Fornari, Fronterotta y Orsucci (2003).

${ }^{11}$ Si Nietzsche no conocía este pasaje directamente de la lectura de Goethe, probablemente lo vio citado en la Historia del materialismo de Friedrich Albert Lange (Lange, 1974 [1873-75], p. 694).
} 
El hombre aparece aquí como una organización sociopolítica de células e instintos (Triebe) que se combinan en acciones individuales, así como en el proceso de vida en su conjunto, para formar una unidad particular. El intelecto no es el soberano controlador de esta competencia, sino el objeto de la misma. Por regla general él sirve a la racionalización y a la explicación apologética de aquello que ha llegado al poder en todo el organismo. Nietzsche considera como un engaño moral la afirmación de que solo el intelecto debe gobernar sobre los otros instintos (Instinkte), porque se estima que solo su voluntad es "libre". "El deseo de superar un afecto es en última instancia, sin embargo, solamente el deseo de otro afecto" (Nachlass 1882/83 5[1.58], KSA 10, p. 194). Esto también explica las críticas de Nietzsche al concepto de voluntad de Schopenhauer. En el sentimiento soberano del volente no se expresa una instancia autosuficiente, sino que "lo que ocurre es que en cada comunidad bien construida y feliz la clase dominante se identifica con los éxitos de la comunidad" (KSA 5, p. 33) ${ }^{12}$. De acuerdo con la jerarquía fisio-política respectiva, uno u otro afecto tiene la supremacía, y este orden se manifiesta en todas las expresiones de vida del sujeto. Cual afecto prevalece es de segundo orden. Para la función y la supervivencia siempre precaria del todo, al principio es crucial que exista una unidad organizada de la voluntad. Si se está buscando un modelo histórico para esta forma de organización política, debe pensarse en Homero en lugar de Platón. La comunidad aristocrática de los aqueos ante Troya se basa en un equilibrio agonista e inestable de obligaciones, expectativas e intereses mutuos (Ulf, 1990). En él se puede ver el siempre precario "antagonismo moderado con poderes aproximadamente iguales" (Siemens, 2016, p. 187), que se identificó de manera convincente como el núcleo de la concepción nietzscheana de la subjetividad soberana. Los aristócratas reunidos participan en la lucha común por razones diferentes. Se organizan y, según la situación, forman una "pluralidad con un

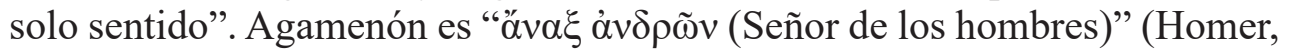
2013, p. 1-442), su voluntad tiene cierta autoridad y su palabra tiene un peso considerable en la congregación. La causa común solo puede tener éxito si, y en la medida, en que logra ganar a los aqueos para ello, ya sea por amenaza o por un incentivo, ya sea por lealtad o cálculo. Al mismo tiempo, el conflicto con Aquiles muestra claramente que ni Agamenón ni una autoridad

\footnotetext{
${ }^{12}$ Lo que se aplica al sujeto según Nietzsche, se aplica a la sociedad según Marx y Engels: "Los pensamientos de la clase dominante son los pensamientos predominantes en cada época, es decir, la clase que es el poder material dominante de la sociedad es al mismo tiempo su poder espiritual dominante" (Marx und Engels, 1986 [1845], p. 46).
} 
superior del deber socio-moral o de los intereses objetivos tienen un simple poder de coerción sobre los otros aristócratas. La discusión de Aquiles con Ulises, Áyax y Fénix, en el noveno libro de la Iliada, ilustra acertadamente que no hay poder externo o interno, ni oferta social o económica, ni argumento político o moral que subordine a Aquiles al interés de la comunidad. Los aristócratas de Troya tienen diferentes fortalezas, habilidades e intereses; entre ellos hay una competencia jerárquica por el prestigio y el honor, aunque todos ellos son del mismo tipo.

Mientras que hasta ahora las dimensiones psicofisiológicas individuales de los hombres en tanto organización corporal estaban en primer plano, en lo subsiguiente el enfoque deberá centrarse en los aspectos intersubjetivos. El individuo humano es biológica y socioculturalmente parte y producto de la historia del género. Si él es entendido en tanto "estructura social de los instintos y los afectos", debe tenerse al mismo tiempo en cuenta que los componentes de esta organización son parte y producto de la historia humana: "Nuestros instintos (Triebe) y pasiones son monstruosas etapas a través de las cuales han sido cultivadas las relaciones sociales y sexuales (a lo mejor previamente en las hordas de simios)" (Nachlass 1881 11[130], KSA 9, p. 487). Nietzsche concibe al sujeto, no solo interna sino también externamente, como una realidad social organizada. Al hacerlo, no solo contradice toda concepción esencialista, sino también la robinsonada especulativa de los conceptos contractualistas: "La sociedad no se configura a partir de individuos ya existentes por medio de un contrato; más bien, es la sociedad la que educa y da forma a los individuos para que sean el producto de la sociedad" (Siemens, 2016, p. 172). En el seno de las asociaciones biológicas, el especimen delimitado físicamente se desarrolla a partir de un órgano, de una función del todo, en una organización más o menos autónoma, que sin embargo permanece constitutivamente relacionada con los demás. Ya hemos visto que Nietzsche considera la construcción de la estabilidad mundial externa como una condición de la subjetividad. Pero las "experiencias egoístas internas" son también de acuerdo con esta imagen "reducidas a nuestras posiciones practicadas y aprendidas en relación con los otros" (Nachlass 1880 6[70], KSA 9, p. 212 ${ }^{13}$. En este sentido, el sujeto está, y sigue estando, indisoluble-

\footnotetext{
${ }^{13}$ Siemens afirma acertadamente: "Incluso en la retirada a la soledad, que a menudo se entiende como sintomática del individualismo autárquico de Nietzsche, practicamos las relaciones sociales con nosotros mismos y todos llevamos nuestros hábitos e impulsos sociales" (Siemens, 2016, p. 181). Por lo tanto, la objeción de que "la defensa del egoísmo de Nietzsche" es una prueba de una forma de pensamiento antisocial tampoco llega a ningún lado.
} 
mente vinculado a la sociedad: "Antaño estuvo el yo oculto en el rebaño: y ahora está el rebaño aun oculto en el yo" (Nachlass 1882 5[1.273], KSA 10, p. 220).

Las aculturadas y encarnadas posiciones respecto a los demás no solo se manifiestan en aquellos instintos (Triebe) referidos a los otros, como por ejemplo el deseo sexual, el amor, la envidia, el odio o la necesidad de reconocimiento, sino también en las 'capacidades superiores' del hombre. La naturaleza social se extiende en particular al lenguaje y, por tanto, a todo aquello que buscamos articular de manera consciente. Esto es particularmente claro en la reinterpretación nietzscheana de la formulación schopenhaueriana del "genio de la especie" (García, 2010). Las expresiones lingüísticas son, por una parte, signos de "grupos de sensaciones" (KSA 5, p. 221), que son esencialmente solipsistas, mientras que, por otro lado, el lenguaje sirve principalmente para el propósito social de la comprensión, especialmente en situaciones de crisis: "Para entenderse uno al otro no es suficiente que se usen las mismas palabras: se deben usar las mismas palabras también para el mismo tipo de experiencia interna, se debe tener, finalmente, una experiencia en común con el otro" (KSA 5, p. 221). La comunidad de experiencia resulta de mundos de la vida y de experiencias compartidas duraderamente a través de las generaciones, y esto permite una rápida comprensión, por ejemplo, al interior del pueblo o entre amigos, parientes y amantes. Sin embargo, el lenguaje solo expresa con éxito las dimensiones de grupos privados de sentimientos, entendibles y comprensibles por parte de otros.

Sin embargo, Nietzsche no solo sostiene aquí que el lenguaje es una institución social y, por tanto, que no es un asunto privado. Más bien, el genio de la especie tiene miedo de "(...) que uno de los dos, usando las mismas palabras, sienta, piense, barrunte, desee, tema de un modo distinto al otro" (2013, p. 289; KSA 5, p. 222). Con esta idea, Nietzsche introduce una conexión entre su concepción fisio-política del sujeto y una socio-fisiología de la especie. Con este fin retoma la idea del sujeto como estructura social, que se desarrolló sobre todo en el primer capítulo de Más allá del bien y del mal: "Cuáles son los grupos de sensaciones que se despiertan más rápidamente dentro de un alma, que toman la palabra, que dan órdenes: eso es lo que decide sobre la jerarquía entera de sus valores (...)", con lo que estas "valoraciones" a su vez dejan reconocer "(...) algo de la estructura de su alma, y nos dicen en qué ve ésta sus condiciones de vida, sus auténticas necesidades” (2013, pp. 289-290; KSA 5, p. 222). Esta concepción está vinculada a un proceso de 
selección que continuamente prefiere lo promedio frente a lo extraordinario. Suponiendo que los hombres con sentimientos similares se entiendan más rápida y más fácilmente, la presión histórica cultural y natural favorece “(...) una fácil comunicabilidad de las necesidades, es decir, en su último fondo, el experimentar vivencias solo ordinarias y vulgares" (Nietzsche, 2013, p. 290; KSA 5, p. 222). Por esta razón sostiene Nietzsche: "Los hombres más similares, más habituales, han tenido y tienen siempre ventaja; los más selectos, más sutiles, más raros, más difíciles de comprender, esos fácilmente permanecen solos en su aislamiento, sucumben a los accidentes y se propagan raras veces" (2013, p. 290; KSA 5, p. 222).

Las realidades sociales y políticas satisfacen siempre las necesidades de la comunidad, en última instancia determinadas por la naturaleza. Ciertamente Nietzsche reconoce esta necesidad e incluso percibe las dimensiones potenciadoras, profundizadoras y refinadoras de la socialización. Sin embargo, su simpatía parece pertenecer claramente a las excepciones y su fracaso produce compasión (KSA 5, pp. 222s.), lo que es comprensible en el contexto de una concepción agonal de transformación. Los inusuales son los heraldos de lo nuevo; el impulso excéntrico en el que se basa el desarrollo. En consecuencia, el aforismo concluye persuasivamente con una invitación: "Es preciso apelar a ingentes fuerzas contrarias para poder oponerse a este natural, demasiado natural, progressus in simil (progreso hacia lo semejante), al avance del hombre hacia lo semejante, habitual, ordinario, gregario - ¡ hacia lo vulgar!-" (Nietzsche, 2013, p. 290; KSA 5, p. 222). Para romper la nivelación se requieren significativos esfuerzos. A la luz de esta conclusión condicional, al final de esta investigación, surgen dos preguntas que revelan el humanismo fundamental de Nietzsche, no en el sentido de una doctrina ideal, sino en el sentido de una filosofía amigable dirigida al hombre real y a sus reales posibilidades: primero, ¿en qué sentido es posible en general impedir el 'progressus' natural? Y, segundo, ¿por qué deberíamos intentarlo?

\section{EI humanismo como una posibilidad humana-sobrehumana}

A diferencia de la tradición dualista de los despreciadores platónico-cristianos del cuerpo, Nietzsche no reconoce la libertad en el dominio supuestamente autosuficiente de una voluntad pura y racional sobre los impulsos conflictivos de la naturaleza interior. Él cuestiona tanto la realidad como la idealidad reguladora de tal libertad. Sin embargo, presupone claramente que es posible y deseable intervenir creativamente en el curso natural de las cosas. 
El hombre, por tanto, parece ser indeterminado en sus acciones y capaz de cambiar el mundo a propósito ${ }^{14}$. Es útil recordar aquí con Ernst Tugendhat la diferencia entre trascendencia ontológica y trascendencia antropológica. De hecho, Nietzsche rechaza la idea de un ser trascendente; en este sentido es un naturalista. Por otro lado, la dimensión antropológica, según la cual los hombres en una actividad del trascender pueden referirse a un espacio de representación más allá de la realidad espacio-temporal, sigue siendo central para él: "Una idea que diferencia a Nietzsche de otros naturalistas es que él, sin embargo, en el trascender humano se adhirió a algo" (Tugendhat, 2007, p. 14). La antropología de Nietzsche está siempre relacionada con una praxis de la superación, a partir de la cual la libertad humana y la trascendencia del mundo interior pueden entenderse de una manera nueva y diferente. Trascender no tiene necesariamente que referirse a un más allá y a un ideal, sino que puede referirse a algo que es posible, a un no-real-aún (Noch-NichtWirkliches). La capacidad para hacerlo resulta del poder transformador y dinámico del propio organismo vivo. Sin embargo, la conveniencia de lo que aún no es real no resulta de su posible valor per se, sino de la fuerza normativa de lo posible. Con esta formulación me refiero a la persuasiva atracción de dar sentido a cualquier posibilidad que haya surgido, a través de su realización intencional en retrospectiva. De esta manera, el superhombre puede ser el significado de la tierra.

Para una mejor comprensión de esta idea, nuevamente es esclarecedora la distinción ante la tradición platónica. En el preludio del Fedro, Sócrates se lamenta: "Hasta ahora y siguiendo la inscripción de Delfos, no he podido conocerme a mí mismo. Me parece ridículo, por tanto, que el que no se conoce todavía, se ponga a pensar lo que ni le va ni le viene" (Platón 1990a, 229e-230a). Según una antigua tradición, a la entrada del templo de Apolo en Delfos estaba escrito: $\Gamma \nu \tilde{\omega} \theta \imath$ $\sigma \varepsilon \alpha v \tau o ́ v$ - conócete a ti mismo. Al poner este requerimiento en el centro de sus esfuerzos intelectuales, Sócrates explica el adecuado conocimiento de uno mismo como condición de toda comprensión consciente. Con la pretensión de autoconocimiento, el individuo se convierte

\footnotetext{
${ }^{14}$ Ocasionalmente Nietzsche ha sido leído como un fatalista-determinista para quien el sujeto está totalmente involucrado en una causalidad natural: "Nietzsche sostiene que la vida de una persona continúa a lo largo de una trayectoria fija, determinada por hechos 'naturales' sobre dicha persona. Nietzsche, el fatalista, ve a una persona como una planta" (Leiter, 2002, p. 81). Esta interpretación expresa una concepción mecanicista de los hechos causales esenciales, que ya no es de Nietzsche. Incluso una mirada más cercana a su concepción de la vida vegetal podría haber aclarado este error, como lo ha demostrado Vanessa Lemm (2016).
} 
simultáneamente en un destinatario crítico del preguntar. Sócrates es desconocido para sí mismo, con los medios del $\lambda o ́ \gamma o \varsigma$ indaga por su esencia supuestamente verdadera. Esta búsqueda se inspira en la esperanza de que podamos encontrar una fecunda respuesta normativa a la pregunta acerca de nosotros mismos. Nietzsche no comparte esta esperanza. En esto difiere también de Volker Gerhardt cuando éste ata la "realidad y efectividad de un concepto íntegro de la individualidad humana", en primer lugar, y ante todo a Sócrates, para luego afirmar: "Solamente con Sócrates se vuelve certeza que un ser humano singular tome conciencia de su singularidad y que en esta conciencia busque la ley de su propia acción" (Gerhard, 1997, p. 12). La pregunta por las leyes de la propia acción no puede resolverse mediante una investigación, especialmente no mediante una búsqueda de razones universalmente vinculantes, sino que debe ser respondida activamente y probada experimentalmente por los hombres y según el criterio humano.

Por esta razón Nietzsche no suspende de ninguna manera la pregunta por el sí-mismo, sino que determina el objeto del conocimiento, los instrumentos del autoconocimiento, así como el objetivo de los esfuerzos, de una manera fundamentalmente diferente a la del Sócrates platónico. No comprende el sí-mismo como una entidad espiritual estable, ni cree que éste pueda ser captado adecuadamente con los instrumentos del análisis teórico. En el aforismo de La gaya ciencia “¡Arriba la física!” resalta: “"Cada uno es para sí mismo el más lejano» -eso lo saben, para su desasosiego, todos los que ponen a prueba los riñones de los hombres; y la sentencia «¡conócete a ti mismo!»es, en boca de un Dios y dicho a los hombres, casi una maledicencia" (Nietzsche, 1990, p. 192; KSA 3, p. 560). Los hombres están limitados en este esfuerzo; el gran riesgo, especialmente, es confundir el autoconocimiento con la construcción egoísta de una autoimagen moralmente sólida. En lugar de la introspección mojigata, Nietzsche se basa en la "purificación de nuestras opiniones y valoraciones" y, luego, sobre todo, en la "(...) creación de nuestras propias nuevas tablas de lo que es bueno" (1990, p. 194; KSA 3, p. 563).

El elogio de la física (de la fisiología, del naturalismo) y el conocimiento de "todo lo que es legal y necesario en el mundo" se limita a su función útil para este propósito: "tenemos que ser físicos, para poder ser creadores en ese sentido" (1990, p. 195; KSA 3, p. 563). Frente a los intentos idealistas de diseñar nuevos valores sin tener en cuenta la física, habla finalmente lo que "nosotros" valoramos aún más que la física y "(...) lo que nos obliga a ir hacia ella: ¡nuestra honestidad!” (1990, p. 195; KSA 3, p. 564). Probablemente ha sido también esta honestidad la que muestra los límites del conocimiento 
y de las acciones humanas. Es por esto que Nietzsche pone en el lugar del 'nosce te ipsum' otra demanda: "Sin embargo, nosotros queremos llegar a ser los que somos - ¡los nuevos, los únicos, los incomparables, los que-sedan-leyes-a-sí-mismos, los que-se-crean-a-sí-mismos!” (1990, pp. 194-195; KSA 3, p. 563). La pregunta 'quién se es' ya no es un problema epistémico en el contexto de la antropología fisio-política aquí expuesta. Ya no se trata de descubrir y sacar a la luz la naturaleza oculta de los seres humanos a través de la introspección, el análisis, la neurociencia u otras formas de investigación metódica. 'Quién se es' no es una cuestión teórica ni tampoco ética, sino práctica.

Una idea más precisa de esta concepción creativa y radicalmente autónoma del hombre es transmitida por otro aforismo de La gaya ciencia:

Una cosa es necesaria «Dar estilo» al propio carácter - iun arte grande y escaso! Lo ejerce aquel cuya vista abarca todo lo que de fuerzas y debilidades le ofrece su naturaleza, y luego les adapta un plan artístico hasta que cada una aparece como arte y razón, en donde incluso la debilidad encanta al ojo. Aquí se agregó una gran masa de naturaleza de segunda, allá se quitó un trozo de naturaleza de primera -en ambas ocasiones, luego de un largo ejercicio y trabajo diario con ello (1990, p. 167; KSA 3, p. 530).

El carácter pleno de estilo consiste en la combinación de formación cultural y dispositivos naturales para una obra de arte de buen gusto (Heit, 2016b). Para esto se necesita en primer lugar una visión general de las diversas capacidades del organismo, un conocimiento de los instintos (Triebe) y afectos. Pero también se requiere de un concepto estético, de un plan y de una voluntad que unan las diferentes partes en una organización. Finalmente se requiere, en tercer lugar, la paciente praxis, ya que la jerarquía de los instintos (Triebe) y los afectos solamente se deja desplazar con dificultad. La autoconfiguración se lleva a cabo también en el ejercicio práctico de los pequeños detalles, como en la respiración, la morada, el descanso, la nutrición física y mental. En una personalidad exitosa “(...) se revela que era la coacción del mismo gusto la que dominaba y daba forma a lo grande y a lo pequeño: poco importa si era un buen o un mal gusto, si se piensa que -ibasta con que sea un gusto!" (1990, p. 167; KSA 3, p. 530). En contraste con la "semejanza con el Dios" platónico-moral (Platón 1990b, 176b), el objetivo de esta autoconfiguración ya no es religioso (imitatio Christi) o cuasirreligioso (armonía con la naturaleza), moral (virtud, deber) o social (honor, reconocimiento, prestigio), sino explícitamente estético. 
Es posible que de esta manera los hombres crezcan más allá de sí mismos. Con Nietzsche la vida puede ser entendida como un proceso continuo de organización fisio-política y de autorebasamiento. Mientras algo está vivo, se forma, se organiza y se transforma; en el proceso se constituye como realidad, y al mismo tiempo se proyecta siempre más allá de la realidad presente. Como funciones socialmente necesarias, el animal humano dispone de memoria, lenguaje, voluntad, conciencia, pequeña y gran razón. Estas funciones son de origen histórico de la especie y son precarias en su respectiva efectividad. Precisamente la pequeña razón es sobreestimada fácilmente. Sin embargo, ellas son reales como productos de la naturaleza humana y de la historia cultural. Las posibilidades y habilidades surgidas de esta manera abren al hombre, y a los hombres, nuevas posibilidades para una bella configuración. Mientras que el dualismo deriva en la capacidad para la libertad del dominio autónomo de la razón sobre los peligrosos impulsos de la naturaleza interna y externa, el naturalismo mecánico niega completamente toda posibilidad de una creativa autoconfiguración. Nietzsche evita esta falsa alternativa y entiende la libertad como precaria capacidad de una organización fisio-política. El tipo de organización y, con ello, también la responsabilidad por sus consecuencias, reside en nosotros. Con el acabamiento de la autarquía substancial y de la universalidad de la razón, los ideales del humanismo ya no pueden reclamar una validez universal. Ellos son solamente representaciones humanas-demasiado humanas, que se deben a una historia no extrañamente violenta. Pero en la medida en que esta historia abra la posibilidad de un embellecimiento del hombre, Nietzsche y Gerhardt, a lo mejor, están nuevamente de acuerdo en el punto central, en aquel punto en que este último exige que el hombre tenga "en la conciencia de su responsabilidad con su mundo (...) el coraje de ser un hombre hoy" (Gerhardt, 2019, p. 13). Esa es quizás la tarea ultrahumana.

\section{Referencias}

Abel, G. (2001). Bewußtsein - Sprache - Natur: Nietzsches Philosophie des Geistes. Nietzsche-Studien, 30, pp. 1-43.

Campioni, G., D’Iorio, P., Fornari, M. C., Fronterotta, F., Orsucci, A. (2003). Nietzsches persönliche Bibliothek. (Colaboración de Renate MüllerBuck). Berlin / New York: Walter de Gruyter. 
Clark, M. and Dudrick, D. (2012). The Soul of Nietzsche's Beyond Good and Evil. Cambridge: Cambridge University Press.

Clark, M. and Dudrick, D. (2015). Nietzsche's Philosophical Psychology: Will to Power as Theory of the Soul. Clark, M (Hrsg.). Nietzsche on Ethics and Politics (pp. 260-286). Oxford: Oxford University Press.

Gerhardt, V. (1997) Das individuelle Gesetz. Über eine sokratisch-platonische Bedingung der Ethik. Allgemeine Zeitschrift für Philosophie, $22(1)$, pp 3-21.

Gerhardt, V. (2011). Die „grosse Vernunft“ des Leibes. Ein Versuch über Zarathustras vierte Rede. Heilinger, J. Ch. und Loukidelis, N (Hrsg.). Die Funken des freien Geistes. Neuere Aufsätze zu Nietzsches Philosophie der Zukunft. (pp. 50-86). Berlin: Walter de Gruyter.

Gerhardt, V. (2019). Humanität. Über den Geist der Menschheit. München: C. H. Beck.

Goethe, J. W. von (1998 [1817]). „Zur Morphologie“. In: Blumenthal, Lieselotte et al. (Hrsg.). Johann Wolfgang von Goethe Werke (B. 13). München: dtv.

Heit, H. (2013). „... Was man ist“"? Zur Wirklichkeit des Subjekts bei Nietzsche. (R. Reschke Hrsg.). Nietzscheforschung 20 (pp. 173-192). Berlin: Akademie Verlag.

Heit, H. (2016a): Naturalizing Perspectives. On the Epistemology of Nietzsche's Experimental Naturalizations. Nietzsche-Studien, 45, pp. 56-80.

Heit, H. (2016b). Stilvolles Durchwursteln. Nietzsche und die Lebenskunst im Zeitalter der Beschleunigung. Gödde, G. Loukidelis, N und Zirfas, J (Eds.) Nietzsche und die Lebenskunst. Ein philosophisch-psychologisches Kompendium (pp. 307-315). Stuttgart: J. B. Metzler.

Heit, H (2018). Der Mensch als „Gesellschaftsbau“. Nietzsches PhysioPolitische Anthropologie der Freiheit. Internationales Jahrbuch für Philosophische Anthropologie, 7, pp. 101-118.

Helmholtz, H. von (1867). Handbuch der physiologischen Optik. Leipzig: Leopold Vo. 
Homer (2013). Ilias (Griechisch-Deutsch). Herausgabe und Übersetzung von Hans Rupé. Berlin: Walter de Gruyter.

Ioan, R. (2015). Philosophical Physiology: Schopenhauer and Nietzsche. Ribeiro dos Santos, L and Dawn Hay, K (Hrsg.). Nietzsche, German Idealism and Its Critics (pp. 208-222). Berlin: Walter de Gruyter.

Janaway, Ch. (2014). Nietzsche's Psychology as a Refinement of Plato's. The Journal of Nietzsche Studies, 45 (1), pp. 12-21.

Kim, J. H. (1995). Nietzsches Sozialphilosophie. Versuch einer Überwindung der Moderne im Mittelpunkt des Begriffes „Leib“. Würzburg: Königshausen \& Neumann.

Lange, F. (1974 [1873/75]. Die Geschichte des Materialismus und Kritik seiner Bedeutung in der Gegenwart. Frankfurt a. M.: Suhrkamp.

Leiter, B. (2002). Nietzsche on Morality. London: Routledge.

Lemm, V. (2016): Is Nietzsche a Naturalist?: Or How to Become a Responsible Plant. The Journal of Nietzsche Studies, 47 (1), pp. 61-80.

Lippert, J. (1881). Die Religionen der europäischen Culturvölker: der Litauer, Slaven, Germanen, Griechen und Römer, in ihrem geschichtlichen Ursprunge. Berlin: Hofmann.

Marx, K. und Engels, F. (1986 [1845]). Die deutsche Ideologie. Institut für Marxismus Leninismus beim ZK der SED (Hrsg.). Karl Marx Friedrich Engels - Werke (MEW) (pp. 9-530). Berlin: Dietz.

Muniz Garcia, A. (2010). Nietzsches Umdeutung von Schopenhauers «Genius der Gattung» in Jenseits von Gut und Böse 268 und Fröhliche Wissenschaft 354. Campioni, G. Piazzesi, Ch. Wotling, e P. (Hrsg.). Letture della Gaia scienza. Lectures du Gai savoir (pp. 143-156). Pisa: Edizioni ETS.

Müller-Lauter, W. (1978). Der Organismus als innerer Kampf. Der Einfluss von Wilhelm Roux auf Friedrich Nietzsche. Nietzsche-Studien, 7, pp. 189-235.

Nietzsche, F. (1988). Die Geburt der Tragödie. Unzeitgemäße Betrachtungen. Nachgelassene Schriften 1870-1873 (KSA 1). Kritische Studien Ausgabe. Herausgegeben von Giorgio Colli und Mazzino Montinari. Berlin: Walter de Gruyter. 
Nietzsche, F. (1988). Morgenröte. Idyllen aus Messina. Die fröhliche Wissenschaft (KSA 3). Kritische Studien Ausgabe. Herausgegeben von Giorgio Colli und Mazzino Montinari. Berlin: Walter de Gruyter.

Nietzsche, F. (1988). Also sprach Zarathustra I-IV (KSA 4). Kritische Studien Ausgabe. Herausgegeben von Giorgio Colli und Mazzino Montinari. Berlin: Walter de Gruyter.

Nietzsche, F. (1988). Jenseits von Gut und Böse. Zur Genealogie der Moral (KSA 5). Kritische Studien Ausgabe. Herausgegeben von Giorgio Colli und Mazzino Montinari. Berlin: Walter de Gruyter.

Nietzsche, F. (1988). Nachgelassene Fragmente 1880-1882 (KSA 9). Kritische Studien Ausgabe. Herausgegeben von Giorgio Colli und Mazzino Montinari. Berlin: Walter de Gruyter.

Nietzsche, F. (1988). Nachgelassene Fragmente 1882-1884 (KSA 10). Kritische Studien Ausgabe. Herausgegeben von Giorgio Colli und Mazzino Montinari. Berlin: Walter de Gruyter.

Nietzsche, F. (1988). Nachgelassene Fragmente (KSA 11). Kritische Studien Ausgabe. Herausgegeben von Giorgio Colli und Mazzino Montinari. Berlin: Walter de Gruyter.

Nietzsche, F. (1990). La ciencia jovial. (Trad. Jara, J). Caracas: Monte Ávila editores.

Nietzsche, F. (1993). Así habló Zaratustra. (Trad. Sánchez Pascual, A). Madrid: Alianza.

Nietzsche, F. (2013). Más allá del bien y del mal. (Trad. Sánchez Pascual, A). Madrid: Alianza.

Platón. (1990a). Phaidros. Werke (5). Günter, E (Hrsg.). Darmstadt: WBG Verlag.

Platón. (1990b). Theaitetos. Werke (6). Günter, E (Hrsg.). Darmstadt: WBG Verlag.

Roux, W. (1881). Der Kampf der Theile im Organismus. Ein Beitrag zur Vervollständigung der mechanischen Zweckmässigkeitslehre. Leipzig: Engelmann. 
Schacht, R. (2012). Nietzsche's Anti-Scientistic Naturalism. Heit, H. Abel, $\mathrm{G}$ und Brusotti, M (Hrsg.). Nietzsches Wissenschaftsphilosophie (pp. 161-186). Berlin: Walter de Gruyter.

Schiemann, G. (2014). Nietzsche und die Wahrheitsgewissheitsverluste im Anbruch der Moderne. Heit, H. und Heller, L (Hrsg.). Handbuch Nietzsche und die Wissenschaften. Natur-, geistes- und sozialwissenschaftliche Kontexte (pp. 46-75). Berlin: Walter de Gruyter.

Siemens, H. (2016). Nietzsches Sozio-Physiologie des Selbst und das Problem der Souveräntität. Heit, H. und Thorgeirsdottir, S (Hrsg.). Nietzsche als Kritiker und Denker der Transformation (pp. 167-188). Berlin: Walter de Gruyter.

Sommer, A. (2016). Kommentar zu Nietzsches Jenseits von Gut und Böse. Berlin: Walter de Gruyter.

Tugendhat, E. (2007). Anthropologie statt Metaphysik. München: C. H. Beck.

Ulf, Ch. (1990). Die homerische Gesellschaft. Materialien zur analytischen Beschreibung und historischen Lokalisierung. München: C. H. Beck. 



\title{
El concepto de humanidad en Edmund Husserl: delimitación y proyecciones ${ }^{1}$
}

\author{
Edmund Husserl's Concept of Humanity: \\ delimitation and projections
}

Luis Flores Hernández ${ }^{2}$

Pontifícia Universidad Católica de Chile

Recepción: 06 de junio del 2020

Evaluación: 10 de julio del 2020

Aceptación: 20 de julio del 2020

Investigación realizada en la Facultad de Filosofía de la Pontificia Universidad Católica de Chile.

2 Doctorat de Troisième Cycle en Philosophie, Mention Logique et Philosophie des sciences, Université d'Aix-en-Provence, France.

Correo electrónico: 1floresh@uc.cl

Flores Hernández, L. (2020). El concepto de humanidad en Edmund Husserl: delimitación y proyecciones. Cuestiones de Filosofía, 6 (26), 127-143. 


\title{
Resumen
}

Nuestra propuesta se centra en el concepto de humanidad de Husserl, intentando delimitar la correspondiente familia de conceptos interrelacionados. El foco de nuestro corpus es Die Krisis der europaïschen Wissenschaften und die transzendentale Phänomenologie (Hua VI, 1962) y los artículos para la Revista The Kaizo. Para Husserl, la racionalidad es el concepto clave para interpretar la evolución de la humanidad. El propósito de las investigaciones, que Husserl realiza en estos textos, supone los siguientes aspectos substanciales: 1) Lo que importa es el proceso conducente a una humanidad verdadera. 2) Es esencial a la vida humana el que discurra en la forma del afán. 3) El repertorio conceptual con que Husserl investiga acerca de la humanidad constituye una secuencia ordenada. 4) Lo que es válido para la matemática, en cuanto ciencia pura de la naturaleza, es válido analógicamente para una ciencia pura de la subjetividad. 5) El devenir humano posee unidad y esta es otorgada por la historicidad. 6) El concepto de estilo es aplicado por Husserl al devenir humano. 7) Un concepto importante vinculado al de historicidad es el de Heimatlichkeit. 8) Husserl supone una esencia de la racionalidad, con respecto a la que el racionalismo no es más que un extravío. 9) Distinguimos cuatro intencionalidades en la razón misma. 10) La razón tiene como contraparte negativa a la sinrazón y ciertas opacidades le impiden una transparencia total a la razón.

Palabras clave: humanidad, razón, historicidad, fenomenología, Husserl.

\begin{abstract}
Our proposal is focused on the concept of humanity in Husserl, attempting to delimit the corresponding family of interrelated concepts. The focus of our corpus is Die Krisis der europaïschen Wissenschaften und die transzendentale Phänomenologie (Hua VI, 1962) and the articles in the journal The Kaizo. For Husserl, rationality is the key concept for interpreting humanity's evolution. The purpose of the investigations, that Husserl performs in these texts, supposes the following substantial aspects: 1) What matters is the process leading to a true humanity. 2) It is essential to human life that it goes by in the form of yearning. 3) The conceptual repertory, with which Husserl investigates humanity, constitutes an ordered sequence. 4) What is valid for mathematics, as pure science of nature, is valid analogically for a pure science of subjectivity. 5) Human being becoming possesses unity, which is
\end{abstract}


given by historicity. 6) Husserl applies the concept of style to the human being becoming. 7) A significant concept linked with historicity is that of Heitmatlichkeit. 8) Husserl presupposes an essence of rationality, in which rationalism is nothing more than a deviation. 9) We distinguish four intentionalities concerning reason itself. 10) Reason has unreason as a negative counterpart and certain opacities impede a total transparency of reason.

Keywords: humanity, reason, historicity, phenomenology, Husserl. 
Nuestra propuesta se centra en el concepto de humanidad de Edmund Husserl, intentando delimitar la familia de conceptos interrelacionados-Menschheit, Menschentum, Menschlichkeit und Humanität. Nos interesa determinar su sentido y su interrelación en vistas de sus proyecciones hacia la Antropología, la Ética y la cultura. El foco de nuestro corpus es Die Krisis der europaïschen Wissenschaften und die transzendentale Phänomenologie: Eine Einleitung in die phänomenologische Philosophie (Hua VI, 1962). En ella privilegiamos:

a) La sección I dedicada a "La crisis de las ciencias como expresión de la radical crisis de vida de la humanidad europea", cuyo origen remonta a dos conferencias dictadas en Praga en noviembre de 1935.

b) El § 73. "Conclusión: La filosofía como toma de conciencia de sí mismo, actualización de sí misma de la razón”. Parágrafo incluido por Walter Biemel, el compilador de Hua VI. Dicho texto procede del manuscrito K III 6.

c) Las conferencias de Viena del 7 y 10 de mayo de 1935, incluidas en Hua VI como Tratado (Abhandlung): "Die Krisis des europaïschen Menschentums und die Philosophie".

d) Asimismo, añadimos al foco de nuestro corpus los cinco artículos que Husserl redactó para la revista japonesa The Kaizo entre 1922 y 1923. Tres de ellos aparecidos en 1923 y 1924. Estos ensayos están recogidos en Hua XXVII (1989).

Hay en general en estos textos un movimiento que va desde la mera facticidad descriptible, hacia el seguimiento de la idea (Idee) y del ideal (Ideal). Para Husserl, dicho movimiento está en función de la racionalidad (Rationalität), concepto clave para la interpretación que él hace de la humanidad. En primer lugar, "la razón es lo específico del ser humano como ser que vive en actividades y habitualidades personales" (Hua VI, p. 272; Husserl, 2008, p. $305)^{3}$. En segundo lugar, "decir que la filosofía, ciencia en todas sus formas, es racional es una tautología" (Hua VI, p. 274; Husserl, 2008, p. 306). En tercer lugar, la filosofía "descubre que ésta (la racionalidad) es una idea que se halla en el infinito y en el factum de estar necesariamente en camino (auf dem Wege)" (Hua VI, p. 274; Husserl, 2008, p. 306).

3 La edición castellana, cuya traducción y estudio preliminar corresponden a Julia V. Iribarne, no incluye la del Abhandlung antes señalado, cuya versión al castellano es nuestra. 
Nos parecen substanciales en Husserl los siguientes aspectos:

1. No es el terminus ad quo o el terminus ad quem lo que importa, sino el proceso que conduce a una humanidad más verdadera, más auténtica, "el proceso de llegar a ser hombres" (Menschenwerdens) (Hua XXVII, p. 55; Husserl, 2002, p. 60). Por eso, es posible que el término „Humanismus” no sea usado por Husserl, pues implicaría un congelamiento del devenir. Incluso la ciencia estricta, ligada a ese proceso, "no es un ente objetivo, sino el proceso de devenir (werden) de una objetividad ideal" (Hua XXVII, p. 55; Husserl, 2002, p. 60). Por eso, todo se juega en este devenir y eso justifica el aserto husserliano: "todo esto no ha de entenderse en sentido estático, sino dinámico-genético" (Hua XXVII, p. 55; Husserl, 2002, p. 60). Pero este devenir es orientado y, por eso, es desarrollo (Entwicklung), "en el sentido de un continuo ir escalonando grados de valor (fortgesetzter Wertstufung)" (Hua XXVII, p. 51; Husserl, 2002, p. 56). Se trata, respecto de una colectividad (Gemeinschaft), de "ponerse en el camino (auf die Bahn) de su desarrollo progresivo" (Hua XXVII, p. 55; Husserl, 2002, p. 60). Y ello importa porque el desarrollo en sí mismo no cualifica el sentido del cambio. Husserl introduce dos formas de desarrollo ético, lo que supone distinguir entre la dirección y el sentido. Uno con valor positivo, como elevación (Erhöhung) y otro con valor negativo, como decadencia (Herabsinken). El desarrollo supone estadios (Stufen) y fases que permiten la conexión con el valor absoluto: "Una vez que la ciencia ha conquistado el estadio de la ciencia auténtica, del verdadero logos, su devenir se convierte en un sistema procesual de valores absolutos (ein Werdenssystem absoluter Werte) y de un valor absoluto ya realizado en cada estadio" (Hua XXVII, p. 55; Husserl, 2002, pp. 60-61). Así, el devenir de la ciencia auténtica tiene un "horizonte de futuros incrementos y elevaciones de valor (Werterhebungen)" (Hua XXVII, p. 55; Husserl, 2002 , p. 61). En cuanto a la colectividad que se construye a sí misma y hace suya la idea que le es propia, en cada estadio, "tiene aún ante sí horizontes abiertos, indeterminaciones pendientes de determinarse" (Hua XXVII, p. 56; Husserl, 2002, p. 61).

2. El proceso de lo que podríamos llamar "humanización" es aquel en que comenzamos a ser lo que somos -como diría Píndaro, sé el que eres-, en que lo humano ya no nos es extraño -al decir de Terencio, "soy hombre; nada de lo que es humano lo considero ajeno a mí” (Herrero, 2007, p. 120)-, pues se nos hace entraño, y, por ende, entrañable. Dicha humanización no 
es entonces la aplicación rutinaria y automática de reglas éticas, sino que surge "en un constante combate" (Kampf) (Hua XXVII, p. 58; Husserl, 2002, p. 63), "en una lucha diaria" (Hua XXVII, p. 45; Husserl, 2002, p. 48). No hay aquí sólo un imperativo categórico operando, hay una materialidad de lucha (Kampf), de fe (Glaube), de empuje o brío (Schwung), de afán (Streben), de fuerza de pulsión o de impulso o propulsora (Triebkraft). Así Husserl dice: "De la esencia de la vida humana es, además, el que discurra constantemente en la forma del empeño, del afán (des Strebens)" (Hua XXVII, p. 25; Husserl, 2002, p. 26). La humanización se sitúa entonces en el escenario de los motivos y de las motivaciones, allende las causas y los efectos: "para nosotros resulta más importante comprender el camino de la motivación, el de la donación de sentido y el de la creación de sentido, que conduce de la mera reorientación, es decir, del mero $\theta \alpha v \mu \alpha ́ \zeta \zeta \varepsilon v$ a la teoría" (Hua VI, p. 332). Husserl intenta descender hasta los estratos más originarios desde donde surgen nociones como protomotivo, protofenómeno, protosuelo, protométodo.

3. El repertorio de términos usados por Husserl para hablar de humanidad constituye una secuencia ordenada:

En primer lugar, en el estrato descriptivo más básico aparece die Menscheit, humanidad en cuanto inserta en un mundo circundante (Umwelt) y una cultura, la que es definida como "el conjunto total de logros (Leistungen) que vienen a la realidad merced a las actividades (Tätigkeiten) incesantes de los hombres en sociedad y que tienen una existencia (Dasein) espiritual duradera en la unidad de la conciencia colectiva y de la tradición que la conserva y prolonga" (Hua XXVII, p. 21; Husserl, 2002, p. 22). La distinción husserliana entre Tätigkeit y Leistung corresponde, al menos en cierta medida, a la distinción aristotélica entre energeia y ergon. De hecho, Wilhem von Humboldt aplicó esta distinción al lenguaje, distinguiendo entre Sprache como energeia y como ergon (von Humboldt, 2003). A su vez, ,Menscheit” tiene una aproximación metafórica y otra metafórico-conceptual:

a) La primera se caracteriza así: "Es como un mar en el que los seres humanos y los pueblos son las olas que se forman fugazmente, que cambian y de nuevo desaparecen, unas onduladas más rica y complejamente, otras más primitivamente" (Hua VI, p. 319). Se trata de una totalidad fluyente, semejante al río heraclitano de la conciencia, del 
que Husserl nos habla, por ejemplo, en Die Idee der Phänomenologie: "Nos movemos en el campo de los fenómenos puros. ¿Sin embargo, por qué digo campo? Es, más bien, un eterno río heraclitano de la conciencia" (Hua II, p. 47; Husserl, 1982, p. 59).

b) La segunda es definida así: "En tal proceder, aparece la humanidad (Menscheit) como una única vida de hombres y pueblos, unida por sólo relaciones (Bezüge) espirituales con una abundancia de tipos de humanidad y cultura, sin embargo, fluyendo las corrientes unas en otras" (Hua VI, p. 319). Lo importante es que la noción empírica de tipo corresponde a la Menschheit.

En segundo lugar, aparece das Menschentum, que es humanidad aún en un sentido descriptivo, pero más abstracto, que posee modos de existencia (humanidad antigua, medieval, renacentista o moderna), que plantea cuestiones y problemas específicos, que necesita ser adjetivada. Posee una definición conceptual: "Humanidad (Menschentum) en general es, esencialmente, ser humano en humanidades (Menschheiten) vinculadas generativa y socialmente" (Hua VI, p. 13; Husserl, 2008, p. 59).

En tercer lugar, en las conferencias de Viena, Husserl introduce los términos de die Menschlichkeit (Hua VI, p. 338) y das Menschliche (Hua VI, p. 341) para apuntar a lo más específico del ser humano (in seiner spezifischen Menschlichkeit) (Hua VI, p. 341): el hombre como persona, el hombre en su razón (Hua VI, p. 338). En este mismo sentido específico, Husserl señala: "así como el ser humano, incluso el papúa, representa, frente al animal mismo un nuevo estadio de animalidad, así la razón filosófica representa un nuevo estadio en la humanidad (Menschlichkeit) y su razón" (Hua VI, pp. 337-338). Más aun, en el siguiente texto, contrasta Menschlichkeit con Menschentum: "La humanidad (Menschentum) de la superior humanidad (Menschlichkeit) o razón exige, por consiguiente, una filosofía auténtica" (Hua VI, p. 338).

En cuarto lugar, ya en el ensayo Kaizo I, aparece el término die Humanität, para ser entendido como idea, en contraste con die Menschheit. Esto supone el alejamiento de lo fáctico en dirección a la idealidad; es el salto al limes que nos otorga el infinito. Ahora bien, Husserl no confunde, ya desde las Logische Untersuchungen, entre la idea (Idee) y el ideal o arquetipo (Urbild). La primera responde a una abstracción que implica el paso de lo múltiple a lo uno, en el sentido de una racionalidad explicativa. 
El segundo responde a una racionalidad normativa, la del deber ser. En suma, aquí "humanidad" puede ser una idea, pero también un ideal. Ahora bien, tres notas son esenciales a Humanität: la primera es la reflexión, la que se vincula con autorreflexión (Selbstbesinnung), autocomprensión (Selbstverständnis), autodesvelamiento (Selbstenthüllung). La segunda es la responsabilidad (Verantwortung). ¿De qué responsabilidad se trata? De una doble responsabilidad: "La responsabilidad totalmente personal por nuestro ser propio y verdadero como filósofos, en nuestra íntima vocación personal, comporta en sí, al mismo tiempo, la responsabilidad por el verdadero ser de la humanidad (Menschheit)" (Hua VI, p. 15; Husserl, 2008, pp. 60-61). La segunda nota conviene más con el ideal. Así se refiere como ideal de configuración de "una humanidad auténticamente humana (eine humane Menschheit)" al criterio que otorga la humanitas (Humanität) ${ }^{4}$, en cuanto se trata "de la humanidad (Menschheit) en que la razón se ha cultivado y objetivado en la figura del logos" (Hua XXVII, p. 55; Husserl, 2002 , p. 60). La tercera nota es la libertad presente en el movimiento de libertad religiosa (Hua XXVII, p. 63; 2002, p. 69), en la figura del movimiento de libertad filosófica (Hua XXVII, p. 73; Husserl, 2002, p. 80), en "la peculiaridad del movimiento de liberación (Befreiung) que se inicia en la nación griega y en ella se consuma en un trecho fundamental como creación de una nueva forma cultural: la filosofía" (Hua XXVII, p. 73; Husserl, 2002, p. 80).

4 La argumentación central de Husserl es analógica. Lo que es válido para la matemática, en cuanto ciencia pura de la naturaleza, es válido analógicamente para una ciencia pura de la subjetividad, la fenomenología trascendental o lo que podríamos llamar una neumatología; la ciencia del espíritu. La analogía se basa en el paso al límite que permite alcanzar la idealidad. La analítica del espíritu es perfilada así: "La formación de un método real (wirklich) para aprehender la esencia fundamental del espíritu en sus intencionalidades y construir, a partir de ahí hasta el infinito, una consecuente analítica del espíritu, condujo a la fenomenología trascendental" (Hua VI, p. 346). Como Husserl dice en Kaizo I: "Falta aquí, justamente, la ciencia apriórica paralela, la mathesis del espíritu y de la condición humana (Humanität) por así decir" (Hua XXVII, p. 7; Husserl, 2002 , p. 5). Lo que no implica una geometría de las vivencias -como

4 Sigo la traducción de Agustín Serrano de Haro (Husserl, 2002, p. 47). 
plantea en Ideen I: "y por eso preguntamos especialmente si una fenomenología como una 'geometría' de las vivencias tenga que ser constituida o pueda ser constituida” (Hua III, p. 165), pues en la fenomenología trascendental los conceptos son morfológicos y no exactos.

A su vez, Husserl define la ética pura así: "es la ciencia de la esencia y formas posibles de una vida en renovación tomada en generalidad pura (apriórica)" (Hua XXVII, p. 20; Husserl, 2002, p. 21). Distingue la ética pura de la empírica-humana y divide la ética en ética individual y social. El asunto es que analógicamente lo que es válido para la ética individual lo es nuevamente de un modo analógico para la ética social. Sin embargo, la comunidad de hombres de bien no ha de ser entendida como la simple sumatoria o agregación de individuos buenos.

5. El devenir humano (Menschenwerden) no es caótico, posee unidad. Ésta es otorgada por la historicidad (Geschichtlichkeit), en el sentido más general, la que es definida como "historicidad (Historizität) generativa originaria" (Hua VI, Beilage XXVI, p. 502) y que es un universal que pertenece a la existencia (Dasein) humana, que es un devenir unitario (ein einheitliches Werden) según las personas, en las personas. Y la historicidad, como un medio ambiente (Umwelt) humano, "en la multiplicidad de sus figuras, puede ser considerada como unidad de un 'organismo"” (Hua VI, Beilage XXVI, p. 502). La historicidad según Husserl es diferente a la de Heidegger: "Historicity, for Husserl, does not have quite the same technical sense that it has in Heidegger (...) Note here that Husserl characterizes historicity as a universal and necessary property belonging to human existence. As we shall see below, Heidegger makes historicity into an existential characteristic of Dasein" (Moran, 2012, p. 155).

6. Nos parece importante el concepto operativo de estilo, aplicado al dominio existencial del devenir humano en la actitud natural: "Este movimiento [el de una reformación (Neubildung) progresiva] transcurre desde un principio comunicativamente; despierta un nuevo estilo de existencia personal (einen neuen Stil personalem Daseins) en su círculo vital, en el comprender reviviendo [Nachverstehen $]^{5}$ de un devenir (Werden) correspondiente nuevo" (Hua VI, p. 322). Asimismo, la humanidad (Menschheit) vive en una u otra actitud. ¿Y qué es una actitud (Einstellung)? "Una actitud

5 Sigo la traducción hecha de este término por Antonio Zirión (Husserl, 1997, p. 504).

Flores Hernández, L. (2020). El concepto de humanidad en Edmund Husserl: delimitación 
significa, en términos generales, un estilo (Stil) habitualmente fijo de la vida de la voluntad en direcciones de voluntad o en intereses delineados merced a ello en fines últimos, en rendimientos culturales, cuyo estilo global (gesamter Stil) es, por consiguiente, con ello determinado" (Hua VI, p. 326). En suma, "en este estilo permanente como forma normal transcurre la vida cada vez determinada" (Hua VI, p. 326).

Ahora bien, un cambio de actitud o mutación de la misma (Umstellung, Wendung, Umwendung, Umwandlung, Umbildung) implica un cambio de estilo. Husserl no entiende estas mutaciones como meros cambios o cambios infinitesimales: "Pudiera parecerme que yo, el pretendido reaccionario, soy mucho más radical y revolucionario (revolutionär) que los que hoy en día se manifiestan en palabras tan radicalmente" (Hua VI, p. 337). Se trata, más aun, de una revolucionización (Revolutionierung) (Hua VI, p. 325) de la historicidad. De esta manera el término "Revolution" parece más aplicable al dominio de los eventos. En cambio, la revolucionización implica un cambio en el dominio categorial, constituye un estrato metarrevolucionario.

7. ¿Cuál es el punto de quiebre de Husserl para fundamentar su apuesta por un racionalismo no ingenuo? El ser humano es un animal que, según el

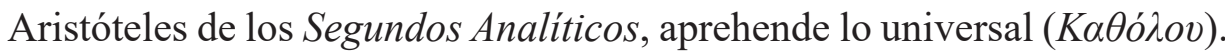
Husserl señala al respecto: "El ser humano de la vida cotidiana, sin embargo, no carece de razón, él es un ser pensante, él tiene el kathólou frente al animal, por eso él tiene habla, descripción, infiere, formula preguntas acerca de la verdad, [él comprueba, argumenta y se decide racionalmente]"'6 (Hua VI, p. 270; Husserl, 2008, p. 303). Entonces humanización supone al menos racionalización, y ésta, al menos, universalización, mediante el acceso a las ideas. Estas son formaciones de sentido (Sinngebilde), "que implican infinitudes intencionales" (Hua VI, p. 322). Sin embargo, la universalización husserliana no corresponde a la globalización, hecha de acuerdo a ciertos patrones económico-tecnológicos. En Husserl, la humanización pasa por la persona y ésta supone la unicidad. Así, los conceptos husserlianos de estilo y de historicidad pueden permitir equilibrar un proceso de creciente homogeneización mundial. El estilo permite la diversidad cultural, en cuanto es un concepto existencial que se aplica a la

\footnotetext{
${ }^{6}$ El pasaje entre paréntesis rectos no está en la traducción.
} 
existencia personal. A su vez, el nuevo tipo de historicidad, que surge con un cierto tipo de desarrollo, cobra un perfil propio, pues "se destaca de la historia general" (Hua VI, p. 323). Por otra parte, un concepto vinculado al de historicidad es el de Heimatlichkeit. Se trata de un "parentesco especial, íntimo en el espíritu, que pasa por ellas [las naciones europeas]" (Hua VI, p. 320). Este parentesco implica diferencias, pero a la vez identifica. Es a la vez unicidad y unidad: "Es así algo como una fraternalidad (Geschwisterlichkeit) que en este círculo nos da la conciencia de una terruñidad (Heimatlichkeit)" (Hua VI, p. 320). Se trata de una "unidad de parentesco familiar" (Hua VI, p. 320). Dicha unidad depende de si es considerada ad intra o ad extra. En el primer caso, los miembros de dicho círculo se viven "sólo mutuamente como coterráneos (Heimgenossen)" (Hua VI, p. 320). En el segundo, los miembros externos nos experimentan (erleben) como extranjeros. En suma, la diferencia esencial entre terruñidad (Heimatlichkeit) y extrañeza (Fremdheit) constituye una categoría fundamental de la historicidad. Así los griegos llamaban "ßá $\beta \beta \alpha \rho \varsigma^{\prime}$ ”, término usado como onomatopeya de un lenguaje ininteligible, al no griego. Por otra parte, ¿es posible superar la Heimatlichkeit? Merleau-Ponty cita un pasaje de Les Sept Piliers de la Sagesse de Thomas Edward Lawrence (Lawrence, 1936, p. 43), en donde éste al final de un proceso deliberado de arabización, se quiebra y reconoce su fracaso. Merleau-Ponty comenta que: "Para asimilar completamente una lengua, sería necesario asumir el mundo que ella expresa y no se pertenece jamás a dos mundos a la vez" (Merleau-Ponty, 1945, pp. 218-219). Es cierto que, para Husserl, el telos espiritual de la humanidad europea yace en el infinito, a diferencia de otras humanidades, aunque conlleve los telos singulares de las naciones y de los hombres?

8. Respecto de la racionalidad, Husserl piensa que el racionalismo no es más que una figura evolutiva de la ratio. Es un extravio, aunque comprensible. ¿En qué consiste el extravío? No es la esencia de la Rationalität la que está en juego. Su extravío consiste "solamente en su enajenabilidad (Veräußerlichung), en su envolverse con los capullos (Versponnenheit) del 'naturalismo' o del 'objetivismo"” (Hua VI, p. 347). A propósito del

${ }^{7}$ La humanidad europea es una idea-fin (Zweck-Idee), por ende no se identifica con un determinado factum histórico, social, genético, geográfico, etc. Este factum varía temporalmente y está sujeto a aproximaciones como a desviaciones con respecto a la idea-fin. 
racionalismo extraviado, Husserl nos advierte que: "Esto no da derecho a la opinión de que la racionalidad como tal sea perjudicial o que sea sólo de significación subordinada en el todo de la existencia humana" (Hua VI, p. 337). En suma, no se trata del retorno a la Aufklärerei $i^{8}$, a "un intelectualismo que se pierde en una teoría ajena al mundo" (Hua VI, p. 337). Por lo demás, el racionalismo del siglo XVIII era una ingenuidad, cuyas últimas implicaciones conducen a un contrasentido.

La alternativa al racionalismo ingenuo es el irracionalismo "tan celebrado que se nos propone" (Hua VI, p. 14; Husserl, 2008, p. 59). Husserl señala también su contrasentido, porque el irracionalista elabora un discurso y solicita audiencia. Entonces Husserl muestra su contradicción performativa, pues su acto comunicativo de intentar convencernos presupone la racionalidad que niega: "¿No debe él [el irracionalismo] convencernos, si hemos de prestarle atención, acerca de cómo examina y funda racionalmente?" (Hua VI, p. 14; Husserl, 2008, p. 59). Husserl se pregunta si esta irracionalidad no es una mala racionalidad, una racionalidad corta de miras, "peor que aquella del viejo racionalismo" (Hua VI, p. 14; Husserl, 2008, pp. 59-60). En suma, se trata de una razón perezosa: “¿No es hasta la de la 'razón perezosa' que rehúye la lucha a favor de la claridad de lo pre-dado último y la de los fines y los caminos verdadera y racionalmente predelineados?" (Hua VI, p. 14; Husserl, 2008, p. 60). Husserl subsumiría, bajo este concepto, desde el positivismo -"El positivismo, por así decir, decapita la filosofía" (Hua VI, p. 7; Husserl, 2008, p. 53)- hasta, pudiera ser, el pensiero debole de Gianni Vattimo (Vattimo y Rovatti, 1983).

Husserl es una solitaria voz que clama en el desierto. Es diciembre de 1935, fecha de las conferencias de Praga, y los nubarrones del nazismo despuntan en el cielo de Europa. Por este motivo, la renovación que lo ocupa desde los artículos de Kaizo conforme al concepto de Erneuerung y, posteriormente, en las conferencias de Praga, según el concepto de reformación (Neubildung), no puede surgir al alero del mero academicismo universitario. Husserl se pregunta: “¿Queríamos nosotros escuchar aquí sólo un discurso académico?” (Hua VI, p. 15). Ciertamente, la filosofía como mera erudición histórica, como seguro de vida formateado según

8 Expresión peyorativa para designar a la Aufklärung, "tradicional desde Hegel” (Husserl, 1976, p. 371). 
los cánones de una carrera académica -el publish or perish, los rankings universitarios, la indexación de revistas académicas, etc.- no basta, diría Husserl, dadas la crisis y la indigencia. Por eso nos dice: "Precisamente en esto se halla nuestro propio desamparo (Not), el de todos nosotros, quienes no hacemos filosofía literaria (Literaten-Philosophen) sino que, formados por los auténticos filósofos del gran pasado, somos y queremos ser viviendo de la verdad, y sólo viviendo en nuestra propia verdad" (Hua VI, p. 15; Husserl, 2008, p. 60).

Tampoco la salida es posible contentándose con una racionalidad unilateral, pues ésta "puede en efecto convertirse en un mal" (Hua VI, p. 338). Mientras esta unilateralidad sea provisoria no atenta a la esencia de la razón. Pero ésta es esencialmente sistémica. A la razón analítica hay que contrapesar la sintética: "Ninguna línea de conocimiento, ninguna verdad particular, tiene el derecho a ser aislada y absolutizada" (Hua VI, p. 339). Por eso, se requiere una razón vigilante: “Ahí amenaza constantemente el caer en unilateralidades y satisfacciones precipitadas, que se vengan en subsecuentes contradicciones" (Hua VI, p. 338). Una de las exigencias del desarrollo científico y filosófico es la especialización. Thomas S. Kuhn ve en ésta un rasgo esencial a la ciencia normal (Kuhn, 1970). Y la filosofía misma se especializa, pero Husserl nos advierte: "A ello se agrega la necesidad y, sin embargo, de nuevo, la peligrosidad de la especialización" (Hua VI, p. 338). Por otra parte, el racionalismo de Husserl se basa en dos axiomas. Según el primero, las ideas filosóficas superan a los poderes empíricos: "Y, sin embargo, las ideas son más fuertes que todos los poderes empíricos" (Hua VI, p. 335). Según el segundo, lo ideal se contrapone a lo real en la ciencia y en la filosofía como formaciones culturales: "Con una palabra, lo que la conducta científica logra, no es real, sino ideal” (Hua VI, p. 323).

9. Allende Husserl, distinguimos cuatro intencionalidades de la razón:

a) La cognitiva, orientada a la producción del conocimiento y guiada por el criterio de verdad como adequatio o correspondencia.

b) La deóntica, orientada a la producción de ideales o de Zweck-Ideen. Es la función arcóntica de la filosofía y, por ende, de la razón: "La filosofía ha de ejercer constantemente, en una humanidad europea, su función como la función arcóntica de toda la humanidad" (Hua VI, p. 336). 
c) La sintomática o expresiva, en virtud de la que la razón posee estratos latentes y patentes. Husserl nos habla del "movimiento infinito de la razón latente a la manifiesta" (Hua VI, p. 13; Husserl, 2008, pp. 58-59). Se trata entonces de la fenomenología como arqueología, que opera sobre lo oculto, lo oscuro y lo latente para que devenga lo manifiesto, lo claro y lo patente. La verdad no ha de ser entendida aquí como adequatio rei et intellectus, sino como alétheia, como manifestación del logos, como logofanía.

d) La estética, por la que la razón es intencionada arquitectónicamente, es tematizada en la belleza de su despliegue lúdico, de su simetría, de su armonía, etc. Husserl sólo se refiere a las normas tradicionales de la belleza a propósito de la idea general de la verdad en sí (Hua VI, p. 334).

10. La contraparte negativa de la razón es la sinrazón (Unvernunft), distinción en curso desde Ideen I: "Naturalmente, es también de considerar en todas partes la 'sinrazón' como contraparte negativa de la razón" (Hua III, p. 353). El dominio de la filosofía pareciera ser sólo el discurso de la razón. Sin embargo, Husserl abre horizontes que no son racionales o que pertenecen a una racionalidad más blanda; en todo caso, a opacidades de la razón. Examinemos algunas de estas:

a) El papel que juega, por ejemplo, die Vorahnung: "Todo esto no quiere ser una interpretación especulativa de nuestra historicidad, sino expresión de un presentimiento (Vorahnung) vivo que surge en una reflexión desprejuiciada" (Hua VI, p. 321). Sin embargo, el presentimiento trasciende el barrunto, pues nos conduce a una certeza: "Éste nos da una conducción intencional para ver conexiones (Zusammenhänge) sumamente significativas, en cuya persecución lo presentido se convierte en certeza profunda" (Hua VI, p. 321). Y así Husserl concluye que: "El presentimiento es el indicador de camino, al modo de los sentimientos (gefühlsmäßiger Wegweiser), de todos los descubrimientos" (Hua VI, p. 321) ¿Es la concesión a l'esprit de finesse de Pascal, a esas razones del corazón que la razón no conoce? Dice Pascal: "El corazón (coeur) tiene sus razones que la razón no conoce; se lo sabe en mil cosas" (Pascal, 1964, p. 146). En todo caso, el presentimiento pertenece al contexto de descubrimiento (Reichenbach, 1938), o al ars inveniendi de Leibniz. 
b) Respecto de la ciencia, Husserl dice sorprendentemente que ésta incluye instinto: "Descubrimiento es una mezcla de instinto (Instinkt) y método" (Hua VI, p. 39; Husserl, 2008, p. 83). Con todo, se pregunta si acaso esto es, en sentido estricto, ciencia. El concepto de instinto científico en Husserl cumple un papel análogo al concepto de sagacidad científica de William Whewell: "The Conceptions by which Facts are bound together, are suggested by the sagacity of discoverers. This sagacity cannot be taught (Whewell, 1847, p. 467). Este sitúa el origen de las ciencias empíricas en la sagacity. Ahora bien, este término deriva del latín sagacitas, que significa finura de olfato en los perros. Por lo tanto, en la mesa del banquete filosófico, en un extremo de la misma, René Descartes, autor del Discours de la Méthode y de las Regulaead directionem ingenii (Descartes,1953) frunce el ceño ante la tesis husserliana; en el otro extremo, Paul K. Feyerabend, autor de Against Method (Feyerabend, 2010), sonríe con aprobación. En suma, ¿qué son entonces las físicas de Galileo, Newton y Einstein? ¿Predomina en ellas el instinto o el método?

c) Ante la crisis de la existencia europea, la salida positiva constituye una épica de la razón: “el renacimiento de Europa a partir del espíritu de la filosofía mediante el heroísmo (Heroismus) de la razón que vence definitivamente el naturalismo" (Hua VI, pp. 347-348). No se trata precisamente de una reengineering de la humanidad, pero entonces ¿qué es? Es la filosofía como epopeya de la razón.

d) El proceso de la racionalización de la cultura europea propuesto por Husserl se destaca como una figura sobre un trasfondo bíblico, enfrentando "el mayor peligro de sumergirnos en el diluvio escéptico (in der skeptischen Sintflut) y con ello renunciar a nuestra propia verdad" (Hua VI, p. 12; Husserl, 2008, p. 58). ¿Qué es entonces esta alegoría bíblica que presupone que la fenomenología trascendental es el Arca de Noé en el mar de la humanidad y que es amenazada por el diluvio escéptico? 


\section{Referencias}

Descartes, R. (1953). Oeuvres et Lettres. Paris: Gallimard.

Feyerabend, P. (2010). Against Method. London/New York: Verso.

Herrero, V. (2007). Verbi gratia. Diccionario de expresiones latinas. Madrid: Gredos.

Husserl, E. (1950). Ideen zu einer reinen Phänomenologie und Phänomenologische Philosophie. (Hua III). Erstes Buch: Allgemeine Einführung in die reine Phänomenologie. Biemel, W (Hrsg.). Den Haag: Martinus Nijhoff.

Husserl, E. (1958). Die Idee der Phänomenologie. Fünf Vorlesungen (Hua II). Biemel, W (Hrsg.). Den Haag: Martinus Nijhoff.

Husserl, E. (1962). Die Krisis der europaïschen Wissenschaften und die transzendentale Phänomenologie: Eine Einleitung in die phänomenologische Philosophie (Hua VI). Biemel, W (Hrsg.). Den Haag: Martinus Nijhoff.

Husserl, E. (1970). The Crisis of European Sciences and Transcendental Phenomenology. An introduction to Phenomenological Philosophy. (Trad. Carr, D). Evanston: Northwestern University Press.

Husserl, E. (1976). La crise des sciences européeennes et la phénoménologie Transcendantale. (Trad. Granel, G). Paris: Gallimard.

Husserl, E. (1982). La idea de la fenomenología. Cinco lecciones. (Trad. García-Baró, M). México: Fondo de Cultura Económica.

Husserl, E. (1989). Aufsätze und Vorträge (1922-1937) (Hua XXVII). Sepp, R (Hrsg.). Dordrecht: Kluwer.

Husserl, E. (1997). Ideas relativas a una fenomenología pura y una filosofía fenomenológica. (Trad. Zirión, A). Libro Segundo: Investigaciones fenomenológicas sobre la constitución. México: Universidad Nacional Autónoma de México.

Husserl, E. (2002). Renovación del hombre y de la cultura. Cinco ensayos.

(Trad. Serrano de Haro, A). Barcelona: Anthropos. 
Husserl, E. (2008). La crisis de las ciencias europeas y la fenomenología trascendental. (Trad. Iribarne, J). Buenos Aires: Prometeo Libros.

Kuhn, T. S. (1970). The Structure of Scientific Revolutions. Second Edition, enlarged. Chicago: The University of Chicago Press.

Lawrence. T. E. (1936). Les Sept Piliers de la Sagesse. Paris: Payot.

Merleau-Ponty, M. (1945). Phénoménologie de la perception. Paris: Gallimard.

Moran, D. (2012). Husserl's Crisis of the European Sciences and Transcendental Phenomenology. An Introduction. Cambridge: Cambridge University Press.

Pascal, B. (1964). Pensées. Paris: Garnier Frères.

Reichenbach, H. (1938). Experience and Prediction. An Analysis of the Foundations and the Structure of Knowledge. Chicago: University of Chicago Press.

Torretti, R. (1999). The Philosophy of Physics. Cambridge: Cambridge University Press.

Vattimo, G. e Rovatti, P. A. (1983). Il pensiero debole. Milan: Feltrinelli.

Von Humboldt, A. (2003). Über die Verschiedenheit des menschlichen Sprachbaues: Über die Sprache. Wiesbaden: Fourier.

Von Humboldt, W. (2003). Über die Verschiedenheit des menschlichen Sprachbaues und ihren Einfluss auf die geistige Entwicklung des Meschengeschlechts: Über die Sprache. Wiesbaden: Fourier.

Whewell, W. (1847). The Philosophy of the Inductive Sciences, founded upon their History. London: J. W. Parker. 



\title{
Conciencia histórica y relatos identitarios: en búsqueda de una ética de la experiencia social de la historia ${ }^{1}$
}

\author{
Historical consciousness and identity stories: \\ searching for an ethic of history'social experience
}

\author{
Miguel Ángel Guzmán López ${ }^{2}$ \\ Universidad de Guanajuato, México
}

Recepción: 06 de junio del 2020

Evaluación: 02 de julio del 2020

Aceptación: 20 de julio de 2020

1 Este artículo deriva del proyecto de investigación homónimo Conciencia histórica y relatos identitarios: en búsqueda de una ética de la experiencia social de la historia, realizado al interior del equipo de investigación que conforma la línea de Generación y Aplicación del Conocimiento de Teoría y Filosofía de la Historia, de la Universidad de Guanajuato.

2 Licenciado en Historia y Doctor en Filosofía por la Universidad de Guanajuato. Investigador Nivel 1 en el Sistema Nacional de Investigadores de México.

Correo electrónico: miguelguzmanlop2@gmail.com 


\title{
Resumen
}

Este trabajo pretende hacer un análisis a partir de tres preguntas fundamentales. La primera de ellas: ¿Cómo puede derivar una propuesta de carácter ético de un concepto hermenéutico-ontológico de la conciencia histórica?, en el entendido de que en una primera instancia la teoría hermenéutica gadameriana se preocupa por el aspecto situacional-ontológico del sujeto, mientras que acerca de la parte ética no se encuentra un desarrollo teórico comparable en profundidad. La segunda pregunta reza: ¿Qué es lo que debe entenderse por relatos identitarios y cuáles son sus repercusiones teóricas?, dado que aquí se plantea que en dichos relatos se encuentra manifiesta la conciencia histórica de tal manera que es susceptible de ser historiada. Y finalmente, la tercera pregunta es ¿Qué respuesta puede darse a la pregunta de qué debe hacerse desde la historia acontecida?, que lleva la reflexión hacia el campo de la ética, en el sentido de preguntarse por la conciencia histórica desde la experiencia social en favor de un proyecto para el futuro.

Palabras clave: conciencia histórica, discursos identitarios, ética.

\begin{abstract}
This work aims to make a analysis based on three fundamental questions. The first of which is: How can a proposal of an ethical nature derive from a hermeneutic-ontological concept of historical consciousness?, in the understanding that, in a first instance, Gadamerian hermeneutical theory is concerned with the situational-ontological aspect of the subject, while on the ethical side there is no in-depth comparable theoretical development. The second question: What is to be understood by identity stories and what are their theoretical repercussions?, given that here it is stated that in these stories historical consciousness is manifested in a way that is capable of being historized. And finally, the third question is: What answer can be given to the question of what should be done from the history that one has?, which leads reflection to the field of ethics, in the sense of asking about historical consciousness from experience social in favor of a project for the future.
\end{abstract}

Keywords: historical consciousness, identity discourses, ethics. 
En la medida en la que el rostro del Otro nos pone en relación con el tercero, la relación metafísica del yo con el Otro se desliza hacia la forma del Nosotros, aspira a un Estado, a las instituciones, a las leyes, que son la fuente de la universalidad (Levinas, 1977, p. 276).

Si se piensa en la conciencia histórica a partir de consideraciones hermenéutico-ontológicas, es necesario estar al tanto de tres premisas fundamentales:

La primera sostiene que la conciencia histórica es ante todo darse cuenta uno mismo de la condición existencial del Dasein ${ }^{3}$ (Heidegger, 2002). Uno mismo sabe que participa de la condición existencial del ser-ahí pero no lo agota, por lo que tener conciencia histórica, en primera instancia, es saberse Dasein.

La segunda plantea que tomar conciencia de ello no ocurre sino mediante la relación que establece el Dasein con el mundo, relación que es necesariamente dialógica dado el carácter comprensivo del ser-ahí, pues dicho carácter implica la interacción del ser-ahí con el mundo en constante estado de apertura. Apertura, interacción y tiempo son tres claves importantes para entender las diversas tensiones dialógicas que el ser-ahí desarrolla en su propia facticidad, pues de eso se constituyen la historicidad y la efectualidad de la historia ${ }^{4}$ (Gadamer, 1998). Saberse Dasein es saberse en diálogo con el mundo.

La tercera, finalmente, señala que el diálogo con el mundo en interpelación continua es un concernir total. El Dasein, por ello, encara lo que le sale al paso de diferentes formas, todas ellas en incumbencia con el mundo, incluso la indiferencia, pues la indiferencia concierne a quien la ejerce. No es extraño que el ser-ahi tenga la actitud crítica como una posibilidad. Entonces, saberse en diálogo con el mundo es saberse potencialmente crítico.

3 En la filosofía de Heidegger, el Dasein o ser-ahí, es un ente cuya manera de ser es la existencia, no entendida como presencia, sino como posibilidad de ser o no ser. Un ente cualquiera (como una silla o una mesa) cambia en el tiempo, pero no experimenta ese cambio, no lo percibe, y por tanto no puede proyectar su ser como una expectativa. El Dasein es el ente que no solamente puede contar con esa experiencia, sino que le es esencial para llegar a ser lo que es.

4 En el pensamiento de Gadamer, la historia efectual hace referencia al devenir histórico, al acontecer real que determina irremediablemente a los hombres, razón por la cual éstos no pueden contraponerse a su pasado desde un lugar ajeno al devenir histórico mismo, desde una posición trascendente al acaecer de los hechos. De esta manera, el sujeto no puede entender la historia desde fuera de ella, sino solamente inmerso en la misma, siendo él parte del acontecer.

Guzmán, M. (2020). Conciencia histórica y relatos identitarios: en búsqueda de una 
Estas premisas permiten señalar que en la constitución de la conciencia histórica existe un fundamento ontológico, un carácter hermenéutico y una posibilidad ética, que en conjunto contienen el germen de la universalidad de este concepto, pues con ello no es necesario remitirse a un tipo de individuo o de sociedad en particular, ni a un momento histórico específico. No se atribuye la conciencia histórica a una cultura o a una civilización, ni a una sola forma política de ver el mundo: la conciencia histórica es una para todo aquel que la experimenta.

Teniendo en cuenta lo anteriormente enunciado, este trabajo pretende desarrollar una reflexión inicial acerca de las diversas posiciones estratégicas que están implícitas en los relatos identitarios ${ }^{5}$, a través de los cuales la conciencia histórica de una comunidad determinada se expresa en pos de un proyecto que permita sugerir qué debe hacerse desde la historia y con la conciencia histórica que se tiene en la actualidad. Si la conciencia histórica se encuentra manifiesta en los relatos identitarios y en ellos se encara a la tradición desde una perspectiva que puede ser crítica, pero difícilmente neutral, las cuestiones que deriven de este punto pueden conducir la reflexión hacia el campo de la ética, en el sentido de preguntarse por lo que debe hacerse desde la historia y con la conciencia histórica desde la experiencia social, con la meta de un proyecto para el futuro.

Este es el punto central del planteamiento. En este contexto surgen preguntas tales como ¿cómo puede derivar una propuesta de carácter ético de un concepto ontológico de la conciencia histórica? ¿Qué es lo que debe entenderse por discursos identitarios y cuáles son sus repercusiones teóricas? ¿Hay en

\footnotetext{
5 En este trabajo se entiende por relatos identitarios a todas aquellas narraciones orientadas a dar cuenta del pasado de una comunidad o del individuo en una comunidad determinada, que tiene como finalidad, explícita o no, generar un sentimiento de pertenencia o de otredad en las sociedades que los asumen. Pueden adoptar diferentes formas como la historiografía, el mito, la leyenda, la literatura en general y el discurso político. Su carácter es transdisciplinar, pues, por ejemplo, en la medida en la que en ellos se puede dar cuenta del pasado de una comunidad son de interés para el historiador o para el antropólogo, mientras que, como construcciones dotadoras de sentido, son de interés del análisis filosófico-hermenéutico. Cabe resaltar que el término se está empleando desde una perspectiva social y no desde un punto de vista exclusivamente individual, como lo propone Martin Payne (2002) para efectos psico-terapéuticos, aunque claramente existan puntos en común entre la conformación de una identidad individual y la de una colectiva. La diferencia estribaría en que más que hablar de un proceso psicológico de construcción de identidades, estamos haciendo referencia a un proceso de comunicación y participación de elementos dotadores de sentido entre grupos sociales, como parte del ser en el mundo hermenéutico.
} 
ellos usos estratégicos y/o posturas ideológicas que incidan sobre la experiencia social de la historia? ¿Qué respuesta puede darse a la pregunta ética de 'qué debe hacerse' desde la trayectoria histórica que las generaciones del presente han heredado de sus antepasados?

\section{Punto de partida: la historia efectual y la conciencia en torno a ésta}

El punto de partida que llevará a la consideración de la dimensión ética de la proposición ontológica anteriormente descrita, tiene que ver en primera instancia con las nociones gadamerianas de 'historia efectual' y de 'conciencia de la historia efectual'.

La historia efectual supone el acontecer real que determina a los individuos irremediablemente y por lo cual éstos no pueden contraponerse a su pasado desde un lugar ajeno al devenir histórico mismo, desde una posición trascendente al acaecer de los hechos (Gadamer, 1998, p. 137). Por ello el sujeto no puede entender la historia desde fuera de ella, sino solamente inmerso en la misma, siendo él parte del acontecer: "No se trata entonces de una comprensión de la historia como un transcurso, sino de una comprensión de aquello que nos sale al paso en la historia interpelándonos y concerniéndonos" (Gadamer, 1998, p. 136). La historia nos sale al paso, nos interpela en la medida en que estamos determinados por ella, en que constituimos parte y producto de ella, y siempre nos concierne por muy ajena que en un principio pudiera parecer.

En consecuencia, una conciencia histórico-efectual es la conciencia de la situación hermenéutica, es decir, "la situación en la que nos encontramos frente a la tradición en que queremos comprender" (Gadamer, 1998, p. 372). Se está en una situación y no frente a ella, dice Gadamer, y por tanto no se puede tener un saber objetivo de la misma. En consecuencia, no es posible dar cumplimiento por entero al conocimiento de una situación. Sucede lo mismo en lo que respecta a la situación hermenéutica: no se puede hacer la reflexión total sobre la historia efectual, puesto que no sólo se encuentra uno inmerso en ella, sino que el propio devenir histórico nunca está acabado. Al entenderse esta cuestión se está dando cuenta de la esencia misma del ser histórico. En este sentido, Gadamer afirma que "ser histórico quiere decir no agotarse nunca en el saberse” (Gadamer, 1998, p. 372). Muy relacionado con esto está el concepto de horizonte que denota el ámbito de visión que abarca y encierra todo lo que es visible desde un determinado punto (Gadamer, 
1998, p. 372). En términos de conciencia puede hablarse de estrechez de horizonte, de amplitud o apertura del mismo, etc. De esta manera puede afirmarse que quien no tiene horizontes:

(...) es un hombre que no ve lo suficiente y que en consecuencia supervalora lo que le cae más cerca. En cambio, tener horizontes significa no estar limitado a lo más cercano, sino poder ver por encima de ello. El que tiene horizontes puede valorar correctamente el significado de todas las cosas que caen dentro de ellos según los patrones de cerca y lejos, grande y pequeño (Gadamer, 1996, p. 373).

La elaboración de la situación hermenéutica "significa (...) la obtención del horizonte correcto para las cuestiones que se nos plantean de cara a la tradición" (Gadamer, 1996, p. 373). Pero el establecimiento de este horizonte correcto no implica que esto quede fijo de una vez por todas. Muy por el contrario, está en perpetuo movimiento: se desplaza al paso de quien se mueve (Gadamer, 1998, p. 375). Lo que se quiere decir con el horizonte correcto, en todo caso, implica ver las cosas desde su justa perspectiva al momento en que se hace la pregunta, pensando que, en un momento diferente, el horizonte correcto corresponderá a ese otro contexto.

De esta forma se puede apreciar cómo el proceso de la comprensión -la forma en que la comprensión acontece- constituye un desenvolvimiento historizado en el que, conforme ocurre, la conciencia sabe de sí misma desde su propia situación mientras se comprende en el mundo, es decir, se desempeña en él. Por ello Gadamer señala que la conciencia histórica efectual es más ser que conciencia (Gadamer, 1998, p. 18), es decir que da más cuenta de la naturaleza del ser que solamente de la forma en que el conocimiento se presenta como tal.

Por todo lo anteriormente dicho puede afirmarse que la conciencia hermenéutica tiene su centro mismo en su aspecto histórico efectual y que, por tanto, ya es conciencia histórica, dado que se ha visto ya que el carácter finito del ser y su desenvolvimiento hermenéutico están indisolublemente ligados con su historicidad.

\section{La tradición y su encaramiento}

En este sentido, la tradición ocupa un lugar importante porque en ella están depositados todos los elementos culturales que en el transcurso del tiempo se han ido "sedimentando" y generando una presencia continua. La continuidad 
de estos elementos culturales posibilita hacer referencia a la formación (Bildung) del individuo. La tradición genera una tensión dialógica entre sí y el ser-uno-en-cada-caso fáctico, pues al tiempo que el Dasein deviene temporalmente también lo hace históricamente, y esto significa que aunque se viva a cada momento un instante nuevo, nunca se es completamente inédito (se habla un lenguaje, se asume una forma de pensar específica, etcétera, todo ello heredado).

De entrada se puede suponer que el término es retomado en buena medida de Heidegger, quien define la tradición expresa como el retroceso a las posibilidades del "ser-ahi" "sido-ahí", la reiteración propia de una posibilidad de la existencia sida (Heidegger, 2002, p. 416). Pero las alusiones que Gadamer hace al término inducen a pensar que no lo retoma de manera idéntica a como lo hace Heidegger, sino que lo desarrolla de forma más amplia, y con ello parece efectivamente indicar que se trata de lo que es heredado históricamente, a lo que el ser-ahí pertenece en la medida en que es históricamente finito (García, 2004, p. 298), y que esta historia heredada lo envuelve en una dinámica en la que es necesario "avanzar hacia el futuro, para remediar las deficiencias del presente, lo cual, necesita un regreso al pasado" (García, 2004, p. 298), pero en el cual no hay alusión alguna al estado de propiedad que Heidegger considera como condición previa necesaria para poder hablar de una conciencia histórica en cuanto tal.

Gadamer percibe la tradición como una continuidad inmersa dentro de las constantes transformaciones del devenir histórico: "la tradición es esencialmente conservación, y como tal no deja de estar presente en los cambios históricos" (Gadamer, 1998, p. 349). Pero tal tradición no es ella misma inmutable, sino que se encuentra en constante cambio mediante la reafirmación que implica su vivencia por parte de los sujetos. La tradición, en ese sentido, es tradición viva ${ }^{6}$ (García, 2004, p. 299).

En otras palabras, lo que Gadamer señala es que la forma en la cual el individuo interactúa con el mundo es ineludiblemente comprensiva e histórica, aún antes de poder comprenderse a sí mismo reflexivamente. Dado que el

${ }^{6}$ La asunción de la tradición, por otra parte, no se reduce a una aceptación acrítica de lo heredado, sino que implica, en términos epistemológicos, el rechazo de la oposición abstracta que impuso el Iluminismo entre tradición e historia, por un lado, y el conocimiento, por el otro (Dobrosavljev, 2002, pp. 605-618). 
individuo está determinado históricamente - porque ese es su modo de ser-y porque en el devenir histórico, pese a los cambios, también se desarrollan elementos cuya presencia es continua, y con los cuales el individuo entra en contacto, de manera que éste está determinado por la tradición, constituida por esos elementos continuos.

En su cambiante presente el sujeto comprende la realidad y se desenvuelve en el mundo. Al hacerlo, necesariamente lo hace inmerso en la tradición, ya que ésta constituye, en primer lugar, la cuna en la cual el sujeto ha sido formado (gebildet) y, en segundo lugar, el asidero a partir del cual se llevan a cabo la comprensión y el desempeño. Esto constituye a la conciencia hermenéutica y también a la conciencia histórica; en ambas es fundamental el apego a la tradición y su tensión con el movimiento del sujeto.

Vale decir, entonces, que incluso la actitud crítica forma parte de la tradición, pues de lo contrario no se desarrollaría en ella la relación dialógica mencionada anteriormente, y se tendría por resultado que todo acto crítico sería totalmente inédito y no podría heredarse como una postura crítica: sería un acto aislado por su misma singularidad ${ }^{7}$ (Bengoa, 1992, p. 162).

De ahí que, en efecto, el reconocimiento de la tradición no implique un acto sumiso. La tradición puede encararse de diversas maneras y ninguna de ellas ad aeternum. Francisco Manuel López distingue al menos cuatro posturas del sujeto frente a la tradición: de pertenencia, de interpelación, de proclividad y de resistencia (López, 2009, p. 40). En el primero de los casos el individuo reconoce la relación vital que guarda respecto de la tradición; en el segundo, adopta una postura frente a un cuestionamiento que parte de la tradición; en el tercer caso, el individuo busca a la tradición y, en el cuarto caso la rechaza, en un acto crítico que puede ser aquel sobre el que Habermas y Apel, principales críticos de Gadamer, llaman la atención. Pero en ninguno de los casos el individuo se desvincula ontológicamente de la tradición, pues aún en el caso en el que se presenta el rechazo de una tradición específica, la alternativa que surge deriva siempre de otra tradición particular.

\footnotetext{
7 Ricoeur señala que el crítico, al apelar a la reflexión, habla justamente desde el lugar denunciado por él mismo como inexistente, del sujeto trascendental y, por tanto, desde el fondo de una tradición que sería la tradición Ilustrada y, aún más, desde la tradición de las acciones liberadoras, cuya remisión llega hasta los tiempos antiguos.
} 
En estas cuatro actitudes se presenta un reforzamiento identitario del individuo; es decir que con la postura que éste establece respecto a la tradición, sin importar el tipo de relación que tenga, se refuerza la conciencia que se tiene de ser sí mismo respecto a los demás, cosa que forma parte fundamental del carácter dialógico de la hermenéutica. Siendo la conciencia histórica al mismo tiempo conciencia hermenéutica, tal y como Gadamer plantea y, por tanto, expresión de la facticidad y de la finitud de la experiencia de ser-en-elmundo, la pregunta sobre la posibilidad que ésta tiene de ser crítica, no tendría por qué remitirnos fuera del discurso ontológico, toda vez que la actitud crítica se desprendería de una de las posibles formas de encarar la tradición sin perder por ello la dinámica dialogal de la hermenéutica.

Cuando se habla de la posibilidad crítica de la conciencia histórica no se está queriendo decir que la crítica sea una condición de posibilidad para la existencia de la conciencia histórica, sino que se trata de una de las formas en las que la conciencia histórica encara la tradición. Así como la conciencia histórica tiene, por un lado, la posibilidad de ser crítica, por otra parte, no puede eludir el efecto del uso estratégico del lenguaje, mediante el cual la aberración del mensaje y el ejercicio del dominio y la persuasión, sobre los que llaman la atención Habermas y $\mathrm{Apel}^{8}$, tienen lugar.

Por estas razones, la conciencia histórica no consiste solamente en advertir la situación temporal, contingente y finita de la propia facticidad a través de un proceso dialógico con el otro que comparte la misma experiencia, sino también en encarar a la siempre interpelante tradición en su transformación en mundo mediante un proceso mutuo de posicionamiento: la tradición sitúa al individuo en su mundaneidad y el individuo sitúa a la tradición en cuanto que la reconoce y define como mundo.

Pero este encaramiento no constituye en sí mismo un acto develador, sino sólo una toma de postura, a saber, la postura de resistencia frente a la tradición, que es aquella en la cual se encuentra la intención desmitificadora, es decir, la intención crítica. En ninguna de estas actitudes, sin embargo, desaparece la reiteración de la tradición. Esto es así porque aún la posición

8 Hay que recordar al lector el debate entre la hermenéutica y la crítica de las ideologías, que se desarrolló prácticamente a partir de la publicación de Verdad y Método en 1960, y que involucró nombres como Habermas, Apel, Bubner, Wellmer, Giegel, Bormann y Ricoeur, junto al propio Gadamer (Recas, 2006). 
más acendradamente crítica requiere de un marco normativo que establezca el parámetro (regulativo o utópico) del cual pueda partir toda evaluación de lo real. Pero todo marco regulativo constituye un proyecto porque se erige como orientador de las acciones correctivas de los individuos, con el fin de mejorar las actuales condiciones de vida. Habría que hacer notar, entonces, que la utopía, al ser un proyecto, requiere recuperar lo que es -como decía Heidegger- reiterable de la tradición. Tal vez el esfuerzo de Apel, que lo lleva a establecer una dialéctica entre comunidad ideal de la comunicación y comunidad real de comunicación, pueda ser leído en este sentido9 (Apel, 1985).

La conciencia histórica toma postura frente a la tradición en alguna de las maneras posibles. Si se consideran las cuatro posibilidades enunciadas anteriormente, es posible afirmar que la conciencia histórica puede derivar en actitudes que denotan pertenencia, interpelación y proclividad, además de la actitud crítica, que habría que identificar con la resistencia frente a la tradición. Pero entonces se debe reconocer que en la conciencia histórica es posible encontrar tanto actitudes críticas como acríticas, y aún más, debe reconocerse que la conciencia histórica, para ser tal, no depende de los criterios de verdad como sí ocurre con la ciencia (incluyendo a la ciencia social y a la investigación histórica).

\section{Relatos identitarios e ideología}

Sería importante señalar que en el encaramiento que ocurre ante la tradición, la conciencia histórica se expresa mediante la construcción de relatos identitarios, cuyas características dependerán justamente del modo en que la tradición sea encarada. Estos relatos desarrollan diferentes valores que dependen del tipo de encaramiento frente a la tradición: relatos de pertenencia a una

\footnotetext{
9 Apel establece sus nociones de comunidad real de comunicación y comunidad ideal de comunicación, que se diferencian de las propuestas por Pierce en cuanto que éstas no remiten sólo a un grupo de científicos, sino a toda colectividad humana, ya que desde su perspectiva "en todo juego de lenguaje humano tiene que estar dado a priori el paso posible al discurso argumentativo". De esta forma la argumentación se convierte en el punto clave sobre el cual se asientan no sólo las aspiraciones de verdad científica, sino también las aspiraciones de corrección normativa, la crítica de las concepciones humanas del mundo, la reflexión, la acción racional y la responsabilidad del obrar humano. Con la comunidad ideal de la comunicación, Apel realiza lo que él denomina 'la transformación de la filosofía', es decir, la transformación de la filosofía trascendental tradicional en el sentido de una pragmática lingüística trascendental. Una filosofía que no es la filosofía del sujeto de la conciencia, sino de la comunidad argumentativa.
} 
comunidad específica, relatos de libertad de albedrío al modo de la interpelación de la tradición, relatos que buscan una tradición a la cual sumarse (melancólicos), y relatos que buscan una ruptura con la tradición.

En consecuencia, todos estos relatos, que no deben entenderse necesariamente como relatos escritos, sino como percepciones de mundo, pertenecen al campo de lo ideológico desde la perspectiva con la que Paul Ricoeur adopta el término: como un sistema simbólico integrante, un cuerpo coherente de imágenes, ideas e ideales compartidos, que suministra a los participantes una coherente orientación general en cuanto al espacio y al tiempo (Ricoeur, 1996).

Ricoeur se distancia de Marx y de Althusser para proponer un concepto de ideología que en primera instancia remite a la mediación simbólica de todo acto social, en cuyo caso ésta no será concebida como una deformación de la comunicación, sino como la retórica de la comunicación básica: "Existe una retórica de la comunicación básica porque no podemos excluir del lenguaje los recursos retóricos; éstos constituyen una parte intrínseca del lenguaje corriente. En su función integradora, la ideología es analógicamente básica e ineluctable" (Ricoeur, 1996).

Ante la pregunta de si es posible erigir una ciencia no ideológica, Ricoeur responde negativamente, señalando que esto podría afirmarse solamente en el caso de la ciencia natural, pero no en el de la ciencia social, ya que ésta no satisface los criterios de cientificidad consistentes en la generación de una explicación satisfactoria de fenómenos anteriormente ininteligibles y la resistencia de dichas explicaciones a los intentos de falsación emprendidos sistemática y rigurosamente (Bengoa, 1992, p. 163).

Aun cuando las ciencias sociales no fundamentaran su cientificidad con base en criterios positivistas, sino a partir de la acción crítica, no podrían, desde la perspectiva de Ricoeur, acceder a un estatuto no ideológico, porque, en primer lugar, toda ciencia combativa corre el riesgo de caer en los vicios que denuncia en el adversario. En segundo lugar, porque no puede dar una explicación en términos no ideológicos de la formación de las ideologías, mientras en tercer lugar, porque ella está imposibilitada para realizar una reflexión total, es decir, una reflexión que implique que el sujeto crítico se posiciona más allá de todos sus condicionamientos históricos (argumento fundamental de la hermenéutica gadameriana, por cierto) (Ricoeur, 1988, p. 139). 
Pese a esto Ricoeur reconoce que la acción crítica es posible, si no en su totalidad sí a través de una "relativa autonomía", que el saber puede alcanzar en virtud del factor de distanciamiento incluido en la conciencia histórico-efectual. El distanciamiento del individuo frente a lo otro que forma parte de la relación dialógica del ser fáctico es, para Ricoeur, la condición de posibilidad de una crítica de las ideologías que no se sitúe fuera ni en contra, sino en el seno mismo de la hermenéutica (Bengoa, 1992, p. 164).

Con lo dicho hasta el momento respecto al concepto de ideología propuesto por Ricoeur, puede entenderse mejor que los relatos que la conciencia histórica genera pueden ser tanto ideológicos como críticos respecto a la ideología, pues ésta constituye en primera instancia el medio simbólico que integra toda acción social y, en una segunda instancia, representa el esfuerzo que los individuos y las comunidades hacen por liberarse de situaciones de engaño y dominio que se han vuelto insoportables, pero cuya acción no se encuentra fuera de la tradición.

\section{Comunidad y ética en la experiencia social de la historia}

En El giro lingüístico, Gadamer reconoce la importancia de lograr el acuerdo en virtud de ser conscientes de la existencia de una participación común del mundo entre los individuos, es decir, que pese al carácter fáctico y contingente del ser-en-el-mundo es posible llegar al acuerdo respecto al mundo, de tal manera que la experiencia individual no obstaculiza la puesta en común de importantes afirmaciones respecto a la cosa acerca de la que se habla (Gadamer, 1995, p. 15).

Posteriormente, en un diálogo sostenido con Reinhardt Koselleck (publicado bajo el título de Historia y Hermenéutica), Gadamer señala que este hecho no es asumido de manera pasiva, pues ante esta participación común en el mundo se origina la responsabilidad del ejercicio de la libertad - derivada de encararse frente al entorno y situarlo, mediante designación lingüística, como mundo- asentada en uno mismo, pero que involucra a los semejantes; se trata de la responsabilidad de sí mismo y de sí mismo para con los demás (Gadamer y Koselleck, 1997, p. 100). Esta responsabilidad compartida tiene que ver con el objetivo de buscar incesantemente lo comprensible y el sentido, frente al sinsentido y la absurdidad:

Soy plenamente consciente de que la mirada de quien comprende sigue toda huella de sentido y busca siempre el sentido que le permite abrir 
constantemente, en medio de la insensatez del acontecer y de la historia, algo parecido a horizontes de expectativa, de esperanza, de osadía y de no abyección. Quizás habría que decir que la fuerza suprema del hombre consiste en esto: resistir a todos los desafíos que la realidad nos impone mediante el sin sentido (Unsinn), la demencia (Wahnsinn) y la desconcertante absurdidad (Sinnlosigkeit), y hacerlo perseverando en una búsqueda incansable de lo comprensible y del sentido (Gadamer y Koselleck, 1997, p. 100).

Dado que este diálogo con Koselleck ocurre años después de realizado el debate con Habermas y Apel, es posible sugerir que Gadamer estaba siendo conciliatorio con el punto de vista de la crítica de las ideologías, y que trataba de complementar su propuesta hermenéutica con aquello que sus críticos le extrañaban: una propuesta ética.

Más allá de esta consideración, sin embargo, lo importante del caso radica en que, aunque resulte problemático hablar del sostenimiento de una ciencia crítica meta hermenéutica, esta cuestión estará revestida de la mayor importancia si es que realmente se quiere ofrecer una respuesta desde la hermenéutica, que atienda a las repercusiones éticas de la conciencia histórica. El propio Ricoeur admite la importancia de las consideraciones éticas respecto al papel de la ideología en la sociedad, no sólo por constituir parte fundamental sobre la que se erige la mediación simbólica básica de todo acto social, sino también por la posibilidad de futuro que ofrece. Es por esta razón que señala:

(...) la muerte de las ideologías se convertiría en la lucidez más estéril, ya que un grupo social sin ideología y sin utopía carecería de proyecto, de distancia respecto a sí mismo, de una representación de sí. Sería una sociedad sin proyecto global, en manos de una historia fragmentada en acontecimientos iguales y por consiguiente insignificantes ${ }^{10}$ (Ricoeur, 1988, p. 141).

En este sentido, la propuesta de Apel de tomar en cuenta una comunidad real de comunicación y una comunidad ideal de comunicación, constituye una alternativa que media entre la pretensión de lograr una crítica completamente desligada de la facticidad y una hermenéutica que no desdeñe la importancia de la crítica.

Para hablar de la conciencia histórica es muy importante tener en cuenta, entonces, dos factores que van de la mano: el reconocimiento de la pertenencia

${ }^{10}$ Nótese el acercamiento de Ricoeur a Heidegger cuando dice que la falta de un proyecto hace que la historia sea percibida de manera fragmentada e insignificante; es la forma en cómo vive el Dasein en estado de impropiedad. 
a una comunidad y el posible desarrollo de la crítica desde dentro de dicha comunidad y desde su vida fáctica. Pero ambos elementos no están autoimplicados, pues la conciencia histórica puede encontrar cimentación solamente en el reconocimiento de pertenencia a una comunidad y no desarrollar una actitud crítica al respecto.

Es por ello que en este contexto se habla de la posibilidad crítica de la conciencia histórica, pues constituye una alternativa real, aunque no se cumpla en todos los casos. Desde esta perspectiva, la conciencia histórica no garantizaría la puesta en evidencia de los actos de manipulación porque puede formar parte de ellos, a menos que, efectivamente desarrolle una actitud de rechazo frente a una determinada tradición, en cuyo caso tal vez pueda hablarse de una conciencia histórica crítica, que representaría uno de los modos en los que la conciencia histórica puede manifestarse.

Por su parte, para vivir históricamente, ya sea de manera crítica o no, es necesaria la comunidad, pues ésta constituye siempre el rasero desde el cual un determinado modo de pensar adquiere importancia política en el más amplio sentido de la palabra y, en consecuencia, requiere de una ética que no debe ser entendida necesariamente como desmitificadora, sino como una ética estructuradora de un orden simbólico dado y orientadora de la acción. De este modo, entonces, todo actuar político tiene una dimensión ética, pero sólo determinadas formas del actuar político encuentran en la crítica su justificación para la ética. En la comunidad, la conciencia histórica fundamenta sus nociones de pertenencia e identidad ${ }^{11}$, y también encuentra el ámbito en el cual es posible realizar las acciones derivadas de la asunción de un proyecto. Siguiendo a Heidegger es posible sostener que en la forma en que el Dasein asume la historicidad -de manera resuelta o irresuelta- estaría implicada también la forma en cómo se asume la idea de comunidad: de forma irresuelta es posible encontrar la idea de pertenencia e identidad, pero no volcada a la realización de un proyecto, cosa que se encontraría en la forma resuelta.

\footnotetext{
${ }^{11}$ La identidad es entendida aquí como resultado del interactuar con el mundo que tiene el sujeto con el medio social en el que se encuentra, por lo que en primera instancia ocurre en el ámbito individual, que en una segunda instancia se presenta colectivamente, no en virtud de la creencia en la existencia de un sujeto colectivo sino en la medida en que los individuos comunican sus propios puntos de vista y generan acuerdos sociales, a partir de la conocida fusión de horizontes planteada por Gadamer. La identidad, además, conlleva una historia, que no sólo hace referencia a los acontecimientos del pasado, sino que atiende también a lo que está en construcción en el presente de cara al futuro, por lo que "el concepto de identidad también connota la noción de proyecto" (Toledo, 2012).
} 
El proyecto no implica, en primera instancia, la adopción de una actitud crítica, sino el acto de tomar "en las propias manos" el destino, y evitar de esta manera ser conducido por el mundo de lo impersonal, del uno o man. Asumir, por ejemplo, un proyecto de carácter religioso no implica la realización de acciones críticas comparables a las del científico natural, pero sí actos de argumentación que se realizan en el ámbito comunitario. Esto deriva en dos conclusiones: la primera, que el valor del carácter de resolución que lleva a la conformación de un proyecto no reside en que dicho proyecto tenga fundamentos crítico-científicos, sino sólo existenciarios en la medida en que el individuo asume la responsabilidad de guiar su propia existencia. La segunda conclusión es que aún en el caso de proyectos que no impliquen acciones crítico-científicas, éstos si implican el desarrollo de argumentaciones que se presentan en el ámbito comunitario y que se sancionan y regulan desde éste.

De ahí que sea un gran acierto el que Apel proponga sus comunidades de comunicación, distinguiéndolas de la comunidad de investigadores de Pierce, por el hecho ya señalado de incluir en ellas no sólo a la comunidad científica, sino a toda comunidad que esgrima argumentos y que los someta a la consideración de los demás en busca del acuerdo y del interés común. Al reconocer en la comunidad real de la comunicación el contrapeso fáctico de la comunidad ideal de la comunicación, Apel se aproxima a la idea de que el consenso y la acción crítica pueden lograrse sin la pretensión de situar a los individuos por encima de su propia facticidad, contingencia e historicidad.

\section{A manera de conclusión}

Es importante conocer estos rasgos de la conciencia histórica, porque a partir de la plataforma conceptual que ellos configuran se deriva un nuevo campo de reflexión, que desde el ámbito de la ontología nos conduce al de la ética, sin abandonar el enfoque comprensivo y hermenéutico que ha caracterizado a esta investigación hasta este momento. Esto es así porque de la caracterización de la conciencia histórica, como la puesta en evidencia del Dasein frente a sí mismo, como un acontecer comprensivo y potencialmente crítico en el mundo, deriva la pregunta ¿para qué una conciencia histórica? Esta cuestión involucra tres asuntos fundamentales: 1) A los relatos identitarios a través de los cuales la conciencia histórica se manifiesta socialmente; 2) a la composición ideológica de tales discursos, y 3) a la experiencia social de la historia y de su conciencia como sustrato en el que la conciencia histórica cobra sentido comunitariamente. 
Una de las conclusiones a las que se llega al abordar la conciencia histórica desde una perspectiva hermenéutico-ontológica es que ella no constituye una opción para el ser humano, es decir, no es algo que pueda ser elegible por el hecho de formar parte del ser del ser-en-el-mundo y que, debido a ello, la pregunta del para qué de la conciencia histórica no debe ser pensada desde el plano de lo accesorio. Pero en la medida en que la conciencia histórica pueda ser orientada por una ética argumentativa, como la que Apel propone (1985), la cuestión cobra sentido a un nivel ético, en el cual el quid de la cuestión no es si se debe tener o no tener conciencia histórica, sino qué hacer desde la conciencia histórica que se tiene.

En este escrito se ha insistido en señalar que la conciencia histórica no necesita ser crítica para ser tal, no obstante que la crítica es una posibilidad de la conciencia histórica. Se trata además de una posibilidad deseable, no porque se considere que una conciencia histórica crítica conduzca a una vida más auténtica, sino porque ella puede aportar una orientación razonada que permita realizar las acciones del proyecto que ha sido asumido.

Se pretendería, entonces, en el marco de una perspectiva ética, que las decisiones del individuo busquen ser más autónomas respecto a los dictados de la tradición, aunque no en el sentido de superar ontológicamente su facticidad -hecho imposible por demás-, sino en el de mantener equilibrada la relación dialógica con la tradición y evitar convertirla en un monólogo. La libertad del individuo no residiría, según este marco, en la ruptura de todo condicionamiento histórico, sino en la presencia constante de un sujeto dialogante que hace concesiones al interlocutor, pero que también presenta ante éste sus propias exigencias. El peor de los casos estaría representado por la evasión de la responsabilidad de erigirse como ente dialogante.

Sería ingenuo suponer que en los procesos de diálogo la comunicación acaece de manera transparente, pues, por el contrario, puede estar mediada por un uso estratégico - simulado o abierto- del lenguaje. También resultaría ingenuo suponer que el individuo, como ente dialogante, no emplea eventualmente de manera estratégica el lenguaje: que una persona sea objeto de enajenación de parte de un poder político o mediático no implica que ella misma no haga uso estratégico del lenguaje en otros ámbitos. Asimismo, alguien que política o mediáticamente sea sujeto de dominio en un ámbito determinado, no es un impedimento para ser objeto de dominio en otro ámbito. Las prácticas de dominio no deberían representarse mediante la reducción maniquea de procesos dialógicos que son mucho más complejos. 
El establecimiento del diálogo, en cuanto requiere de la participación de dialogantes activos que no sólo se dedican a entender, sino también a conceder y a exigir -en una palabra: a negociar-, no es o no debería ser ajeno a la coacción, pues ésta constituye un recurso mediante el cual se puede favorecer que se llegue a un acuerdo. Lamentablemente la coacción puede también favorecer un completo rompimiento del diálogo.

La conciencia histórica del sujeto tiene como interlocutor al otro-del-pasado, ante el cual puede reflejarse e identificarse, lo que no implica que no haya exigencias en esta relación dialógica: el pasado tiene sus códigos y sus formas sin cuyo conocimiento no es posible comprenderlo; por su parte, el intérprete del pasado, que actúa desde un presente, no puede conformarse con la comprensión del pasado: necesita ser exigente en términos de lo que el pretérito ha representado y puede representar en cada presente. Si esto no sucede, la relación se reduce, entonces, a un infructuoso intercambio de información.

¿Qué hacer desde la conciencia histórica que se tiene? La respuesta, según lo dicho, sería deseablemente hacer crítica a ella mediante el ejercicio dialogante exigente y dentro de un marco comunitario de sanción, sin entender no obstante este elemento crítico como una superación del nivel ontológico-comprensivo de la facticidad, sino como un ejercicio intersubjetivo de negociación, susceptible del establecimiento de razones ideales válidas mediante la argumentación.

\section{Referencias}

Apel, K. O. (1973). Transformation der Philosophie (Bd. 2). Das Apriori der Kommunikationsgemeinschaft. Frankfurt a. M.: Suhrkamp.

Apel, K. O. (1985). La transformación de la filosofía II. El apriori de la comunidad de comunicación. (Trad. Cortina, A., Chamorro, J y Conill, J). Madrid: Taurus.

Bengoa, J. (1992). De Heidegger a Habermas. Hermenéutica y fundamentación últimas de la filosofía contemporánea. Barcelona: Herder.

Dobrosavljev, D. (2002). Gadamer's Hermeneutics as Practical Philosophy. Facta Universitatis, 2 (9), pp. 605-618. 
Gadamer, H. G. (1995). El giro hermenéutico. (Trad. Parada, A). Madrid: Cátedra.

Gadamer, H. G. (1996). Verdad y Método I. (Trad. Agus Aparicio, A y de Agapito, R). Salamanca: Sígueme.

Gadamer, H. G. y Koselleck, R. (1997). Historia y hermenéutica. (Trad. Oncina, F). Barcelona: Paidós.

Gadamer, H. G. (1998). Verdad y Método II. (Trad. Olasagasti, M). Salamanca: Sígueme.

García, D. E. (2004). Gadamer y la conciencia histórica. La callada herencia viquiana. Acero, J. J et al. (Ed.). El legado de Gadamer (pp. 293-318). Granada: Universidad De Granada.

Heidegger, M. (2002). El ser y el tiempo. (Trad. Gaos, J). México: FCE.

Levinas, E. (1977). Totalidad e infinito. Ensayo sobre la exterioridad. (Trad. Guillot, D). Salamanca: Sígueme.

López, F. M. (2009). Comprensión, lenguaje y mundo. Un esbozo de la ontología hermenéutica de Hans-Georg Gadamer. Guanajuato: Azafrán y Canabrio / Universidad de Guanajuato.

Payne, M. (2002), Terapia narrativa: una introducción para profesionales. Barcelona: Paidós.

Recas, J. (2006). Hacia una hermenéutica crítica. Gadamer, Habermas, Apel, Vattimo, Rorty, Derrida y Ricoeur. Madrid: Biblioteca Nueva.

Ricoeur, P. (1988). Hermenéutica y acción. De la hermenéutica del texto a la hermenéutica de la acción. Buenos Aires: Prometeo Libros.

Ricoeur, P. (1988). Hermenéutica y acción. De la hermenéutica del texto a la hermenéutica de la acción. (Trad. Prelooker, M., Adúris, L., Fornari, A., Gorlier, J. y La Valle, T). Buenos Aires: Prometeo Libros.

Ricoeur, P. (1996). Lectures on Ideology and Utopia. New York: Columbia University Press.

Ricoeur, P. (1996). Lectures on Ideology and Utopia. New York: University Press. 
Ricoeur, P. (1996). Ideología y utopía. (Trad. Bixio, A). Barcelona: Gedisa.

Toledo, M. I. (2012). Sobre la construcción identitaria. Atenea, No. 506. Revisado el 12 de julio de 2020, en: https://scielo.conicyt.cl/scielo. php?script=sci_arttext\&pid=S0718-04622012000200004 



\title{
Nunca hemos sido animales. El posthumanismo de Heidegger
}

\author{
We have never been Animals. \\ Heidegger's Posthumanism ${ }^{I}$
}

Steven Crowell ${ }^{2}$

Rice University, Estados Unidos

Recepción: 23 de julio del 2020

Evaluación: 31 de julio del 2020

Aceptación: 11 de agosto del 2020

1 Traducción de Carlos Rincón Zabala, Centro Internacional de Estudios sobre el Nihilismo Contemporáneo (CeNic).

2 Doctor por la Universidad de Yale y Magister en la Northen Illionis University. Actualmente es Profesor en la Rice University (USA).

Correo electrónico: crowell@rice.edu

Crowell, S. (2020). Nunca hemos sido animales. El posthumanismo de Heidegger.

Cuestiones de Filosofía, 6 (26), 165-193. 


\title{
Resumen
}

La pregunta por la relación entre el Dasein y el ser humano nunca fue adecuadamente caracterizada en Ser y tiempo. En la década siguiente a esta publicación, Heidegger examinó este problema cuando trata de elaborar una "metafísica" fundada fenomenológicamente. Un momento crucial en este intento se encuentra en su reflexión acerca del animal en su curso magistral de 1929/30, Conceptos fundamentales de la metafísica. Este escrito explora el tratamiento heideggeriano de la diferencia entre el animal (incluyendo al homo sapiens) y el "Dasein en nosotros". Esto es hecho en diálogo con un reciente ejemplo de lo que yo denomino "bio-posthumanismo", el punto de vista de que normativamente no existe una distinción significativa a considerar entre el ser humano y otros animales. Surge de esta manera una imagen del post-humanismo fenomenologico de Heidegger.

Palabras clave: vida, fenomenología, teoría de sistemas, posthumanismo, normatividad, metafísica.

\begin{abstract}
The question of the relation between Dasein and the human being was never adequately characterized in Being and Time. In the decade following that publication, Heidegger explored this problem as he tried to work out a phenomenologically based "metaphysics." A key moment in this attempt is found in his discussion of the animal in his 1929/30 lecture course, Fundamental Concepts of Metaphysics. This paper explores Heidegger's treatment of the difference between the animal (including homo sapiens) and the "Dasein in us." It does so in dialogue with a recent example of what I call "bio-posthumanism," the view that there is no normatively meaningful distinction to be drawn between human beings and other animals. A picture of Heidegger's phenomenological post-humanism emerges.
\end{abstract}

Keywords: life, phenomenology, systems theory, posthumanism, normativity, metaphysics. 
En su Carta sobre el humanismo (1946) Heidegger se mueve por una línea retórica entre rechazar y adoptar el "humanismo" como una etiqueta para su propio pensamiento. Por un lado, el término pertenece a una tradición (llamada aquí "metafísica") en la cual "el hombre es la medida de todas las cosas", tradición criticable por cierto para Heidegger. Por otro lado, a diferencia del humanismo tradicional (que no se percata aún "de la verdadera dignidad del hombre"), el "pensamiento del ser" no-metafísico de Heidegger pretende hacer justicia a la condición particular del hombre como "pastor del ser" (Heidegger, 1993, pp. 225, 233, 234).

El presente ensayo pretende desarrollar algunas de las razones e implicaciones de esta aporía retórica. Eso hace que el título "posthumanismo de Heidegger", más que "humanismo heideggeriano", tenga que ver con el camino que el ulterior pensamiento continental ha tomado. Recurriendo a los tratados conocidos de Foucault (1973) y Derrida (1982), esta reflexión rechaza el "subjetivismo" fenomenológico y tiende a ver a Heidegger simplemente como otro humanista. A pesar de sus intentos de romper con la fenomenología "empírico-trascendental" -según esta argumentación-, Heidegger refuerza el humanismo metafísico cuando, por ejemplo, resalta el "abismo" que nos separa de lo que hemos solido llamar "otros" animales, y elogia, en su lugar, nuestra proximidad a "la esencia de lo divino" (Heidegger, 1993, p. 230).

La distinción normativa a la que este tipo de diferencia abismal parece conllevar, es el objetivo de cierto posthumanismo que admite muchas diferencias entre especies de seres vivos, pero no le concede a ninguno de ellos el tipo de estatus normativo que permitiría hablar de un abismo. En ¿What is Posthumanism?, Cary Wolfe sostiene, por ejemplo, que cualquiera que sea el camino adecuado para una "bioética", "no tiene sentido proponer la distinción entre humanos y animales (no importa cómo esté establecida esta diferencia)" (2010, p. 98). Con respecto a lo primero, denominado por él los "dos tipos de finitud" - concretamente, la finitud de la carne, "vulnerabilidad física, la encarnación y, finalmente, la muerte"-, a los cuales nos referiremos, no hay distinción que pueda ser concluyente ${ }^{3}$. Este posthumanismo no es

3 El pasaje completo en el que se definen estas dos tesis debe ser citado aquí, ya que nos ocuparemos de la primera en el apartado 3 y de la segunda en el 4. Comentando el trabajo de Cora Diamond, Wolfe sostiene que "hay dos clases de finitud, dos tipos de pasividad y vulnerabilidad. El primer tipo (vulnerabilidad física, encarnación, y finalmente la muerte) es paradójicamente inaccesible, 
un "transhumanismo" que se modele a sí mismo en el concepto de cyborg y proclame tecnologías postéticas que encumbren al ser humano más allá de su contingente constitución biológica: una "evolución diseñada" que promete nuestro "triunfante desencarnamiento" (Wolfe, 2010, pp. xiii, xv). Este es más bien un tipo de bioposthumanismo que se mueve en la dirección opuesta a "las fantasías de la encarnación y la autonomía heredada del humanismo mismo" (Wolfe, 2010, p. xv). Para Wolfe, quien recurre a la deconstrucción y a la teoría de sistemas de segundo orden -a Derrida y a Luhmann-, el "espíritu" de la Ilustración implica un giro posthumanista, un rechazo de los "dogmas" y los "universales antropológicos" tomados prestados de "la religión, la ciencia y la política", las "represiones culturales y las fantasías, los protocolos filosóficos y las evasiones del humanismo como un fenómeno históricamente específico" (Wolfe, 2010, p. xvi). Esto requiere rechazar, en particular, el "tipo de subjetividad normativa" con la cual la filosofía (y con esto él quiere decir filosofía como tal, a diferencia de la "teoría"4) busca tratar asuntos, por ejemplo, en bioética. Esto significa "que la naturaleza del pensamiento mismo debe cambiar si pretende ser posthumanista" (Wolfe, 2010, p. xvi).

Los lectores de Heidegger encontrarán familiares tales indicaciones. Con escritos como "El final de la filosofía y la tarea del pensar" en mente, podemos ser dispensados por considerar que el pensamiento de Heidegger cuenta como "posthumanista" en el sentido de Wolfe 5 . Y, de hecho, como veremos, hay una considerable superposición entre la fenomenología heideggeriana y el bioposthumanismo, cuando éste aborda la pregunta acerca del animal. Aun así, el posthumanismo de Heidegger (si éste es eso) está excluido de

inapropiable, para nosotros, por la misma razón que la hace accesible -concretamente, un segundo tipo de "pasividad" o "no estar disponible"-, que es la finitud que experimentamos en nuestro sometimiento a un tecnicismo o mecanicismo radicalmente a-humano del lenguaje, un tecnicismo que tiene profundas consecuencias, por supuesto, para lo que apresuradamente también pensamos de 'nuestros' conceptos, que no son, por tanto -en un sentido relevante- 'nuestros' en lo absoluto" (Wolfe, 2010, p. 88).

4 La "teoría" es la respuesta a "la pregunta en el despertar del escepticismo", según lo analizado por Stanley Cavell: "lo que puede significar hacer filosofía después de la filosofía, en un cierto sentido, ¿se ha vuelto imposible?” (Wolfe, 2010, p. 70).

5 Por ejemplo, ya en el primer párrafo de este escrito Heidegger sostiene: "El título nombra el intento de una meditación que se queda en pregunta. Las preguntas son caminos para una respuesta. Esta consistiría -en el caso de que alguna vez se accediera a ella- en una transformación del pensar, no en un enunciado acerca de un contenido" (Heidegger, 1972, p. 55; 2000, p. 77; mi énfasis). 
este canon por lo que parecen ser, de alguna manera, fundamentos dudosos: concretamente que Heidegger rechaza la idea (central para el bioposthumanismo) de que la vida o la animalidad proveen de algo así como una piedra angular ético-teórica ${ }^{6}$. Si un transhumanismo del cyborg puede ser resumido con el eslogan "ya no somos más animales", el posthumanismo de Heidegger debe ser entendido como una suposición de que nunca hemos sido animales. Esta paradoja está ampliamente tratada en el curso de 1929/30 Los conceptos fundamentales de la metafísica. En este producto maduro de su década metafísica ${ }^{7}$, Heidegger defiende una forma de posthumanismo fenomenológico, que es tan consistente con la posición de Ser y tiempo como lo es con el pensamiento de Heidegger en Carta sobre el humanismo, para adoptar su maniobra retórica. Pero a lo largo de este curso Heidegger insiste en que la fenomenología solo puede llevarnos a un punto donde podamos ver qué es lo que está en juego; ella no puede dar lugar a la decisión que surge entre pensar que nosotros siempre hemos sido animales o que nunca lo hemos sido (Heidegger, 1995, pp. 355- 425).

\section{Fenomenología, vida y el problema del mundo}

Empecemos con el método que Heidegger emplea en el texto. Heidegger quiere conducir a sus estudiantes hacia un conocimiento del "mundo", y con este objetivo plantea una distinción entre entidades que son "sin mundo" (como la piedra), entidades que son "pobres de mundo" (y que él llama "animales") y entidades que son "configuradoras de mundo" (reciben aquí el nombre de "hombre" [Mensch]. Tal nombre es engañoso, ya que el argumento subsecuente señala que no es el ser humano, sino el Dasein en el ser humano el "configurador-de-mundo"). ¿Qué significa la "pobreza-de-mundo" de los animales? Heidegger recuerda a sus oyentes que responderá a esta pregunta, practicando la fenomenología: un "modo de ver y comprender que resulta ajeno y molesto al entendimiento común”, un "preguntar y comprender (...)

6 Para algunas comparaciones fenomenológicas confróntese: Weigelt (2002), Barbaras (2006), Lawlor (2006), Toadvine (2009) y Figal (2010). Ya en 1929 Heidegger advertía en contra de esta tentación siempre presente, criticando el intento de Max Scheler por desarrollar una "visión de mundo biológica" que interpretara "al ser humano" desde "la perspectiva de la vida" (Heidegger, 2007, p. 242).

7 Acerca de la designación "década metafísica", véase Crowell (2001, cap. 12), donde también se explica por qué Heidegger renuncia al enfoque metafísico, apenas asociable a sus convicciones fenomenológicas. 
anterior a toda argumentación", que fue "vuelto a despertar, y en su sentido más radical, a través de Husserl” (Heidegger, 1995, p. 232).

Heidegger acepta la esencia del animal con el fin de entender al ser humano (1995, pp. 169-173) y aplaude a la biología contemporánea por resistir a la reducción de las categorías "ontológico-regionales" de la física (1995, p. 188). Pero ¿qué clase de categorías regionales y ontológicas pertenecen a la vida? Aunque "no podemos separar la investigación positiva y metafísica" (Heidegger, 1995, p. 189), una metafísica de la vida no debe, sin embargo, abdicar de sus propios intereses por convertirse en una visión de mundo biológica (o zoológica). La fenomenología heideggeriana se acerca al asunto a través de la idea de "transposición", explicada en contraste con la "empatía" (1995, pp. 202-206). Si la empatía es entendida para abarcar cierta distancia entre mi consciencia y la de mi prójimo, depende ya en sí misma de la "transposición", es decir, de nuestro "poder de acompañar al otro ente aun siendo distintos de él" (1995, p. 203). Como Mitsein, mi ser en el mundo incluye ya siempre la transposición "en" otros que no son yo. ¿Se mantiene lo mismo para animales no humanos? El hecho de que nosotros hayamos sido transpuestos en otros seres humanos, junto con el hecho de que los seres humanos sean seres vivos, ¿significa que "la transponibilidad en otros animales, en lo vivo", pertenece a "la esencia del ser humano"? (1995, p. 209).

Sí y no. En la base de la "vida”, el “(...) animal (...) permite y exige esta transponibilidad del hombre en él, (...) sin embargo a su vez niega al hombre la posibilidad de acompañarlo (Heidegger, 2007, p. 261). Este rechazo es la "pobreza" de mundo del animal, su "tener y, no obstante, no tener" (Heidegger, 1995, p. 210; 2007, p. 280). Si como Heidegger admite "esta pobreza solo puede ser captada si sabemos previamente qué es el mundo" -por consiguiente, de una manera que está tácitamente orientada hacia el ser humano-, esto no debe impedir cierto tipo de intento fenomenológico por elucidar positivamente "la esencia de la pobreza de mundo", al clarificar "la animalidad misma" (1995, p. 211; 2007, p. 262). Al explorar lo que significa decir que el animal invita y rechaza nuestra transponibilidad, la fenomenología heideggeriana plantea la pregunta acerca de si las categorías de la vida son adecuadas para entender el mundo ${ }^{8}$.

8 Para un tratamiento general de la ambigüedad del concepto de vida en la fenomenología trascendental y algunas de sus críticas, confróntese Crowell (2014). 
Heidegger se acerca al concepto de vida a través del concepto de organismo, y al concepto de organismo a través del concepto de órgano". Un órgano, que tiene la "capacidad" (Fähigkeit) para cumplir alguna función determinada, difiere de una herramienta, que está disponible para cumplir una función. Un bolígrafo que está "listo" para escribir no tiene una capacidad para ello, ya que para funcionar debe ser empleado de acuerdo a la "prescripción" (1995, p. 228; 2007, p. 280) que deriva de una totalidad respeccional (Bewandtnisganzheit) o "mundo" (1995, p. 215; 2007, p. 266). Un órgano, en contraste, no requiere de esta totalidad de implicaciones. Más bien, su función está prescrita -y así, su mismo ser como órgano está constituido- a través de su incorporación en un organismo: "El organismo tiene capacidades", mientras que el órgano mismo es "una posesión de una capacidad" (1995, pp. 221-222; 2007, p. 273). Heidegger ilustra esto con referencia a organismos unicelulares cuyos órganos son "temporales"; la misma "abertura" sirve primero como una boca, luego como estómago, luego como intestino y, finalmente, como ano.

Las bases para esta diferenciación de capacidades en un órgano residen en el ser del organismo gobernado por un "impulso" o instinto (Trieb), que "siempre se ha pro-puesto el posible ámbito de realización” (1995, p. 228; 2007, p. 281). El carácter prescriptivo del impulso del organismo es la esencia de éste y, en términos más generales, la esencia de la "vida" (1995, p. 235; 2007, p. 287). La "particularidad" de un organismo consiste en este modo de ser-una-capacidad de cierto tipo. Este punto es fundamental para la explicación heideggeriana de la vida. Antes de profundizar en ella será útil traducirla al lenguaje teórico-sistémico del bioposthumanismo, enfatizando de esta manera el carácter fenomenológico del posthumanismo de Heidegger. De acuerdo al bioposthumanismo, lo que Heidegger llama 'la capacidad del animal' se entiende mejor como un código recurrente que funciona para reducir la abrumadora complejidad del entorno animal. Esto, tal como Heidegger sostiene, cede el paso a un "mundo".

9 Los detalles de la discusión de Heidegger en torno a la vida del animal en el curso de 1929/30 son esclarecedores y fiablemente expuestos en McNeill (1999). Más adelante en este trabajo retornaré a algunos desacuerdos interpretativos con McNeill. 


\section{Propuesta bio-posthumanista del mundo de Cary Wolfe}

El bio-posthumanismo no inicia como una imposición directa de las categorías biológicas sobre la ontofilosofía, sino como una "forma-de-teoría" que prescinde de las presumibles aspiraciones fundamentalistas de la filosofía -tanto racionalistas como empiristas- a favor de una distinción entre "sistema" y "entorno". El mundo circundante no es un ámbito determinado y dado con antelación (por ejemplo, la naturaleza), sino que es, paradójicamente, el entorno de un sistema dado (Wolfe, 2010, p. xiv). Su "diferencia" con el sistema reside en su abrumadora complejidad, relativa a las condiciones que definen el sistema. Estas condiciones yacen en el código interno del sistema, en su manera de reducir esa complejidad a través de la "selectividad" (Wolfe, 2010, p. 14). Lo que hace que un sistema sea sistema es su autorreflexividad o recursividad -la manera en que sus resultados se convierten, uno por uno, en entradas que proveen las bases para nuevos resultados (Wolfe, 2010, p. 111). De esta manera, el sistema puede ser llamado "autopoiético" o autorreproductivo (Wolfe, 2010, p. xxiii) ${ }^{10}$. Además, el carácter recursivo del código implica que tal sistema produce una clase de apertura en las configuraciones, alguna vez nuevas, una "apertura a través de la clausura" (Wolfe, 2010, p. xxi). Ya que el entorno no es algo neutral que se da por hecho, sino que incluye los resultados del sistema mismo, "entra" al sistema en forma de una complejización interna que, a su vez, provee las bases para nuevas modalidades del sistema -para el aprendizaje, la evolución y el desarrollo.

La raíz de todo esto, sin embargo, es una paradoja que ha permitido acusaciones de solipsismo que recaen sobre la teoría de sistemas: la distinción entre sistema y entorno es una diferenciación que se hace solo dentro del sistema. Para usar uno de los ejemplos de Wolfe: el sistema legal es el que establece la distinción entre lo "legal" y su entorno (es decir, lo que es "lo otro de" lo legal). Su código se ramifica en una forma de sistema inmanente de complejidad (las varias subcategorías de lo legal), pero éste no puede determinar empíricamente la legitimidad de su distinción inicial codificada. Tampoco puede establecer internamente esa legitimidad, a través de una comprensión

\footnotetext{
${ }^{10}$ Como es usado en debates contemporáneos, el término "autopoiesis" remite al trabajo de Humberto Maturana, especialmente a su colaboración con Francisco Varela. Obsérvese, por ejemplo, Maturana y Varela (1996).
} 
autorreflexiva de su propio código ${ }^{11}$. Para Wolfe, esto es lo que hace de la teoría de sistemas una teoría en lugar de "filosofía". Esta teoría se concibe a sí misma como capaz de justificar la distinción inicial entre lo que está incluido y lo que está excluido, a través de algo parecido a una comprensión racional de sus propias condiciones de posibilidad (Wolfe, 2010, pp. xx-xxi). Este es también el punto en el que la teoría de sistemas une fuerzas con su "complemento", la deconstrucción, que recala en la misma "imposibilidad" de autoforjarse a través de su noción de "iterabilidad". Lo que es iterable (por ejemplo, el código recurrente) debe englobar "en un momento dado la necesidad de pensar tanto la regla como el evento", un evento que es heterogéneo, "y no simplemente opuesto al orden del ideal, de lo calculable, de lo puro, y así sucesivamente" (Wolfe, 2010, p. 12).

Necesitamos movernos desde estas consideraciones generales hacia algo que nos lleve más cerca del abordaje que hace Heidegger en torno al animal. El puente está provisto por el concepto de significado. ¿Cómo es entendido el significado desde la teoría de sistemas? Para empezar, se debe reconocer una "estricta separación de los sistemas psíquico y social como entidades discretas y autopoiéticas" (Wolfe, 2010, p. 19). El sistema psíquico (mente, consciencia individual) implica un código para reducir la complejidad del entorno, convirtiéndolo así en "información". La información difiere de una mera estimulación porque, al haber sido producida por el código, su condición de entorno ha sido "virtualizada" (Wolfe, 2010, p. 18) -esto es, ahora incluye "la presentación simultánea (...) de actualidad y posibilidad"; con esto se ha convertido en "significado" (Wolfe, 2010. p. 16). Luhmann escribe: "la totalidad de las referencias presentadas por cualquier objeto significativamente deseado, ofrece a la mano más que lo que pueda de hecho ser actualizado en cualquier momento" (Wolfe, 2010, p. 16). Pero el significado entorpece a menos de que permanezca abierto a la actualización de (algunas

\footnotetext{
11 "Lo que esto significa no es únicamente que todos los sistemas y todas las observaciones son autorreferenciales. También significa que, paradójicamente, la diferencia entre la autorreferencia y la referencia externa (o 'heterorreferencia') es en sí misma un producto de autorreferencia, en la misma manera en que el 'exterior' del entorno es siempre el exterior de un 'interior' específico. Este hecho, sin embargo, no puede ser observado por el sistema que, al mismo tiempo, quiere usar la distinción para llevar a cabo sus operaciones. Esa observación solo puede ser hecha por un observador de segundo orden, usando un código diferente (...), el cual, asimismo, debe permanecer 'ciego' ante la naturaleza paradójica de $s u$ distinción constitutiva, que solo puede ser revelada por otro observador, etc." (Wolfe, 2010, p. 113). En la sección final de este artículo discutiré acerca de una explicación diferente -heideggeriana- de lo que implica la autorreflexividad.
} 
de) esas referencias, en el curso de lo cual se convierte en "información", es decir, en algo nuevo. Lo crucial aquí es el hecho de que el significado no está limitado a la mente humana. No todo sistema produce significado. No obstante, Luhmann sostiene: "pero para aquellos que lo hacen, esta es la única posibilidad [para procesar la complejidad]. El significado se convierte para ellos en la forma del mundo y, consecuentemente, solapa la diferencia entre sistema y entorno" (Wolfe, 2010, p. 19).

No obstante, si el significado corresponde al sistema psíquico, también surge al interior del sistema social de acuerdo con los imperativos del código autopoiético propio de este último. Ese código está circunscrito por el concepto de comunicación. Dos sistemas psíquicos no se comunican el uno con el otro; por el contrario, hay un sistema (el social) en el cual el significado es una función de la manera en que ciertos eventos del entorno (digamos gestos y ruidos) están codificados de acuerdo a un esquema tripartito: información ("contenido"), expresión ("comportamiento") y entendimiento ("procesamiento": la diferencia entre información y expresión) (Wolfe, 2010, p. 22). Tal como el significado en el sistema psíquico, el significado en el sistema social implica la virtualidad, la demanda por la actualización de potencialidades implícitas en el evento comunicativo. Estos hechos le permiten a Luhmann tratar el significado como "la verdadera 'sustancia' de este nivel evolutivo emergente". El significado no está basado en el sistema psíquico ni en el social: "Es imposible encontrar una 'substancia de soporte' para el significado" (Wolfe, 2010, p. 20).

De esta manera, los sistemas psíquico y social son complejizaciones internas del sistema autopoiético del significado mismo, tal como el derecho fiscal y las leyes de inmigración son complejizaciones dentro del sistema autopoiético legal: "El significado se apoya en aquello que permite su propia reproducción autorreferencial. Y únicamente las formas de esta reproducción diferencian las estructuras psíquica y social" (Wolfe, 2010, p. 20). De hecho, "el significado permite a los sistemas psíquicos y sociales interpenetrarse, mientras protegen su autopoiesis" (Wolfe, 2010, p. 21). Esto se logra a través del lenguaje -algo que no es psíquico ni social, pero es "un fenómeno de segundo orden: un "tipo de comunicación mediática simbólicamente generalizada"-, que es utilizado por esos sistemas al servicio de procesos de significado de primer orden (Wolfe, 2010, p. 22). Pero esto conlleva, a su vez, a una decisión. La diferencia, previamente discutida, entre información y significado dentro de un sistema, implica un cierto tipo de indecibilidad 
pragmáticamente determinada (Wolfe, 2010, p. 90)-concretamente, el hecho de que para que el significado sea información, más allá de la actualización de una expresión, debe llevar al horizonte de posibilidad que pertenece a la virtualidad del significado. Pero esto significa que "el sistema debe decidir", esto es, "procesar selectivamente la diferencia entre información y expresión”, es decir, entendimiento (Wolfe, 2010, p. 23).

En este punto encontramos una convergencia ulterior entre la teoría de sistemas y la deconstrucción, debido a que el lenguaje no está gobernado por ningún proceso social ni psíquico. Para Luhmann, la tecnología de la escritura, como opuesta a la lengua oral, "impone la clara distinción entre información y expresión". Pero la reflexión de Derrida acerca de "la estructura de huella de la escritura-comunicación" muestra que la distinción entre información y expresión no está "limitada solo al dominio de lo humano y lingüístico", sino que caracteriza lo "recursivo, las dinámicas iterables del significado" como tal (Wolfe, 2010, pp. 24-25). Toda comunicación, incluyendo el lenguaje, y así también todo pensamiento, está por consiguiente atada al sistema autopoiético del significado que ha emergido a través de la evolución biológica. Y es solamente por esta razón que el pensamiento, en términos de significado, debe convertirse en "posthumanista" en el mismo sentido que el bioposthumanismo concede a este término: una apelación a formas lingüísticas de comunicación desarrolladas específicamente en el homo sapiens, no es suficiente para poner un "corte" entre sistemas de significado-producido y significado-no-producido. Si es de este modo, entonces, no hay un fundamento en la teoría del significado para distinguir entre el "entorno" de un animal y el "mundo" de un ser humano: todo sería mundo.

A partir de aquí no hay sino un corto paso para la concreta aplicación del bioposthumanismo de la teoría de sistemas deconstructivista. Mientras que la teoría de sistemas no reconoce "naturaleza o algún otro hecho dado con anterioridad" (Wolfe, 2010, p. xxiv), la eliminación del "significado desde el dominio ontológicamente cerrado de la consciencia, de la razón, de la reflexión etc.", significa que nosotros (teóricos) podemos "recontextualizar" nuestras gastadas concepciones humanistas de la percepción, de la afectividad etc. "en términos de todo el sensorium de otros seres vivos y de sus propias maneras autopoiéticas de 'traer a presencia un mundo' -maneras que, puesto que nosotros mismos somos animales humanos, son parte de la historia evolutiva y psicológica, y del repertorio comportamental del mismo ser humano-" (Wolfe, 2010, p. xxv). Esta suposición -de que no somos soberanos 
dentro del "dominio ontológicamente cerrado de la consciencia, de la razón, de la reflexión etc.", y entonces el "mundo" solo podría ser entendido como un código de animal autopoiético-, es precisamente lo que el posthumanismo fenomenológico de Heidegger pone en cuestión. Puesto que por ahora debe estar claro que la teoría de sistemas y la deconstrucción pueden converger únicamente en que ellas atribuyen a la filosofía los pecados de un cierto tipo de fundacionalismo cartesiano-kantiano (individualismo) o hegeliano (social), este proyecto es, entonces, fácil de "descentrar", ya que estas dos opciones se neutralizan una con la otra. Pero ¿son ellas las únicas opciones disponibles para comprender filosóficamente el concepto de significado?

El obstáculo con el que tropiezan tanto Derrida como Luhmann es el cuidado (Sorge) fenomenológico de Heidegger, que Wolfe asimila al "idealismo" de Descartes (2010, p. 41). Hacer esto le permite a Wolfe descartar el posthumanismo de Heidegger e introducir el concepto ontológico de "sujeto de una vida" del bioposthumanismo (2010, p. 66). Pero mientras que Heidegger estaría de acuerdo con que el significado no está anclado al sistema psíquico ni al sistema social como la teoría de sistemas los concibe, y mientras que Heidegger también estaría de acuerdo en que el significado es "virtual" -es decir, lo parcialmente determinado, pero a su vez el eje abierto-cerrado de una decisión-, esto no significa que la especificidad fenomenológica del significado esté adecuadamente reconocida por los enfoques de la teoría de sistemas. Y si es así, no podemos simplemente seguir al bioposthumanismo en su suposición de que nosotros, quienes estamos en un mundo significativo, somos animales humanos.

Para argumentar a favor de esta idea, debemos retornar a Heidegger y, específicamente, a su explicación de los animales como 'pobres-de-mundo'. Para hacer esto debemos examinar primero lo que Wolfe llama las "dos finitudes" que compartimos con "otros" animales: la finitud de la carne, encarnación, y "en última instancia, la muerte".

\section{La primera finitud: la vida como perturbamiento}

La explicación de Heidegger acerca del animal tiene algo similar a la idea de un código autopoiético. La "conducta" (Benehmen) de un animal es función de una autopoiesis particular a la especie -en el lenguaje de Heidegger, las "capacidades" que están establecidas por su "ser-impulsado por lo impulsivo" (1995, p. 237; 2007, p. 290)-, y tal "impulsar" permite cierta apertura, un "estar referido a..." o "un tender hacia" (1995, p. 240; 2007, p. 292). 
Esta apertura o acceso no debe ser entendida como si el mundo circundante (Unwelt) del animal fuera una totalidad de cosas presentes-a-la-mano, a las cuales éste se tuviera que adaptar; una totalidad que estaría igualmente disponible a otra especie de animal, en lugar de que el entorno perteneciera al impulso o al código mismo como su "apertura a través de la clausura" específica (Wolfe, 2010, p. xxi). Siguiendo a von Uexküll, Heidegger sostiene que el concepto "darwiniano" de adaptación defrauda en lo fundamental la "esencia de la animalidad" (Heidegger, 1995, pp. 260 y 277; Heidegger, 2007, pp. 314 y 335). En lugar de ello, el instinto comportamental del animal, que constituye su "apertura a...", lo mantiene dentro de una esfera propia de la especie o dentro de un "anillo" (Umring) -se está tentado a calificarlo como un cierto tipo de ser-en-el-mundo ${ }^{12}$. La vida del animal "es justamente el pugnar por este anillo que le rodea” (Heidegger, 2007, p. 309). Examinemos estas afirmaciones un poco más de cerca.

El término de Heidegger para la "totalidad del comportamiento instintivo" que pertenece al código autopoiético de una especie dada es "perturbamiento" (Benommenheit). El perturbamiento describe la manera específica del estar abierto del animal. En términos de Heidegger, el animal no "aprehende" 'lo que es', sino que es "tomado por las cosas" (1995, p. 242). La abeja, por ejemplo, no es atraída por el néctar de las flores como tal; más bien, su capacidad de impulso la provee instintivamente de un margen de maniobra (Spielraum) en el que ella puede ser "tomada" por el néctar. Las capacidades instintivas hacen esto (en el lenguaje de la teoría de sistemas) a través de la reducción de la complejidad, permitiendo al animal recibir información. En términos de Heidegger, el instinto del animal tiene un carácter "eliminativo" (1995, p. 250; 2007, p. 303): este excluye lo que no es relevante para la capacidad, permitiendo al animal, de este modo, ser estimulado por aquello a lo que está abierto. El "estímulo" no es un móvil libre del mundo circundante, sino un correlato del impulso animal; algo que desinhibe el carácter eliminativo del impulso en cuestión y, de esta manera, llama a un cierto modo de

\footnotetext{
${ }^{12}$ Aunque no debe ser llamado así. Cuando Heidegger dice cosas como "El animal tiene mundo. Del animal, pese a todo, no forma parte la carencia absoluta de mundo" (2007, p. 249), el contexto deja en claro que está proponiendo una interpretación (concretamente, el mundo consiste en "la accesibilidad de lo ente") (2007, p. 249) que cuestionará y rechazará en lo que resta del escrito. En contraste, su ponderado punto de vista es expresado en la afirmación de que el "perturbamiento es la condición de posibilidad de que el animal, conforme a su esencia, se conduzca en un medio circundante, pero jamás en un mundo" (2007, p. 291).
} 
la conducta del animal: la capacidad que define el funcionamiento de sus órganos (Heidegger, 1995, p. 253).

Con base en este análisis, entonces, se puede decir que cada especie animal consiste en el "anillo" constituido por la perturbación, en una conducta impulsiva-específica que dirige la especie. La abeja no ocupa el mismo entorno que la lombriz, el antílope o el homo sapiens. Ella es su mundo-circundante y puede comunicarse con otros mundos-circundantes únicamente al alcance que su estructura de impulso, o código, le permite precisamente para tales desinhibiciones. El animal, por consiguiente, no puede ser identificado en lo absoluto con el organismo en sentido estricto -esto es, con su cuerpo concebido como una entidad discreta entre otras entidades. El cuerpo del animal, por el contrario, pertenece $a$ su "anillo" como un órgano de su capacidad, pertenece al ser del animal como una "unidad del perturbamiento" (Heidegger, 1995, p. 258). Así, la idea del bioposthumanismo de que la "encarnación", la "finitud de la carne", tiene un solo significado a lo largo de la biósfera, que puede proveer una piedra angular para la teoría, parece simplista. Lo que nuestro "parentesco corporal con el animal" (Heidegger, 1993, p. 230; 2006, p. 31) augura, debe ser abordado de un modo diferente.

Heidegger se empeña en una larga explicación acerca del animal, con el fin de aclarar la tesis de que éste es pobre-de-mundo. Es sin embargo consciente de que su explicación puede sugerir la conclusión opuesta, porque en el reconocimiento del único tipo de ser del animal -concretamente, el anillo autopoiético y sus formas diversas de "apertura a..."-, percibe que lo denominado por él "pobreza de mundo" no debe ser entendido "simplemente" en un sentido negativo: "Los seres humanos quizás no tienen nada que ver" con los tipos de apertura disponibles de ser de una abeja o un delfín (Heidegger, 1995, p. 255). Aun así, Heidegger rehúsa declarar que cada una de estas especies ocupa un mundo, y acude a von Uexküll para criticar la conjetura de que el mundo humano pueda ser entendido en términos de la estructura del anillo de la animalidad (Heidegger, 1995, p. 263; 2007, p. 318). ¿Pero por qué no? Obviamente, si tomamos "mundo" para querer señalar la clase de círculo (ring) al que Heidegger da el nombre de "ser-en-el-mundo" en Ser y tiempo, podemos decir que los animales carecen de cierto aspecto de esto; pero por la misma razón, los seres humanos carecen del tipo de mundo constituido por la estructura instintiva de la abeja o del delfín. Heidegger mismo se percata de que podemos llamar a esta "diferencia" del animal, a su propia forma de "apertura perturbada", pobreza de mundo, únicamente "en comparación con 
el hombre” (1995, p. 270; 2007, p. 326), y se pregunta por qué deberíamos tratar esto así como si fuera la norma. ¿Es el hombre la medida de todas las cosas? Hallamos aquí el soporte de la decisión de Heidegger entre humanismo y posthumanismo.

¿Hay en la distinción entre Welt y Umwelt o contorno animal (Umring), algo más que una diferencia de los anillos entre sí? El curso de 1929/30 marca una transición en el preguntar, al sugerir que un análisis propio del mundo puede "obligarnos" en sí mismo a ver, después de todo, la "carencia" de mundo de los animales en términos de "privación o pobreza" (1995, p. 270; 2007, p. 326). Las partes del texto que posteriormente llevan a cabo este análisis, pueden ser interpretadas como el restablecimiento de un tipo de humanismo en el que una distinción dentro de la categoría general de vida, concuerda con una prioridad normativamente relevante para el ser humano. Pero esto no es, de hecho, la manera en que procede el argumento.

Esto es porque Heidegger da por sentado una de las premisas del bioposthumanismo, concretamente que el homo sapiens está transpuesto en el anillo circular de las cosas vivas (1995, p. 278; 2007, pp. 335-336). La ontología regional de la naturaleza o de la vida, que surge en la explicación heideggeriana del organismo, incluye a los seres humanos. La naturaleza no es "la suma total de entes presentes a la mano" ni es "el 'fundamento' sobre el que surge la "humanidad", como lo es en los humanismos teológico y tradicional (Heidegger, 1995, p. 278; 2007, pp. 335-336). La vida humana pertenece a la naturaleza. Como la abeja y el delfín, el homo sapiens tiene su propio ani110 -“(...) la naturaleza viviente nos mantiene apresados a nosotros mismos en tanto que hombres" (Heidegger, 2007, p. 336)- y, como ellos, estamos transpuestos en estos otros anillos de una manera tal que, estando disponible dentro de nuestro propio anillo de especie (Heidegger, 1995, p. 278; 2007, p. 336), se rechaza el modo de "acompañarlos". Aun así, Heidegger no se acoge al bioposthumanismo, sino que insiste en la importancia "metafísica" de una distinción entre mundo y anillo (ring). Si el mundo no es algo por lo cual "nosotros", los seres humanos, estamos "elevados" sobre la vida y la naturaleza, entonces ser-en-el-mundo no puede corresponder ontológicamente al ser humano. Tal y como Heidegger lo expresa en este curso, ser-enel-mundo es el "Dasein en nosotros", y el Dasein en nosotros no puede ser concebido como parte de nuestra estructura pulsional o código autopoiético. Nosotros, que somos en el mundo, nunca hemos sido animales. Hay una distinción ontológica que "trasciende" (Heidegger, 1995, p. 308; 2007, p. 369) 
el anillo-como apertura de las cosas vivas, así como también las categorías de vida. Pero por esta misma razón, esto no es algo que pueda soportar el tropo humanístico del "hombre" como medida.

\section{La segunda finitud: comportamiento, significado y lenguaje}

La discusión previa acerca del animal ha suprimido los pasajes en los cuales Heidegger anticipa la diferencia decisiva entre el anillo del animal y el mundo del Dasein. Como Heidegger enfatiza repetidamente, el animal tiene acceso a las cosas, pero no tiene acceso a ellas en tanto lo que ellas son (1995, p. $198 ; 2007$, p. 250). Esto significa que los animales no "aprehenden" las cosas, sino que son "tomados por" ellas. La forma de apertura que el perturbamiento del animal hace posible, su conducta, no le permite a la cosa "ponerse" o estar "presente" (Heidegger, 1995, pp. 252 y 242; 2007, pp. 293-294 y 305-306). En contraste, el comportamiento humano (Verhalten) -o, mejor, el comportamiento del Dasein- permite encontrar algo en tanto que algo. Para ponerlo esquemáticamente, el Dasein puede encontrar la roca en tanto que una roca (esto es, en el propio ser de la roca), mientras que el anillo de la lagartija tiene permitido acceder únicamente a la "roca-de-la-lagartija", el anillo del escarabajo tiene permitido acceder únicamente al "camino-del-escarabajo" (Heidegger, 1995, p. 198; 2007, p. 249) ${ }^{13}$. La pregunta obvia es: ¿por qué esto no es sencillamente lo mismo en el ser humano, quien debería tener acceso únicamente a la "roca-del-humano" o al "camino-del-humano"?

Todo gira aquí en torno a entender que el camino de una fenomenología del significado requiere una distinción que no puede ser suscitada dentro del horizonte conceptual de una metafísica de la vida. Al mismo tiempo debemos recordar un punto anotado anteriormente: la fenomenología heideggeriana no está orientada a proveer algo, sino a llevarnos a una situación en la cual

\footnotetext{
${ }^{13}$ McNeill (1999, p. 240) especula que los animales deben ser capaces de encontrarse con las cosas en tanto que "algo" (por ejemplo, como comida), pero no en tanto que "entes". Yo no pienso que este sea el punto de vista de Heidegger, sino que parte del asunto debe ser meramente terminológico. Si el "en tanto que" significa que el animal habita lo que la teoría de sistemas llama la "virtualidad" del significado, entonces, ya que esto comprende una capacidad de respuesta a la posibilidad en tanto que posibilidad, y puesto que esto no parece ser parte de la capacidad del animal, en este sentido el animal no puede encontrar las cosas "en tanto que". Pero si esto únicamente significa que el ser "tomado" del animal por las cosas comprende la expresión de capacidades diferenciadas, entonces, ciertamente los animales están abiertos a las cosas en tanto comida, en tanto refugio, y así sucesivamente.
} 
sea posible decidir (krinein) cuáles son los riesgos de la pregunta (Heidegger, 1995, p. 351).

Nos limitaremos a tres tesis que rigen la reflexión de Heidegger: 1) la estructura del "en cuanto" ( $A l s)$, o significado, no está fundamentada en el lenguaje (logos), sino que fundamenta al lenguaje; 2) el "en cuanto", expresado en la cópula ( es b), indica formalmente la "dimensión" en la que esta estructura debe ser entendida fenomenológicamente; concretamente, "el Dasein en nosotros" y, 3) esta dimensión no es un sistema autopoiético o un anillo animal, sino un tipo de "comportamiento fundamental" que hace posible la manifestación de los entes como tal, junto con un "temple de ánimo fundamental" que hace posible la manifestación de los entes como un todo (diferencia ontológica). Estas aseveraciones circunscriben conjuntamente lo que significa sostener que el "hombre" es "configurador-de-mundo" (Heidegger, 1995, p. 285; 2007, p. 344), e indican por qué razón, como Heidegger lo expresa, la "consciencia" (o el sistema intra-psíquico autopoiético del animal) "no es suficiente" para configurar mundo (Heidegger, 1995, p. 361; 2007, p. 427).

Empecemos con el ejemplo de Heidegger acerca de la estructura del "en cuanto". Cuando estoy impartiendo una lección ante una clase, puedo hacer la vivencia del tablero como (als) estando en una mala posición. En una vivencia como esta no tengo simplemente acceso a los entes; más bien, éstos se manifiestan en cuanto algo -como un tablero y en mala posición. Si yo expreso ahora esto como "el tablero está en una mala posición", el enunciado no establece en primer lugar el "en cuanto", sino que lo presupone: "La proposición «a es b» no sería posible (...) si ella no pudiera surgir de la vivencia que subyace al a en cuanto b" (Heidegger, 1995, p. 301). El último es un tipo de "percibir que configura unidad" (Heidegger, 1995, p. 314; 2007, p. 375), y que precediendo permite el rasgo característico del enunciado: su virtud de ser verdadero $o$ falso. Puesto que Heidegger, en el curso en cuestión, rastrea el origen de estos asuntos hasta Aristóteles, puede decir que "el logos se fundamenta, conforme a su posibilidad interna, en el nous" (Heidegger, 1995, p. 314; 2007, p. 375).

Como Luhmann, el Aristóteles de Heidegger concibe el lenguaje (logos) ante todo como comunicación: "El discurso da a entender y exige comprensión. Conforme a su esencia, se dirige al libre comportamiento y actuar de los hombres entre sí" (Heidegger, 1995, p. 306; 2007, p. 367). Pero para Heidegger, en contraste con Luhmann (quien sigue la tradición que Heidegger está 
criticando), la comunicación es secundaria en relación con la "aprehensión original que forma una unidad" (nous); es decir, no es un sistema social autopoiético. Tanto la teoría de sistemas como aquello que Heidegger denomina la tradición "lógica" - que deriva del análisis aristotélico de la enunciaciónanalizan el "en cuanto" mismo como una función del "es" de la enunciación, de la cópula. De este modo, ellos reducen la unidad producida a una relación formal entre términos y, en últimas, a "un tecnicismo o mecanicismo radicalmente a-humano" (Wolfe, 2010, p. 88). Al hacer esto, la lógica entiende el carácter distintivo del ser humano como algo que reside en la razón en tanto capacidad de operar con relaciones formales. Pero Heidegger ofrece una explicación alternativa en la cual el "en tanto que" se convierte en el "es" de la predicación únicamente en la comunicación, y la razón (o nous) precede a la lógica.

Esto nos lleva a nuestra segunda tesis, que concierne a la dimensión fenomenológica formalmente indicada por la cópula (Heidegger, 1995, p. 291). Si bien es verdad que "a en cuanto b" es formalmente una relación, la noción de relación es filosóficamente inútil porque postula automáticamente "a" y "b" como entidades "presentes". La fenomenología, en contraste, tomará esta relación formal entre a y b como una indicación o guía hacia "la tarea decisiva de concebir la relación a partir de su dimensión propia” (Heidegger, 1995, p. 293; 2007, pp. 352-353). ¿Cuál es entonces la dimensión propia del "en cuanto" o del significado? En sus primeros cursos de Friburgo, lo que Heidegger denomina "dimensión propia" era expresado como "Evidenz-Situation", la experiencia concreta en primera persona, en la que el tipo específico de relación en cuestión puede ser "intuido en persona", en su ser genuino ${ }^{14}$. Para tener éxito en esta tarea formalmente indicada-ocupar la dimensión apropiada o la situación de evidencia- hay que pensar filosóficamente. Pensar, en este sentido fenomenológico, es aceptar el tipo de aprehensión que pertenece al nous. En contraste con la tradición lógica, que no presta atención a la dimensión propia y trata la cópula como formalmente vacía, la fenomenología heideggeriano-aristotélica descubre en la cópula una articulación interna en el ser-qué (what-being), ser-que (that-being) y ser "en el sentido de verdadero" (Heidegger, 1995, p. 326; 2007, p. 389); una articulación cuya unidad deriva de la dimensión del "en cuanto". De esta manera, si el "logos se funda,

${ }^{14}$ Para una explicación de la indicación formal en términos de Evidenz-Situation, obsérvese Crowell (2001, cap. 7). 
conforme a su posibilidad, en el nous" -es decir, en "un percibir que configura unidad" (Heidegger, 1995, p. 314; 2007, p. 375)-, el pensar que pretenda ocupar la dimensión a la cual pertenece el significado (el "en cuanto") será un pensar en sí mismo, será un "tomar en consideración"15 o un aceptar el camino en el que acontece el significado.

Los detalles pueden ser aquí controversiales, incluso misteriosos. Nuestra preocupación no es, sin embargo, en torno a ellos, sino acerca del posthumanismo de Heidegger, acerca de la comprensión del "Dasein en nosotros" que surge de la discusión. En este sentido bien podría parecer que Heidegger está simplemente repitiendo los rasgos más comunes del humanismo, en los cuales el significado y el lenguaje están fundados en el nous (reason) que, aceptando la forma en que acontece el significado (thinking), tiene la capacidad -negada a los sistemas autopoiéticos- de comprender las condiciones de posibilidad de su propio funcionamiento. Pero mientras las relaciones conceptuales son aquí abrumadoras, la fenomenología es relativamente sencilla y puede ser abordada observando que Heidegger identifica el nous con el comportamiento. Como "aprehensión original que forma una unidad", el nous pertenece a todo comportamiento (Heidegger, 1995, p. 342; 2007, p. 406), y es a través de la fenomenología de este último -que en Ser y tiempo se llama el "por-mor-de-qué" (Worumwillen) - que podemos entender la naturaleza del nous como la dimensión del significado.

En contraste con la conducta vital del animal, el comportamiento es una capacidad existentiva que involucra al ser en aras de algo. Pero retornemos a nuestro ejemplo: puedo tener la vivencia del tablero como estando en una mala posición porque no puedo hacer con él lo que debo llevar a cabo (concretamente, escribir en él de una manera tal que los estudiantes puedan verlo). Pero yo puedo experimentar la insuficiencia de mi habilidad de usarlo adecuadamente, solo porque estoy comprometido en cierto tipo de comportamiento - esto es, porque hago lo que hago en aras de ser un profesor. Esta no es una habilidad o capacidad, sino una "posibilidad" existentiva; algo cuyo ejercicio requiere que yo sea consciente de mí mismo en cuanto que posiblemente tenga éxito o fracase. De este modo el comportamiento es una especie de norma-regulada tratando de ser. Al ejercitar mi capacidad para ser

${ }^{15}$ Traducción de Heidegger de noein en ¿Qué significa pensar? (1968, p. 207; 2005, p. 170). La versión alemana (Heidegger, 1971, p. 172) dice: "nous bedeutet das Sinnen, das etwas im Sinn hat und sich zu Herzen nimmt". Acerca de todo esto, cfr. Crowell (2016). 
un profesor, estoy tratando de cumplir con los estándares que configuran lo que es o significa ser un profesor. Si no estuviera normativamente orientado de esta manera, el tablero podría no presentarse a sí mismo como en una mala posición. De acuerdo con Heidegger, ningún animal trata de ser una abeja, un delfín, o un "humano", aunque todos ellos puedan tener éxito o fracasar al hacer lo que su estructura instintiva les provee con una capacidad para hacerlo. Contrariamente, el comportamiento está esencialmente orientado hacia una medida de éxito o fracaso, que aunque indefinida puede ser algo que yo puedo tratar de satisfacer. Solamente porque el comportamiento implica este aspecto normativo, los entes pueden estar ahí para mí en cuanto tales -esto es, en tanto entes, en tanto lo que ellos son y en tanto eso que son en realidad. El comportamiento es el origen de la "multiplicidad indivisa" expresada en la cópula (Heidegger, 1995, p. 333; 2007, p. 396).

La idea de que el comportamiento (nous) fundamenta el significado (el en cuanto), es central en la distinción heideggeriana entre el homo sapiens y el "Dasein en nosotros", y así también en la diferencia entre bioposthumanismo y posthumanismo fenomenológico. Desde el punto de vista fenomenológico, el tipo de expresión que puede ser verdadero $o$ falso depende del comportamiento. Como una realización que incorpora una norma, es posible únicamente dentro de la dimensión de algo que nosotros estamos tratando de ser. Por consiguiente, esta habilidad no es una "capacidad", y no puede ser concebida como una función del código autopoiético del animal humano (Heidegger, 1995, p. 337; 2007, pp. 400-401). Heidegger caracteriza esta distinción con el término "libertad". El comportamiento es "ser libre para los entes en cuanto tales", precisamente porque su propio ser es normativamente la cuestión que él trata de llevar a cabo.

El bioposthumanismo denomina este "estar-en-cuestión" la "virtualidad" del significado: el hecho de que todo objeto deseado implique un horizonte de posibilidad y, de esta manera, la "presentación simultánea de actualidad y posibilidad" (Wolfe, 2010, p. 16). Pero esto traza un código autopoiético a este fenómeno, cuyas normas (si hay normas) no pueden convertirse en un conflicto al interior del sistema de significado. De acuerdo con Heidegger, sin embargo, si las medidas son esenciales para el tipo de posibilidades del horizonte que acompañan la presentación de un objeto, y no pueden estar explícitamente en riesgo por el sistema en sí mismo, éste no puede ser entonces un sistema de significado en lo absoluto. El tipo de posibilidad requerido para la experiencia de algo en tanto que algo demanda libertad, un 
“(...) libre ofrecerse, dejándose vincular, a aquello que está dado como ente" (Heidegger, 1995, p. 342; 2007, p. 406). Tal libertad no es una facultad misteriosa que nos saca del orden causal; es un "estar abierto a los entes" por medio de la necesidad de medidas normativas en tanto que normativas. En sentido heideggeriano, la libertad está siempre demarcada, pero tal demarcación es totalmente diferente al perturbamiento autopoiético del animal. El "mundo" es la diferencia entre una aprehensión normativamente demarcada de entes en cuanto tales y una "apertura a" perturbada.

La fuerza de este argumento puede ser observada si regresamos al análisis realizado por Heidegger acerca del enunciado. El enunciado "a es b" es un enunciado únicamente si, afirmándolo, estoy orientado hacia la posibilidad de la verdad $o$ la falsedad -esto es, orientado hacia una distinción normativa en la cual las cosas en el mundo son reconocidas como medidas de lo dicho por mí. Pero ¿cómo es posible esto? ¿Cómo se convierten las cosas en medidas? Un sistema autopoiético puede tener "interferencia" - 0 , en términos de Heidegger la 'vida', en tanto que perturbamiento, puede ser tomada por las cosas de modo que éstas estimulen sus capacidades-, pero carece de recursos para virtualizar su entorno a través de la medida. De este modo carece de una condición para el significado (mundo). El comportamiento del Dasein provee la condición que hacía falta. El comportamiento particular que hace una enunciación (un "señalar que puede ser verdadero $o$ falso"), por ejemplo, implica una "(...) adecuación a (...) y una vinculación a (...), de tal modo que aquello con lo que se establece la vinculación, lo ente, se manifiesta en su vinculatoriedad" (Heidegger, 1995, p. 339; 2007, p. 403). De esta manera el comportamiento lleva a cabo el espacio de juego (Spielraum) que abre lugar a una verdad $o$ falsedad regida normativamente.

Esto puede ser ilustrado regresando a nuestro ejemplo, para con ello mostrar cómo el comportamiento suscita la articulación interna de la cópula. Ya hemos visto que el tablero puede presentarse estando en una mala posición únicamente porque yo estoy tratando de hacer uso de él con el objetivo de ser un profesor. Tratar de ser un profesor requiere que yo sea libre, es decir, que sea capaz de "dejarme vincular" por las medidas de la enseñanza (Heidegger, 1995 , p. 342; 2007, p. 406). Pero al dejarme a mí mismo ser regido (ser vinculado) de esta manera, este "dar la medida" necesariamente "(...) se transfiere de entrada, en el sentido del comportamiento que se deja vincular, a lo ente, de modo que en éste se regula la adecuación y la inadecuación" (Heidegger, 1995 , p. 342; 2007, p. 406). Por consiguiente, el tablero puede mostrarse 
como estando en mala posición porque los entes que hacen parte del ámbito del enseñar tienen una virtualidad $u$ horizonte de actualidad-posibilidad muy específica y normativamente regida. Los tableros, se supone, existen para estar de esta o aquella manera; su "ser-qué" les provee la medida. Este ("serqué") no cumple la medida a causa de algún defecto propio, sino únicamente porque yo mismo me he dejado vincular por las medidas de la enseñanza. Finalmente, mi enunciado de que el tablero está en mala posición establece, como su medida, el ser de verdad de la cosa en mala posición: la cosa misma ("ser en el sentido de verdad") mide mi comportamiento debido a que en la enunciación actúo en aras de señalar lo que en verdad es la cosa; esto es parte de lo que está en juego en aquello que estoy tratando de ser. Puesto que todo comportamiento está vinculado con una distinción normativa entre éxito y fracaso, Heidegger puede denominarlo "(...) manifestabilidad antipredicativa, o mejor, verdad prelógica" de las cosas (1995, p. 341; 2007, p. 405).

La explicación que Heidegger hace del significado se convierte así en algo que elude totalmente el concepto de sistema psíquico de la teoría de sistemas, concretamente, la orientación hacia la dimensión de la primera persona. La posibilidad intrínseca de la estructura del "en tanto que" (Heidegger, 1995, p. 335; 2007, pp. 338-339) depende del comportamiento. El comportamiento implica el hecho de ser en aras de algo, en el que el ser humano se mantiene junto con otras cosas que le permiten convenir (come into agreement) con ellas (Heidegger, 1995, p. 308; 2007, pp. 368-369), para aprehenderlas en lo que ellas son. Este 'convenir' no está, sin embargo, simplemente dado: al mantenerme en mi comportamiento junto con las cosas, puedo fracasar al (buscar) aprehenderlas en lo que son. Todo esto explica por qué Heidegger puede sostener que "el «ser» y el «en tanto que» apuntan al mismo origen" (1995, p. 333; 2007, p. 397): la necesidad normativa del comportamiento es la raíz común de ambos (2007, p. 402), y ésta constituye la diferencia ontológicamente decisiva entre el anillo del animal y el mundo.

De esta manera (en 1929/1930), Heidegger no encuentra en la posesión del lenguaje $^{16}$ la diferencia entre seres humanos y animales. Más bien sitúa a

\footnotetext{
${ }^{16}$ McNeill (1999, p. 234) reconoce este "arraigo del logos" -y esto incluye "cada logos"- "en el acontecer del mundo". Aunque también sostiene que el "traer a la presencia" que el Dasein en nosotros cumple -algo que el animal es incapaz de hacer- es una función del lenguaje: "Al ser traídas al lenguaje, las cosas también logran, en primera instancia, una cierta resistencia y permanencia de la presencia; pueden estar frente a nosotros (...) en varios tipos de presencia a la mano" (1999, p. 239). Pero mientras que la presencia-a-la-mano puede requerir del lenguaje, esto no es "lo que nosotros denominamos ser". Puesto que una condición del lenguaje en sí mismo es que el Dasein
} 
ésta como previa al lenguaje, en una especie de aprehensión, regulada por normas, que forma una unidad. El significado, el rasgo fundamental del mundo, es exclusivamente este tipo de aprehensión. En contraste con la estructura "indicativa" de la comunicación del animal, el comportamiento lingüístico no deriva de un sistema autopoiético psíquico o social, sino del "Dasein en nosotros". Y puesto que el Dasein en nosotros nunca ha sido animal, no está expuesto a la segunda finitud que el bioposthumanismo asegura que es ignorada por la tradición fenomenológica: el sometimiento del significado al juego de la iteración y del signo, del "tecnicismo y el mecanicismo a-humano" de los sistemas de la semiótica ${ }^{17}$. Por supuesto, la comunicación del Dasein, su empleo de signos, no puede evitar las coacciones de la semiosis: Sorge no sirve para "fijar el referente" más allá de todo juego de significantes. Pero esto no debilita la tesis fenomenológica de que el cuidado, la orientación hacia la medida en un ser cuyo propio ser es un problema para él, es el fundamento de una diferencia ontológica entre el entorno del animal y el mundo.

Pero si la orientación hacia una norma destaca en todos sus comportamientos - es decir, si la libertad de (tratar de) ser algo pertenece al Dasein en cuanto tal-, ella no relata aún la historia completa acerca de cómo el "es" y el "en tanto que" surgen con tal comportamiento, ya que el origen de la unidad indiferenciada que se expresa en la cópula (el significado del "ser") no puede ser rastreado en ningún comportamiento específico, como cuando se trata de ser un padre o un filósofo ${ }^{18}$. La manifestación de los entes "en cuanto tal" y "en tanto que un todo" (mundo), está cimentada en un comportamiento fundamental y en un temple de ánimo fundamental.

debe ser capaz de tomar una posición, orientarse a sí mismo hacia un tipo de medida a la cual se vincule -por lo menos para el Heidegger de la "década metafísica". McNeill parece introducir en sus análisis la concepción posterior del lenguaje en Heidegger, aunque esta concepción no tiene nada que ver con el tipo de crítica semiótica que se constituye en el punto de discusión entre Heidegger y los bioposthumanistas.

${ }^{17}$ Esta tampoco es la posición expuesta por Heidegger en la crítica derridiana, según la cual la fenomenología está incapacitada por la operación de "iteración" que pertenece a todos los sistemas de signos. En contraste con la imagen fonocéntrica criticada por Derrida, Heidegger concibe que no es el caso en el que "el hombre tiene emisión de voz que, en adición, tiene un significado conectado a ésta" -digamos, por alguna intención interna de la consciencia (Heidegger, 2007, p. 367). Más bien, es porque nuestra esencia aprehende [el nous, es decir, la libertad en el comportamiento] el significado que tienen nuestras emisiones.

${ }^{18}$ En un interesante pasaje, Heidegger hace referencia a lo que parece ser una implicación de su análisis; concretamente, que no hubo Dasein (entendimiento del ser) antes de que los seres humanos comenzaran a filosofar. Rechaza sin embargo esto (2007, pp. 420-421).

Crowell, S. (2020). Nunca hemos sido animales. El posthumanismo de Heidegger. 


\section{La diferencia ontológica ${ }^{19}$}

En Ser y tiempo Heidegger había analizado el "comportamiento fundamental" como muerte existencial, la capacidad-de-ser radicalmente en primera persona "sí-mismo" del Dasein, incluso cuando su habilidad-para-ser-algo (profesor, padre) fracasa. En el curso de 1929/30 Heidegger llama a esta capacidad ser 'sí-mismo': "el ser libre en un sentido original" (Heidegger, 1995 , p. $343 ; 2007$, p. 407). La libertad originaria no es un comportamiento guiado por las medidas de alguna identidad específica, sino por la responsabilidad de medir en cuanto tal. Ser responsable por ser es lo que está ahí por ser Dasein; éste provee "la medida para toda medición" (Heidegger, 1995, p. 346; 2007, p. 410). Por esta razón él es la base sobre la cual puede aparecer 'lo que es' en tanto ente (ente en cuanto tal). Para ocupar esta dimensión del "en tanto que", esta dimensión de responsabilidad -el comportamiento fundamental de la libertad originaria-, se debe asumir "(...) sobre nosotros el esfuerzo de transformar al hombre (...) en una existencia más original": el Dasein en nosotros (Heidegger, 1995, p. 350; 2007, p. 415). De esta manera, este posthumanismo fenomenológico no concibe al ser humano ni al Dasein como la medida; más bien, el Dasein está obligado a la medida, que precisamente en tanto que medida, trasciende su "poder"20.

Esto se evidencia también en el "temple de ánimo fundamental", que junto con el comportamiento fundamental forma parte esencial de la responsabilidad. En la disposición afectiva de la angustia (o en el "aburrimiento" fundamental de 1929/30), los entes en tanto totalidad se hacen fenomenológicamente patentes en su peculiar "integridad"21. Esto no significa que la totalidad de los entes esté presente para mí a la mano. Más bien significa que

\footnotetext{
${ }^{19}$ Para una discusión detallada de los análisis mencionados aquí, cfr. Crowell (2013), especialmente la parte II.

${ }^{20}$ Obsérvese la discusión en Ser y tiempo: "El sí-mismo que, como tal, tiene que poner el fundamento de sí mismo, jamás puede adueñarse de éste" (Heidegger, 1962, p. 330; 1997, p. 279). La medida tampoco puede ser equiparada con el Ser (Sein) en sí mismo, puesto que "el «ser»y el «en tanto que» apuntan al mismo origen", es decir, el comportamiento. La medida hacia la cual el comportamiento está orientado y que trasciende su poder está, así, "más allá del ser".

${ }^{21}$ Tal como en todo comportamiento, los entes "en cuanto tal" son de alguna manera el asunto más importante. De esta manera, en todos los temples de ánimo, los entes "en tanto que un todo" importan de algún modo. Pero esta estructura se hace evidente gracias al "sistema" (Dasein), cuya estructura está solamente en ciertos comportamientos y modos distintivos que son, por consiguiente, metodológicamente privilegiados. Acerca de la distinción metodológica del Angst, cfr. Heidegger (1962, pp. 228ss.; 1997, p. 206).
} 
lo que es, en tanto un todo, importa de alguna manera para mí, "previo a toda toma de postura" (Heidegger, 1995, p. 353; 2007, p. 419). En contraste con el carácter selectivo de la estructura de impulso del animal, el temple de ánimo fundamental es un tipo de "cumplimiento", el "predominante" del mundo (Heidegger, 1995, p. 351; 2007, p. 416).

Heidegger llega a este punto haciendo referencia a una objeción de la que ha sido objeto por parte de generaciones de filósofos. Si yo rastreo el origen de la mala posición del tablero en relación con mi comportamiento (por ejemplo, mi intento de ser un profesor), ¿no es esto constituirme en el sentido de que su mala posición es relativa a mi propia posición? ¿No es "subjetivizar el significado al que el ente en cuestión está direccionado? Heidegger responde que el tablero está en mala posición no solamente en relación a mi posición. Él está "en sí mismo" en mala posición en relación con "toda" el aula de clases (1995, p. 344; 2007, p. 408). Mi intento de ser algo, en sí mismo, no configura el mundo; lo que lo configura es mi intento, junto con la manera en que las cosas -en tanto que un todo- "prevalecen" o hacen que se logre esto de forma efectiva. Otorgando importancia al develamiento de una esfera en la cual estoy "arrojado" -pero dado que tal arrojamiento es inseparable del comportamiento-, mi esfera o mundo no puede ser visto como una versión del perturbamiento del anillo del animal ${ }^{22}$. En lugar de ello el temple de ánimo fundamental implica que las medidas a las cuales se ata el comportamiento, y por las cuales yo-mismo soy responsable, no son meros datos dados

\footnotetext{
${ }^{22}$ Por esta razón no puedo estar de acuerdo con la propuesta de McNeill de que nuestro temple de ánimo atestigua nuestra propia forma de "perturbamiento" (animal). Después de citar un pasaje en el que Heidegger declara que "el temple de ánimo justamente nos hace manifiesto lo ente en su totalidad", no como un objeto sino como una forma de "ser traído a la presencia (...) y eso significa a la manifestación de la existencia en cuanto tal, según se halla en cada caso en medio de esta totalidad". McNeill sostiene: "la primacía del temple de ánimo en la revelación de nuestro propio ser conlleva a que la naturaleza viviente, al mantenernos apresados [mi énfasis], nunca sea reducible a un objeto de contemplación teórica. En lugar de esto, es decir a lo que siempre estamos atados con antelación; que nos ata [mi énfasis] previo a todas nuestras actividades y acciones" (1999, p. 236). Pero en ninguna parte del pasaje citado (y en ninguna otra parte que yo conozca) Heidegger dice que la naturaleza ("nuestro ser", el Dasein en cuanto tal) nos mantenga apresados. El tipo de atadura de los entes en tanto que un todo que pertenece al temple de ánimo, no menos que el tipo de atadura como tal que pertenece al comportamiento debe ser pensado en términos de la diferencia ontológica entre el homo sapiens y el Dasein. No podemos tratar lo que el temple de ánimo revela simplemente como un tipo de hecho dado; la marca de nuestra "pertenencia" a "la naturaleza viva", ni podemos contrastar este aspecto de nuestro ser con otro aspecto "histórico". El Dasein no es "el animal histórico" más de lo que es "el animal racional".
} 
(das Man) ni simples medidas mías para inventar. Ellas se ponen en juego en aquello que estoy haciendo dentro del todo que impera.

La unidad original del comportamiento y del temple de ánimo fundamental -el cimiento para la diferencia ontológica entre ser y entes en cuanto tales, y en tanto que un todo- explica por qué el Dasein no está sujeto a la objeción de que un sistema autopoiético no pueda operar de acuerdo con su código autorreflexivo y simultáneamente identificar la lógica de esta operación del código. Puesto que el Dasein en nosotros no es vida o animalidad, opera de acuerdo con normas, pero no a la luz de ellas. Más bien es el margen de acción en el cual todo código o medida es puesto en discusión. El "código" del Dasein es un problema por sí mismo si se insiste en ponerlo de esa manera. De esta forma, ni la primera finitud de la encarnación (muerte, sufrimiento) ni la segunda finitud de la diferencia semiótica pueden llegar al Dasein en nosotros. Nosotros, Dasein, nunca hemos sido animales.

¿Qué distinción genera esta "diferencia ontológica" en relación a las preguntas (sobre todo a las éticas) que motivan el bioposthumanismo? ¿En qué sentido esta diferencia es normativamente más importante (constituyendo un abismo) que todas las otras diferencias que separan al homo sapiens y a las otras especies de animales? En respuesta a estas preguntas debe decirse que esta diferencia es solo más importante dados los intereses de la filosofía (o "teoría"). Si lo que tenemos que hacer es encontrar nuestro camino en la oscuridad, entonces la capacidad del murciélago, debido a su radar de navegación, bien puede ser más importante que la diferencia ontológica. Pero si lo que está en riesgo es lo que nosotros debemos entender por ética -por nuestra responsabilidad con nuestro comportamiento hacia los otros (incluyendo otros animales)-, entonces estamos confrontados con una pregunta de riesgos y medidas como tal. Si Heidegger está en lo correcto, tal preocupación está presente solo en los entes con la estructura del Dasein; entes que pueden asumir responsabilidad en relación con la medida, porque en su comportamiento aquello que significa 'ser' es (normativamente) el problema a discutir.

Afirmar con el bioposthumanismo (siguiendo a Bentham), que la pregunta ética no es "¿pueden ellos hablar o pueden ellos razonar, pero no pueden sufrir?” (Wolfe, 2010, p. 81), es tomar una posición, decidir (krinein) lo que la medida de nuestro ser debe ser. Esto ya opera, por tanto, dentro de la diferencia ontológica, y se erige a sí mismo como un modelo acerca de la mejor 
manera de continuar nuestro trato con los animales. Pero la preocupación que motiva al bioposthumanismo no puede de ninguna manera surgir desde el sistema que teoriza y deconstruye. Tomar el "sufrimiento" como una consideración normativamente relevante (y de hecho predominante) solamente es posible por parte de nosotros, que nunca hemos sido animales. Nosotros -el Dasein en nosotros- no podemos escapar de la responsabilidad a través del recurso a una teoría que prescinda de la filosofía en general, con el fin de plantear preguntas críticas a "nosotros" en nombre de "otro animal". El post-humanismo de Heidegger viene tanto antes como después del animal humano, y a pesar de su afirmación al final del curso impartido entre 1929 y 1930, que sostenía que "También la filosofía trascendental tiene que caer" (1995, p. 359; 2007, p. 425), la fenomenología trascendental es la única manera de dar sentido a este tipo de asuntos.

\section{Referencias}

Barbaras, R. (2006). Desire and Distance: Introduction to a Phenomenology of Perception. (Trad. Milan, P). Stanford: Stanford University Press.

Crowell, S. (2001). Husserl, Heidegger, and the Space of Meaning: Paths Toward Transcendental Phenomenology. Evanston: Northwestern University Press.

Crowell, S. (2013). Normativity and Phenomenology in Husserl and Heidegger. Cambridge: Cambridge University Press.

Crowell, S. (2014). "Transcendental Life." Phenomenology and the Transcendental. Heinämaa, S., Hartimo M., and Miettinen, T (Eds.), Phenomenology and the Transdendental (pp. 21-48). London: Routledge.

Crowell, S. (2016). What Is It to Think?. Breyer, Th. and Gutland, Ch. (Eds.), Phenomenology of Thinking (pp. 183-206). London: Routledge.

Derrida, J. (1994). Márgenes de la filosofía (Trad. C. González Marín). Madrid: Cátedra.

Figal, G. (2010). Objectivity. The Hermeneutical and Philosophy. (Trad. George, Th). Albany: SUNY Press. 
Foucault, M. (2010). Las palabras y las cosas: una arqueología de las ciencias humanas. (Trad. Frost, E. C). México: Siglo XXI.

Heidegger, M. (1962). Being and Time. (Trad. Macquarrie, J. and Robinson, E). New York: Harper \& Row.

Heidegger, M. (1968). What Is Called Thinking?. (Trad. Gray, J. G). New York: Harper \& Row.

Heidegger, M. (1971). Was Heißt Denken? Tübingen: Max Niemeyer Verlag. Heidegger, M. (1972). On Time and Being. (Trad. Stambaugh, J). New York: Harper \& Row.

Heidegger, M. (1993). Letter on Humanism. Basic Writings. (Trad. Krell, D. F). (pp. 193-242). New York: Harper Collins.

Heidegger, M. (1995). The Fundamental Concepts of Metaphysics: World, Finitude, Solitude. (Trad. McNeill, W. and Walker, N). Bloomington: Indiana University Press.

Heidegger, M. (1997). Ser y tiempo. (Trad. Rivera, J. E). Santiago de Chile: Editorial Universitaria.

Heidegger, M. (2000). Tiempo y ser. (Trad. Garrido, M., Molinuevo, J. L. y Duque, F). Madrid: Tecnos.

Heidegger, M. (2005). ¿Qué significa pensar? (Trad. Gabas, R). Madrid: Trotta.

Heidegger, M. (2006). Carta sobre el Humanismo. (Trad. Cortés, H. y Leyte, A). Madrid: Alianza.

Heidegger, M. (2007). Los conceptos fundamentales de la metafisica: mundo, finitud, soledad. (Trad. Ciria, A). Madrid: Alianza.

Lawlor, L. (2006). The Implications of Immanence: Toward a New Concept of Life. New York: Fordham University Press.

Maturana, H. y Varela, F. (1996). El árbol del conocimiento: las bases biológicas del conocimiento humano. Santiago de Chile: Editorial Universitaria. 
McNeill, W. (1999). Life Beyond the Organism: Animal Being in Heidegger's Freiburg Lectures 1929-30. Animal Others: On Ethics, Ontology, and Animal Life (pp. 197-248). Albany: State University of New York Press.

Toadvine, T. (2009). Merleau-Ponty's Philosophy of Nature. Evanston: Northwestern University Press.

Weigelt, C. (2002). The Logic of Life: Heidegger's Retrieval of Aristotle's Concept of Logos. Stockholm: Almqvist \& Wiksell International.

Wolfe, C. (2010). What is Posthumanism? Minneapolis: University of Minnesota Press. 

Reseña Bibliográfica

Cuestiones de Filosofía

ISSN: 0123-5095

E-ISSN: 2389-9441

Vol. $6-\mathrm{N}^{\circ} 26$

Enero - junio, año 2020

pp. 195-199

\section{Valencia, A. (2008). Conversaciones con Estanislao Zuleta. Medellín: Hombres Nuevos Editores.}

Jorge Alberto Valcárcel Guzmán ${ }^{1}$

Universidad Pedagógica y Tecnológica de Colombia

1 Estudiante de la Escuela de Filosofía de la Universidad Pedagógica y Tecnológica de Colombia. Miembro del grupo de apoyo del Centro Internacional de Estudios sobre el Nihilismo Contemporáneo (CeNic).

Correo electrónico: jorge.valcarce101@uptc.edu.co 


\section{Introducción}

La obra titulada Conversaciones con Estanislao Zuleta surge de varios análisis que hace el filósofo colombiano a lo largo de diversas entrevistas, concedidas en la última década de su vida. En las primeras secciones, destinadas a una relación entre la filosofía y la literatura, es posible apreciar cómo para Zuleta el punto de referencia privilegiado y más significativo de su trabajo académico es la literatura. A partir de esta relación Estanislao Zuleta analiza problemas filosóficos en el marco del contexto colombiano y de la filosofía occidental, tomando como base experiencias propias, es decir, no acudiendo a la crítica académica convencional que se hace tradicionalmente a los problemas filosóficos. Y es que para Antonio Valencia el horizonte de reflexión de Estanislao Zuleta:

No se inscribe de manera fácil en las coordenadas convencionales para la creación y el desarrollo del trabajo intelectual de nuestro medio (...) sino en referencia crítica a la meditación de un tercer elemento: la exégesis de los autores, el estudio de las situaciones humanas que la literatura ofrece, la crítica del prejuicio, la revaloración de la tradición, el análisis de las representaciones concretas de la vida cotidiana (Valencia, 2008, p. 7).

Conversaciones con Estanislao Zuleta pretende abordar una larga serie de cuestiones filosóficas y literarias estudiadas por el filósofo colombiano, y expresadas abiertamente a través de las conversaciones traídas por Valencia en el texto. El libro busca reconstruir (en orden temático) el trabajo intelectual que realizó Zuleta en su larga trayectoria académica, y sirve cómo testimonio de su enseñanza así como de su manera de reflexionar, similar (cómo lo menciona Valencia) a un diálogo socrático, ya que en él predomina el dialogó frente a la producción escrita, no muy extensa en su caso.

Entre sus reflexiones encontramos la idea de amor, que abarca más que una mera definición conceptual. El amor recorre, según Zuleta, toda una serie de hechos en el margen de las relaciones de la vida diaria ${ }^{2}$, y es esto, para el filósofo colombiano, aquello que hace del amor una experiencia tan significativa, aunque a su vez, tan incomprensible. La razón de esta caracterización es porque el amor hace afable las condiciones de la existencia, dado que nos permite vivir plenamente en el mundo, logrando establecer una consonancia

\footnotetext{
2 Conocer a una persona, identificarse con alguien, establecer una conversación amena, incluso, conocer un libro, está permeado todo por la idea de amor.
} 
con las entidades que habitan en él, y esto se logra mediante la creación de un vínculo, de un redescubrimiento de la vida, que nos separa de la angustia de estar ante la vastedad del mundo. Sin embargo - dice Zuleta (y nos muestra Valencia) en discusión con Luis Antonio Restrepo ${ }^{3}-$, es frecuente que la idea de amor (y de su relación con la existencia) se nuble bajo la falta de comprensión de las experiencias que cada día vivimos, puesto que no logramos entender que la vida puede ser magnífica por el simple hecho de ser (es decir, de tener la posibilidad de vivir), sin tener que "lograr" o "cumplir" un propósito magnánimo o redentor.

Reflexionando acerca de la existencia, Zuleta aborda la figura de $J_{o s e ́}$, de Tomas Mann, señalando que este personaje -quien se rige bajo la idea de búsqueda de una vida mejor - termina nublando el sentido del mundo en sí mismo, y por ello no es capaz de ver el presente, es decir, aquello que estamos viviendo en el instante. El filósofo colombiano -en la recopilación de Valencia- sostendrá que aquello que resulta importante en nuestras vidas no son los acontecimientos, sino el significado que damos a esos acontecimientos. Para él la condición del existir está fuertemente caracterizada en una mítica; la identificación que hacemos con los otros no se queda en el ámbito de la realidad, sino en aquello que nosotros suponemos como real, al brindarle un significado por medio de las relaciones que establecemos.

Los anteriores planteamientos resuenan, en gran medida, en uno de los pilares de la filosofía de Nietzsche: su consideración del instante, cuando hace referencia a que el presente es el portal en que pasado y futuro se encuentran. Siendo indiscutible la influencia de Nietzsche en Thomas Mann y, a su vez, de ellos en Zuleta, es notable su reflexión acerca del personaje de Hans Castorp, ya que la vida de éste simboliza un suceso que va más allá de la experiencia de un individuo hacia la búsqueda de otras identidades. En esta afirmación, se hace evidente la afinidad entre ambos pensadores, que para Zuleta comparten la importancia de re-significar la voluntad de vivir. Sin embargo, podemos pensar que Zuleta al mencionar la ironía de Thomas Mann acerca de la obra de Nietzsche, también intenta ejemplificar claramente las diferencias entre el pensamiento del escritor y del filósofo, que pueden

3 Entrevista realizada en Bogotá en 1988 por Luis Antonio Restrepo, profesor del departamento de Historia de la Universidad Nacional de Colombia, sede Medellín.

4 De la obra José y sus hermanos (Joseph und seine Brüder). 
quedar reflejadas en sus consideraciones acerca de la muerte. Pero también habría que ver con mayor detenimiento hasta qué punto Zuleta responde solamente a las preguntas de estas entrevistas, en lugar de estar haciendo una comparativa detallada entre Nietzsche y Thomas Mann.

En torno a la cuestión del sentido de la posibilidad -en conversación con Ramón Pérez Mantilla ${ }^{5}$-, Zuleta dirá que no podemos limitar el impacto social de la literatura únicamente a su contexto geográfico, ya que parte de la grandeza de ésta es precisamente permitir un acercamiento a diferentes formas de pensamiento, sin importar su lugar de origen, sin pasar no obstante por alto las consideraciones de los movimientos del saber, en el instante en que fueron escritas las obras. Para Zuleta la obra de autores como Thomas Mann o Robert Musil permiten con gran finura describir, por ejemplo, a la sociedad colombiana. En la obra El hombre sin atributos, de Musil, se encuentran caracterizadas las manías de la mentalidad capitalista y positivista. Musil logra hacer una crítica al positivismo ferviente de la época, que de acuerdo con él atenta contra el sentido de la vida.

Zuleta dirá, también, que la obra de Robert Musil ilustra con gran acierto las condiciones del mundo capitalista, en conjunto con las prácticas cotidianas de los sujetos permeados por tal mundo, puesto que los personajes de su obra se limitan a contrastar sus percepciones únicamente con los fundamentos estadísticos que les proporciona el mundo positivista. Sin dejarse afectar significativamente por algo más allá de la utilidad, su realidad es entonces frágil, porque las afecciones dependen enteramente de lo que los modelos le imponen. Como menciona Zuleta, "en última instancia llega a mostrar que la sociedad capitalista, en su conjunto, más bien juega con la psicosis que con cualquier otra cosa" (Valencia, 2008, p. 41) porque, en ese juego, el sentido de la existencia, tal como nos relata Musil, carece de una importancia mayor que la que brinda el capitalismo y el positivismo (problema que ve el filósofo colombiano en la sociedad de nuestro país). Zuleta dirá que el hombre sin atributos es aquel que no deja atribuirse una identidad predeterminada; explora, con el gran peso que ello conlleva, el sentido de su propia vida, y encuentra así el sentido de su posibilidad.

\footnotetext{
5 Entrevista llevada a cabo en la ciudad de Cali en 1981, con la participación de Ramón Pérez Mantilla, profesor de la Universidad Nacional, Ciro Roldán, también profesor de la Universidad Nacional y Jaime Galarza, profesor de la Universidad del Valle.
} 
Parte del problema de encontrar un sentido de la posibilidad, es que hay una brecha entre el saber (como un conocimiento significativo) y la cotidianidad, puesto que estos dos fenómenos parecen no relacionarse. Para el filósofo colombiano, la educación en el siglo XX se divide en ramas (especializaciones) que restan significación al mundo. Y es que el saber no se especializa; se entrama para intervenir a través de varios saberes, así como nosotros en tanto individuos vivimos de esa manera: en múltiples devenires que afectan de diversas formas nuestro actuar. Es por ello que hasta que no se lleve a cabo un cambio estructural a nuestro sistema educativo, el problema de la educación en Colombia seguirá presente.

El estado de la educación puede relacionarse con la posición de Estanislao Zuleta frente a la forma en que abordamos las cuestiones filosóficas, puesto que los planteamientos de autores tan enigmáticos como Nietzsche, Marx o Freud, no pueden leerse llanamente bajo una única concepción, pues de ser así sus obras solamente son trivializadas. Y aunque -como aclara Zuleta- es cierto (en el caso de Nietzsche, Heidegger, Kant) que los filósofos sufren de una inmodestia en la forma en que ellos exhiben con vehemencia sus logros, lo importante allí es analizar la forma en cómo ellos (al igual que otros pensadores) establecieron una relación sincera con el saber, es decir, consecuente entre un deseo de conocer y poner a discusión lo aprendido, sin caer en dogmatismos, en esferas aisladas o en conocimientos herméticos (cuestión que precisamente criticará a las corrientes de la filosofía contemporánea francesa), ya que para Zuleta el conocimiento no debe ser resultado de una mentalidad pasiva a la espera de una entidad exterior que le imponga "verdades", ya sea por argumentos de autoridad, por tradiciones o prejuicios.

El filósofo colombiano hace una apuesta por el saber más allá de la institucionalidad; presenta lo bello de la búsqueda en un diálogo interdisciplinar, porque es allí donde verdaderamente surge un afloramiento crítico de la formación en el conocimiento. 



\section{INDICACIONES PARA AUTORES IAS}

Cuestiones de Filosofía es una publicación que nace desde la Escuela de Filosofía y Humanidades, de la Facultad de Educación de la Universidad Pedagógica y Tecnológica de Colombia. Fue fundada en el año 1998; está dirigida a lectores interesados en reflexiones e investigaciones en el ámbito de la filosofía, la educación y las ciencias humanas.

Cuestiones de Filosofía es de periodicidad es semestral. Publica artículos de investigación originales, teorizaciones y reflexiones de carácter conceptual que indagan sobre diversos campos del saber y corrientes de pensamiento de la filosofía, la educación y las ciencias humanas y tiene por objeto difundir y visibilizar procesos investigativos, en apoyo al fortalecimiento de redes académicas a nivel regional, nacional e internacional, de esta forma, contribuir a la comprensión de nuestras sociedades y del pensamiento humano.

Los textos pueden ser presentados bajo modalidad de artículo de investigación científica, artículo de reflexión o artículo de revisión. También se tienen en cuenta otras modalidades de publicación, tales como artículo corto, reporte de caso, revisión de tema, cartas al editor, editorial y traducción. Actualmente se publican artículos y reseñas en español, portugués y, en determinadas ocasiones, inglés en todas las áreas de la filosofía. También se reciben traducciones al español de textos que hayan perdido los derechos de autor o cuyos derechos de publicación hayan sido comprados o cedidos por quien los posee al traductor y, por extensión, a Cuestiones de Filosofía.

Con el objetivo de mejorar la calidad científica y editorial de la revista, los artículos son evaluados en primera instancia por el comité editorial, en cual garantiza la pertinencia del tema y del objeto de la investigación, así como el cumplimiento de los requisitos exigidos para cada modalidad de publicación. Una vez efectuado este proceso, los artículos son enviados a dos (2) evaluadores externos quienes valoran su aporte conceptual, teórico y metodológico al campo de estudio. Aquellos que sean aceptados por los evaluadores y corregidos por los autores, serán publicados en un plazo de tres meses contados a partir de la fecha de aprobación final. La presentación de textos, reseñas y demás son totalmente gratuitos.

Nota:

a. Se entiende que las opiniones de los autores son responsabilidad exclusiva de estos y que, por ende, no representan la posición frente a un tema ni de Cuestiones de Filosofía, ni de la Universidad Pedagógica y Tecnológica de Colombia. 
b. La aceptación de publicidad no implica la aprobación ni el respaldo de los respectivos productos o servicios por parte de Cuestiones de Filosofía o de la Universidad Pedagógica y Tecnológica de Colombia.

\section{Nota sobre costos y derechos de autor:}

Cuestiones de Filosofía no cobra a los autores el trámite de evaluación ni el proceso de preparación editorial de los manuscritos. Los autores conservan los derechos de autor sobre su producción y pueden reproducir y difundir su documento siempre y cuando otorguen el debido crédito a la revista.

\section{Secciones de la revista}

Filosofía del arte; trabajos de autor; filosofía clásica y contemporánea; humanidades; ética y filosofía política; educación; epistemología, filosofía de la ciencia y del lenguaje y reseñas. Todas las secciones están directamente ligadas a un desarrollo conceptual filosófico.

Estética y Filosofía del arte: La sesión busca dar cabida a las reflexiones en torno a la belleza, el fundamento de ésta, así como el quehacer artístico en sus múltiples manifestaciones. Lo anterior desde un horizonte que involucra interpretaciones hechas a este respecto desde la antigüedad hasta nuestros días.

Filosofía clásica y contemporánea: En lo que atañe a ésta sesión, conviene subrayar que ésta tiene como objetivo hacer visible las consideraciones hechas por los autores a propósito de los problemas tratados al interior de la filosofía clásica y contemporánea.

Autor: Esta sesión está abierta a todas las reflexiones cuyo eje central lo constituye el pensamiento de un autor en particular. Lo anterior con el objetivo de profundizar en la obra y los temas relevantes del dicho autor.

Epistemología, filosofía de la ciencia y del lenguaje: Aquí lo que se pretende es publicar artículos que tengan como fin la reflexión acerca de las dinámicas propias de las ciencias, las investigaciones en torno al conocimiento humano y los problemas del lenguaje.

Ética y Filosofía Política: esta sección busca dar a conocer las reflexiones más recientes entorno al ámbito de la ética y la filosofía política desde las perspectivas más diversas. Lo anterior en una época en la que muchos buscan dar respuestas a los problemas más enunciados de la humanidad, tomando como punto departida, precisamente, la pregunta misma por el Ser humano.

Si bien es cierto la revista Cuestiones de Filosofía es una publicación que tiene como fin la divulgación de los resultados alcanzados en investigaciones llevadas a cabo en el ámbito de la filosofía, acoge otro tipo de reflexiones provenientes de otros ámbitos. Tal es la razón de que la revista tenga una larga tradición en la 
publicación de artículos procedentes de otros campos ligados con las humanidades y la educación.

Humanidades y educación: Esta sección propone publicar resultados de investigaciones en torno a la filosofía de la educación, así como conceptualizaciones inscritas en el ámbito de las humanidades.

\section{Reserva de derechos y propiedad intelectual}

La recepción de un artículo no implica su aprobación ni un compromiso respecto a la fecha de publicación; sin embargo, el autor será informado permanentemente acerca del proceso de selección y edición de su propuesta. El texto presentado a la revista será de carácter inédito.

En cuanto a los derechos de propiedad intelectual, el autor autoriza, por medio de la firma de la carta de cesión de derechos de la revista, a copiar, reproducir, distribuir y publicar el artículo objeto de la cesión por cualquier medio digital o reprográfico. De igual modo, el envío de los escritos a la revista Cuestiones de Filosofía implica que sus autores ceden los derechos patrimoniales de ellos a la Universidad Pedagógica y Tecnológica de Colombia, que a su vez podrá cederlos a terceros con fines no lucrativos.

En cuanto a lo que respecta los derechos de propiedad intelectual de terceros, el autor manifiesta que respeta y se compromete a responder por cualquier acción de reivindicación, plagio u otra clase de reclamación que al respecto pudiera sobrevenir.

Cuestiones de filosofía, tiene la obligación de respetar los derechos morales de autor contenidos en el artículo 30 de la ley 23 de 1982. El editor se reserva el derecho de realizar modificaciones menores de edición, para una mejor presentación del trabajo.

Esta revista científica se encuentra registrada bajo la licencia Creative Commons Reconocimiento no comercial 4.0 Internacional. Por lo tanto, esta obra se puede reproducir, distribuir y comunicar públicamente en formato digital, siempre que se reconozca el nombre de los autores y a la Universidad Pedagógica y Tecnológica de Colombia. Se permite citar, adaptar, transformar, autoarchivar, republicar y crear a partir del material, para cualquier finalidad (excepto comercial), siempre que se reconozca adecuadamente la autoría, se proporcione un enlace a la obra original y se indique si se han realizado cambios.

La Universidad Pedagógica y Tecnológica de Colombia no retiene los derechos sobre las obras publicadas y los contenidos son responsabilidad exclusiva de los autores, quienes conservan sus derechos morales, intelectuales, de privacidad y publicidad.

El aval sobre la intervención de la obra (revisión, corrección de estilo, traducción, diagramación) y su posterior divulgación se otorga mediante una cesión de 
derechos, lo que representa que la revista y la Universidad Pedagógica y Tecnológica de Colombia, se eximen de cualquier responsabilidad que se pueda derivar de una mala práctica ética por parte de los autores. En consecuencia de la protección brindada por la cesión de derechos, la revista no se encuentra en la obligación de publicar retractaciones o modificar la información ya publicada, a no ser que la errata surja del proceso de gestión editorial. La publicación de contenidos en esta revista no representa regalías para los contribuyentes.

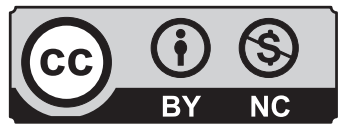

CUESTIONES DE FILOSOFIA is licensed under a Creative Commons Reconocimiento-NoComercial 4.0 Internacional License.

Creado a partir de la obra en http://revistas.uptc.edu.co/revistas/index.php/ cuestiones_filosofia/user/register

\section{Tipología de publicaciones}

\section{1) Artículo científico}

Es un informe que presenta los resultados originales de una investigación. La estructura generalmente utilizada contiene cuatro apartes importantes: introducción, metodología, resultados y conclusiones.

- Introducción: presenta el objeto de la investigación a partir de un desarrollo conceptual o teórico e incluye sus antecedentes históricos y la explicitación del propósito de la investigación.

- Método: describe los procedimiento para llevar a cabo la investigación.

- Resultados: Informa detalladamente los resultados.

- Discusión: analiza las implicaciones de los resultados.

- Referencias: mínimo (30) treinta.

\section{2) Artículo de revisión}

Es la sistematización, análisis y balance de lo investigado sobre un problema en partículas. Tiene por objeto dar cuenta de sus referentes conceptuales, metodológicos y epistemológicos, así como de los avances y tendencias en el campo de lo investigado. Se caracteriza por presentar una revisión analítica de por lo menos cincuenta referencias, a partir de las cuales el autor:

- Sintetiza las investigaciones previas para informar al lector acerca del estado actual de la investigación.

- Identifica las relaciones, contradicciones, vacíos e inconsistencias en la literatura. 
Los componentes de la literatura se pueden observar de diversas maneras. Po ejemplo mediante la similitud de los conceptos de las teorías de interés, las semejanzas metodológicas entre los estudios revisados o el desarrollo histórico del campo (APA. 2010, P.10).

3) Artículo teórico: Es un documento en el cual el autor apoya su investigación en la literatura existente para avanzar en una teoría. Se espera que los artículos teóricos amplíen y refinen constructos teóricos, analicen una teoría, señalen algunas o demuestren la ventaja de una teoría sobre otra. Las secciones de un artículo teórico -como los de una versión de literatura- pueden variar de acuerdo con el fin de su contenido.

4) Artículo metodológico: Este tipo de contribución presenta nuevos enfoques metodológicos, modificaciones de los métodos existentes o discusiones en torno a diferentes aproximaciones para el análisis de la información. En este caso, el uso de datos empíricos sirve solo como una ilustración de la aproximación metodológica que plantea el autor.

\section{Otros escritos}

- Artículo de reflexión. Documento que presenta resultados de investigación terminada desde una perspectiva analítica, interpretativa o crítica del autor, sobre un tema específico, recurriendo a fuentes originales.

En menor número se estudiará la posibilidad de realizar publicaciones del siguiente tipo:

- Artículo corto. Documento breve que presenta resultados originales preliminares o parciales de una investigación científica o tecnológica, que por lo general requieren de una pronta difusión.

- Reporte de caso. Documento que presenta los resultados de un estudio sobre una situación particular con el fin de dar a conocer las experiencias técnicas y metodológicas consideradas en un caso específico. Incluye una revisión sistemática comentada de la literatura sobre casos análogos.

- Revisión de tema. Documento resultado de la revisión crítica de la literatura sobre un tema en particular.

- Cartas al editor. Posiciones críticas, analíticas o interpretativas sobre los documentos publicados en la revista, que a juicio del Comité editorial constituyen un aporte importante a la discusión del tema por parte de la comunidad científica de referencia.

- Traducción. Traducciones de textos clásicos o de actualidad o transcripciones de documentos históricos o de interés particular en el dominio de publicación de la revista.

- Recensiones de libro. Resumen y una valoración personal de una obra cultural, literaria o artística. No pueden exceder ocho páginas, tamaño: carta, con márgenes derecho e izquierdo de 3 centímetros; formato: Word; fuente: Times New Roman 12 puntos; interlineado: espacio y medio. 
- Editorial. Documento escrito por el editor, un miembro del comité editorial o un investigador invitado sobre orientaciones en el dominio temático de la revista.

\section{Aspectos generales}

Una vez que el documento es enviado a nuestra dirección de correo o subido a nuestra página web, se confirmará con el autor o autores el plazo de publicación (este depende de la agenda de la revista que se establece de acuerdo con el orden de aprobación de los artículos). Una vez tengamos la respuesta, si esta ha sido afirmativa, el artículo es enviado a evaluación.

Los artículos presentados a Cuestiones de Filosofía deben ser originales e inéditos; no se aceptarán aquellos que hayan sido publicados en otros medios, sean impresos o en internet. Estos serán sometidos de modo anónimo a evaluadores pares, en un tiempo de 4 a 6 meses. Los momentos de evaluación de los textos son:

a. Una vez recepcionado el artículo, se acusa el recibido por correo electrónico y se informa al autor que ha comenzado el proceso de revisión.

b. El comité editorial verifica si el artículo cumple con los requerimientos básicos que Cuestiones de Filosofía presenta en las indicaciones para autores, y si tiene pertinencia temática, coherencia, claridad y las condiciones expuestas "sobre la presentación del texto" en el presente documento. Si el texto no cumple con los requerimientos básicos, será devuelto al autor con las sugerencias pertinentes.

c. Si el texto cumple con los requisitos será sometido a un proceso de evaluación doblemente ciego (anónimo) de pares expertos, quienes emitirán un concepto acerca de la calidad académica del material. Los pares evaluadores podrán sugerir cambios, con el fin de mejorar la calidad del texto en evaluación.

Las observaciones de los árbitros, así como las del Comité Editorial, se sugiere sean tenidas en cuenta por los autores, quienes harán los ajustes solicitados en un plazo no mayor a quince días.

Luego de recibir el artículo modificado, este será sometido a una nueva revisión y posteriormente se la informará al autor de su aprobación. El comité se reserva el derecho de aceptar los artículos que serán publicados en cada número.

La revista se reserva el derecho de hacer correcciones de estilo, que serán siempre consultadas con los autores. Durante el proceso de edición, los autores podrán ser requeridos por el editor para resolver inquietudes que se presenten tanto en el proceso de evaluación como en el de edición.

\section{Proceso de arbitraje}

Evaluadores: El Comité de Evaluadores está integrado por profesionales de amplia trayectoria y reconocimiento académico en los temas desarrollados en cada artículo. Los criterios de evaluación son: originalidad del contenido; rigor conceptual; 
aspectos metodológicos; claridad y coherencia, tanto en la argumentación como en la exposición; la calidad de fuentes y referencias bibliográficas; aportes al conocimiento; adecuada elaboración del resumen; pertinencia del título y de las conclusiones. Esto garantiza que los artículos publicados en la Revista Cuestiones de Filosofía sean de excelente calidad.

Confidencialidad: El proceso de arbitraje de los artículos se realiza en la modalidad de doble ciego, garantizando la confidencialidad y anonimato de autores y árbitros. En caso de discrepancia entre uno de los dos evaluadores, el texto será enviado a un tercer árbitro, cuya decisión definirá su publicación.

Tiempos de Evaluación: El proceso de evaluación de un documento tarda alrededor de seis (6) meses entre la convocatoria de los evaluadores, su aceptación y entrega del concepto. Este periodo puede ser mayor o menor y depende principalmente de la consecución del evaluador pertinente, su notificación de aceptación del evaluador y de su prontitud en el envío del concepto.

Decisión: Los artículos postulados serán sometidos a un proceso editorial que se desarrollará en varias fases. Los artículos recibidos son evaluados por los miembros del Comité Científico/Editorial, el Editor y el asistente editorial, quienes determinarán la pertinencia de su publicación. Una vez establecido que el artículo cumple con los requisitos temáticos, además de las normas editoriales indicadas en estas instrucciones, será enviado a dos árbitros (pares evaluadores) de la revista, quienes determinarán en forma anónima:

1. Publicable;

2. Publicable con ajustes; $y$

3. No publicable.

Cuando un artículo es catalogado como "publicable con ajustes", el o los conceptos que lo sustentan, son puestos a consideración del autor para que efectúe las reformas propuestas. El equipo de trabajo de la revista mantendrá informado al autor (es) durante las diferentes etapas del proceso editorial.

Entrega de correcciones: Si los conceptos de los pares sugieren modificaciones leves, los autores deberán ceñirse a una línea de tiempo que no exceda las ocho (3) semanas. Si un artículo recibe conceptos que suponen modificaciones sustanciales, y la Dirección estima que puede ser aceptado para un nuevo ciclo de evaluaciones, los autores tendrán que remitir sus ajustes en un periodo no mayor a 8 semanas. En todos los casos, se deberá entregar un reporte anexo relacionando los cambios que se efectuaron en la propuesta.

Rechazo de artículos: El propósito del proceso de evaluación en la revista Cuestiones de Filosofía, además de validar los avances en el conocimiento en nuestras áreas temáticas, es el de ofrecer una oportunidad a los autores de mejorar sus propuestas y afinar sus planteamientos, hacia la construcción de artículos más sólidos. 
En este sentido, esperamos que los autores se beneficien de los comentarios de los evaluadores cuando su documento resulta descartado para publicación. Aunque la revista está dispuesta a recibir artículos replanteados, se pide a los autores no volver a someter una versión corregida de un artículo rechazado antes de un lapso que oscila entre los tres (3) a seis (6) meses. El autor debe informar detalladamente al editor que el artículo ha sido reestructurado conforme a los comentarios previos. El editor informará a los autores del tiempo que deberán esperar, si expresan interés de volver a someter su artículo. El rechazo definitivo de un artículo, se dará cuando no corresponda a la línea editorial o temática de la revista.

Notas de Interés: El Editor y el Comité Científico/Editorial de la revista Cuestiones de filosofía, son las instancias que deciden la publicación de los originales. Aclaramos que el envío de material no obliga a su publicación. Los errores de formato y presentación, el incumplimiento de las normas de la revista o la incorrección ortográfica y sintáctica, podrán ser motivo de rechazo del trabajo sin pasarlo a evaluación.

La revista Cuestiones de filosofía podrá hacer públicas, en caso de que haya constatado, las siguientes malas prácticas científicas: plagio, falsificación o invención de datos, apropiación individual de autoría colectiva y publicación duplicada para ello todos los artículos se someten al software antiplagio Turnitin.

\section{Sobre la presentación del texto}

Toda contribución textual o gráfica que haya sido aceptada se acogerá a las normas vigentes de Derechos de Autor. Si esta es aceptada, el (las/os) autoras (es) Y deberá diligenciar, firmar y reenviar a Cuestiones de Filosofía el Formato oficial para la cesión de Derechos de Autor; formato que le será enviado oportunamente. No se devolverá ninguna de las contribuciones entregadas.

\section{Características}

Los artículos, ponencias, traducciones, recensiones o reseñas bibliográficas han de ser inéditas. En su defecto, deben justificarse por escrito los méritos de una nueva publicación, junto con la autorización escrita del editor anterior y la referencia completa de la publicación original.

\section{Textos tipo Artículo}

- Título. Debe estar relacionado directamente con la temática que se desarrolla. Se recomienda que no supere las doce (12) palabras, y debe ir en español e inglés. En nota al pie de página se informa sobre la investigación de la cual deriva el artículo, la organización que lo ejecuta o grupo de investigación, con nombre del proyecto al que pertenece. Del mismo modo, nombre de la institución financiadora (si es el caso).

- Autores. Nombre completo del autor o los autores y afiliación institucional. En nota a pie de página se consignan para cada autor los siguientes datos: títulos 
académicos y correo electrónico. Además, debe indicarse la dirección postal fuera del país o la dirección residencial del autor principal.

- Resumen. El resumen de un artículo varía según la tipología, pero a manera general debe introducir el problema, la teoría o las teorías en que se basa el estudio, menciona la tesis central de autor, introduce los conceptos fundamentales de la discusión, traza el método a partir del cual se abordan los conceptos y presenta conclusiones de estudio. Se redacta en un solo párrafo con una extensión de 200 a 250 palabras. Debe ser presentado en español e inglés.

- Palabras clave. Son palabras que describen el contenido del documento y su número no debe ser mayor a seis. Se recomienda utilizar el thesaurus de la Unesco: http/databases.unesco.org/thessp/.

- Referencias. En la lista de referencias el autor incluye solo aquellas fuentes que utilizó en su trabajo. En este sentido, "una lista de referencias cita trabajos que apoyan específicamente a un artículo en particular" APA (Asociación Americana de Psicología). Nunca debe referenciarse un autor que no haya sido citado en el texto, y viceversa.

- Formato: los artículos no pueden exceder 25 páginas; tamaño: carta, con márgenes derecho e izquierdo de 3 centímetros; formato: Word; fuente: Times New Roman12 puntos; interlineado: espacio y medio.

- Encabezado: título del escrito; nombre y dirección electrónica del autor; afiliación institucional a la que pertenece y la ciudad en la que esta tiene su sede; un resumen del artículo, en español e inglés, que no exceda las 150 palabras; cinco palabras clave (key words) también en español e inglés. A pie de página debe aparecer: breve identificación del autor, último título obtenido, áreas de interés, dos (2) referencias bibliográficas completas y recientes —artículos u obras- de su autoría.

- Subtítulos: en altas y bajas (no mayúsculas fijas), sin negrilla ni cursiva; numerados y alineados a la derecha.

- Citas textuales de más de cuatro líneas: transcritas en párrafo aparte, con un margen izquierdo superior al resto del texto; interlineado sencillo, sin entrecomillado ni en cursivas.

- Llamados a pie de página: números arábigos volados (preferiblemente 8pts, elevado 2 pts.), ordenados consecutivamente y puestos antes del signo de puntuación.

- Notas a pie de página: solo se emplearán para hacer aclaraciones o para aportar datos adicionales; no para hacer referencias bibliográficas; estas irán dentro del cuerpo del texto (sistema APA de citación).

- Citas bibliográficas: en paréntesis debe aparecer apellido del autor, año de publicación, dos puntos y el número de la página o de las páginas a la que corresponde la cita.

- Material gráfico: todo material gráfico debe presentarse en archivo separado indicando el programa empleado, preferiblemente formato TIF. 
- Referencias: aparecen al final del texto en orden alfabético y deben acogerse a las normas bibliográficas APA, tal como se muestra a continuación:

\section{Libros}

- Apellido, iniciales del nombre del autor —en altas y bajas-. (Año de publicación). Título del libro —en cursiva一. Ciudad: Editorial.

- Williamson, T. (2000). Knowledge and its Limits. Oxford: Oxford University Press.

\section{Libros con traductor}

- Apellido, iniciales del nombre del autor -en altas y bajas-. (Año de publicación). Título del libro -en cursiva-. (Trad. Iniciales nombre y apellido). Ciudad: Editorial.

- Arendt, H. (1993). La condición humana. (Trad. R. Gil Novales). Barcelona: Paidós.

\section{Libros con editor}

- Apellido, iniciales del nombre del autor. (Ed.). (Año de publicación). Título del libro -en cursiva-. Ciudad: Editorial.

- Going, C.; Lambert, P. \& Tansey, C. (Eds.). (1982). Caring About Meaning: Patterns in the Life of Bernard Lonergan. Montreal: Thomas More Institute.

\section{Capítulo de libro}

- Apellido, iniciales del nombre del autor. (Año de publicación). Título del capítulo sin cursiva-. Título del libro -en cursiva- (páginas del capítulo). Ciudad: Editorial.

- Baier, A. (1995). What do Women Want in a Moral Theory? Moral Prejudices (pp. 1-17). Cambridge: Harvard University Press.

\section{Artículos en libros con editor o compilador}

- Apellido, iniciales del nombre del autor del artículo. (Año de publicación). Título del artículo -sin cursiva-.Iniciales nombre del editor o compilador del libro. Apellido (Comp. / Ed), Título del libro -en cursiva- (páginas del artículo). Ciudad: Editorial.

- Davidson, D. (2001). Externalisms. P. Kotatko, P. Pagin \& G. Segal (Eds.), Interpreting Davidson (pp. 1-16). Stanford: CSLI Publication.

\section{Artículos en revistas impresas}

- Apellido, iniciales del nombre del autor del artículo. (Año de publicación). Título del artículo -sin cursiva-. Título de la revista -en cursiva-, volumen(número), páginas del artículo. 
- Chalmers, D. J. (1995). Facing Up to the Problem of Consciousness. Journal of Consciousness Studies, 2(3), pp. 200-219.

\section{Tesis}

- Apellido, iniciales del nombre del autor -en altas y bajas-. (Año de la tesis). Título -sin cursiva-. Tesis de doctorado/de maestría. Nombre de la universidad. (Sin publicar).

- Capdevila, P. (2005). Experiencia estética y hermenéutica. Tesis doctoral. Universidad Autónoma de Barcelona. (Sin publicar).

\section{Fuentes electrónicas}

Todo escrito (libro, capítulo de un libro, artículo en una revista o artículo en un libro) debe referenciarse de la misma manera que sus homólogos en papel, pero al final debe hacerse mención a la fecha en la cual se revisó la web site y dónde.

Por ejemplo, referencia de un artículo de una revista.

- Apellido, iniciales del nombre del autor del artículo. (Año de publicación). Título del artículo -sin cursiva-. Título de la revista -en cursiva-, volumen(número), páginas del artículo. Revisado el día, mes, año, en dirección de la web.

- Mansbach, A. (1997). "El inmortal” de Borges a través de la concepción heideggeriana de la muerte y de la individualidad. Revista Hispánica Moderna- JSTOR. Revisado el 23 de agosto de 2010, en http://www.jstor.org/pss/30203446.

\section{Lista de comprobación para la preparación de envíos}

Como parte del proceso de envío, los autores/as están obligados a comprobar que su envío cumpla todos los elementos que se muestran a continuación. Se devolverán a los autores/as aquellos envíos que no cumplan estas directrices.

$\checkmark$ El envío no ha sido publicado previamente ni se ha enviado previamente a otra revista (o se ha proporcionado una explicación en Comentarios al / a la editor/a).

$\checkmark$ El fichero enviado está en formato Microsoft Word, RTF, o WordPerfect.

$\checkmark$ Se han añadido direcciones web para las referencias donde ha sido posible.

$\checkmark$ La extensión del texto es la recomendada para artículos es de mínimo 3.000 a 8.000 palabras -según la tipología del texto- a espacio 1.5. Fuente Time New Roman 12; para citas mayores de cinco renglones, centradas, fuente Time New Roman 11, y para las notas, Time New Roman 10.

$\checkmark$ El texto usa cursiva en vez de subrayado (exceptuando las direcciones URL); y todas las ilustraciones, figuras y tablas están en formato aparte y dentro del texto indica el sitio que les corresponde. 
$\checkmark$ El texto cumple con los requisitos bibliográficos y de estilo indicados en las Indicaciones para autoras/es, que se pueden encontrar en Acerca de la revista.

$\checkmark$ El texto No se encuentra con paginación.

$\checkmark$ Las normas que se deben tener en cuenta en el estilo, las citas y las referencias son las establecidas por la Asociación Americana de Psicología (APA, sexta edición.

\section{Correspondencia}

Los artículos se envían al comité editorial en medio digital al correo electrónico cuestiones.filosofia@uptc.edu.co para el primer paso de la evaluación. Los autores se deben registrar en la plataforma Open Journal System con licencia creative commons. (OJS), en: http://revistas.uptc.edu.co/revistas/index.php/cuestiones_filosofia. 


\section{INDICATIONS FOR AUTHORS / AS}

Issues of Philosophy is an institutional magazine of the School of Philosophy and Humanities, Faculty of Education of the Pedagogical and Technological University of Colombia. It was founded in 1998; It is aimed at readers interested in thinking and research in the field of philosophy, education and human sciences.

Philosophy is questions is published biannually. Publishes original research articles, theorizing and reflections of conceptual inquiring about various fields of knowledge and of thought of philosophy, education and human sciences and aims to disseminate and visualize research processes in support of the strengthening of academic networks regional, national and international levels, thus contributing to the understanding of our societies and of human thought.

Texts can be submitted under article mode of scientific research, reflection article or review article. other forms of publication, such as a short article, case report, review of subject, letters to the editor, editorial and translation are also taken into account.

In order to improve the scientific and editorial quality of the magazine, the articles are evaluated in the first instance by the editorial committee, which ensures the relevance of the subject and object of research, as well as compliance with the requirements for each manner of publication. Upon completion of this process, the items are sent to two (2) external evaluators who value their conceptual, theoretical and methodological contribution to the field of study. Those who are accepted by the evaluators and corrected by the authors, will be published within three months from the date of final approval.

\section{Reservation of Rights}

The reception of an article does not imply approval or commitment regarding the date of publication; however, the author will be constantly informed about the process of selecting and editing your proposal. The text submitted to the journal will be unprecedented nature.

Regarding intellectual property rights, the author authorizes, through the signing of the letter of transfer of rights to the magazine, copy, reproduce, distribute and publish the article under the assignment by any digital medium or reprographic. Similarly, sending written questions to the journal Philosophy implies that their authors give them economic rights of the Pedagogical and Technological University of Colombia, which in turn will sell them to third party non - profit. 
As to respect the intellectual property rights of third parties, the author states that respects and is committed to answer for any action claim, plagiarism or other type of claim that might arise in this regard.

Questions of philosophy, has the moral obligation to respect copyrights contained in Article 30 of Law 23 of 1982 . The publisher reserves the right to make minor editing changes for a better presentation of the work.

This journal It is registered under the Creative Commons Attribution 4.0 noncommercial International. Therefore, this work may be reproduced, distributed and publicly communicated in digital format, provided that the names of the authors and the Pedagogical and Technological University of Colombia is recognized. It is allowed to quote, you adapt, transform, self-archive, republish and create from the material, for any purpose (commercial except), provided the authorship is properly recognized, a link is provided to the original work and indicate whether changes have been made .

The Pedagogical and Technological University of Colombia does not retain the rights to works published and the contents are the sole responsibility of the authors, who retain their moral rights, intellectual, privacy and publicity.

The guarantee on the intervention of the work (revision, editing, translation, layout) and its subsequent disclosure is provided through a transfer of rights, representing the magazine and the Pedagogical and Technological University of Colombia, are exempted from any liability that may arise from a bad ethical practice by the authors. As a result of the protection afforded by the transfer of rights, the magazine is not obliged to publish retractions or modify information already published, unless the errata arises editorial management process. Publishing content in this magazine does not represent royalties for taxpayers.

ISSUES OF PHILOSOPHY by ISSUES OF PHILOSOPHY is licensed under a Creative Commons Attribution-NonCommercial 4.0 International License .

Created from the work in http://revistas.uptc.edu.co/revistas/index.php/ cuestiones_filosofia/user/register

\section{Types of publications}

\section{Art í ass cient fic}

It is a report that presents the original results of an investigation. The structure generally used contains four important sections: introduction, methodology, results and conclusions.

- Introduction: presents under investigation from a conceptual or theoretical development and includes its historical background and explanation of the purpose of the investigation. 
- Method: describes the process for carrying out the investigation.

- Results: Reports detail the results.

- Discussion: analyzes the implications of the results.

- References least thirty (30).

\section{Art í ass of revision or $\mathbf{n}$}

It is the systematization, analysis and assessment of what researched problem particles. It aims to account for their conceptual, methodological and epistemological references, as well as developments and trends in the field of the investigation. It is characterized by an analytical review of at least fifty references, from which the author:

- Synthesizes previous research to inform the reader about the current state of research.

- Identifies relations, contradictions, gaps and inconsistencies in the literature.

The components of the literature can be observed in various ways. Po example by the similarity of the concepts of the theories of interest, methodological similarities between the reviewed studies or historical development of the field (APA. 2010, P.10).

\section{3) Art í ass or you rich:}

It is a document in which the author supports his research in the literature to advance a theory. It is expected to expand and refine theoretical articles theoretical constructs, analyze a theory, point out some or demonstrate the advantage of one theory over another. Sections of a theoretical paper like those of a version of literature- may vary according to their content.

\section{4) Art í ass methodological or logical:}

This type of contribution presents new methodological approaches, modifications of existing methods or discussions about different approaches to the analysis of information. In this case, the use of empirical data serves only as an illustration of the methodological approach presented by the author.

\section{Other writings}

- Art í ass of reflection or $\mathbf{n}$. A document that presents finished research results from an analytical, interpretative or critical perspective of the author on a specific topic based on original sources.

In fewer the possibility of publication of the following type must be considered: 
- Art í short ass. A brief text presenting the original or part of a scientific or technological research that generally require a quick diffusion preliminary results.

- Case report. A document that presents the results of a study on a particular situation in order to publicize the technical and methodological experiences considered in a specific case. It includes a systematic review of literature on similar cases.

- Revision or $\mathbf{n}$ the subject. A document resulting from a critical review of the literature on a particular topic.

- Letters to the editor. Critical, analytical or interpretative Documents published in the journal, which in the opinion of the Editorial Board constitute an important discussion of the subject by the scientific community of reference.

- Traducci or $\mathbf{n}$. Translations of classical texts or current or historical or transcripts of particular interest in the domain of magazine publishing documents.

- Book reviews book. Summary and a personal assessment of a cultural, literary or artistic work. They can not exceed eight pages, size: letter, left and right margins of $3 \mathrm{~cm}$; format: Word; source: Times New Roman 12 points; line spacing: spacing.

- Editorial. Document written by the editor, a member of the editorial committee or a guest researcher on orientations in the subject domain of the magazine.

\section{Sections of the magazine}

Philosophy of art; Author; classical and contemporary philosophy; humanities and education; epistemology, philosophy of science and language and reviews. All sections are directly linked to a philosophical conceptual development.

Aesthetics and Philosophy of Art. The session seeks to accommodate the reflections on the beauty, the foundation of it and artistic work in its many manifestations. This from a horizon that involves interpretations made in this regard from antiquity to the present day.

Classical and contemporary philosophy. With regard to this meeting, it should be stressed that it aims to make visible the considerations made by the authors concerning the problems discussed within classical and contemporary philosophy.

Author. This session is open to all reflections whose central focus is the thought of a particular author. This with the aim of deepening the work and relevant topics that author.

Epistemology, philosophy of science and language. Here 's what the aim is to publish articles that are intended to reflect about the own dynamic science, research about human knowledge and language problems.

While it is true the journal Questions of Philosophy is a publication that is aimed at the dissemination of the results achieved in research conducted in the field of 
philosophy, welcomes other reflections from other areas. Such is the reason that the magazine has a long tradition in publishing articles from other fields related to humanities and education.

Humanities and education. This section intends to publish results of research on the philosophy of education and conceptualizations registered in the field of humanities.

\section{About presentation of text}

Any contribution is submitted to arbitration by two (2) academic peers in the form of double - blind (authors and anonymous referees). Questions of Philosophy reserves the right to accept or reject, according to the concepts issued by the arbitrators and the Editorial Committee, any of the writings. The decision will be communicated to the author within a period not exceeding three (3) months from its receipt. Any textual or graphical contribution that has been accepted is host to the existing rules of copyright. If this is accepted, the author (s) (s) (AS) must fill out, sign and return to issues of Philosophy the official format for the transfer of copyright; format that will be sent promptly. None of the submitted contributions will be returned.

\section{Characteristics}

Articles, papers, translations, book reviews or book reviews must be unpublished. Failing that, they must be justified in writing the merits of a new publication, along with the written authorization of the previous editor and complete reference of the original publication.

\section{Type texts Article}

- Tí title. It must be directly related to the theme that develops. It is recommended that not more than twelve (12) words, and must be in Spanish and English. In footnote page reports on research which derives the article, the organization that runs or research group, called the project it belongs. Similarly, the funding institution name (if applicable).

- Authors. Full name of the author or authors and institutional affiliation. In a note footnotes are given for each author the following: academic degrees and email. In addition, postal address outside the country or the residential address of the principal author should be indicated.

- Summary. The summary of an article varies according to type, but generally should introduce the problem, theory or theories in which the study is based, mentions the central thesis author introduces the fundamental concepts of the discussion, trace the method from which the concepts are discussed and presented conclusions of study. It is written in a single paragraph with an area of 200 to 250 words. It must be presented in Spanish and English. 
- Keywords. They are words that describe the content of the document and their number should not exceed six. It is recommended to use the thesaurus Unesco: http / databases.unesco.org / thessp /.

- References. In the list of references the author includes only those sources he used in his work. In this sense, "a list of references cited work that specifically support a particular item" APA (American Psychological Association). should never referenced an author who has not been cited in the text, and vice versa.

- Format: Articles can not exceed 25 pages; Size: letter, right and left margins of $3 \mathrm{~cm}$; format: Word; source: Times New Roman12 points; line spacing: spacing.

- Headline: brief title; name and email address of the author; institutional affiliation to which it belongs and the city in which this is based; a summary of the article in Spanish and English, not exceeding 150 words; five key words (key words) also in Spanish and English. A footnote should appear: brief identification of the author, last title obtained, areas of interest, two (2) complete bibliographical references and recent -sugar or works- of his own.

- I Subt titles: high and low (no fixed capital), no bold or italics; numbered and right-aligned.

- Quotes from $\boldsymbol{m}$ to I $\boldsymbol{t} \mathbf{s}$ four lines: transcribed in a separate paragraph with more than the rest of the text left margin; single space, without inverted commas or italics.

- Called walk PAGE: frilly Arabic numerals (preferably 8pts, high 2pts.), Arranged consecutively and placed before the punctuation.

- Footnotes PAGE: they shall be used only for clarification or to provide additional data; not to references; these will within the text (APA citation system) body.

- Bibliographical citations to ficas: parenthetical author 's surname, year of publication, colon and page number or page to the corresponding appointment should appear.

- Fico gr Material: all artwork must be submitted separate file indicating the program used, preferably TIF format.

- References appear at the end of the text in alphabetical order and should benefit from the APA bibliographic standards, as shown below:

\section{Books}

- Surname, initials of the high and bajas--in author. (Year of publication). Title of the book-in Italics. City: Publisher.

- Williamson, T. (2000). Knowledge and Its Limits. Oxford: Oxford University Press.

\section{Books with translator}

- Surname, initials of the high and bajas--in author. (Year of publication). Title of the book-in Italics. (Trad. Initial name). City: Publisher. 
- Arendt, H. (1993). The human condition. (Trad. R. Gil Novales). Barcelona: Polity Press.

\section{Books editor}

- Surname, initials of the author. (Ed.). (Year of publication). Title of the book-in Italics. City: Publisher.

- Going, C .; Lambert, P. \& Tansey, C. (Eds.). (1982). Caring About Meaning: Patterns in the Life of Bernard Lonergan. Montreal: Thomas More Institute.

\section{Book chapter}

- Surname, initials of the author. (Year of publication). Chapter title without Italics. -in Italics book title (pages of chapter). City: Publisher.

- Baier, A. (1995). What do Women Want in a Moral Theory? Moral Prejudices (pp. 1-17). Cambridge: Harvard University Press.

\section{Articles in books editor or compiler}

- Surname, initials of the author. (Year of publication). Article title without italic-. Iniciales name of the editor or compiler of the book. Name (Comp. / Ed), Book title-in Italics (pages of article). City: Publisher.

- Davidson, D. (2001). Externalisms. P. Kotátko, Pagin P. \& G. Segal (Eds.), Interpreting Davidson (pp. 1-16). Stanford: CSLI Publication.

\section{Articles in print magazines}

- Surname, initials of the author. (Year of publication). Article Title without Italics. Title of the magazine-in Italics, volume (number), article pages.

- Chalmers, DJ (1995). Facing Up to the Problem of Consciousness. Journal of Consciousness Studies, 2 (3), pp. 200-219.

\section{Thesis}

- Surname, initials of the high and bajas--in author. (Year of the thesis). Title without Italics. PhD thesis / master. University name. (Unpublished).

- Capdevila, P. (2005). aesthetics and hermeneutics experience. doctoral thesis. Autonomous University of Barcelona. (Unpublished).

\section{Electronic sources}

All written (book, chapter in a book, magazine article or article in a book) should be referenced in the same way as their counterparts on paper, but in the end must be made to the date on which the web site was reviewed and where. 
For example, reference to an article in a magazine.

- Surname, initials of the author. (Year of publication). Article Title without Italics. Title of the magazine-in Italics, volume (number), article pages. Revised the day, month, year, towards the web.

- Mansbach, A. (1997). "The Immortal" Borges through Heidegger's concept of death and individuality. Hispanic Magazine Moderna- JSTOR. Revised August 23, 2010, in http://www.jstor.org/pss/30203446.

\section{Checklist for preparing shipments}

As part of the submission process, the author $/ \mathrm{s}$ are required to check that your shipment meets all the items shown below. the author / $\mathrm{s}$ will be returned consignments that do not meet these guidelines.

The submission has not been previously published nor is it before another journal for consideration (or an explanation has been provided in Comments to / the publisher / a).

- The file is sent in Microsoft Word, RTF, or WordPerfect format.

- They have been added to the references web addresses where it has been possible.

- The length of the text is the recommended items is 4,000 to 10,000 words, according to the typology of the text to space 1.5. Source Time New Roman 12; dating over five lines, centered, font Times New Roman 11, and for notes, Time New Roman 10.

- The text uses italics rather than underlining (except with URL addresses); and all illustrations, figures and tables are in a separate format and within the text indicates where they belong.

- The text meets the style and bibliographic requirements stated in the Guidelines for authors / s, which can be found in About the Journal.

- The text is not paged.

- The rules should take into account the style, citations and references are those established by the American Psychological Association (APA, sixth edition).

\section{Correspondence}

Items are sent to the editorial board in digital media email cuestiones.filosofia@ uptc.edu.co for the first step of the evaluation. The authors must register in the Open Journal System platform with creative commons license (OJS), in:. Http://revistas. uptc.edu.co/revistas/index.php/cuestiones_filosofia.

\section{Arbitration Process}

Once the document is sent to our e-mail or uploaded to our website, you will be confirmed with the author the publication deadline (this depends on the agenda 
of the magazine that is established in accordance with the order of approval the articles). Once we have the answer if this is yes, the item is sent to evaluation.

Articles submitted to Questions of Philosophy must be original and unpublished; They not accept those that have been published in other media, whether print or online. These will be subject to peer evaluators anonymous way, in a time of 2 to 4 months. Moments evaluation of texts are:

a. Once recepcionado article, accused the received email and author who has begun the process of reviewing reported.

b. The editorial committee checks whether the item meets the basic requirements of Philosophy issues presented in the directions for authors, and if you have thematic relevance, consistency, clarity and exposed conditions "on the display of the text" in this document. If the text does not meet the basic requirements, it will be returned to the author with relevant suggestions.

c. If the text meets the requirements shall be subjected to a process of (anonymous) double-blind peer evaluation of experts who will give a concept about the academic quality of the material. Peer evaluators may suggest changes, in order to improve the text quality evaluation.

The comments of the referees and the Editorial Committee, it is suggested to be taken into account by the authors, who will make the requested adjustments within no more than fifteen days.

After receiving the amended article, this will be subject to further review and subsequently inform the author's approval. The committee reserves the right to accept the articles that will be published in each issue.

The magazine reserves the right to make corrections of style that will always consulted with the authors. During the editing process, authors may be required by the editor to resolve concerns that arise both in the evaluation process and the editing.

\section{Statement of Ethics and good scientific practice and editorials}

This journal is governed by international standards published by the Ethics Committee in Publication (COPE) . In turn, it is based on the Best Practice Guide for editors of scientific journals and Resource Pack for publication ethics (PERK), developed by the Elsevier publishing group, to ensure transparency in both the publication of contributions and procedures associated conflict resolution.

The editorial board of this journal will ensure that all parties (editors, peer reviewers and authors) fully follow ethical standards throughout the publishing process.

\section{Ethical considerations for Authors / as}

Before sending your manuscript to Questions of Philosophy asked to read carefully the following considerations: 


\section{Exclusivity in the application}

Jobs that are running for Philosophy issues should not be sent simultaneously to other journals, as this compromises the originality of the articles and publication rights. Any previous version that has been placed on the Internet for reading and feedback from other academic peers, must be removed at the time of sending the article to the journal.

\section{Plagiarism and autoplagio}

a) It is considered unacceptable reproduce texts from other authors without clearly indicating its origin.

b) It is considered unacceptable incorporate fully or partially own texts that have already been published without clearly indicating its original place of publication in a footnote on page.

\section{Diligence}

The authors undertake to perform the tasks arising from the arbitration process and publication, such as:

a) Review and incorporating corrections suggested by the assessment.

b) Response to comments and questions result of publishing the document (copyediting and fitness for editorial guideline).

These tasks must be done within the terms agreed between the author and the journal.

\section{Ethical considerations Assessor / as}

\section{Appropriateness}

a) Evaluators should only accept reading on subjects they know enough.

b) If the evaluator during the reading of the document realizes that does not have sufficient knowledge of the subject matter, please inform the editorial team to proceed to assign another evaluator (cuestiones.filosofia@uptc.edu.co).

\section{Independence}

The arbitration is done under a system "double blind" to ensure, where possible, independence and thoroughness of evaluations. If at some point in reading the article, the evaluator finds that there is an ethical impediment or conflict of interest that might affect their judgment, he must notify the Editor in the shortest time possible.

\section{Approach concepts}

a) It is expected that evaluators address from an academic work, rigorous and coherent perspective. The very brief concepts, poor arguments to approve or reject 
a job, are not useful collaboration, as they can generate replicas of the author justified, which unnecessarily extends the evaluation process.

b) What is evaluated is the presentation and argumentative consistency of the text, regardless of whether the evaluator is or disagree with the ideas in it.

c) The result of the evaluation must be profitable for both the author and the Editor. Therefore, it is expected that from this, the author can rethink, correct or validate their work and Editor can make a reasoned decision on publication or rejection of the article.

\section{Stagecoach}

a) After the date of acceptance of the request for arbitration, the evaluator will have 30 days for delivery of the result of it.

b) If in the course of evaluating compliance with the agreed delivery time is not feasible, the evaluator should inform the editor to reorganize the originally agreed schedule.

c) Please remember that timely response to the authors also depends on the cooperation of the evaluators.

\section{Impersonation}

If the Editor and his team call for an evaluator to assist in the reading of a job after analyzing their academic training, background and experience in research, and publications, it is not acceptable that, after taking the job, transfer the responsibility acquired to a third party (eg co-researcher, graduate student or others).

\section{Use of Information}

The work that the evaluator receives are unpublished and original. Any use or misappropriation of approaches, information or sections of text work received will be considered a very serious moral offense.

\section{Ethical Considerations for the Editorial Committee}

\section{Decisions publication}

Issues Editor of Journal of Philosophy (refereed academic peer) and the Editorial Committee, are responsible for deciding which of the articles submitted to the journal should be published. The approval of the work in question and its importance for researchers and readers are part of these decisions. The Editor is guided by the policies of the Editorial Board of the magazine, taking up the legalities in force concerning defamation, violation of copyright and plagiarism. The Editor can go to support other editors or reviewers for making this decision. 


\section{Editor / a}

\section{Transparency}

- Ensuring transparency of contributions and assessment processes and publication. An editor should evaluate manuscripts for their intellectual content without regard to race, gender, sexual orientation, religious beliefs, ethnic origin, nationality, or political philosophy of the authors.

- Reply to compliance with international standards of ethics, research and publication in all scientific and editorial processes related to the magazine.

- Respect and respond quickly to questions and notifications.

\section{Ensure Confidentiality}

Editor and any editorial staff must not disclose any information about a submitted manuscript to anyone other than the authors, reviewers, potential reviewers, other relevant editorial advisers, and the publisher, if appropriate.

\section{Disclosure of conflicts of interests and objective dialogue}

Unpublished materials disclosed in a manuscript submitted for publication in the journal should not be used in an editor's own without the express written consent research and author.

Privileged information or ideas obtained through peer review must be kept confidential and not used for personal gain. Editors should nonconceptuality on an article if it considers that the document may generate conflicts of interest arising from relationships or competitive connections, partnership or otherwise with any of the authors, companies, or (possibly) institutions connected to magazines .

\section{Participation and cooperation in investigations}

The editor must respond when complaints arise regarding a published article, whose cooperation the respective credit claim. Such measures shall promptly notify the author of the article also apply due process to the request, it shall also provide information deemed relevant to the competent institutions and research organizations, and if the complaint is sustained, the publication should make the correction, retraction, la expresión de preocupación, u otra nota, que pueda ser relevante para aclarar tal situación. Each act of unethical conduct identified in the publication will be considered, even if it is discovered years after publication.

\section{Code of ethics of publication}

The journal Issues of Philosophy develops a serious process of arbitration of articles submitted in accordance with basic principles of respect for copyright 
and information; in addition, their editorial processes are aimed to meet political orientations of the indices, databases and more suitable bibliographic directories.

The magazine considers the ethics of piublicación as a fundamental mission to protect copyright and information.

The authors posit Articles certify that their proposals are the result of original research and own; for it is has a form of transfer of rights by which it is shown that the text is the author 's exclusive and original product. 



\title{
DECLARACIÓN DE ÉTICA Y BUENAS PRÁCTICAS EDITORIALES REVISTA CUESTIONES DE FILOSOFÍA
}

\begin{abstract}
Esta revista científica se rige por los estándares internacionales publicados por el Comité de Ética en la Publicación (COPE). A su vez, se basa en la Guía de mejores prácticas para editores de revistas científicas y el Paquete de recursos para la ética en la publicación (PERK), desarrollado por el grupo editorial Elsevier, a fin de garantizar transparencia tanto en la publicación de las contribuciones como en los procedimientos de resolución de conflictos asociados. El equipo editorial de esta revista científica se asegurará de que todas las partes (editores, pares evaluadores y autores) sigan a cabalidad las normas éticas en todo el proceso editorial.
\end{abstract}

\section{Consideraciones éticas para Autores /as}

Antes de enviar su manuscrito a Cuestiones de Filosofía le pedimos leer atentamente las siguientes consideraciones:

\section{Exclusividad en la postulación}

Los trabajos que se postulen a Cuestiones de Filosofía no deben enviarse simultáneamente a otras revistas, ya que esto compromete la originalidad de los artículos y los derechos sobre su publicación. Cualquier versión previa que haya sido colocada en la Red para su lectura y retroalimentación por parte de otros pares académicos, deberá ser retirada en el momento de enviar el artículo a la revista.

\section{Plagio y autoplagio}

A) Se considera inaceptable reproducir total o parcialmente textos de otros autores sin indicar con claridad su procedencia.

B) Se considera inaceptable incorporar total o parcialmente textos propios que ya hayan sido publicados sin indicar claramente su lugar original de publicación en una nota a pie de página.

\section{Diligencia}

Los autores se comprometen a realizar las tareas que se deriven del proceso de arbitraje y publicación, tales como:

A) Revisión e incorporación de las correcciones sugeridas por el evaluador. 
B) Respuesta a las observaciones y dudas resultado de la edición del documento (corrección de estilo y adecuación a la pauta editorial).

Dichas labores han de realizarse dentro de los plazos acordados entre el autor y la revista.

\section{Consideraciones éticas para Evaluadores /as}

\section{Idoneidad}

A) Los evaluadores solo deben aceptar la lectura de trabajos sobre temas que conozcan suficientemente.

B) Si el evaluador durante la lectura del documento se da cuenta de que no tiene suficiente conocimiento del tema en cuestión, deberá comunicarlo al equipo editorial para que se proceda a asignar otro evaluador (cuestiones.filosofia@uptc.edu.co).

\section{Independencia}

El arbitraje se realiza bajo un sistema "doble ciego" para garantizar, en lo posible, la independencia y rigurosidad de las evaluaciones. Si en algún punto de la lectura del artículo, el evaluador encuentra que hay algún impedimento ético o conflicto de intereses que pueda afectar su juicio, ha de informarlo al Editor en el menor tiempo posible.

\section{Enfoque de los conceptos}

A) Se espera que los evaluadores aborden los trabajos desde una perspectiva académica, rigurosa y coherente. Los conceptos muy escuetos, pobres en argumentos para aprobar o rechazar un trabajo, no son una colaboración útil, pues pueden generar réplicas justificadas del autor, lo que extiende innecesariamente los procesos de evaluación.

B) Lo que se evalúa es la forma de presentación y la consistencia argumentativa del texto, sin importar si el evaluador está o no de acuerdo con las ideas expuestas en él.

C) El resultado de la evaluación ha de ser provechosa tanto para el autor como para el Editor. Por ende, se espera que, a partir de esta, el autor pueda replantear, corregir o validar su trabajo y el Editor pueda tomar una decisión argumentada sobre la publicación o rechazo del artículo.

\section{Diligencia}

A) Después de la fecha de aceptación de la solicitud de arbitraje, el evaluador contará con 30 días para la entrega del resultado de la misma. 
B) Si en el desarrollo de la evaluación el cumplimiento del plazo de entrega pactado resulta inviable, el evaluador debe informar al editor para reorganizar el cronograma inicialmente acordado.

C) Por favor, recuerde que la respuesta oportuna a los autores depende también de la colaboración de los evaluadores.

\section{Suplantación}

Si el Editor y su equipo convocan a un evaluador a colaborar en la lectura de un trabajo luego de analizar su formación académica, trayectoria y experiencia en investigación, y publicaciones, no es aceptable que este, luego de asumir la tarea, transfiera la responsabilidad adquirida a un tercero (e.g. coinvestigador, estudiante de posgrado u otros).

\section{Uso de información}

Los trabajos que el evaluador recibe son inéditos y originales. Cualquier uso o apropiación indebida de los planteamientos, información o apartados de texto de los trabajos que recibe será considerado como una falta ética de suma gravedad.

\section{Consideraciones Éticas para el Comité Editorial}

\section{Decisiones publicación}

El Editor de la Revista Cuestiones de Filosofía (arbitrada por pares académicos) y el Comité Editorial, son los responsables de decidir cuál de los artículos presentados a la revista deben publicarse. La aprobación de la obra en cuestión y su importancia para los investigadores y los lectores hacen parte de estas decisiones. El Editor se guía por las políticas del Consejo Editorial de la revista, acogiéndose a los aspectos legales vigentes en materia de difamación, violación de derechos de autor y plagio. El Editor puede acudir al apoyo de otros editores o revisores para la toma de esta decisión.

\section{Editor /a}

\section{Transparencia}

A. Garantizar la transparencia de las contribuciones y los procesos de evaluación y publicación. Un Editor debe evaluar manuscritos para su contenido intelectual sin distinción de raza, género, orientación sexual, creencias religiosas, origen étnico, nacionalidad, o filosofía política de los autores.

B. Responder al cumplimiento de las normas internacionales de ética, de la investigación y la publicación en todos los procesos científicos y editoriales relacionados con la revista.

C. Responder con celeridad y respeto a las preguntas y notificaciones. 


\section{Garantizar la Confidencialidad}

El Editor y cualquier equipo de redacción no deben revelar ninguna información sobre un manuscrito enviado, a nadie más que a los autores, revisores, potenciales revisores, otros asesores editoriales correspondientes, y al editor, si es apropiado.

\section{Revelación de conflictos de intereses e interlocución objetiva}

Los materiales inéditos revelados en un manuscrito presentado para su publicación en la revista no deben utilizarse en investigaciones propias de un editor sin el consentimiento expreso y por escrito del autor.

La información privilegiada o las ideas obtenidas mediante la revisión por pares deben ser confidenciales y no se utilizarán para beneficio personal. Los editores no deben conceptuar sobre un artículo si considera que el documento puede generar conflictos de intereses que resultan de las relaciones o conexiones competitivas, de colaboración o de otro tipo con cualquiera de los autores, empresas, o (posiblemente) instituciones conectadas a las revistas.

\section{Participación y cooperación en las investigaciones}

El editor debe dar respuesta cuando se presenten quejas con relación a un artículo publicado, cuya colaboración reclame el crédito respectivo. Dichas medidas se comunicarán oportunamente al autor del artículo, además aplicará el debido proceso a la solicitud, también emitirá comunicaciones que considere pertinentes a las instituciones competentes y organismos de investigación, y si la denuncia se sostiene, la publicación debe hacer la corrección, la retracción, la expresión de preocupación, u otra nota, que pueda ser relevante para aclarar tal situación. Cada acto identificado de conductas poco éticas en la publicación será examinado, aunque sea descubierto años después de la publicación.

\section{Código de ética de la publicación}

La revista Cuestiones de Filosofía desarrolla un serio proceso de arbitraje de los artículos postulados de acuerdo con principios básicos de respeto por los derechos de autor y de la información; además, sus procesos editoriales están dirigidos a cumplir orientaciones políticas de los índices, las bases de datos y directorios bibliográficos más idóneos.

La revista considera la ética de la publicación como una misión fundamental que protege los derechos de autor y de la información.

Los autores que postulan sus artículos certifican que sus propuestas son resultado de investigaciones propias y originales; para ello se cuenta con un formato de cesión de derechos mediante el cual se demuestra que el texto es producto exclusivo y original del autor. 


\section{DECLARATION OF ETHICS AND GOOD SCIENTIFIC AND EDITORIAL PRACTICES}

This journal is governed by international standards published by the Ethics Committee in Publication (COPE) . In turn, it is based on the Best Practice Guide for editors of scientific journals and Resource Pack for publication ethics (PERK), developed by the Elsevier publishing group, to ensure transparency in both the publication of contributions and procedures associated conflict resolution.

The editorial team of this journal will ensure that all parties (publishers, peer reviewers and authors) fully follow ethical standards throughout the editorial process.

\section{Ethical Considerations for Authors}

Before sending your manuscript to Questions of Philosophy asked to read carefully the following considerations:

\section{Exclusivity in the application}

Papers that are submitted to Philosophy Questions should not be sent simultaneously to other journals, as this compromises the originality of the articles and the rights to their publication. Any previous version that has been placed on the Web for reading and feedback by other academic peers, should be withdrawn at the time of sending the article to the magazine.

\section{Plagiarism and autoplagio}

A) It is considered unacceptable to reproduce totally or partially texts of other authors without clearly indicating their origin.

B) It is considered unacceptable to incorporate all or part of own texts that have already been published without clearly indicating their original place of publication in a footnote.

\section{Diligence}

The authors undertake to carry out the tasks deriving from the arbitration and publication process, such as:

A) Review and incorporation of corrections suggested by the evaluator. 
B) Response to the observations and doubts resulting from the editing of the document (correction of style and adaptation to the editorial agenda).

Such work must be done within the deadlines agreed between the author and the journal.

\section{Ethical Considerations for Evaluators}

\section{Suitability}

A) The evaluators should only accept the reading of works on subjects that they know enough.

B) If the evaluator during the reading of the document realizes that does not have sufficient knowledge of the subject matter, please inform the editorial team to proceed to assign another evaluator ( cuestiones.filosofia@uptc.edu.co ).

\section{Independence}

Arbitration is conducted under a "double-blind" system to guarantee, as far as possible, the independence and rigor of evaluations. If at any point in the reading of the article, the evaluator finds that there is any ethical impediment or conflict of interests that may affect his judgment, he must inform the Editor in the shortest possible time.

\section{Conceptual approach}

A. Evaluators are expected to approach the work from a rigorous and coherent academic perspective. The very brief concepts, poor in arguments to approve or reject a work, are not a useful collaboration, because they can generate justified replicas of the author, which unnecessarily extends the evaluation processes.

B. What is evaluated is the presentation form and the argumentative consistency of the text, regardless of whether or not the evaluator agrees with the ideas expressed in it.

C. The result of the evaluation must be of benefit to both the author and the Editor. Therefore, it is hoped that, from this, the author can rethink, correct or validate their work and the Editor can make an informed decision about the publication or rejection of the article.

\section{Diligence}

A. After the date of acceptance of the request for arbitration, the evaluator will have 30 days for the delivery of the result of the same.

B. If, in the course of the evaluation, compliance with the delivery deadline is not feasible, the evaluator must inform the editor to reorganize the initially agreed schedule. 
C. Please remember that the timely response to the authors also depends on the collaboration of the evaluators.

\section{Impersonation}

If the Editor and his team summon an evaluator to collaborate in the reading of a work after analyzing its academic formation, trajectory and experience in research, and publications, it is not acceptable that this one, after assuming the task, transfers the acquired responsibility To a third party (eg co-investigator, graduate student, or others).

\section{Use of information}

The works that the evaluator receives are unpublished and original. Any use or misappropriation of the approaches, information or text sections of the works that you receive will be considered as a serious ethical misconduct.

\section{Ethical Considerations for the Editorial Committee}

\section{Decisions publication}

Issues Editor of Journal of Philosophy (refereed academic peer) and the Editorial Committee, are responsible for deciding which of the articles submitted to the journal should be published. The approval of the work in question and its importance for researchers and readers are part of these decisions. The Editor is guided by the policies of the Editorial Board of the journal, taking advantage of the legal aspects in force regarding defamation, copyright infringement and plagiarism. The Editor may rely on the support of other editors or reviewers to make this decision.

\section{Editor}

\section{Transparency}

A. Ensure transparency of evaluation and publication contributions and processes. An Editor should evaluate manuscripts for their intellectual content without distinction of race, gender, sexual orientation, religious beliefs, ethnicity, nationality, or political philosophy.

B. Respond to compliance with international standards of ethics, research and publication in all scientific and editorial processes related to the journal.

C. Respond promptly and respect the questions and notifications.

\section{Guarantee Confidentiality}

The Editor and any writing team should not disclose any information about a submitted manuscript to anyone other than the authors, reviewers, potential reviewers, other appropriate editorial advisors, and the publisher, if appropriate. 


\section{Disclosure of conflicts of interest and objective interlocution}

Unpublished materials disclosed in a manuscript submitted for publication in the journal should not be used in an editor's own research without the express written consent of the author.

Insider information or ideas obtained through peer review should be confidential and will not be used for personal gain. Publishers should not conceptualize an article if it considers that the document may generate conflicts of interest resulting from competitive, collaborative or other relationships or connections with any of the authors, companies, or (possibly) institutions connected to the journals.

\section{Participation and cooperation in research}

The editor must respond when complaints are filed in relation to a published article, whose collaboration claims the respective credit. Such measures shall be communicated in a timely manner to the author of the article, and shall also apply due process to the request, also issue communications that it deems pertinent to the competent institutions and research organizations, and if the complaint is sustained, the publication must make correction, retraction, The expression of concern, or other note, that may be relevant to clarify such a situation. Each identified act of unethical conduct in the publication will be examined, even if it is discovered years after publication.

\section{Publication code of ethics}

The Issues Magazine of Philosophy develops a serious process of arbitration of articles submitted in accordance with basic principles of respect for copyright and information; In addition, its editorial processes are aimed at complying with political guidelines of indexes, databases and bibliographic directories more suitable.

The journal considers the ethics of publication as a fundamental mission that protects copyright and information.

The authors who postulate their articles certify that their proposals are the result of their own original research; for it is has a form of transfer of rights by which it is shown that the text is the author 's exclusive and original product. 


\section{Sesión de derechos y autorización para la publicación de artículos puestos en consideración a la Revista: Cuestiones de Filosofía}

\section{Información del artículo postulado}

- Título de artículo:

- Tipología:

\section{Datos del Autor(a)(es)(as)}

- Nombres y apellidos completos:

- Fecha de nacimiento:

- Filiación institucional (lugar donde labora):

- Título de pregrado y último de posgrado:

- Dirección: Código Postal (si aplica)

- Número de teléfono:

- E-mail:

- Tipo y número de documento de identificación:

- Departamento:

- País:

Por medio del presente documento autorizo a la revista Cuestiones de Filosofía, de la Universidad Pedagógica y Tecnológica de Colombia, publicar, difundir a través de medios impresos o electrónicos el artículo anteriormente descrito.

Me declaro responsable de los contenidos publicados y me comprometo a respetar los derechos morales de autor y a entregar contenidos lícitos que no vulneren derechos a terceras personas tales como la intimidad y el buen nombre, entre otros. En consecuencia, asumo personalmente las sanciones legales que generen la vulneración a lo anterior.

Declaro que el artículo que someto para su publicación respeta los derechos de otras obras que lo documentan y que cuento con las licencias y los permisos necesarios, según sea el caso para su utilización.

Aclaro que el artículo como material inédito, NO ha sido o está siendo postulado en otra revista académica para su publicación.

De conformidad:

Firma

№ identificación: 
Esta revista se terminó de imprimir en el mes de julio de 2020 en los talleres de Editorial Jotamar S.A.S., con un tiraje de 250 ejemplares.

Tunja, Boyacá, Colombia. 


\section{Prof. Dr. Jacinto Rivera de Rosales}

\section{Editor Invitado}

Dr. en Filosofía por la Universidad Complutense de Madrid, y licenciado en Filosofía por la misma Universidad. Especialista en filosofía del idealismo alemán y filosofía contemporánea. Ha publicado numerosos artículos, capítulos de libros y libros en España, Portugal, Alemania, Francia, Serbia, Colombia, Brasil, México, Italia, Estados Unidos, Argentina, Rusia, Polonia, Chile y Japón. Traductor al español de obras de Kant, Fichte, Schelling, Jung y Lauth. Presidente de la Sociedad Fichteana Internacional y de la Sociedad de Estudios Kantianos en Lengua Española. Miembro del Consejo de Redacción de la revista Daimon, de los Fichte-Studien y del Consejo Asesor de varias revistas internacionales. Fue Profesor ayudante y Profesor encargado de Curso desde 1979 hasta 1987 en la Facultad de Filosofía de la Universidad Complutense de Madrid. Desde 1989 es Profesor de Historia de la Filosofía Moderna en la Universidad Nacional de Educación a Distancia (UNED), de cuya Facultad de Filosofía fue Decano entre 2011 y 2015. Estancias de investigación postdoctoral en la Universidad Johann-Gutenberg de Maguncia (Alemania), en la Kant-Forschungsstelle de la Universidad Johann-Gutenberg de Maguncia y en la Universidad de Stanford (California).

\section{Prof. Dr. Alfredo Rocha de la Torre}

Editor

Gastwissenschaftler por la Alexander von Humboldt-Stiftung (Marie Curie COFUND Fellow). Doctor en Filosofia por la Bergische Universität Wuppertal (Alemania). Becas de estudios doctorales del Katholischer Akademischer Ausländer-Dienst (KAAD), COLFUTURO y del Deutscher Akademischer AustauschDienst (DAAD. Declinada). Fue miembro del grupo asesor de la "Organización de Estados Iberoamericanos" en el proyecto "La enseñanza de la Filosofía en Iberoamérica", es miembro del 
FORhUM for the humanities (Forum zahumanistiko / Forum für Humanwissenschaften), codirector del International Center of Studies on Contemporary Nihilism (CeNic), miembro fundador de la Sociedad Iberoamericana de Estudios Heideggerianos (Presidente 2009-2011), de comités científico y editorial de las revistas Teoría (Università di Pisa), Phainomena (Universidad de Lubjana), Topologik (Università della Calabria), Signos (UNIVATES), Revista de Filosofía (UIS), Límite (Universidad de Tarapacá), Franciscanum (Universidad de San Buenaventura). Publicaciones en Alemania, España, Italia, Eslovenia, México, Chile, Venezuela, Argentina, Perú, Colombia. Visiting Professor Universitá di Pisa (2021). Profesor asociado de la Escuela de Filosofía de la Universidad Pedagógica y Tecnológica de Colombia, Tunja (Colombia). 